Prepared in cooperation with the New Jersey Department of Environmental Protection

\title{
Method to Support Total Maximum Daily Load Development Using Hydrologic Alteration as a Surrogate to Address Aquatic-Life Impairment in New Jersey Streams
}

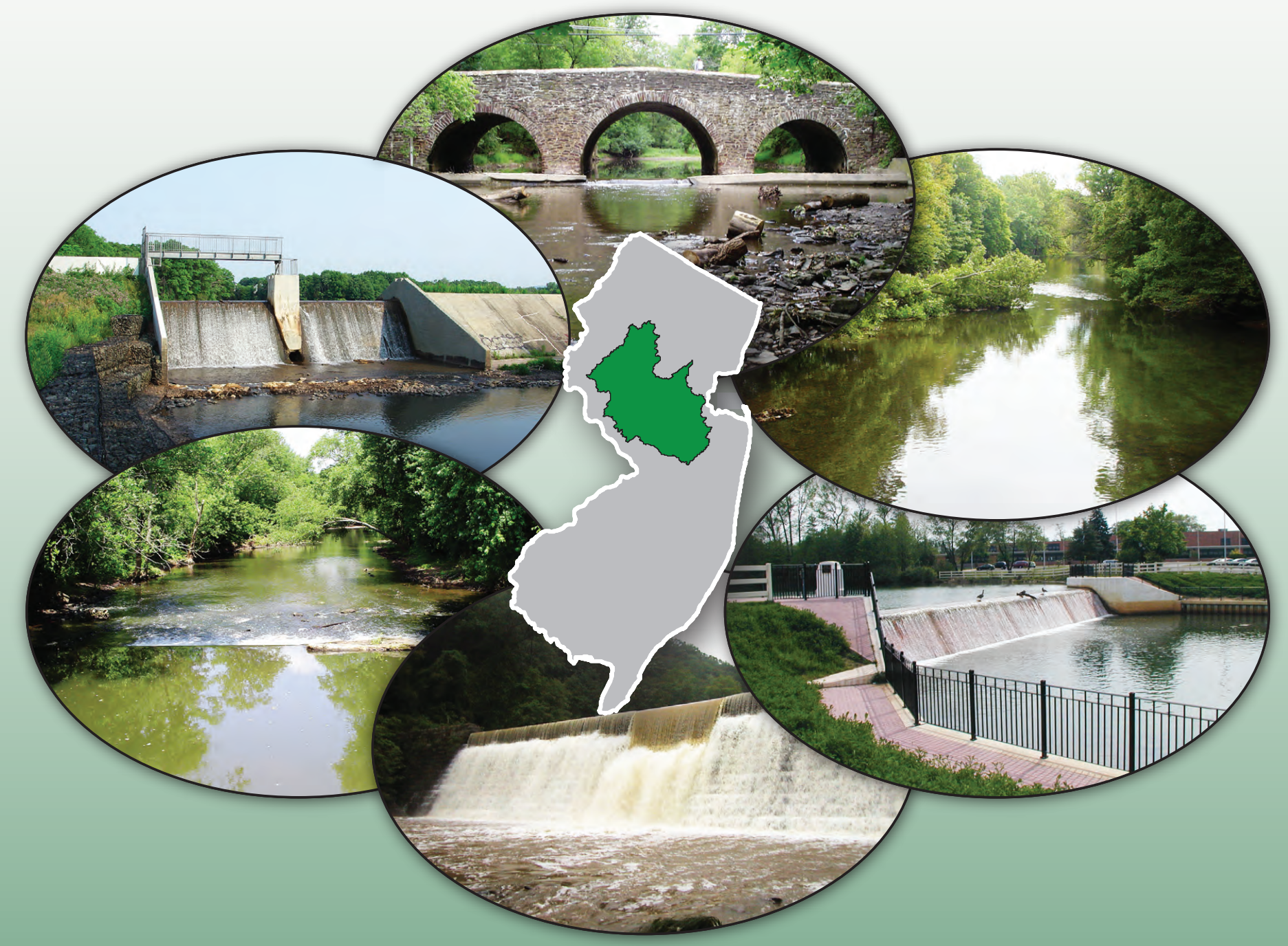

Scientific Investigations Report 2013-5089 


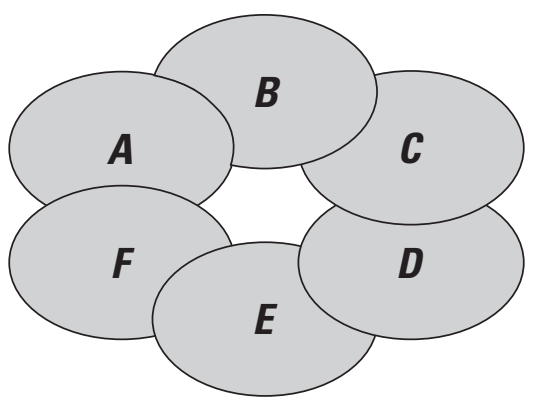

Cover. Photographs showing examples of hydrologic alteration near U.S. Geological Survey streamflow-gaging stations in the Raritan River watershed, New Jersey: A, gated flow-regulating dam, South Branch Rockaway Creek at Whitehorse Station, NJ; $B$, concrete weir in stream channel, Stony Brook at Princeton, NJ; $C$, stream subject to reservoir releases and streamwater diversions, South Branch Raritan River at Stanton, NJ; D, gated flow-regulating dam, Manalapan Brook at Spotswood, NJ; E, masonry dam, North Branch Raritan River at Far Hills, NJ; and $F$, concrete weir across stream channel, Millstone River at Blackwells Mills, NJ. (Photographs by U.S. Geological Survey.) 


\section{Method to Support Total Maximum Daily Load Development Using Hydrologic Alteration as a Surrogate to Address Aquatic-Life Impairment in New Jersey Streams}

By Jonathan G. Kennen, Melissa L. Riskin, Pamela A. Reilly, and Susan J. Colarullo

Prepared in cooperation with the

New Jersey Department of Environmental Protection

Scientific Investigations Report 2013-5089 


\title{
U.S. Department of the Interior SALLY JEWELL, Secretary
}

\section{U.S. Geological Survey Suzette M. Kimball, Acting Director}

\author{
U.S. Geological Survey, Reston, Virginia: 2013
}

For more information on the USGS - the Federal source for science about the Earth, its natural and living resources, natural hazards, and the environment, visit http://www.usgs.gov or call 1-888-ASK-USGS.

For an overview of USGS information products, including maps, imagery, and publications, visit http://www.usgs.gov/pubprod

To order this and other USGS information products, visit http://store.usgs.gov

Any use of trade, firm, or product names is for descriptive purposes only and does not imply endorsement by the U.S. Government.

Although this information product, for the most part, is in the public domain, it also may contain copyrighted materials as noted in the text. Permission to reproduce copyrighted items must be secured from the copyright owner.

Suggested citation:

Kennen, J.G., Riskin, M.L., Reilly, P.A., and Colarullo, S.J., 2013, Method to support Total Maximum Daily Load development using hydrologic alteration as a surrogate to address aquatic life impairment in New Jersey streams: U.S. Geological Survey Scientific Investigations Report 2013-5089, 86 p., http://pubs.usgs.gov/sir/2013/5089/ 


\section{Acknowledgments}

The authors thank the many individuals of the New Jersey Department of Environmental Protection, especially Barbara Hirst, Donna Milligan, Dean Bryson, Kimberly Cenno, Jeffrey Hoffman, Alfred Korndoerfer, and Victor Poretti, who dedicated time and resources in support of this cooperative study. Additional technical support from Donald Rice and James Henriksen of the U.S. Geological Survey (USGS), New Jersey Water Science Center and Fort Collins Science Center, respectively, is immensely appreciated. Special thanks to Brian Cade of the USGS Fort Collins Science Center for his help and insight regarding quantile-regression modeling. We are indebted to the many USGS scientists, including Blaine White, Richard Edwards, Andrew Watson, Jason Shvanda, John Trainor, Brian Painter, Aric Vanselous, Heidi Hoppe, Robert Atkinson, Sarina Howell, Charlie Shivers, Jerilyn Collenburg, Vincent Brown, Patrick Bowen, and Michal Niemoczynski, who, on an annual basis, carry out the continuous-record monitoring of New Jersey streams. Their hard work and dedication to collecting and publishing timely hydrologic information represents the scientific backbone of studies such as this. Additionally, Jason May, Brian Caskey, Tanja Williamson, and Dale Simmons of the USGS provided many useful suggestions that helped improve this report.

\section{Contents}

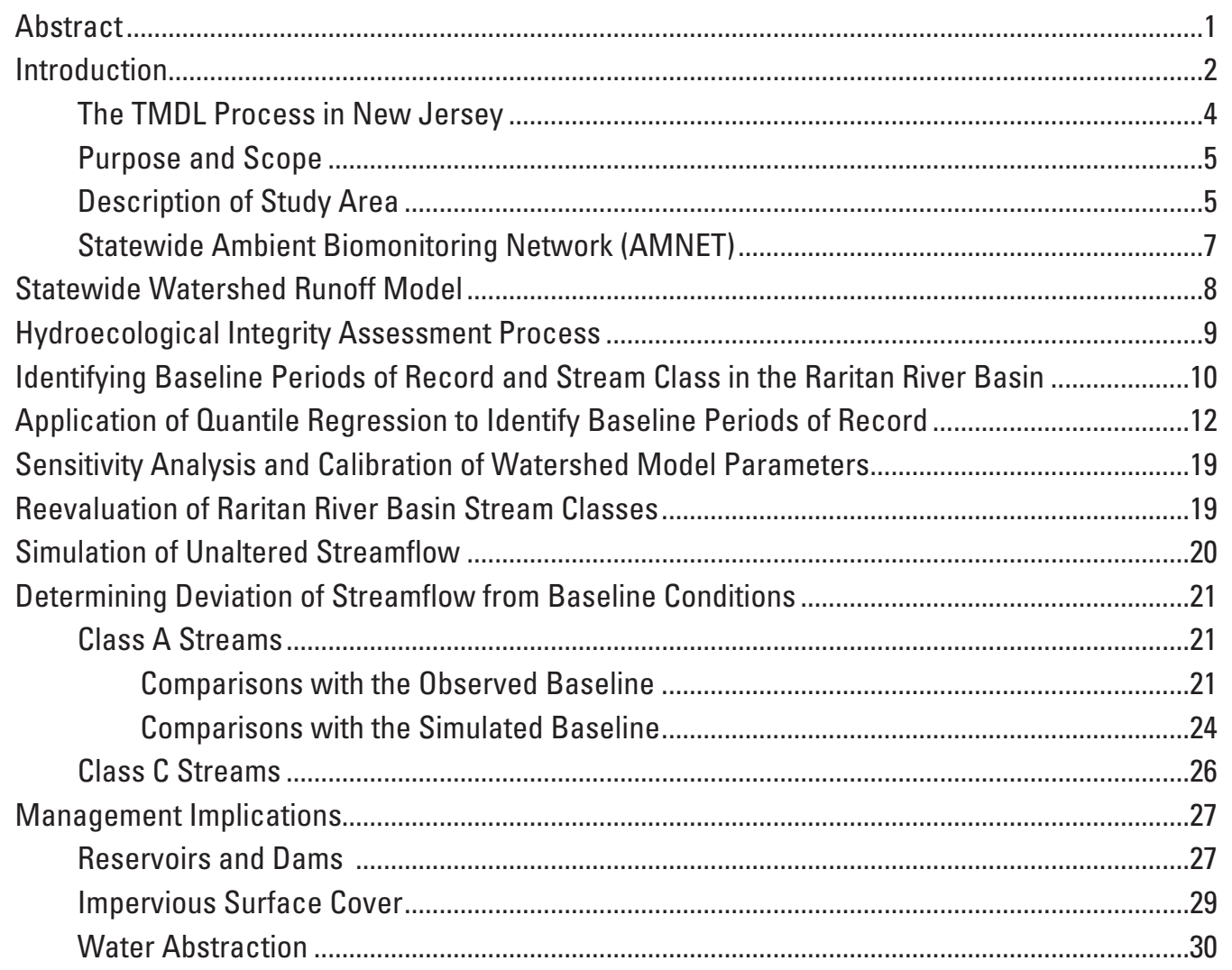


Linking Hydrologic Alteration to Invertebrate-Assemblage Response .........................................31

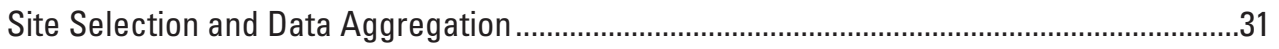

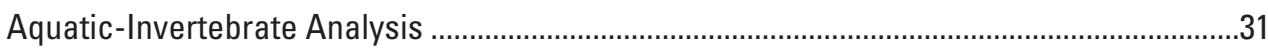

Use of Ecological Impairment to Define a Hydrologic Disturbance Gradient ........................34

Data-Reduction Procedures and Analytical Approach.........................................................34

Evaluation of Aquatic-Invertebrate Metrics as a Basis for Flow-Ecology Response Model

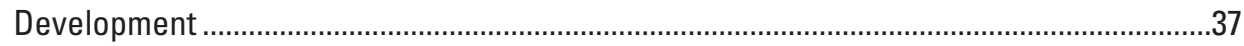

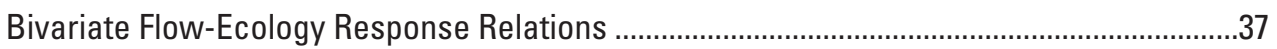

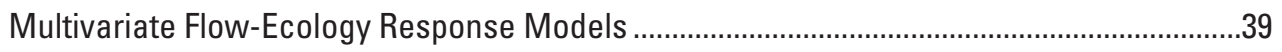

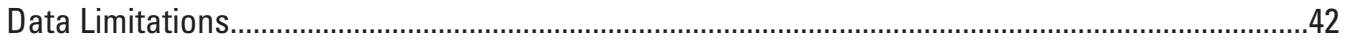

Differences between Observed and Simulated Baseline Periods of Record........................42

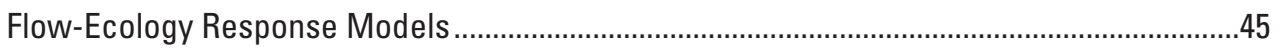

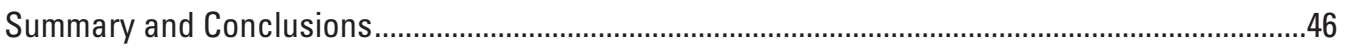

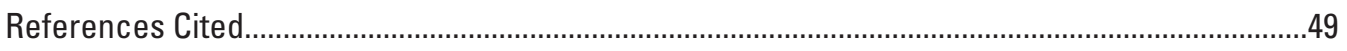

Appendix 1. Definitions of the 171 hydrologic indices .............................................................61

Appendix 2. Deviations of flow-management targets for the Raritan River Basin study area,

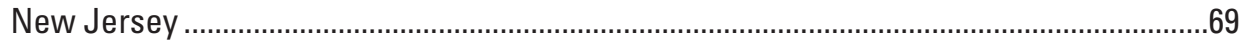

\section{Figures}

1. Location of study sites in the Raritan River Basin study area, New Jersey......................6

2. Hydrograph for U.S. Geological Survey streamgage Raritan River below Calco Dam at Bound Brook, New Jersey, 1945-2006.

3. Percent impervious surface cover and location of wells and discharge sites that may influence streamflow quantity and quality in the North Branch Raritan River at Far Hills, New Jersey, study basin in the Raritan River Basin study area, New Jersey.

4. Quantile Regressions for $A$, daily streamflow and $B$, hourly precipitation at U.S. Geological Survey streamgage Raritan River at Far Hills, New Jersey...........................14

5. Percent impervious surface cover and location of wells and discharge sites that may influence streamflow quantity and quality in the Raritan River at Manville, New Jersey study basin in the Raritan River Basin study area, New Jersey.

6. Hydrograph for U.S. Geological Survey streamgage Raritan River at Manville, New Jersey, 1922-2005.

7. Quantile regression for $A$, daily streamflow and $B$, hourly precipitation at Raritan River at Manville, New Jersey.

8. Interactive window for selecting nonredundant hydrologic indices for stream classes $A$ and $C$ as identified in the New Jersey Hydrologic Assessment Program ......20

9. Location of hydrologic and ecological sites used for the flow-ecology response analysis for the Raritan River Basin study area, New Jersey 


\section{Tables}

1. Baseline periods of record for Raritan River Basin study sites determined by using quantile regression....................................................................................58

2. Site abbreviations and baseline dataset types for the 29 class $A$ and $C$ streams used in the hydrologic analysis ............................................................................2

3. Aquatic-invertebrate sampling sites and their corresponding U.S. Geological Survey streamgage station numbers used in the flow-ecology response analysis........33

4. Flow-ecology response relations of selected New Jersey Department of Environmental Protection (NJDEP) Ambient Monitoring Network (AMNET) metrics significantly correlated (Spearman's rho) with the reduced set of hydrologic indices...

5. Flow-ecology response relations of selected invertebrate-assemblage metrics significantly correlated (Spearman's rho) with the reduced set of hydrologic indices

6. Two- and three-variable multiple regression models relating selected New Jersey Department of Environmental Protection Ambient Monitoring Network (AMNET) and Invertebrate Data Analysis System (IDAS) metrics to hydrologic indices................40

7. Deviations of flow-management targets for the observed and simulated baseline records for the Raritan River at Manville, NJ, study site that fall outside the established 25th-to-75th-percentile range..

8. Deviations of flow-management targets for the observed and simulated baseline records for the Raritan River at Stanton, NJ, study site that fall outside the established 25th-to-75th-percentile range.

9. Deviations of flow-management targets for the observed and simulated baseline record for the Neshanic River at Reaville, NJ, study site that fall outside the established 25th-to-75th-percentile range.. 


\section{Conversion Factors and Datums}

\begin{tabular}{lcl}
\multicolumn{1}{c}{ Inch/Pound to SI } & & \multicolumn{1}{c}{ To obtain } \\
\hline & By & \\
\hline inch (in.) & Length & \\
inch (in.) & 2.54 & centimeter $(\mathrm{cm})$ \\
inch (in.) & 25.4 & millimeter $(\mathrm{mm})$ \\
foot (ft) & 25,400 & micrometer $(\mu \mathrm{m})$ \\
\hline & 0.3048 & meter $(\mathrm{m})$ \\
\hline acre & Area & \\
square foot $\left(\mathrm{ft}^{2}\right)$ & 0.004047 & square kilometer $\left(\mathrm{km}^{2}\right)$ \\
square mile $\left(\mathrm{mi}^{2}\right)$ & 0.09290 & square meter $\left(\mathrm{m}^{2}\right)$ \\
\hline & 2.590 & square kilometer $\left(\mathrm{km}^{2}\right)$ \\
\hline gallon $($ gal) & Volume & \\
\hline & 3.785 & liter $(\mathrm{L})$ \\
\hline foot per second $(\mathrm{ft} / \mathrm{s})$ & Flow rate & \\
cubic foot per second $\left(\mathrm{ft}{ }^{3} / \mathrm{s}\right)$ & 0.3048 & meter per second $(\mathrm{m} / \mathrm{s})$ \\
cubic foot per second per day & 0.02832 & cubic meter per second $\left(\mathrm{m}^{3} / \mathrm{s}\right)$ \\
$\quad\left[\left(\mathrm{ft}^{3} / \mathrm{s}\right) / \mathrm{d}\right]$ & 0.02332 & cubic meter per second per day \\
million gallons per day $(\mathrm{Mgal} / \mathrm{d})$ & & {$\left[\left(\mathrm{m}^{3} / \mathrm{s}\right) / \mathrm{d}\right]$} \\
\hline
\end{tabular}

Temperature in degrees Celsius $\left({ }^{\circ} \mathrm{C}\right)$ may be converted to degrees Fahrenheit $\left({ }^{\circ} \mathrm{F}\right)$ as follows:

${ }^{\circ} \mathrm{F}=\left(1.8 x^{\circ} \mathrm{C}\right)+32$

Temperature in degrees Fahrenheit $\left({ }^{\circ} \mathrm{F}\right)$ may be converted to degrees Celsius $\left({ }^{\circ} \mathrm{C}\right)$ as follows:

${ }^{\circ} \mathrm{C}=\left({ }^{\circ} \mathrm{F}-32\right) / 1.8$

Vertical coordinate information is referenced to the North American Vertical Datum of 1988 (NAVD 88).

Horizontal coordinate information is referenced to the North American Datum of 1983 (NAD 83).

Altitude, as used in this report, refers to distance above the vertical datum.

Concentrations of chemical constituents in water are given in either milligrams per liter (mg/L) or micrograms per liter $(\mu \mathrm{g} / \mathrm{L})$.

\section{Acronyms, abbreviations, and symbols}

$\begin{array}{ll}\text { AIC } & \text { Akaike Information Criterion } \\ \text { AMNET } & \text { Ambient Biomonitoring Network } \\ \text { BMPs } & \text { best management practices } \\ \text { CWA } & \text { Clean Water Act } \\ \text { ELOHA } & \text { Ecological Limits of Hydrologic Alteration } \\ \text { ERHIs } & \text { ecologically relevant hydrologic indices } \\ \text { EPT } & \text { Ephemeroptera, Plecoptera, and Trichoptera } \\ \text { FBI } & \text { Family Biotic Index }\end{array}$




\begin{tabular}{|c|c|}
\hline GIS & geographic information system \\
\hline HEC-HMS & $\begin{array}{l}\text { U.S. Army Corps of Engineers, Hydrologic Engineering Center-Hydrologic } \\
\text { Modeling System }\end{array}$ \\
\hline HIP & Hydroecological Integrity Assessment Process \\
\hline HIT & Hydrologic Index Tool \\
\hline HSPF & U.S. Environmental Protection Agency Hydrologic Simulation Program—Fortran \\
\hline IDAS & Invertebrate Data Analysis System \\
\hline ISC & impervious surface cover \\
\hline MIKE SHE & Danish Hydraulic Institute Integrated Hydrologic Modeling System \\
\hline MLR & multiple linear regression \\
\hline NAWQA & National Water Quality Assessment \\
\hline NFRP & Natural Flow Regime Paradigm \\
\hline NJDEP & New Jersey Department of Environmental Protection \\
\hline NJHAT & New Jersey Hydrologic Assessment Tool \\
\hline NJIS & New Jersey Impairment Score \\
\hline NJSCT & New Jersey Stream Classification Tool \\
\hline NJPDES & New Jersey Pollutant Discharge Elimination System \\
\hline NWIS & National Water Information System \\
\hline $\mathrm{OB}$ & observed baseline hydrograph \\
\hline POR & period of record \\
\hline PRESS & predicted residual sum of squares \\
\hline QR & quantile regression \\
\hline SB & simulated baseline hydrograph \\
\hline SWRM & Statewide Watershed Runoff Model \\
\hline TMDL & total maximum daily load \\
\hline TOPMODEL & physically based, semidistributed topographical watershed model \\
\hline USEPA & U.S. Environmental Protection Agency \\
\hline USGS & U.S. Geological Survey \\
\hline VIF & variance inflation factor \\
\hline WaterSMART & Sustain and Manage America's Resources for Tomorrow \\
\hline$>$ & greater than \\
\hline$<$ & less than \\
\hline
\end{tabular}


(This page intentionally left blank.) 


\title{
Method to Support Total Maximum Daily Load Development Using Hydrologic Alteration as a Surrogate to Address Aquatic-Life Impairment in New Jersey Streams
}

\author{
By Jonathan G. Kennen, Melissa L. Riskin, Pamela A. Reilly, and Susan J. Colarullo
}

\section{Abstract}

More than 300 ambient monitoring sites in New Jersey have been identified by the New Jersey Department of Environmental Protection (NJDEP) in its integrated waterquality monitoring and assessment report (that is, the 305(b) Report on general water quality and 303(d) List of waters that do not support their designated uses) as being impaired with respect to aquatic life; however, no unambiguous stressors (for example, nutrients or bacteria) have been identified. Because of the indeterminate nature of the broad range of possible impairments, surrogate measures that more holistically encapsulate the full suite of potential environmental stressors need to be developed. Streamflow alteration resulting from anthropogenic changes in the landscape is one such surrogate. For example, increases in impervious surface cover (ISC) commonly cause increases in surface runoff, which can result in "flashy" hydrology and other changes in the stream corridor that are associated with streamflow alteration. The NJDEP has indicated that methodologies to support a hydrologically based Total Maximum Daily Load (hydro-TMDL) need to be developed in order to identify hydrologic targets that represent a minimal percent deviation from a baseline condition ("minimally altered") as a surrogate measure to meet criteria in support of designated uses.

The primary objective of this study was to develop an applicable hydro-TMDL approach to address aquatic-life impairments associated with hydrologic alteration for New Jersey streams. The U.S. Geological Survey, in cooperation with the NJDEP, identified 51 non- to moderately impaired gaged streamflow sites in the Raritan River Basin for evaluation. Quantile regression $(\mathrm{QR})$ analysis was used to compare flow and precipitation records and identify baseline hydrographs at 37 of these sites. At sites without an appropriately long period of record (POR) or where a baseline hydrograph could not be identified with $\mathrm{QR}$, a rainfall-runoff model was used to develop simulated baseline hydrographs. The hydro-TMDL approach provided an opportunity to evaluate proportional differences in flow attributes between observed and baseline hydrographs and to develop complementary flow-ecology response relations at a subset of Raritan River Basin sites where available flow and ecological information overlapped.

The New Jersey Stream Classification Tool (NJSCT) was used to determine the stream class of all 51 study sites by using either an observed or a simulated baseline hydrograph. Two New Jersey stream classes (A and C) were evaluated to help characterize the unique hydrology of the Raritan River Basin. In general, class C streams (1.99-40.7 square miles) had smaller drainage areas than class A streams (0.7-785 square miles). Many of the non-impaired and moderately impaired class A and C streams in the Raritan River Basin were found to have significant hydrologic alteration as indicated by numerous flow values that fell outside the established 25th-to-75thand the more conservative 40th-to-60th-percentile boundaries. However, percent deviations for the class $\mathrm{C}$ streams (defined as moderately stable streams with moderately high base-flow contributions) were, in general, much larger than those for the class A streams (defined as semiflashy streams characterized by moderately low base flow). The greater deviations for class $\mathrm{C}$ streams in the hydro-TMDL assessments likely resulted from comparisons that were based solely on simulated baseline hydrographs, which were developed without considering any anthropogenic influences in the basin. In contrast, comparisons for many of the class A streams were made by using an observed baseline, which already includes an implicit level of ISC and other human influences on the landscape.

By using the hydro-TMDL approach, numerous flow deviations were identified that were indicative of streams that are highly regulated by reservoirs or dams, streams that are affected by increasing amounts of surface runoff resulting from ISC, and streams that are affected by water abstraction (that is, groundwater or surface-water withdrawals used for 
agricultural and human supply). Eight of the reservoir- and (or) dam-affected sites showed flow deviations that are indicative of flow-managed systems. For example, indices that account for the timing and magnitude of high and low flows were often found to fall outside the 25th-to-75th-percentile range. In general, at regulated class $\mathrm{C}$ streams, annual summer low flows are arriving later and tend to be lower, and high flows are arriving earlier with higher magnitudes of longer duration. At class A streams, high and low flows are arriving later with an overall increase in discharge with respect to the prereservoir baseline conditions.

The drainage basins of eight of the study sites had large values of ISC ( $>10$ percent), most likely as a result of expanding urban development. In general, the magnitude and frequency of high flows at class A and C sites with high ISC are increasing and were commonly found to fall outside the 25th-to-75th-percentile range. Additionally, magnitudes of low flows are becoming lower and, although the timing of high flows was highly variable, low-flow events appeared to be arriving earlier than would be expected under normal low-flow conditions. Three of the study sites appeared to be affected by hydrologic changes associated with water abstraction. At these sites, the timing of flows appeared to be altered. For example, low flows tended to arrive earlier and high flows arrived later at two of the three sites. Additionally, the magnitude and duration of low flows were commonly less than the 25th-percentile value and the duration of high flows appeared to increase.

A reduced set of hydrologic and ecological variables was used to develop univariate and multivariate flow-ecology response models for the aquatic-invertebrate assemblage. Many hydrologic variables accounting for the duration, magnitude, frequency, and timing of flows were significantly correlated with ecological response. Multiple linear regression (MLR) models were developed to provide a more holistic evaluation of the combined effects of hydrologic alteration and to identify models with two or three hydrologic variables that account for a significant proportion of the variability in invertebrate-assemblage condition as represented by assemblage metric scores. MLR models, derived on the basis of hydrologic attributes, accounted for 35 to 75 percent of the variability in assemblage condition.

The hydro-TMDL method developed herein for non- to moderately impaired Raritan River Basin streams utilizes a "surrogate" approach in place of the traditional "pollutant of concern" approach commonly used for TMDL development. Managers can use the results obtained by using the hydroTMDL method to offset the effects of impervious-surface runoff and altered streamflow and to implement measures designed to achieve the necessary load reductions for the "pollutant of concern" (that is, percentage deviations of stream-class-specific flow-index values outside the established 25th-to-75th-percentile range). In this case, such deviations could represent all or a subset of the altered flow indices that prevent the stream from meeting designated aquatic-life criteria. This hydro-TMDL uses a reference, or attainment stream approach for developing the TMDL endpoint. That is, either observed or simulated baseline hydrographs were selected as appropriate reference conditions on the basis of results of $\mathrm{QR}$ analysis and watershed modeling procedures, respectively. For any stream in the Raritan River Basin evaluated as part of this study, the hydro-TMDL can be expressed as the greatest amount of deviation in flow a stream can exhibit without violating the stream's designated aquatic-life criteria. Use of this surrogate approach is appropriate because flows that fall outside the established percentile ranges are ultimately a function of many anthropogenic modifications of the landscape, including the amount of stormwater runoff generated from impervious surfaces within a given basin, the presence of manmade structures designed to retain or divert water, the magnitude of ground- and surface-water abstraction, and the presence of water-supply processes implemented to support human needs. In addition, the stream-type-specific flow indices used as the basis for the hydro-TMDL approach are useful for representing the hydrologic conditions of class $\mathrm{A}$ and $\mathrm{C}$ streams/basins because they incorporate the full spectrum of flow conditions (very low to very high) that occur in the stream system over a long period of time, as well as those flow properties that change as a result of seasonal variation.

Ultimately, an estimate of the maximum percentage flow reduction that could be allowed will be needed to address the aquatic-life impairments in many of the study streams in the Raritan River Basin and will be necessary for identifying appropriate target flow conditions for hydro-TMDL implementation. As described in this report, a target flow value equal to the 25 th- or 75 th-percentile flow rate could be selected as the point useful for setting specific hydrologic targets. This selection, however, is a management decision that could vary depending on the designated use of the stream or other regulatory factors (for example, water-supply protection, trout production, antidegradation policies, or special protection designations). In New Jersey streams where no unambiguous stressors can be identified, State monitoring agencies, such as the NJDEP, could choose to require the implementation of a flow-based TMDL that not only supports designated uses, but meets the regulatory requirements under the Clean Water Act, and represents a balance between water supply intended to meet human needs and the conservation of ecosystem integrity.

\section{Introduction}

Biotic impairment in New Jersey streams is considered by the New Jersey Department of Environmental Protection (NJDEP) to be an indicator that some type of anthropogenic process has occurred and has resulted in aquatic-assemblage degradation. More than $300 \mathrm{New}$ Jersey streams are listed in the New Jersey 2010 integrated water-quality monitoring and assessment report (includes 305(b) Report on general water quality and 303(d) List of waters that do not support their 
designated uses) (N.J. Department of Environmental Protection, 2012a) as "biologically impaired"; however, no specific, unambiguous stressor has been identified. Unlike impairments caused by contaminants such as phosphorus or metals, which can be specifically quantified, the cause of aquatic-life impairment in many New Jersey streams is not readily apparent. Therefore, directly measurable and quantifiable surrogate parameters need to be identified to provide State and other resource managers with the ability to allocate a percentage of the remedial response necessary to address aquatic-life impairment. Some State agencies have had success with using sediment loads (for example, Virginia Department of Environmental Quality, 2004) or stormwater pollutants (for example, Massachusetts Department of Environmental Protection, 2003; Maine Department of Environmental Protection, 2004) as surrogates for biotic impairment on a site-specific basis; however, hydrologic alteration more holistically encapsulates the full suite of potential environmental stressors and has a greater potential for application to the Total Maximum Daily Load (TMDL; that is, the maximum amount of a pollutant that a waterbody can receive without violating water-quality standards) in New Jersey streams. In streams where a single unambiguous stressor (for example, sediment, nutrients, bacteria, or another specific pollutant) has not been identified, it can be inferred that increases in impervious surface cover (ISC) can facilitate increased surface runoff, which can result in an increase in the loads of associated pollutants washed from impervious surfaces, reduced groundwater recharge, "flashy" stream hydrology, habitat degradation, riparian corridor encroachment, and channel modification. These types of stressor responses have been seen in numerous studies relating urbanization and increases in ISC to aquatic-assemblage impairment in streams (Roy and others, 2003; Coles and others, 2004; Cuffney and others, 2005; Meyer and others, 2005; Kennen and others, 2005; Wang and others, 2008; Cuffney and others, 2010; and many others). These stressors may be acting in individual, synergistic, and (or) cumulative ways to cause impairment. As a result, novel approaches are required to develop a TMDL that will address aquatic-life impairment and also can serve as a basis for implementing management actions. The challenge, therefore, is to develop surrogate indicators that can be expressed as quantitative targets. The common thread that links most of the stressors identified is hydrologic alteration, which can be viewed as a master variable that represents the cumulative effects of multiple stressors contributing to aquatic-life impairments in these stream systems. Consequently, an alternative approach for developing TMDLs for aquatic-life impairment in New Jersey streams could incorporate a modeling approach that accounts for changes in hydrologic variability and provides a quantitative pathway for evaluating the deviation of altered flow regimes from relatively unaltered (baseline) streamflow.

The flow characteristics of many New Jersey streams have changed substantially over the past several decades (Watson and others, 2005), primarily in response to increases in ISC and water use as a result of population growth.
Alterations in the natural streamflow regime arise from many factors, including changes in climate (Sefton and Boorman, 1997; Legesse and others, 2003; Palmer and others, 2008), but in most New Jersey basins, hydrologic instability can be attributed primarily to anthropogenic influences (Kennen and Ayers, 2002; Kennen and others, 2008; Kennen and others, 2010). With an estimated 2010 population of roughly 8.8 million (U.S. Census Bureau, 2012) distributed over an area of 7,354 square miles $\left(\mathrm{mi}^{2}\right)$, New Jersey is the most densely populated state in the United States, and has undergone periods of accelerated development during the last several decades. Urban and suburban development have substantially increased the fraction of ISC, yielding rapid surface runoff and changing patterns and timing of streamflow (Kennen and others, 2008). Increased ISC caused by development also inhibits recharge to aquifers, decreasing the magnitude of reliable base flow and increasing the frequency and duration of low flows. Diversion of both surface- and groundwater in heavily developed basins further exacerbates hydrologic instability by introducing unnatural variations in streamflow characteristics. These observed changes in the hydrologic regime are likely to be compounded by future economic development within the State of New Jersey unless regulatory measures are enacted to mitigate the effects of hydrologic alteration.

Much evidence exists that hydrology accounts for a significant portion of the variability in the composition, structure, and function of aquatic systems (Richter and others, 1996; Ward and Stanford, 1989; Bunn and Arthington, 2002; Poff and Zimmerman, 2010). Studies indicate that management practices that promote natural hydrologic patterns and processes are likely to reduce the effects of hydrologic alteration on stream biota (for example, Poff and others, 1997). Therefore, both ecological theory and abundant evidence of ecosystem degradation in flow-altered rivers support the need for a scientifically sound and empirically robust foundation for flow-based management of streams and rivers (Poff and others, 2010). It is not always a question of how much water a stream "needs," but of the degree to which flow regimes can be altered before a measurable effect on ecosystem integrity is observed. Hydrologic alterations have resulted in varying degrees of long-term biotic impairment to aquatic ecosystems in New Jersey by changing the availability and persistence of stream habitat, the composition and quality of channel substrate, the rate of nutrient flux and uptake, and the connectivity between streams and biologically productive riparian zones in adjacent flood plains.

By targeting hydrologic variability, as represented by the anthropogenic alteration of streamflows, the hydro-TMDL approach also addresses many of the concomitant geomorphologic impairments that cumulatively degrade aquatic life. The environmental costs of hydrologic alteration on stream geomorphology are many, and include habitat fragmentation (Dynesius and Nilsson, 1994), loss of wetlands and flood plains that help buffer against flood flows and attenuate loads (Rosenberg and others, 1997), and increased streambank erosion and sediment transport resulting from alteration of natural 
seasonal patterns of discharge (Vorosmarty and Sahagian, 2000). In particular, increased peak streamflow and streamflow variability have been linked to degradation in the composition, structure, and function of aquatic assemblages, which are good predictors of the biological integrity of aquatic ecosystems (Ward and Stanford, 1989; Poff and Allan, 1995; Richter and others, 1996; Clausen and Biggs, 1997; Pusey and others, 2000; Bunn and Arthington, 2002; Kennen and others, 2010). Kennen and Ayers (2002) have shown that increases in peak discharge, streamflow variability, ISC, and human population density contribute to impairment of stream assemblages in New Jersey. When hydrologic alterations persist over long periods, they can result in substantial loss of abundance and diversity in both the aquatic and riparian habitats. Even though recent studies have indicated that some aquatic invertebrates appear to be resilient to stress associated with short-term reductions in streamflow (Miller and others, 2007; James and others, 2008), aquatic assemblages that have undergone severe and chronic flow disturbance might reach a point beyond resistance or resilience and may never recover to their predisturbance ecological function (McCabe and Gotelli, 2000; Paul and Meyer, 2001; Biggs and others, 2005; Urban and others 2006; Miller and others, 2007; Utz and others, 2009; Cuffney and others, 2010). Managing watersheds to reduce hydrologic alteration not only reduces the loading of associated contaminants but also helps to restore natural aquatic species (Poff and Ward, 1989; Bunn and Arthington, 2002). The goal of State monitoring agencies is to promote a balance between water supply intended to meet human needs and conservation of biological integrity. Therefore, a science-based framework for assembling data to develop appropriate hydrologic-alteration-based TMDLs that account for assemblage impairment through changes in hydrologic processes and provides options for making sound environmental recommendations supports this goal.

Maintenance or restoration of hydrologic variability is critical to protecting biodiversity and enhancing the integrity of aquatic, riparian, and wetland ecosystems, and is the foundation of the Natural Flow Regime Paradigm (NFRP) presented by Poff and others (1997). The NFRP emphasizes the need to account for the full range of natural intra- and interannual variation in the hydrologic regime, as summarized by broad categories of flow characteristics such as magnitude, frequency, duration, timing, and rate of change, all of which are important in maintaining aquatic-ecosystem integrity (Richter and others, 1997). For example, seasonal timing of flow can be crucial to supporting the emergence and reproduction of certain species in perennial streams (Grossman, 1982; Poff and Ward,1989; Peckarsky and others, 2000), but seasonal flow between years generally is not so predictable that it favors one species over most others and constrains the natural diversity of the aquatic ecosystem. Some optimal balance between flow seasonality and interannual variability that is unique to the particular basin needs to be maintained if the basin is to support an aquatic assemblage comparable to that present prior to the onset of hydrologic disturbance. An intermittent stream that supports a different suite of species and is characterized by an entirely different flow "signature" than a perennial snowmelt stream, for example, may require the development of an entirely different restoration strategy than the perennial stream. One goal may be to restore streamflow to its natural condition; however, that goal may not be achievable, especially in some moderately to highly degraded urban systems or in streams with reservoirs designed for water-supply purposes. The same may be true for streams in basins where streamflow-restoration needs change over time as a result of climatic variability or ongoing anthropogenic alterations of the landscape.

In this study, conducted by the U.S. Geological Survey (USGS) in cooperation with the NJDEP, an applicable hydrologically based TMDL (hereafter referred to as "hydroTMDL") approach was developed to address aquatic-life impairments associated with hydrologic alteration of New Jersey streams. This approach includes (1) applying a Statewide Watershed Runoff Model (SWRM) (Kennen and others, 2008) to simulate streamflow at selected New Jersey locations and develop a "least impaired" hydrologic endpoint by modifying parameters in the model that are associated with anthropogenic alteration of streamflow (for example, ISC); (2) identifying a set of ecologically relevant flow parameters within predefined hydrologic stream classes (Kennen and others, 2007) for direct comparison of streamflow between the simulated "least impaired" (baseline, or reference) hydrograph and the current, anthropogenically modified (present-day) hydrograph by using the Hydroecological Integrity Assessment Process; (3) developing percentage differences for a subset of streamtype-specific hydrologic indices to evaluate the proportion of flow needed to meet designated aquatic-life uses (for example, do the streams fall within the targeted 25th-to-75th-percentile range of flow and, if not, how far does the stream deviate from this flow target); (4) developing predictive linear and nonlinear flow-ecology response models linking aquatic assemblages to altered flow; and (5) developing higher (that is, multivariate) models that incorporate multiple predictor hydrologic variables. The ultimate goal of this study was to develop methods to support a hydro-TMDL that provides a viable scientific pathway that can be used by the NJDEP and other State management agencies to understand the extent of hydrologic alteration of river systems and reduce the effect of hydrologic stress so that the beneficial uses of a stream can be restored.

\section{The TMDL Process in New Jersey}

New Jersey is one of a few states in the Nation that require an implementation plan that identifies specific remedial actions as part of a complete TMDL for all water bodies that have been listed under section 303(d) of the U.S. Environmental Protection Agency (USEPA) guidance and requirements pursuant to the Clean Water Act (CWA). These sites may be impaired as a result of a suite of anthropogenic modifications, including hydrologic alteration. Biotic impairment in 
New Jersey streams is commonly accompanied by pronounced alterations in the natural streamflow record, indicating that biological degradation of aquatic assemblages could also result from physical disturbances, such as flow alteration, rather than solely from contaminants or other identified "pollutants." Some studies have shown that in lightly to moderately urbanized watersheds, water quality typically bears little relation to biotic impairment (for example, May and others, 1997; Horner and May, 1999), lending additional support to the likelihood that the biotic integrity of aquatic systems is at least partly influenced by physical changes associated with flow rather than water quality alone.

Load-reduction goals established through TMDLs are achieved through the issuance of waste-load allocations for point-source discharges and load allocations for nonpointsource discharges. Because nonpoint-source pollution, by definition, does not have discrete, identifiable sources, load allocations would consist of the identification of categories of nonpoint sources that contribute to the parameters of concern, such as hydrologic alteration, and the resulting degradation of biological assemblages in receiving streams. The load allocation will then necessarily include specific load-reduction measures that can be instituted to address the impairment. The NJDEP has indicated that hydrologic targets need to be identified that represent a minimal percent deviation from a baseline (reference or "minimally altered") condition to meet designated aquatic-life uses. Regulating and managing watersheds by reducing hydrologic alteration not only reduces the potential loading of associated pollutants contained in streamflow runoff, but also helps restore the natural hydrologic variability that is known to support many sensitive aquatic species (Poff and others, 2007). This approach is consistent with the USEPA Water Quality Management and Planning Regulations for the implementation of TMDLs that allow the expression of a TMDL in terms of a surrogate measure (that is, 40 CFR 130.2(i)), such as percent change in a hydrologic attribute relative to baseline stream conditions, as an appropriate surrogate for assessing hydrologic impairments to aquatic-life use.

\section{Purpose and Scope}

This report establishes an applicable hydro-TMDL approach to address aquatic-life impairments associated with hydrologic alteration of New Jersey streams. The goal of every TMDL is to achieve water-quality standards for the impaired water body; therefore, it is important to identify the appropriate target so that the water body will meet the water-quality standard or designated aquatic-life use. For a hydrologicalteration-based TMDL, the surrogate target is developed by comparing streamflow characteristics to an observed baseline hydrograph (minimally altered stream, where the period of record (POR) reflects minimal hydrologic alteration) or a simulated baseline hydrograph (where anthropogenic modification in a specific basin has been minimized by adjusting model parameters). Ecologically relevant flow parameters are identified for streams within the Raritan River Basin that have known aquatic-assemblage impairments. These attributes are used to (1) identify a series of critical flow parameters as surrogates for defining aquatic-life impairment and (2) compare and normalize flow statistics of hydrologically altered streams by using those from minimally altered reference streams to develop hydrologic targets (percent deviation from reference streamflows) for use by water managers for the purpose of streamflow protection, maintenance, or restoration. Numeric targets are based on hydrologic attributes that deviate from the expected in comparison to a reference stream or from a modeled parameter that was assessed by using a hydrograph simulated from less anthropogenically modified conditions. These targets (for example, the 25th and 75th percentiles of flow), therefore, are based on percent deviation from the expected hydrologic response under least modified conditions as opposed to the required minimal loading of a specific pollutant. Percent deviations that take the place of load scenarios are developed by comparing current conditions to baseline hydrology, and the proportional deviation (that is, the difference between baseline and observed streamflow) is presented as a basis for evaluating mitigation options. In addition, flowecology models predicting aquatic-assemblage response along a gradient of hydrologic degradation in a specified hydrologic region (watershed, state, region, or province), as in Poff and others (2010), that can be used to support broader regional flow targets for a subset of classified streams are developed (Kennen and others, 2007). Although this study focuses on the Raritan River Basin, the methods developed in this study should have broad transferability to river systems throughout the United States and abroad.

\section{Description of Study Area}

All hydrologic and corresponding ecological study sites targeted to support hydro-TMDL development based on hydrologic alteration in this study are in the Raritan River Basin. The Raritan River Basin is in central and northern New Jersey and is the largest drainage basin entirely within the State of New Jersey, encompassing an area of 1,105 $\mathrm{mi}^{2}$ (fig. 1) (Reiser, 2004). The basin contains six major drainages: the Millstone River ( $\left.287 \mathrm{mi}^{2}\right)$, South Branch Raritan River (279 mi ), North Branch Raritan River (190 mi $)$, South River (133 mi ), Bound Brook (65 $\left.\mathrm{mi}^{2}\right)$, and Lawrence Brook (46.3 $\mathrm{mi}^{2}$ ). Spruce Run Reservoir, Round Valley Reservoir, and Budd Lake are the major impoundments in the basin, with Spruce Run Reservoir releasing water to the South Branch Raritan River and Round Valley Reservoir. The basin drains all or parts of 100 municipalities in Hunterdon, Mercer, Middlesex, Monmouth, Morris, Somerset, and Union Counties (Reiser, 2004). Site-selection criteria were based on a USGSNJDEP cooperative approach in which sites were identified where anthropogenic degradation of the aquatic system generally was slight to moderate and where, at a subset of sites, biological samples were collected at or near (slightly upstream or downstream from) an existing USGS continuous real-time streamflow-gaging station. Fifty-one subbasins in the Raritan 


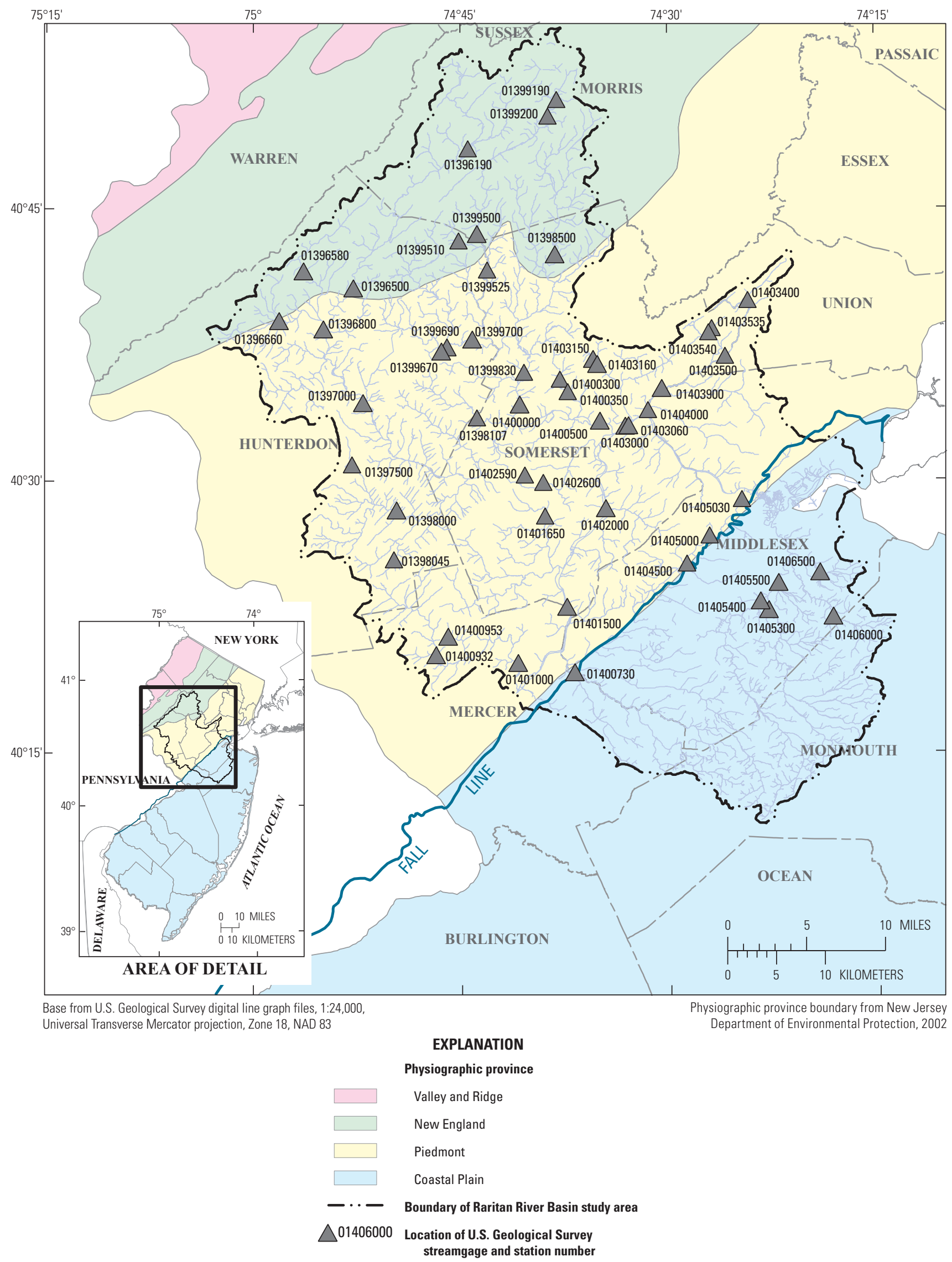

Figure 1. Location of study sites in the Raritan River Basin study area, New Jersey. 
River Basin were initially chosen for this study on the basis of available hydrographic information, proximity of hydrologic and ecological sampling locations, and impairment criteria.

New Jersey spans four physiographic provinces - the Valley and Ridge, New England, Piedmont, and Coastal Plain. The Raritan River Basin study area drains an area spanning three physiographic provinces - the New England, Piedmont, and Coastal Plain (fig. 1). The New England physiographic province features broad, flat-topped highlands and long, narrow valleys that range in elevation from 490 to 1,500 feet ( $\mathrm{ft}$ ). The Piedmont Physiographic Province, characterized by northwestward-dipping sedimentary rocks that form broad, gently sloping lowlands and rolling hills, has an average elevation of $390 \mathrm{ft}$. The Coastal Plain Physiographic Province is an area dominated by flat to gently rolling topography and unconsolidated sedimentary deposits that range in elevation from about 80 to $390 \mathrm{ft}$. These physiographic features have a strong influence on streamflow, with flow in the high-relief northern portions of the State being dominated by surface runoff, and flow in Coastal Plain streams largely sustained by groundwater contributions. Large-scale natural spatial variations in climate, geology, soils, and vegetation imposed by a wide range in physiographic conditions within New Jersey have given rise to several classes of streamflow behavior, each characterized by a natural flow regime unique to that class (see Kennen and others (2007) for a review of the hydrologic classes present in New Jersey).

The diverse flow regimes encountered in the study area are caused by nonuniform patterns of urbanization that produce a broad spectrum of flow behaviors. In addition, portions of the Raritan River Basin drain large impervious areas, which yield runoff rapidly and produce peak streamflows that greatly exceed those associated with preurbanization flood events. These floods can scour fine-grained sediment from channel bottoms, erode stream banks, and inundate productive flood plains at times of the year when these events may not be beneficial to the life cycles of certain aquatic species. Groundwater withdrawals have substantially reduced base-flow contributions to some coastal streams (Zapecza, 1989), modifying concentrations of nutrients and potentially altering seasonal spawning cycles of long-lived aquatic species. Groundwater withdrawals may have a less pronounced effect, however, on aquatic-assemblage health in upland basins, where stream base flow is not largely sustained by groundwater. Large interbasin transfers of surface water through tightly coupled watersupply systems may also adversely affect the biotic integrity of aquatic ecosystems, but the complex routing and timing of these transfers makes it difficult to evaluate how extensively they influence biological impairment in a given watershed. It is within the constraints of this complex set of natural and anthropogenic factors that State watershed planners, managers, and policy makers must make decisions regarding trade-offs between streamflow needed for economic development and human use and streamflow necessary to maintain the integrity of aquatic ecosystems in New Jersey.

\section{Statewide Ambient Biomonitoring Network (AMNET)}

In 1992, the NJDEP Bureau of Freshwater and Biological Monitoring developed the Ambient Biomonitoring Network (AMNET) program to provide long-term monitoring of aquatic-invertebrate assemblages to support sound policy decisions in water-quality/watershed management (N.J. Department of Environmental Protection, 2007). Collecting samples of aquatic invertebrates is a primary, cost-effective biomonitoring tool as these organisms are ubiquitous in distribution, are more stationary than fish but less transient than algae and other microscopic assemblages, and are easily collected and quantified (N.J. Department of Environmental Protection, 2008). Aquatic invertebrates also integrate environmental stressors over time and provide an ecological measure of environmental conditions (Kennen and others, 2012). As a result, the invertebrate assemblage holistically reflects conditions in its environment.

The AMNET consists of more than 800 stream sites in New Jersey where samples are collected and analyzed once every 5 years. Approximately 150 to 200 sites are located in each of the five major drainage basins, or Water Regions (upper and lower Delaware, Northeast, Raritan, and Atlantic) throughout the State (N.J. Department of Environmental Protection, 2008). The AMNET program is designed so that sampling occurs at each site within a given Water Region within 1 year's time, with all aquatic-invertebrate samples collected during an index period from April to November. Sampling is curtailed through the coldest months (December to March) because of difficulties encountered in obtaining representative samples during this period (N.J. Department of Environmental Protection, 2008). At the time of data compilation for this study (2008), three rounds of sampling had been conducted and the data analyzed for most sites. AMNET "round 3" data were used to evaluate the relative level of biotic impairment in the Raritan River study basins and to support the development of flow-ecology response models that relate the aquatic-invertebrate assemblage to changes in flow processes for a subset of streams in this study. Round 3 samples for the Raritan Water Region were collected from April to early September 2004, during the established index period.

The standardized sample-collection procedures used for the AMNET program are a modification of the USEPA "Rapid bioassessment protocols for use in streams and wadeable rivers" (Barbour and others, 1999). Assessments of impairment can be made on the basis of standardized procedures, which can show perturbations measured as changes or differences in assemblage structure by means of comparisons with assemblage characteristics at designated reference sites (Barbour and others, 1999). These standardized procedures use invertebrate-assemblage metrics or traits (Poff and others, 2006; Vieira and others, 2006) to provide information on structural and functional composition, diversity, dominance, 
and tolerance (or intolerance) of aquatic organisms to anthropogenic disturbance.

For each site the NJDEP derives five invertebrate-assemblage metrics, which are ranked and summarized to produce a New Jersey Impairment Score (NJIS) (see N.J. Department of Environmental Protection (1994, 2007)). The NJIS, which ranges from severely impaired to non-impaired, is one of the criteria used by the NJDEP to evaluate stream biotic integrity, especially for those streams previously identified as having some level of aquatic-life impairment. It is also used to support the biennial New Jersey integrated water quality monitoring and assessment report (that is, the 305(b) Report and 303(d) List), which supports the development of waterquality criteria to protect aquatic life and human health (N.J. Department of Environmental Protection, 2007). The metrics from which the NJIS is derived are (1) taxa richness (based on the number of families); (2) percent dominance - the percentage of the total abundance composed of the dominant family in the subsample; (3) EPT index - the number of families represented within the orders Ephemeroptera, Plecoptera, and Trichoptera; (4) percent EPT- the percentage of the total abundance (at family level) composed of EPT taxa; and (5) modified Family Biotic Index - a weighted sum of the Family Tolerance Values, based on Hilsenhoff's tolerance scores assigned to families, which range from 0 (intolerant) to 10 (tolerant) (Hilsenhoff, 1987; N.J. Department of Environmental Protection, 2007). Detailed descriptions of the individual metrics used to derive the NJIS and results of each sampling round can be found on the NJDEP Bureau of Freshwater and Biological Monitoring Web page at http://www.state.nj.us/dep/ wms/bfbm/publications.html.

\section{Statewide Watershed Runoff Model}

To help understand the linkages between hydrologic alteration resulting from increased urbanization and biotic impairment of aquatic assemblages, the USGS, New Jersey Water Science Center, developed the physically based SWRM to simulate streamflow characteristics at AMNET sites (Kennen and others, 2008). The SWRM incorporates advantages of existing and well-documented modeling tools by integrating the Natural Resources Conservation Service (NRCS) empirically based TR-55 model (Natural Resources Conservation Service, 1986) of runoff from impervious areas with the physically based, semidistributed watershed model (TOPMODEL) equations of Beven and Kirkby (1979), as modified by Wolock (1993) and Kennen and others (2008). The SWRM, like traditional rainfall-runoff process models, tracks the movement of water as it enters the basin in the form of rain or snow and exits through evapotranspiration, direct withdrawal, or streamflow. The SWRM is also highly parsimonious, and typically requires less parameterization than many of the traditional process models.
TOPMODEL is a physically based, semidistributed watershed model that offers computational efficiencies over many of the more parameter-intensive, fully distributed hydrologic models such as MIKE SHE (Graham and Butts, 2005), HSPF (Bicknell and others, 1997), and HEC-HMS (U.S. Army Corps of Engineers, 2000; Merritt and others, 2004). The TOPMODEL component of the SWRM routes precipitation that falls on pervious areas of the watershed. The major processes considered are subsurface flow, Dunne saturation excess overland flow, and return flow. TOPMODEL, chosen because of its simple parameterization using available digital topographic and soils data, was developed during the late 1970 s in response to concerns about large computational burdens associated with spatially distributed watershed models. Such fully distributed models require that parameters be specified in each cell over a spatially discretized watershed to handle the complexity of rainfall-runoff processes. TOPMODEL, however, was one of the first models to reduce the number of parameters to a more manageable size. In its most simplistic form, TOPMODEL uses only three primary watershed parameters, each of them physically based. This small number of parameters helps ensure that their values do not become statistical artifacts of the calibration process.

TOPMODEL is well documented (Beven, 2001) and has been successfully applied in many environments (Boyer and others, 1996; Beaujouan and others, 2001; Engel and others, 2002); however, it does not account for runoff from impervious surfaces, surface- and groundwater withdrawals, wastewater contributions, or lake-storage effects. The foundation of TOPMODEL is built on the assumption that the land surface is pervious to rainfall. The SWRM approach builds on TOPMODEL by adding separate calculations derived from the NRCS TR-55 method (Natural Resources Conservation Service, 1986) to estimate runoff for portions of the basin that are covered with impervious material. These equations are based on runoff curve numbers specific to pavement, and are used to compute impervious surface area runoff as a function of the estimated ISC. This estimated impervious surface area runoff is then input to the TOPMODEL mass-balance equation at the beginning of each time step to partition runoff derived from pervious areas into its surface and subsurface components. The SWRM also incorporates equations to add wastewater contributions and remove surface- and groundwater withdrawals from appropriate flow partitions, and implements an exponential decay function to account for the effects of lake-storage delay on watershed runoff (Kennen and others, 2008).

Because the SWRM is a physically based model that can reliably predict streamflow (that is, can be used to develop a simulated hydrograph) under natural conditions or a variety of hydrologic disturbance scenarios, it is also useful for estimating potential changes in streamflow indices that could contribute to aquatic-assemblage impairment. Its use of a process-based approach is consistent with the recommendations proposed by Arthington and others (2006), who advocate development of flow-response relations between indicators 
of ecological condition and degrees of flow modification. In basins lacking long-term streamgage records, many researchers, including Snelder and others (2005), Sanborn and Bledsoe (2006), Henriksen and others (2006), Stuckey (2006), Waldron and Archfield (2006), and Poff and others (2010), support the use of flow modeling using physically based or statistical models to develop baseline hydrographs and estimate streamflow indices.

The SWRM, as applied in this study, builds on efforts of previous researchers. Gibson and others (2005), for example, used the Precipitation Runoff Modeling System to evaluate flow-regime alterations under climate change. Similarly, Thoms and Parsons (2003) applied the Integrated Quantity Quality Model to estimate the effects of land-use change on flow measures and Bobba and others (2000) used mathematical models to assess the effects of point and nonpoint sources on the quality of surface water. Statistical approaches, as opposed to process-oriented or flow models, also have been used to predict hydroecological indices. Sanborn and Bledsoe (2006) estimated streamflow indices for pristine streams in Colorado, Washington, and Oregon by using regression techniques. Van Sickel and others (2006) also used statistical methods, but estimated both flow and biological conditions for streams throughout the Willamette River Basin in Oregon. The SWRM approach is an integrated application of a robust process-oriented watershed model and is ideal for simulating hydrographs and developing linkages between anthropogenic processes and streamflow response.

By offering a physically based linkage between anthropogenic change and streamflow response, the SWRM represents an important tool for assessing the extent and degree of biotic impairment of aquatic-invertebrate assemblages as a result of watershed and streamflow alterations. It provides State watershed managers with a systematic means for developing basinspecific plans necessary to protect, maintain, or restore flow conditions that best balance the competing demands of human growth and maintaining biotic integrity in targeted watersheds. Kennen and others (2008) successfully used the SWRM to predict several flow-dependent variables, including the average number of storms per year that produce quick flow (that portion of streamflow that moves rapidly to the stream during a storm event as surface runoff; Woodruff and Hewlett, 1970), the ratio of 25-percent exceedance flow to 75-percent exceedance flow (a measure of stream flashiness), the minimum size of storms needed to produce quick flow, the average annual quick flow, and the statistical relation between streamflow characteristics and the biotic integrity of aquatic ecosystems in New Jersey, as reflected by the impairment score derived from data collected at New Jersey AMNET sites. As the hydrologic basis of this study, the SWRM is used to derive the simulated baseline (minimally altered) hydrographs necessary to evaluate changes in streamflow processes and supports the development of streamflow criteria for implementing a hydro-TMDL and flow-ecology response models.

\section{Hydroecological Integrity Assessment Process}

The Natural Flow Regime Paradigm (Poff and others, 1997) synthesizes existing scientific knowledge to argue that the natural flow regime plays a critical role in sustaining native biodiversity and ecosystem integrity in rivers. Decades of observation of the effects of human alteration of natural flow regimes have established that altering the hydrologic regimes in rivers can be ecologically deleterious (for example, Johnson and others, 1976; Tyus, 1990; Hill and others, 1991; Arthington and others, 1992; Sparks, 1995; Toth, 1995; Castleberry and others, 1996; Stanford and others, 1996; Richter and others, 1997; and many others). These authors argue that streamflow quantity and timing are critical factors that affect the ecological integrity of river systems. Many studies have documented ecological responses to alterations of the natural flow regime; examples include fish life-cycle disruption, encroachment of vegetation, loss of sensitive aquatic-invertebrate species, and loss of fish access to backwaters and wetlands (Poff and others, 1997). Work by Olden and Poff (2003) provided a statistically based scientific pathway to help investigators identify hydrologic indices that adequately differentiate stream types on the basis of five critical elements of the flow regime: magnitude, frequency, duration, timing, and rate of change. The Hydroecological Integrity Assessment Process (HIP) (Kennen and others, 2007) builds on this scientifically based foundation. Flow characteristics of streams differ with basin size, local gradient of the stream channel, physiographic province, vegetative cover, climate, and the type of human activity causing the flow disturbance. Treating all basins as if they behave in a hydrologically similar way confounds efforts to identify linkages among streamflow alteration, level of urbanization, and aquatic-assemblage response because differing classes of streams can show distinctly different responses to the same anthropogenic stressors. In recognition of these differences, gaged basins in the Raritan River system were classified according to hydrologic similarity by using the HIP classification scheme (Kennen and others, 2007). When streams are grouped into classes on the basis of similar hydrologic characteristics, deterministic streamflow influences are removed from the analysis and changes in streamflow behavior can be evaluated within each individual class.

The HIP represents a suite of software tools that can be used to identify and relate aquatic-assemblage response to ecologically relevant hydrologic indices (ERHIs) determined from water-depletion or hydrologic-alteration scenarios (Kennen and others, 2007). The HIP incorporates many of the NFRP principles, which recognize that the diversity and integrity of aquatic ecosystems depend on preserving natural streamflow variability. The structure and function of riverine ecosystems are strongly influenced by hydrologic variability, which can be used to characterize the entire range of flows, as well as the 
specific hydrologic events critical to maintaining the integrity of river ecosystems.

The HIP consists of (1) a statewide classification of streams into hydrologic stream types on the basis of streamflow data from long-term gaging-station records for a subset of streams in relatively unmodified basins; (2) an identification of stream-type-specific indices that address 10 subcomponents (that is, a subset of important ERHIs) of the flow regime; (3) an ability to establish environmental flow standards; (4) an evaluation of hydrologic alteration; and (5) a capacity to conduct alternative analyses (Kennen and others, 2007, 2009). HIP includes the Hydrologic Index Tool (HIT), the New Jersey Stream Classification Tool (NJSCT), and the New Jersey Hydrologic Assessment Tool (NJHAT) (Henriksen and others, 2006). The HIT is a stand-alone program that uses USGS daily mean and peak flow discharges from the National Water Information System (NWIS) databases (available at $h t t p: / /$ waterdata.usgs.gov $/ n w i s / s w)$ to generate a series of ERHIs that are used to help characterize and classify stream flow regimes that are thought to be important in shaping ecological processes in streams (Olden and Poff, 2003; Kennen and others, 2007).

In this study, the HIP software was used to assess the baseline hydrographs (the minimally altered or reference hydrographs) identified through either quantile regression (QR) analysis (refer to section on Application of Quantile Regression to Identify Baseline Time Periods for Streams in the Raritan River Basin) or simulated using the SWRM for each study basin. It was also used to derive a suite of ERHIs for the baseline hydrograph and the current, anthropogenically modified hydrograph (that is, the observed or present-day hydrograph) in an effort to evaluate proportional differences between them for use in hydro-TMDL development. The HIP accomplishes this task by using flow statistics, trend analysis, and 10 primary stream-class-specific indices chosen from the available hydrologic indices (Henriksen and others, 2006; Kennen and others, 2007). The software generates 171 hydrologic indices (see appendix 1 for definitions of all 171 indices) that are widely accepted as having ecological significance (Olden and Poff, 2003) by using daily mean and peak flow discharge data. If peak flows are not available, then eight HIT indices (FH11, DH22, DH23, DH24, TA3, TH3, TL3, and TL4) are not calculated.

By using the HIP approach, four distinct New Jersey stream classes were identified on the basis of streamflow behaviors observed in 88 minimally altered streams. Stream classes include semiflashy streams characterized by moderately low base flow (class A), stable streams supported by large base-flow contributions (class B), moderately stable streams with moderately high base-flow contributions (class $\mathrm{C}$ ), and flashy streams that receive little base flow and yield large volumes of runoff over short periods of time (class D). (For more information about stream class, see
Kennen and others (2007)). The New Jersey Stream Classification Tool (NJSCT) can also be used to classify streams that were not included in the original analysis and is based on direct comparison of statistically significant streamflow attributes for specific stream classes using discriminant function analysis (Kennen and others, 2007, 2009). For this study, only stream classes A and C in the Raritan River Basin were used for the hydro-TMDL assessment because of their relatively similar streamflow characteristics.

The New Jersey Hydrologic Assessment Tool (NJHAT; Kennen and others, 2007) was used in this study to examine baseline time periods and help identify periods in the hydrograph that show a response to human activities. Through close examination of contrasting stream hydrographs with NJHAT and using statistical tools (for example, QR), streamflow characteristics were directly compared. If changes in the streamflow characteristics could not be related directly to changes in precipitation by using QR, it was assumed that changes in the hydrograph were the result of anthropogenic activities (for example, surface-water withdrawals or diversions, groundwater pumping, or land-use changes) that altered natural patterns of streamflow somewhere in the study basin or in a tributary stream. Observed changes in critical streamflow indices relative to those calculated for natural or simulated baseline conditions were used to provide a quantitative indication of the proportional difference to which natural flow patterns have been modified by anthropogenic alterations or have deviated from natural streamflow patterns.

\section{Identifying Baseline Periods of Record and Stream Class in the Raritan River Basin}

Accurately determining base-flow components and baseline conditions of stream hydrographs depends on expert judgment and institutional knowledge; however, evaluation of baseline periods of streamflow record can be biased if information about patterns of population growth, timing of reservoir releases or water withdrawals, and discharge records in existing databases is in error or is incomplete. Hydrograph analysis also requires that hydrologists be able to discern subtle patterns in the streamflow record and judge which are indicative of systematic changes in the natural flow regime. Study basins for this project were chosen in cooperation with the NJDEP, and the Raritan River Basin was targeted because of existing TMDL concerns and the need to choose an area with streams that are known to be relatively similar hydrologically (primarily New Jersey stream classes A and C). Examples of the stream sites evaluated for inclusion in this study and the analytical process used to classify streams 
and examine hydrographs for discerning baseline periods of streamflow record are presented below.

For the 1945-2006 hydrograph of the Raritan River below Calco Dam at Bound Brook, NJ (USGS station number 01403060, fig. 2), streamflow at the gage appears relatively unaltered in its mean behavior. If the statistical distribution of flow from year to year is examined, however, it becomes evident that streamflow in the Raritan River below Calco Dam underwent identifiable changes in behavior beginning in the 1950s. On the basis of this example (fig. 2), however, determination of the period of unaltered flow by means of direct observation of the hydrograph may not be the most appropriate way to identify baseline time periods for streams whose behavior has been modified by anthropogenic influences.

A more objective and informative approach to defining the onset of streamflow alteration resulting from anthropogenic alteration of the landscape (for example, urbanization and development) might focus on examining the extremes of the probability distribution of daily streamflow. It is in these extremes, or "tails," of the probability distribution where flow alterations are likely to be most evident. For example, increased ISC typically associated with road and parking-lot construction tends to inhibit infiltration of rainfall into the soil and underlying aquifers (Dunne and Leopold, 1978; Klein, 1979; Schueler, 1994; Arnold and Gibbons, 1996) as well as change discharge and stormwater runoff patterns (Espey and others, 1966; Leopold, 1968; Seaburn, 1969; Hirsch and others, 1990; Arnold and Gibbons, 1996). This reduction in infiltration not only yields rapid overland flow during storms and produces higher flood-flow events, it also decreases groundwater contributions in the days, months, or even years following the storm event. Loss of infiltration capacity can also generate critical low-flow conditions in the stream during intervals of the year when streamflow would have been sustained by groundwater storage in the absence of urbanization. A second example is surface-water diversions from reservoirs for municipal and agricultural water use, which can produce low-flow events by removing water from reservoir storage, from which it is no longer available for release during dry periods. Both peak-flow and low-flow events are of particular concern because such flows provide the conditions necessary to support natural assemblage complexity (Stanford and others, 1996; Poff and others, 1997; Richter and others, 1997; Mathews, 2005). Any measurable change in these extreme flow components may compromise the biotic integrity of aquatic ecosystems by modifying substrate quality, altering water temperature and nutrient concentrations, and reducing connectivity between the stream channel and adjacent productive riparian zones, thereby degrading conditions essential for maintaining the abundance and diversity of aquatic assemblages (Grossman, 1982; Poff and Ward, 1989; Lytle and Poff, 2004).

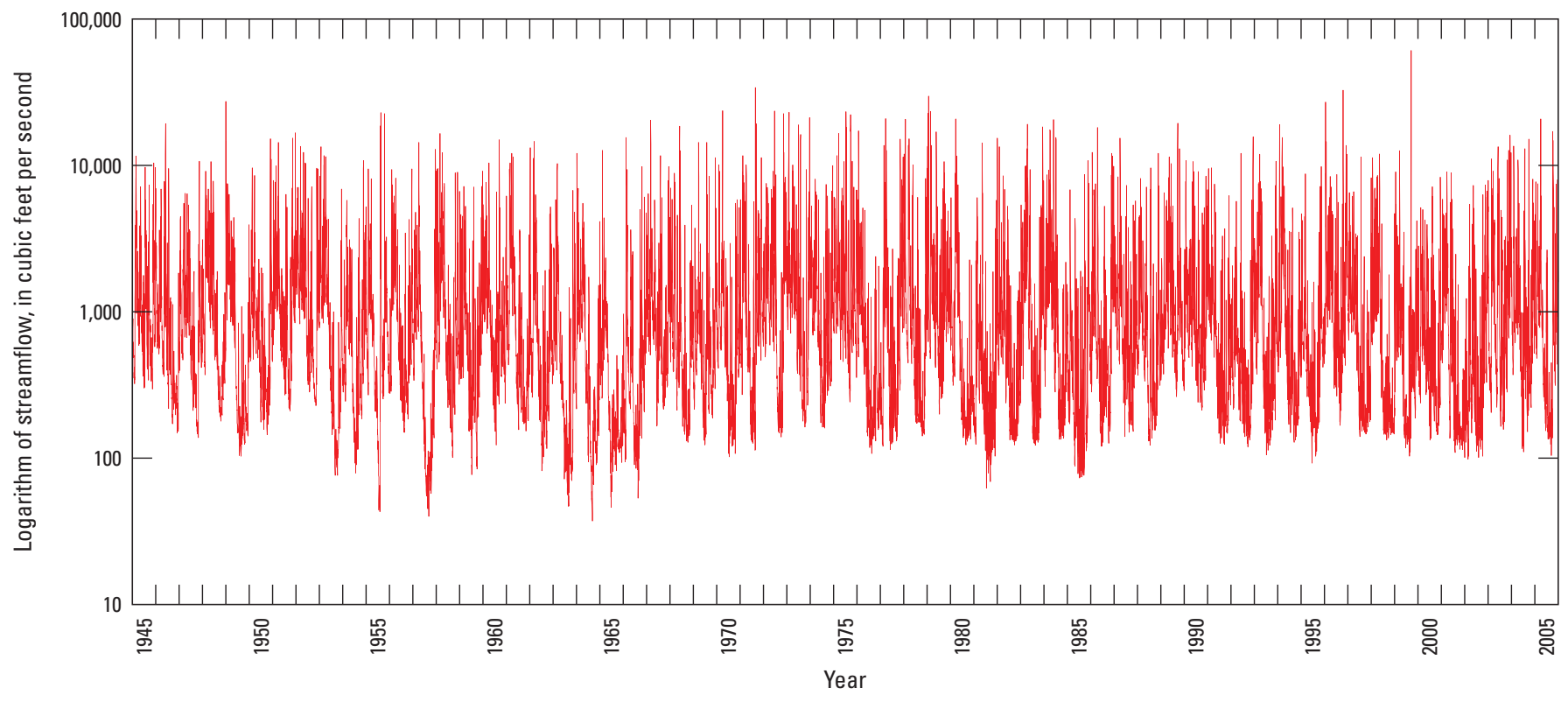

Figure 2. Hydrograph for U.S. Geological Survey streamgage Raritan River below Calco Dam at Bound Brook (station number 01403060), New Jersey, 1945-2006. 


\section{Application of Quantile Regression to Identify Baseline Periods of Record}

In some cases, direct inspection of stream hydrographs can be used to identify the baseline period of record (POR) during which a stream has remained relatively undisturbed by anthropogenic alterations of the landscape. In most cases, however, a more objective approach is needed to define a baseline time period (for example, Esralew and Baker, 2008). Although the timing, frequency, and magnitude of peak- and low-flow events are observable in the historical hydrograph, it is often difficult to discern how the properties of these events have changed through time without the aid of statistical analysis. To determine how the statistical properties of daily streamflow might have changed from year to year, probability density functions can be constructed for each year by using all daily flows that occurred within that year. QR (for example, Cade and Noon, 2003) can be used to more objectively identify baseline periods of record for streams for which flow has remained relatively unaltered by human activity or estimate the onset of streamflow alteration in hydrologically modified basins.

Consider the area draining to the North Branch Raritan River at Far Hills, NJ (USGS station number 01398500, fig. 3). This drainage basin has few wells, a small number of New Jersey Pollutant Discharge Elimination System (NJPDES) surface- and groundwater sites, and no reservoirs or other impoundments. With only 5.3 percent total impervious surface cover (ISC) in 2002 (N.J. Department of Environmental Protection, 2008), it is not considered to be an intensively developed basin. Five AMNET sites distributed throughout the upstream reaches of the basin showed minimal biological impairment. On the basis of the HIP-identified baseline streamflow, the stream draining the North Branch Raritan River at Far Hills, NJ, was classified as stream class C (see Kennen and others, 2007, app. 4, p. 38).

QR analysis of daily observed streamflows at the streamgage from 1922 to 2006 are presented in figure $4 \mathrm{~A}$, where each set of vertical points can be viewed as the probability density for the corresponding year against which streamflows are plotted. Streamflow shows a consistently positive skew across the years of record, with a long tail in the direction of higher quantile flows. Such a positive skew is common, particularly for flashy streams that are not dominated by base-flow contributions. If a line of least squares is fit to all of the points by using traditional regression, allowing the slope of the line to change at breakpoints every 10 years, it will trend through the mean daily streamflow at each breakpoint year. It is not mean streamflow, however, that is of greatest interest, but rather extreme flow behavior. The conditional mean provided by conventional regression does not contain information necessary to determine whether significant alterations have occurred in the statistical behavior of extreme flow events, because it considers only average changes. Given the strong asymmetries in the distributions of daily streamflows throughout the years, the mean provides only limited information about typical flow response in the basin.

In contrast, QR (fig. 4) fits a line to a particular quantile rather than to the conditional mean and is especially useful for assessing changes in extreme high- or low-flow events. Quantiles are related to the more traditional concept of exceedance probabilities, with 10-percent exceedance probability corresponding to the 90 th quantile, 20 -percent exceedance probability corresponding to the 80th quantile, and so on. Regression lines for nine equally spaced (10th, 20th, 30th, 40th, 50th, 60th, 70th, 80th, and 90th) daily streamflow quantiles were plotted on a log scale. Breakpoints, where the slope of the regression line was allowed to change, are seen at years 1930, 1940, 1950, 1960, 1970, 1980, 1990, and 2000. The QR plot (fig. $4 A$ ) shows that streamflows are not symmetric about the 50th quantile, as they would be if the streamflow values were normally distributed. In the presence of asymmetry, the conditional mean, which is determined by means of traditional regression by minimizing the sum of squared deviations, would yield a biased estimate of the average streamflow response for the basin.

To determine whether observed changes in streamflow quantiles over time could be related to temporal climatic influences, precipitation was also analyzed by using QR (fig. $4 B$ ). Because precipitation intensity governs the partitioning of rainfall into overland runoff and subsurface flow and ultimately dictates how flow is distributed probabilistically during any given year, hourly rather than daily precipitation values were used for the QRs. If patterns in hourly precipitation quantiles closely follow patterns in daily streamflow quantiles, then changes in precipitation likely explain much of the observed changes in streamflow. Relations between rainfall and streamflow would be particularly evident in the higher quantiles, because intense storms are highly correlated with peak-flow events. This relation is especially true when the flow geometry of the basin is highly convergent, with the main flow channel oriented parallel to the direction of longer basin dimension, as in the Raritan River Basin. The correlation between rainfall and streamflow tends to be weaker in lower rainfall-runoff quantiles, because small storms generally do not produce immediate runoff in undeveloped basins unless the basin overlies valley-fill or coastal-plain deposits where depth to groundwater and subsurface storage are typically small (Zapecza,1989).

All hourly rainfall values, including zero values, were required to be included in the precipitation regression in order to accurately reflect the probability distribution of hourly rainfall. Omission of zero-valued hourly precipitation measurements would treat unusually dry years associated with low 

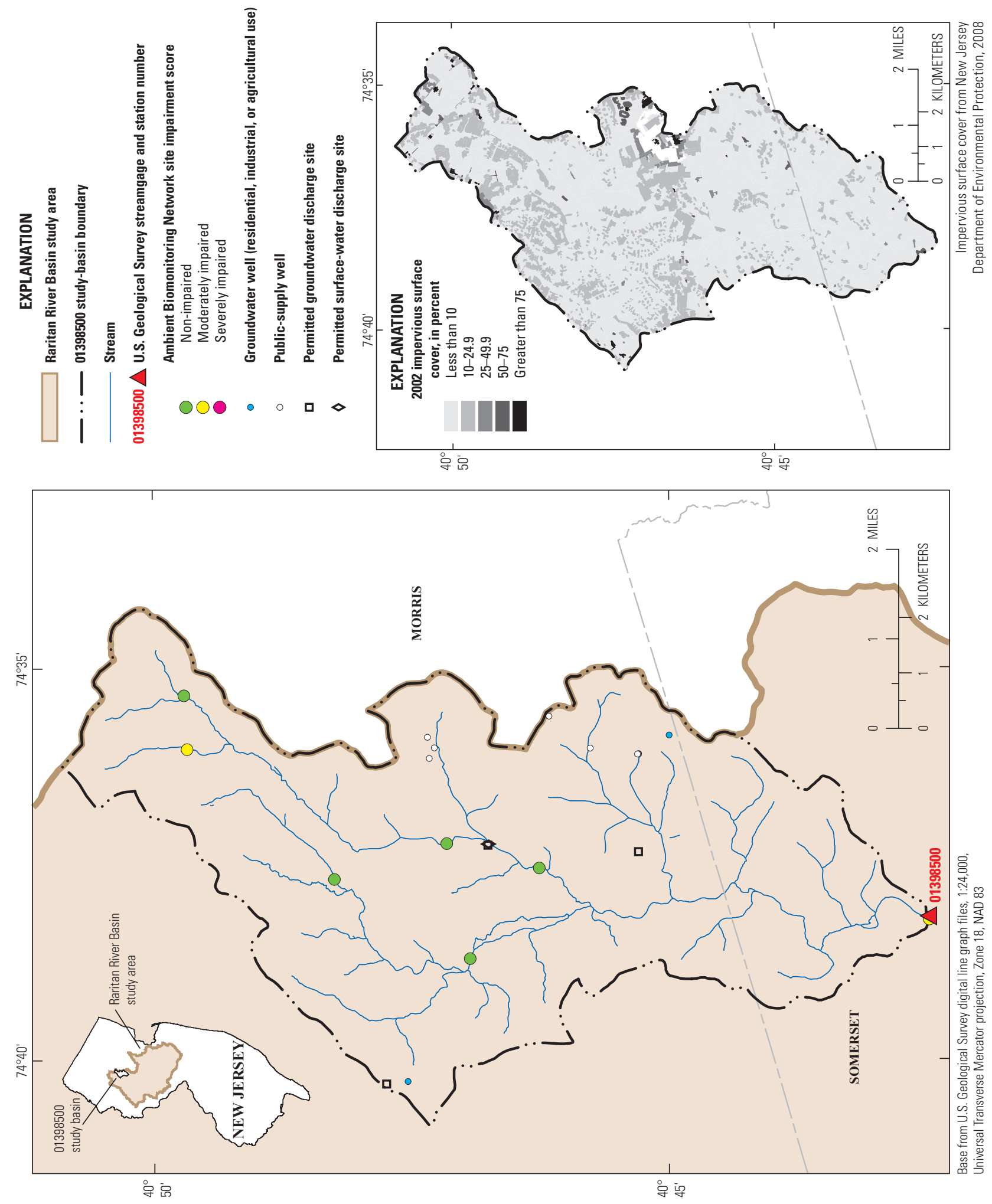

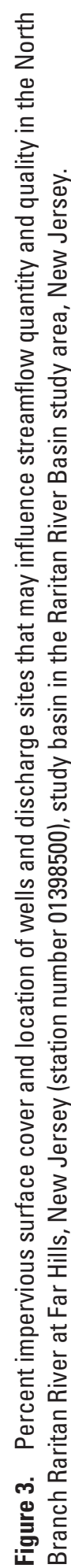



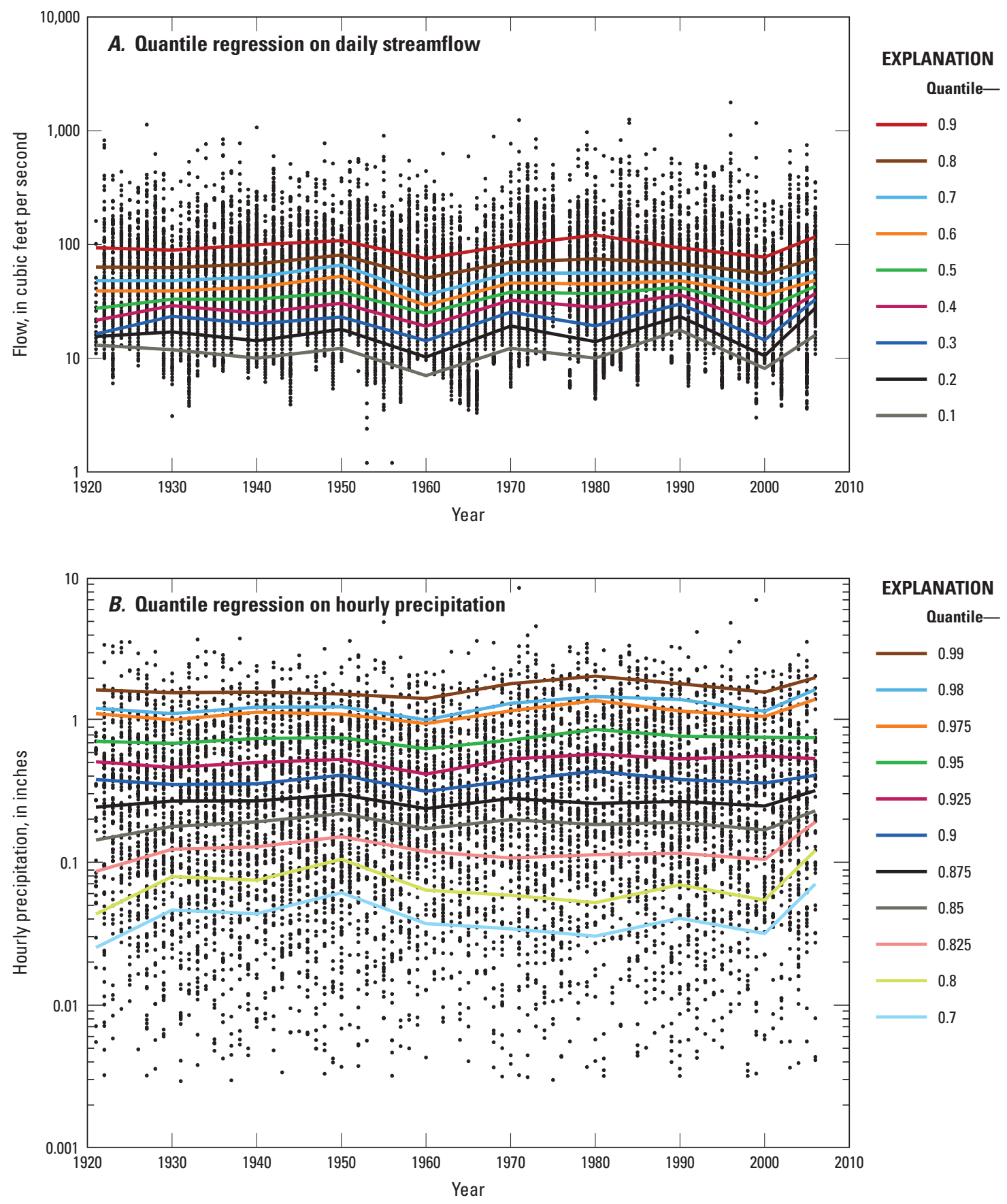

Figure 4. Quantile regressions for $A$, daily streamflow and $B$, hourly precipitation at U.S. Geological Survey streamgage Raritan River at Far Hills, New Jersey (station number 01398500). 
storm frequency not much differently than slightly dry years, and possibly bias the results of the QR. The large number of same-valued zero hourly rainfalls associated with dry days, however, caused matrix singularities that compromised the simplex method (a standard iterative procedure in linear programming for solving an optimization problem; see Dantzig, 1951) used to perform the QR. To overcome this discrepancy, all zero-valued hourly precipitation measurements were randomly perturbed by a small amount, ranging between 0 and 0.0001 millimeters. To enhance resolution of the precipitation plots, the rainfall axis in the QR plots did not include these small values.

The high degree of correspondence between changes in hourly precipitation quantiles and changes in daily streamflow quantiles (fig. 4) appears to indicate that alterations in observed daily streamflow at the North Branch Raritan River at Far Hills site can be attributed largely to climatic fluctuations, and that streamflow essentially remains in its nearnatural, or relatively unaltered (baseline), state. The strong correspondence between rainfall and streamflow quantiles provides clear, objective evidence that properties of daily streamflow within the basin have not been substantially altered since 1922, when the POR for the gage began. Minimal streamflow disturbance is also supported by the impairment status at the five AMNET sites (fig. 3), which indicates that most aquatic-invertebrate assemblages in the basin have been minimally affected by human activities or changes directly associated with flow alteration. By using the entire 1922-2006 POR, NJSCT classified the stream as type C (table 1, at end of report). The 1922-2006 reference baseline POR identified by using QR for the North Branch Raritan at Far Hills, NJ (USGS station 01398500), is in agreement with that found by Esralew and Baker (2008; table 2, p. 11). It is not in direct agreement, however, with that previously used to classify streams for the New Jersey HIP study (Kennen and others, 2007, app. 4), in which a more conservative baseline period of 1922-75 was used to avoid even the most minor anthropogenic effects that might influence streamflow (for example, groundwater withdrawals). The quantile plots show, however, that most fluctuations in streamflow after 1975 can be directly attributed to changes in precipitation. The absence of observable anthropogenic flow disturbance during the available record explains why both the 1922-75 and 1922-2006 PORs result in the same stream classification (class $C$; table 1).

On the basis of results of the QRs, the stream draining to the North Branch Raritan River at Far Hills, NJ, gage would be considered to represent a stream near the "least altered" end of the hydrologic-disturbance gradient. Many other Raritan River subbasins, however, would be expected to show some evidence of flow alteration caused by human activities, especially larger basins downstream from the North
Branch Raritan River at Far Hills, NJ, gage that integrate broader areas of anthropogenic disturbance. Candidates for basins that likely represent more anthropogenically modified locations along the disturbance gradient include those that contain a large number of moderately impaired AMNET sites; are characterized by a greater percentage of ISC (typically greater than 5 percent); and have a long POR that begins prior to development, ends roughly at the present time (2012), and includes a sufficient number of predevelopment years to establish reliable flow indices for relatively unaltered (baseline) flow. Although few basins meet all these criteria and sites chosen for this study were mostly non- to moderately impaired, the basin draining to the streamgage on the Raritan River at Manville, NJ (USGS station number 01400500; fig. 5), may lie closer to the "altered" end of the disturbance gradient than most other streams in the Raritan River Basin evaluated in this study.

Although the area that drains to the Raritan River at Manville streamgage was characterized by only 7.0 percent ISC in 2002, the available 1922-2006 streamflow record for this streamgage indicates that dense urbanization immediately upstream from the gage may have contributed to the long-term alteration of the mean and variance of observed streamflow (fig. 6) at this site. Unlike the North Branch Raritan River at Far Hills basin (fig. 3), the Raritan River at Manville basin drains a relatively large area that encompasses substantial anthropogenic alteration (fig. 5), including concentrated urbanization, diversions at the Spruce Run and Round Valley Reservoirs, permitted surface-water discharges, and groundwater pumping. As a consequence of these factors, most Raritan River basins in this study would be expected to lie somewhere between the North Branch Raritan River at Far Hills (fig. 3) and the Raritan River at Manville (fig. 5) basin endpoints in their degree of hydrologic alteration.

Whereas none of the AMNET sites within the basin draining to the Raritan River at Manville streamgage shows severe biotic impairment, most indicate moderate levels of impairment (fig. 5). The impaired sites tend to be in downstream reaches of the drainage basin where the effects of upstream alterations of flow have accumulated and where ISC tends to be concentrated. Some, however, are in upstream areas where a large number of domestic-supply wells are present, or lie immediately downstream from the Spruce Run and Round Valley operational reservoirs. Over such a large drainage area, it is nearly impossible for flow to remain unaltered in the presence of such diverse and widely diffuse anthropogenic activity. QR analysis of daily observed streamflows at the Raritan River at Manville, NJ, streamgage (fig. $7 A$ ) indicates that mean daily flow changed and streamflow variation decreased sometime during the 1960s, but it is not clear how the statistical distribution of daily flow processes 

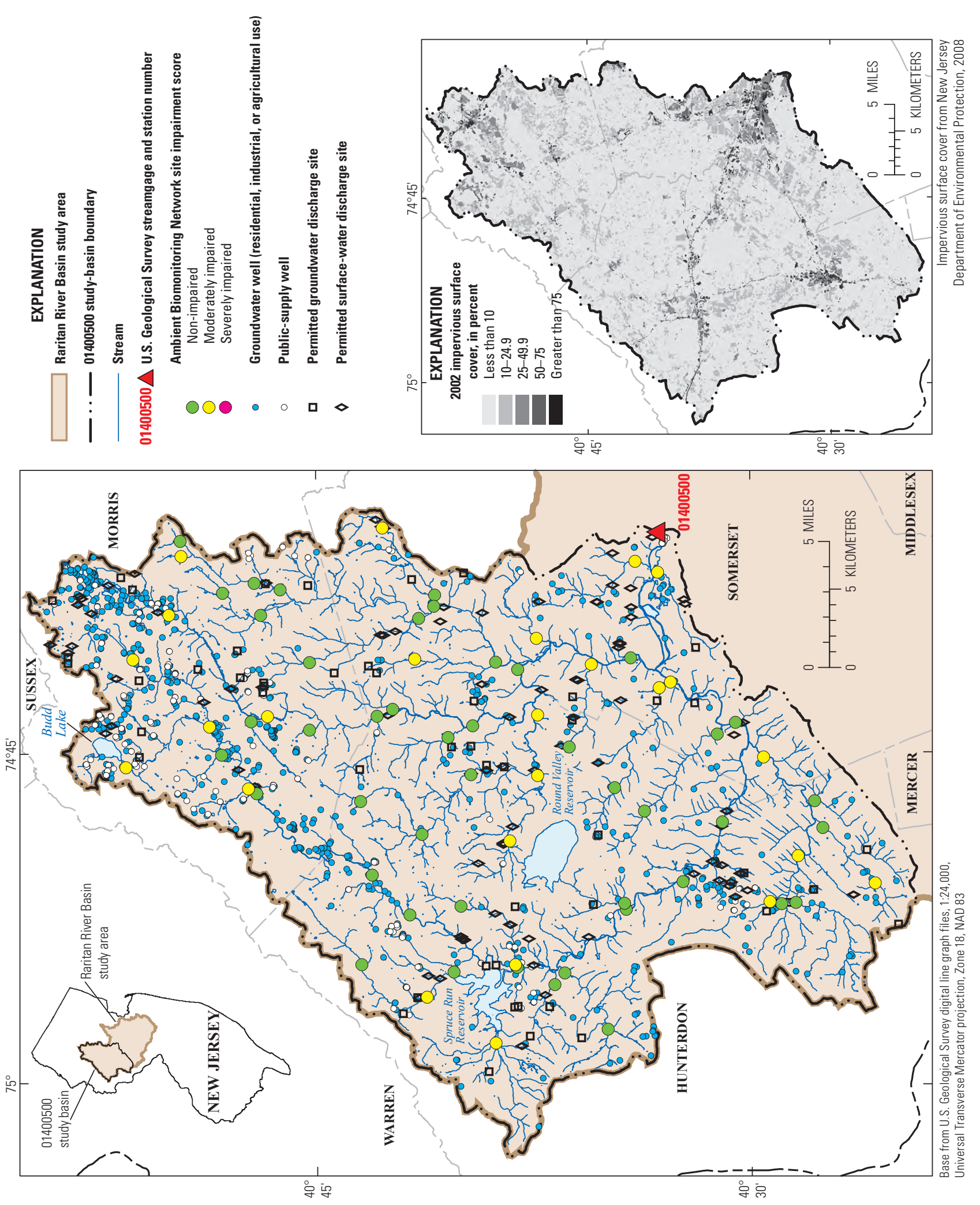

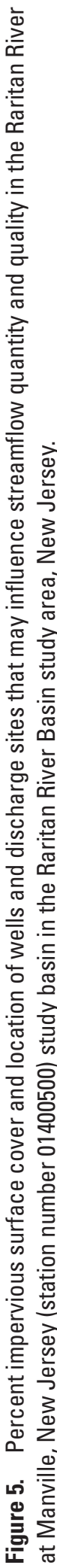


has changed, or precisely when the change occurred. The QRs of daily streamflow (fig. $7 A$ ) indicate that after about 1960, changes in streamflow appeared to show little relation to changes in hourly precipitation (fig. 7B) across all quantiles, indicating anthropogenic mechanisms were likely responsible for the observed flow alteration. ISC for the basin, though estimated at 7.0 percent in 2002, is concentrated just above the streamgage and is likely to have had a pronounced effect on observed streamflow. Reservoir operations, which began during the early 1960s, also likely contributed to the observed flow disturbances.

Breakpoints at 1960, 1963, and 1965 (fig. 7) were included in the QRs to determine as precisely as possible when urban development or reservoir operations began to affect streamflow behavior. Noticeable changes appear to have begun in 1960, indicating that flow alterations associated with reservoir construction may have influenced streamflow even before the onset of reservoir operations. By using observed streamflows over the longest continuous baseline POR (1922-60), NJSCT classified the stream as being in class A (table 1), which is consistent with the classification reported in the New Jersey HIP study (Kennen and others, 2007). The Raritan River at Manville, NJ, streamgage provides an excellent example showing that statistical examination conducted using the probabilistic distribution of streamflow over time provides a more precise determination and understanding of the baseline POR than a historical examination of the streamflow record alone, which might not reveal or explain subtle changes related to climatic or anthropogenic drivers. By using all available streamflow and precipitation data, the same QR approach used for the North Branch Raritan River at Far Hills and Raritan River at Manville, NJ, streamgages (figs. 4 and 7, respectively) was used for the remaining 49 Raritan River Basin study basins to determine whether significant changes in the statistical properties of streamflow occurred and, if so, whether they could be directly related to changes in precipitation.

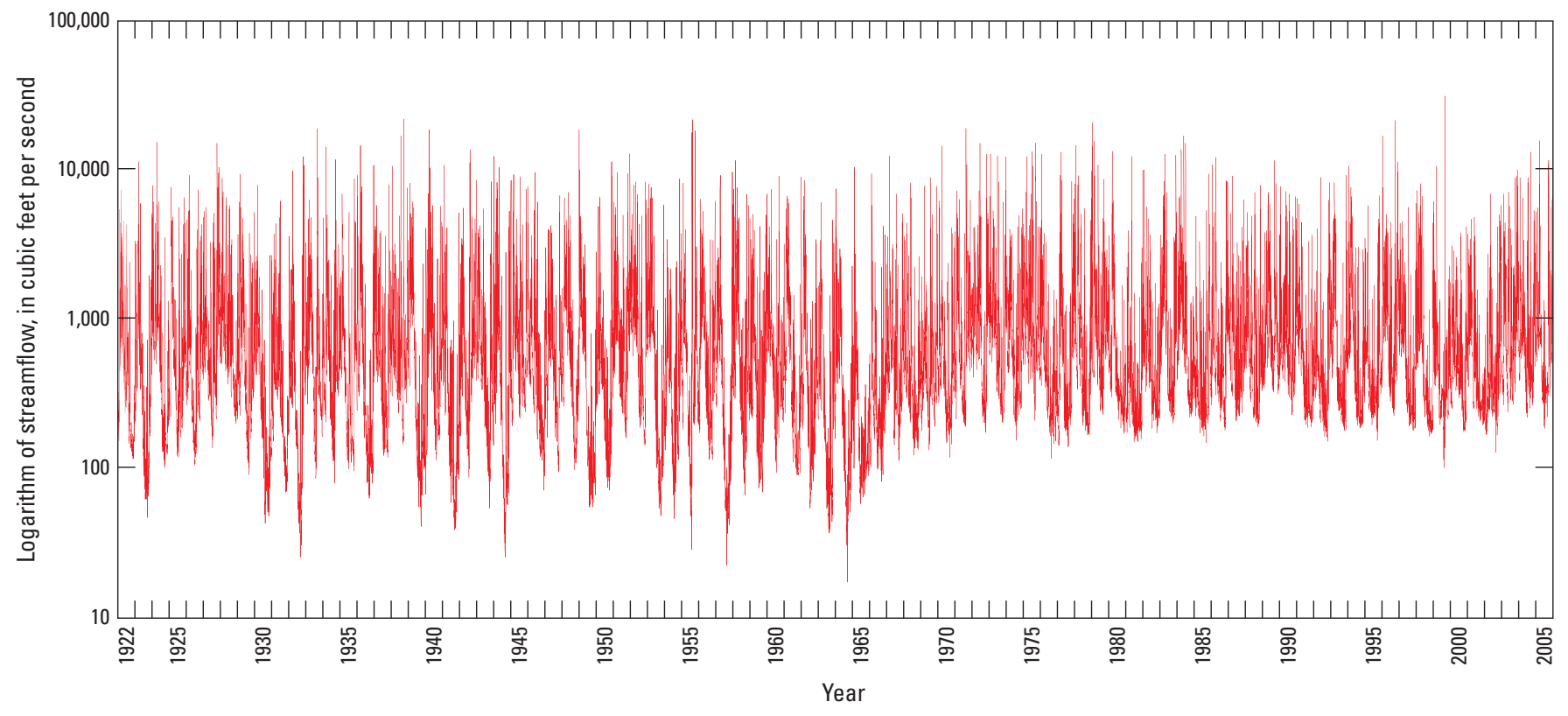

Figure 6. Hydrograph for U.S. Geological Survey streamgage Raritan River at Manville, New Jersey (station number 01400500), 1922-2005. 

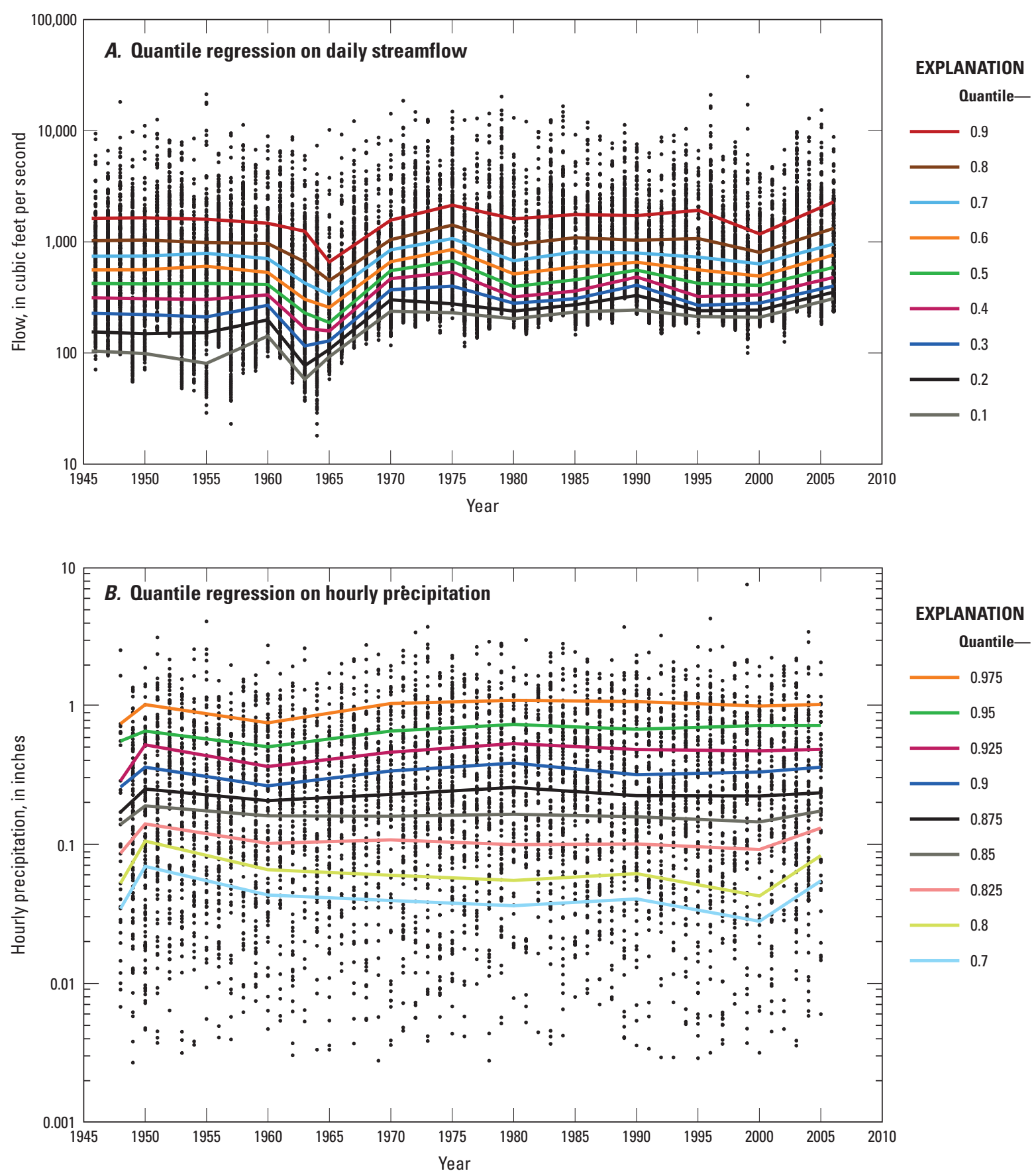

Figure 7. Quantile regressions for $A$, daily streamflow and $B$, hourly precipitation at Raritan River at Manville, New Jersey (station number 01400500). 


\section{Sensitivity Analysis and Calibration of Watershed Model Parameters}

To effectively develop, or synthesize, a baseline hydrograph that can serve as a strong basis for comparison with the hydrograph that is representative of altered flow conditions, the hydrologic parameters used in a watershed model (for example, the SWRM) need to be appropriately calibrated. A procedure for quantifying parameter sensitivity that is an extension of the generalized sensitivity analysis originally proposed by Hornberger and Spear (1981) was implemented for the SWRM. Because correlation among parameters manifests as lack of sensitivity, sensitivity analysis on the SWRM parameters was used to identify parameters that provide redundant information and therefore should be excluded from calibration procedures (Kennen and others, 2008). Failure to remove correlated parameters from the analysis can result in a biased calibration that produces poor parameter estimates. By using a maximum likelihood approach, in which Monte Carlo methods are used to sample uniformly over the SWRM parameter space, the "best" parameter sets for all 51 gaged drainage basins were obtained by using 100 parameter realizations. Only 100 realizations were used because of the large number of basins in the analysis and the fact that two sets of these realizations had to be generated. The first set was to determine to which parameters the model was sensitive and to remove correlation among parameters. The second set was to obtain the optimal ("best") parameter set that minimized the sum of squared error in daily streamflow over the POR unique to the particular basin being considered. This analysis indicated that the 51 gaged basins consistently showed the highest sensitivity to parameter $\mathrm{m}$, which is a function of soil porosity (Kennen and others, 2008). The "best" parameter sets for each of the study basins were identified and used to develop simulated hydrographs; however, parameters for two of the study sites (the two Royce Brook tributary sites, USGS station numbers 01402590 and 01492600 ) could not be fully calibrated, presumably as a result of the intermittent nature of these streams, a condition that is not easily handled with a saturation-excess algorithm like the one used in the SWRM.

\section{Reevaluation of Raritan River Basin Stream Classes}

The New Jersey Stream Classification Tool (NJSCT) was used to reevaluate the stream class of all 51 cooperatively identified study basins on the basis of the existing POR. The purpose of the reevaluation was twofold. First, additional streamflow data have become available since the original classification was done by Kennen and others (2007); these new data potentially could affect some stream classifications. Second, the initial New Jersey HIP work relied on examination of long-term flow records in concert with best professional judgment as a basis for establishing the extent of the baseline POR and for identifying when alteration resulting from human activities first began to influence the hydrograph. In this study, a more comprehensive, statistically based approach (that is, quantile regression) was used to identify when the major effects of anthropogenic streamflow alterations (for example, dams, surface-water withdrawals, interbasin transfers, and other water-management infrastructure) began to alter the natural flow regime. Streams in a given stream class typically exhibit similar hydroecological characteristics and, therefore, are expected to exhibit a hydrologic "signature" that is unique for a given stream class. On the basis of the work of Henriksen and others (2006), a suite of 10 nonredundant hydroecological indices accounting for the five major components of streamflow for each of the two New Jersey stream classes considered in this study (classes A and C) was identified (fig. 8), and these indices were used to help characterize the unique hydrology of these stream classes. All 51 Raritan River study basins included in this assessment were classified by using the NJSCT software (fig. 1) on the basis of either the quantileregression-derived baseline POR or the simulated baseline POR from the SWRM. The latter approach was necessary for study basins classified as "unknown" (table 1), because an observed baseline POR could not be established from the existing hydrologic record.

Of the 51 Raritan River study basins chosen for this study, 12 were identified as members of stream class D (sites that are typically characterized by high peak flows) and therefore were not considered for further analysis in the current study. In addition, the basins of the two Royce Brook tributary sites (USGS stations 01402590 and 01402600), mentioned in the previous section, were removed from analysis because the SWRM could not be calibrated and, therefore, no baseline POR could be simulated for comparison (table 1). On the basis of the results of $\mathrm{QR}$ analysis, baseline streamflow data for 16 of the remaining 37 basins was sufficient to characterize the streams as either class A or class $\mathrm{C}$ by using the NJSCT (table 1), and these 16 basins were retained for further analysis. The remaining 21 basins (referred to as "unknown" in table 1) did not have an observed period of unaltered flow (could not be identified by using QR) to accurately define a stream class. For these streams, simulated unaltered (baseline) hydrographs needed to be developed by using the SWRM in order to accurately identify the stream class. This step was necessary because a basis for hydrologic comparison (whether to a known baseline established from the existing POR or to one that was simulated by using the SWRM) needed to be established for all class $\mathrm{A}$ and $\mathrm{C}$ streams in order to evaluate the proportion of potential deviation of hydrologic indices from those associated with less altered streamflow conditions. Of the 21 streams classified as "unknown," 13 were identified as either class $\mathrm{A}$ or $\mathrm{C}$ on the basis of the simulated baseline hydrograph (table 1) and were retained for further analysis. Ultimately, 29 streams were identified as either class A or class $\mathrm{C}$ streams and were found to be acceptable for use in the comparative hydrologic analysis portion of this study. 

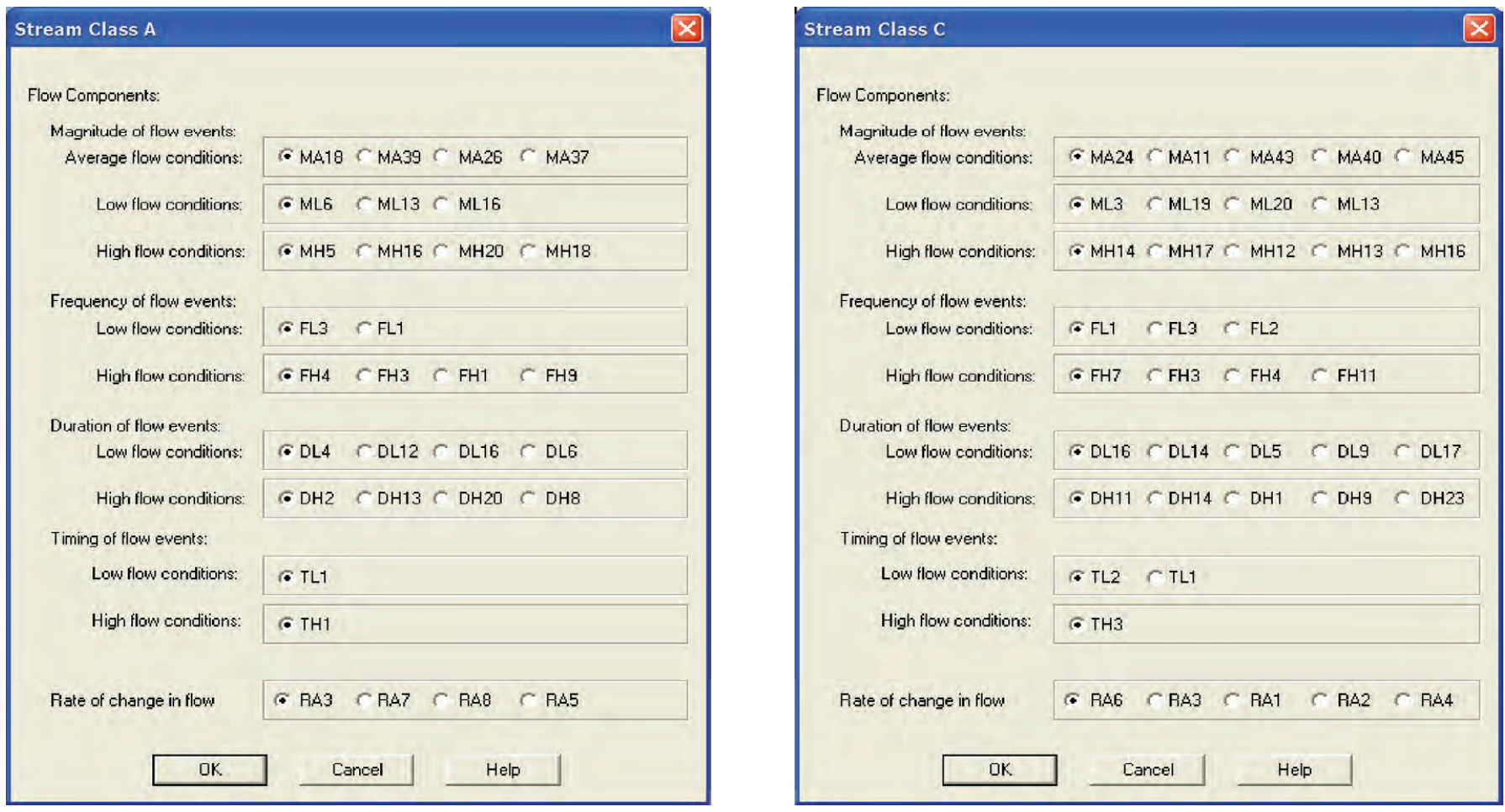

Figure 8. Interactive window for selecting nonredundant hydrologic indices for stream classes $\mathrm{A}$ and $\mathrm{C}$ as identified in the New Jersey Hydrologic Assessment Program (NJHAT). (See appendix 1 or Kennen and others (2007) for hydrologic index definitions.)

\section{Simulation of Unaltered Streamflow}

Once the parameters for the unclassified basins were appropriately calibrated by using the approach described above, modifications were made to portions of the SWRM to set percent ISC and water use (that is, groundwater withdrawals and surface-water diversions and discharges) to zero for all years to reflect unaltered flow conditions. The availability of either daily (1902-48) or hourly (1948-present (2006)) rainfall data from 1902 to 2006 made it possible to generate long-term hydrographs that were NWIS-formatted and ready for input directly into NJSCT and NJHAT for further assessment of stream class and analysis of the unaltered streamflow indices, respectively. Because the NJHAT/NJSCT software accepts only 100 years of data at a time, the period from 1907 to 2006 was chosen as the POR for analysis. At the time the data were run through the SWRM, however, the flow record for 2006 was incomplete (was available only to June 30,2006 ), so the record for 2006 could not be considered a complete water year and was subsequently eliminated from the streamflow analysis. Ultimately, the POR from 1907 to 2005 was used as the final input for all streamflow simulations performed using the SWRM. The SWRM was run in predictive mode and all streamflow simulations were completed by using the parameter set identified by maximum likelihood sensitivity analysis and the calibration procedures described earlier. In general, high-flow events were smaller in magnitude under unaltered flow conditions than under observed conditions and low-flow events were higher in magnitude (which would be expected when flows that have been altered through anthropogenic activity are compared to those that have not), with the greatest difference being between the unaltered baseline flows (that is, the simulated baseline) and the observed daily flow record in basins that have undergone extensive development. On the basis of results of analysis of the simulated baseline hydrographs derived by using the SWRM, a total of 18 class A and 11 class $C$ study sites $(n=29)$ were identified by using $Q R$ and the SWRM analyses.

Because the PORs for four of the sites (USGS station numbers 01396580, 01400730, 01403000, and 01403900) had missing data, the observed data could not be run through NJHAT all at once. Instead, the broken PORs for the observed flow at these sites were entered into NJHAT separately and the mean flow values for the NJHAT flow indices were used for all subsequent comparative analyses. 


\section{Determining Deviation of Streamflow from Baseline Conditions}

Direct comparisons were performed between existing streamflow records and either the hydrologic baseline identified by using quantile regression $(\mathrm{QR})$ (referred to here as the observed baseline, OB) or the SWRM-modeled baseline (referred to here as the simulated baseline, SB) by using the greatly reduced subset of the hydroecological indices generated by NJHAT for stream classes A and C (fig. 8). For sites with an $\mathrm{OB}$ record, the record represents an existing baseline/ reference time period or hydrograph during which the stream was minimally altered with respect to the amount of anthropogenic change that had already occurred. Simulated baselines were created by using the SWRM to reduce the effects of anthropogenic stressors (for example, urban land use, impervious surface, compacted soils, etc.) on the hydrologic response and simulate a "natural" baseline period of record (POR) for comparison to the existing hydrologic record. The natural or simulated baseline typically represents the hydrographic response profile of a time period when anthropogenic disturbance was minimal (that is, when impervious surface cover (ISC) in the basin was near zero and rates of both surface and groundwater use were small relative to rates of natural flow). In this study, ISC and water use were set to zero in the model, indicating no existing anthropogenic disturbance. These comparisons were completed for all study streams to evaluate whether the observed streamflow has deviated from the baseline streamflow (for both OB and SB sites) in an effort to determine whether a measurable change (based on proportional deviation from the $\mathrm{OB}$ or $\mathrm{SB}$ ) had occurred in one or more aspects of the flow regime at each study site (that is, to evaluate whether the hydro-TMDL method used to evaluate each study stream was able to identify statistically significant deviations of the flow indices from the established 25thto-75th-percentile range). In this study, statistical comparisons were computed on the basis of the 10 primary nonredundant flow indices, which include various measures of the five major components of the flow regime: magnitude, frequency, duration, timing, and rate of change for stream classes A and C (fig. 8; Kennen and others, 2007). Hydrologic indices from observed values that fell outside the established 25thto-75th-percentile range (chosen as the ecologically acceptable range on the basis of the work of Richter and others, 1996, 1997) were used to identify study sites that have likely been hydrologically altered by processes associated with anthropogenic changes in the landscape or water-supply infrastructure (for example, dams, reservoirs, surface-water diversions, impoundments, intakes, and various conveyance devices). Consequently, those sites with flow indices that fell outside the 25th-to-75th-percentile range are considered, for the purposes of this report, to not meet the established hydro-TMDL flow criteria and, therefore, do not fully support established aquaticlife uses. Hydrologic indices also were evaluated with respect to the more conservative 40th-to-60th-percentile range as part of the comparative analysis to address NJDEP concerns that the 25th-to-75th-percentile range may not fully meet more stringent standards for streams that need greater protection as a result of existing State regulations - for example, Category One Waters, which are protected from any measurable change in water quality because of exceptional ecological, recreational, or water-supply significance (http://www.nj.gov/dep/ wms/bwqsa/clwaters.htm).

\section{Class A Streams}

Class A stream sites included semiflashy streams characterized by moderately low base flow. Eighteen class A sites were examined in this report. Only seven study sites identified as class A (South Branch Raritan River at Stanton (SBRarSt), Neshanic River at Reaville (NeshRea), North Branch Raritan River near Raritan (NBRarRar), Raritan River at Manville (RarMan), Millstone River at Plainsboro (MillPla), Millstone River at Blackwells Mills (MillBlak), and Raritan River below Calco Dam at Bound Brook (RarCalco), NJ) (table 2) had a hydrologic baseline POR that could be statistically differentiated from the existing observed POR (table 1) by using QR (that is, an OB record). These comparisons may be the most relevant from a management perspective because they represent direct comparisons between an established baseline POR derived from observed rather than simulated data. The drainage areas for the above seven class A sites ranged from 25.7 to $785 \mathrm{mi}^{2}$; of these, five were larger than $100 \mathrm{mi}^{2}$. Percent ISC at these streams ranged from 5.3 to 10.2 (table 1) (see Kennen and others, 2007, for a broader discussion of differences among New Jersey stream classes).

\section{Comparisons with the Observed Baseline}

At SBRarSt (01397000), the annual minimum 30-day moving-average flow (DL4) exceeded the 75th-percentile value by nearly 50 percent (35.8 cubic feet per second $\left(\mathrm{ft}^{3} / \mathrm{s}\right)$ (app. 2)). The Julian date timing of annual minimum flow (TL1) exceeded the 75th-percentile value by 4 percent and represents an 11-Julian-day delay for the timing of the annual low flow. Evaluations performed by using the more conservative 40th-to-60th-percentile range indicated, as would be expected, that more flow attributes exceeded the upper percentile boundary. For example, the mean monthly flow for July (MA18) exceeded the 60th-percentile value by 43 percent $\left(54.1 \mathrm{ft}^{3} / \mathrm{s}\right)$, but did not exceed the 75 th-percentile value. Mean maximum high flow for May (MH5) exceeded the 60thpercentile value by more than 17 percent under this scenario, which is equivalent to $115 \mathrm{ft}^{3} / \mathrm{s}$ greater than the acceptable maximum. The percentage change in annual timing of flows also was greater for the 40th-to-60th-percentile scenario, indicating a nearly 10- and 16-Julian-day shift in the timing of high- and low-flow periods, respectively.

At NeshRea (01398000), flow constancy (TA1) fell below the 25th-percentile value. In general, constancy is a 
Table 2. Site abbreviations and baseline dataset types for the 29 class $A$ and $\mathrm{C}$ streams used in the hydrologic analysis.

[USGS, U.S. Geological Survey; NJSCT, New Jersey Stream Classification Tool; SB, simulated baseline hydrograph derived by using the Statewide Watershed Runoff Model; OB, observed baseline hydrograph identified by using quantile-regression analysis; $\mathrm{mi}^{2}$, square miles; ISC, impervious surface cover]

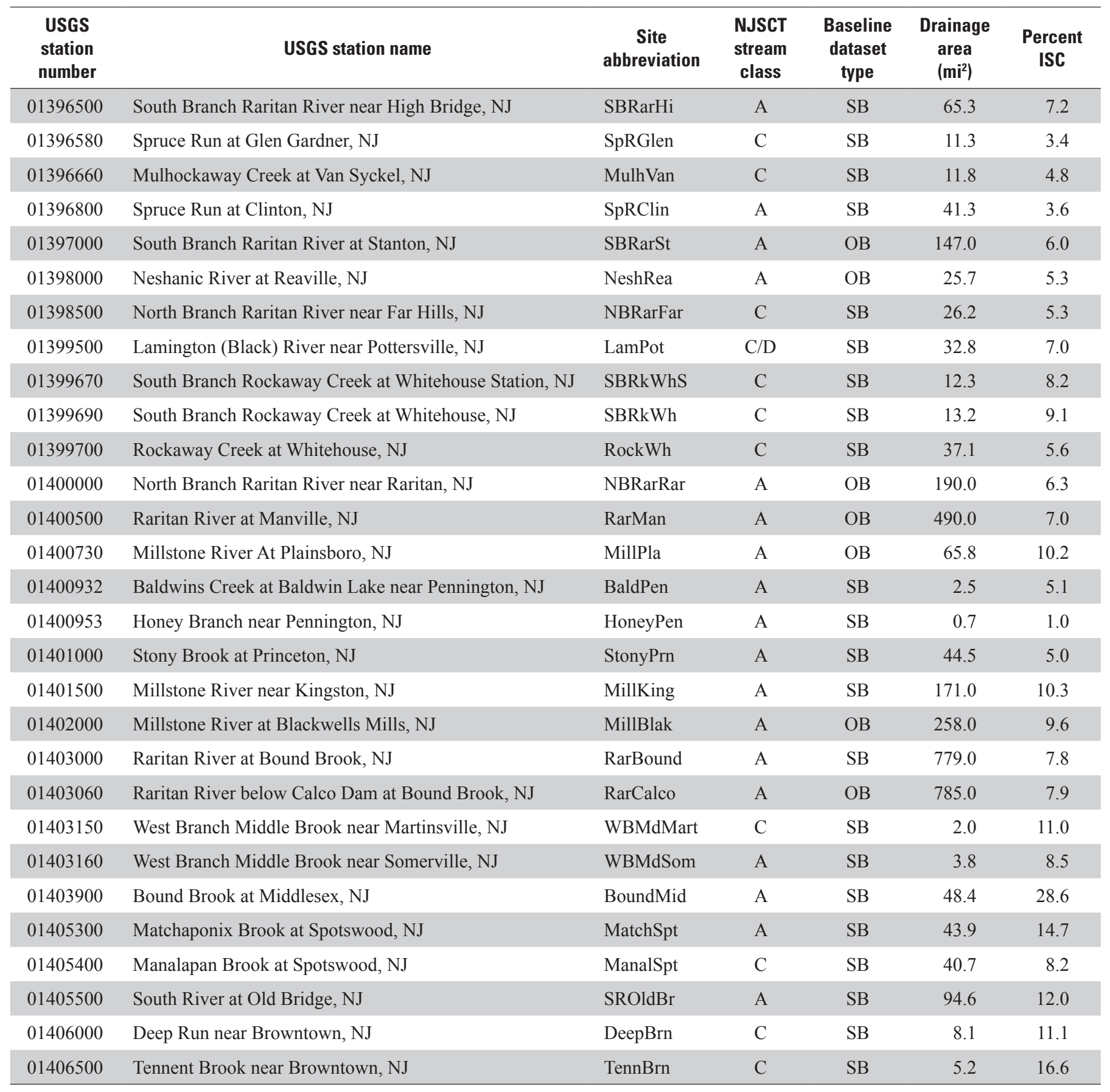


measure of similarity of monthly means within a year and reflects conditions of relative hydrologic stability (Colwell, 1974; Poff and Ward, 1989). Thus, the term "constancy," the degree to which monthly means vary from month to month, is inversely related to streamflow variability (Olden and Poff, 2003). A highly regulated stream with low streamflow variability would have high flow constancy (near 1), whereas a nonregulated stream with high streamflow variability would have low constancy (near 0 ). The observed constancy value (0.197; high variability) at this site was 54.4 percent below the 25 th-percentile value $(0.432)$, indicating that with the onset of anthropogenic influences, the stream appears to be becoming more variable from month to month. NeshRea has many domestic, regulated, and unregulated (that is, they fall within the $<100,000$-gallon-per-day (gal/d) permitting criterion) agricultural water withdrawals that may cumulatively affect streamflow variability over time. TL1 fell below the 25 thpercentile value by 2.3 percent, which indicates that minimum flows are occurring approximately 6 days earlier than they did before streamflow alteration. The Julian date of the annual maximum flow exceeded the 60th-percentile value by 5.6 percent, which is equivalent to about 3 days; thus, the annual low flows at this site appear to be occurring earlier, whereas the annual high flows occur later.

The frequency of high-flow pulse count (FH4) at NeshRea has decreased by nearly 10 percent (with respect to the 40th-percentile value), which indicates that there are about three fewer high flows annually than during observed baseline conditions. The annual maximum of 3 -day moving-average flows (DH2) exceeded the 60th-percentile value by 6.5 percent, which represents a $34.4-\mathrm{ft}^{3} / \mathrm{s}$ increase. The changes in these flow measures indicate that there has been a general change in the timing and duration of seasonal flow processes in the Neshanic River.

Few flow indices exceeded the 25th-to-75th-percentile range at NBRarRar (01400000); with respect to the more conservative 40th-to-60th-percentile range, however, many hydrologic indices were exceeded (app. 2). DL4 did exceed the 75 th-percentile value by 6.0 percent (about $4 \mathrm{ft}^{3} / \mathrm{s}$ ) and also exceeded the 60th-percentile value by nearly 30 percent (about $17 \mathrm{ft}^{3} / \mathrm{s}$ ) (app. 2). TA1 exceeded the 75th-percentile value by 1.4 percent and the observed flow constancy value was 0.561 , indicating a stream with a moderate amount of flow variability. The mean maximum flow for May (MH5) exceeded the 60thpercentile value by 20 percent concurrently with an 8.8-percent change in the Julian date of annual maximum flow (TH1), which is equal to a 5-Julian-day delay in the high-flow period. Results of these hydrologic comparisons indicate that highflow magnitudes are increasing and high flows are occurring later in the season, which may affect the life-history cycles of some sensitive aquatic organisms. DH2 exceeded the 60thpercentile value by 8.0 percent, which is equivalent to about $189 \mathrm{ft}^{3} / \mathrm{s}$. This additional exceedance in the duration of highflow may indicate a further exacerbation of impaired flow conditions at this site because high-flow magnitudes are occurring both later in the season and for a longer duration. Although the estimated ISC for this site is only 6.3 percent (table 1 ), much of this ISC is concentrated in large areas immediately upgradient from the streamgage, which could potentially affect average flows. Many more of the hydrologic indices evaluated at this site likely will deviate from the 25th-to-75th-percentile range if anthropogenic activity, and concomitantly ISC, in this basin continues to increase. For example, examination of the results of analysis of the flow record by means of $\mathrm{QR}$ indicates distinct changes in flow properties at NBRarRar beginning in 2000. Increased ISC, which predictably decreases flow variability and increases flow across all quantiles, could explain these changes in flow characteristics.

At RarMan (01400500), DL4 exceeded the 75th-percentile value by 57 percent $\left(84.2 \mathrm{ft}^{3} / \mathrm{s}\right)$ and the 60 th-percentile value by more than 73 percent $\left(97.8 \mathrm{ft}^{3} / \mathrm{s}\right)$. The timing of flow indices including both TA1 and TH1 exceeded the 75th-percentile value. TA1showed the greatest deviation from natural flow timing and exceeded the 75th- and 60th-percentile values by 18 and 23 percent, respectively (app. 2). The observed constancy value of 0.652 may indicate that the stream is reflecting greater flow regulation and less month-to-month variability than during baseline conditions. TH1 exceeded the 75th- and 60th-percentile values by 4.0 and 33 percent, respectively. The 75th-percentile exceedance is equivalent to a 3-day delay beyond the established maximum (the 75th-percentile value) and 18 days past the more conservative maximum (the 60th-percentile value). The latter may represent a considerable delay in the streamflow timing, especially for sensitive aquatic organisms (for example, mayflies, Ephemeroptera) that rely on the timing of high and low flows for crucial life-cycle stages. Reservoir operations, which began in the early 1960s, may have contributed to the observed flow disturbances. The exceedance of TA1, which represents a shift toward greater flow regulation, would also be expected at any gage downstream from water-supply reservoirs (for example, Spruce Run and Round Valley Reservoirs).

The basin draining to MillPla (01400730) has undergone moderate development that may have altered streamflow properties. Many hydrologic indices deviated from the 25thto-75th-percentile range, some by a large percentage. For example, MA18 and TH1 exceeded the 75th-percentile values by 91 percent and 176 percent, respectively. The 176-percent exceedance for TH1, which represents a 124-day delay in spring high flows, may be an extreme example; however, it may instead indicate that flow has been so greatly modified that natural spring flows no longer occur in this system. The 91-percent exceedance of MA18 is $104.3 \mathrm{ft}^{3} / \mathrm{s}$ above the 75 th-percentile value. DL4 and the annual maximum of 30-day moving average flows (DH4) also exceeded the 75thpercentile values by 9.8 and 4.6 percent, respectively. TL1 fell below the 25 th-percentile value by 3.8 percent, which is 9 days earlier than in the baseline record. Because hydrologic monitoring at this site was discontinued during 1975-85, then restarted in 1986, it is unclear whether these results are fully representative of altered flow conditions, as 10 or more years of post-baseline record typically are needed for substantive 
hydrologic comparisons. Of the streams with an OB record assessed in this study, however, MillPla had the greatest number of flow-index values that fell outside the established 25thto-75th-percentile range. The increases in the magnitude and duration of flows at this site can probably be attributed to the relatively high ISC (10.2 percent as of 2002; table 1) and the rapid suburbanization that has occurred and still is occurring, resulting in increased runoff to streams and decreased stormwater infiltration. Inadequate stormwater controls are common in many older suburban communities in this basin. Results indicate that the average magnitude of high flows and duration of low flows are increasing, summer low flows are occurring earlier, and spring high flows are occurring later than during baseline conditions.

At MillBlak (01402000), timing and frequency of high and low flows were the hydrologic attributes that most commonly fell outside the 25th-to-75th-percentile range. TH1 exceeded the 75 th-percentile value by 4.7 percent, the equivalent of slightly more than a 3-day delay in spring high flows. FH4 exceeded the 75th-percentile value by 2.3 percent, which is a difference of about 0.5 days per year. TL1 arrived 2.5 days earlier than under baseline conditions (1.0 percent below the 25 th-percentile value and nearly 4 percent below the 40th-percentile value). TH1, FH4, and TL1 were the only flow indices that fell outside the 25th-to-75th-percentile range (app. 2); however, additional deviations in the magnitude and frequency of high flows were identified for the more conservative 40th-to-60th-percentile range. For example, MH5 exceeded the 60th-percentile value by 35 percent $\left(390 \mathrm{ft}^{3} / \mathrm{s}\right)$ and $\mathrm{DH} 2$ exceeded the 60th-percentile value by almost 9.0 percent $\left(295 \mathrm{ft}^{3} / \mathrm{s}\right)$. The frequency of high flows increased to more than 32 percent above the 60th-percentile value, which represents an additional 5.5 days per year that flow is greater than a threshold value equal to seven times the median flow for the entire record. Additionally, TH1 exceeded the 60th-percentile value by 34 percent, an 18.8-day delay in high flows. The flow exceedances above the 60th-percentile value identified at this site may indicate that the drainage basin of this stream is being altered hydrologically. TH1 at RarCalco (01403060) exceeded the 75th-percentile value by 12 percent ( 9 days) and the 60 th-percentile value by 44 percent ( 24 days). The timing of low flows fell below the 25 th-percentile value by 2.5 percent, indicating that low flows are occurring nearly 6 days earlier than in the observed baseline record. Changes in the timing of spring high flows and summer low flows appear to be common in many streams where annual variability has been modified by the construction of dams. TA1 exceeded the 75thpercentile value by only 0.18 percent; however, if the more conservative 60th-percentile value is applied, exceedance is 4.3 percent. Although this exceedance is relatively small, the potential difference between the observed TA1 value for the 75th- relative to the 60th-percentile value could indicate that this site may be beginning to show greater monthly changes in annual flow timing than before hydrologic alteration that could continue to increase if not addressed through mitigative measures. The values of three additional hydrologic indices fell outside the more conservative 40th-to-60th-percentile range that did not fall outside the 25th-to-75th-percentile range. For example, mean spring flows (MH5) exceed the 60th-percentile value by 14 percent $\left(510 \mathrm{ft}^{3} / \mathrm{s}\right)$ and the annual maximum of the 3-day moving average flows (DH2) was nearly 11 percent above the 60 th-percentile value $\left(1,133 \mathrm{ft}^{3} / \mathrm{s}\right.$; app. 2). Additionally, the high flood pulse count exceeded the 60th-percentile value by almost 8 percent, which is equivalent to an additional 1.5 days of flooding per year than under baseline conditions. This stream is influenced by a wide array of human activities and its basin has an ISC of nearly 8 percent (table 1). Streamflow at this site is also highly influenced by the 1938 construction of the Calco Dam, which was designed to carry and disperse wastewater into the Raritan River. This dam, however, was removed in 2011 (http://www.nj.gov/dep/ newsrel/2012/12_0085.htm).

\section{Comparisons with the Simulated Baseline}

Eleven streams in the class A group did not have a baseline POR that was long enough to be statistically differentiated from the observed streamflow record; they are South Branch Raritan River near High Bridge (SBRarHi), Spruce Run at Clinton (SpRClin), Baldwins Creek at Baldwin Lake near Pennington (BaldPen), Honey Branch near Pennington (HoneyPen), Stony Brook at Princeton (StonyPrn), Millstone River near Kingston (MillKing), Raritan River at Bound Brook (RarBound), West Branch Middle Brook near Somerville (WBMdSom), Bound Brook at Middlesex (BoundMid), Matchaponix Brook at Spotswood (MatchSpt), and South River at Old Bridge (SROldBr) (table 1). In these cases, the observed record was compared to an SB record derived by using the SWRM. Values of more hydrologic parameters fell outside the 25th-to-75th-percentile range and often by a higher percentage at sites where comparisons were made by using the SB record than at sites where comparisons were made with the $\mathrm{OB}$ record. It is hypothesized that the higher percentage deviations observed with the SB may be related to setting ISC in the Watershed model to 0 percent, indicating no existing anthropogenic disturbance (see the Data Limitations section of this report). The size of the drainage areas of the 11 class A streams whose comparisons are based on an SB record ranges from 0.7 to $779 \mathrm{mi}^{2}$, and the ISC in these basins ranges from 1.0 to 28.6 percent (table 1 ).

The two indices whose values most frequently exceeded the 75th-percentile value and by the greatest percentage at the 11 SB streamgages were MH5 (mean maximum flow for May) and DH2 (annual maximum of 3-day moving average flows) (app. 2). MH5 exceeded the 75th-percentile value at 10 of the 11 SB streams with deviations that exceeded the 75 th-percentile value by 25 to 395 percent. The largest deviation at WBMdSom (01403160) is equivalent to nearly $48 \mathrm{ft}^{3} / \mathrm{s}$ above the 75 th-percentile mean maximum flow. This large exceedance, however, may be somewhat skewed as a result of the availability of only 5 years of flow data, which is considered by some to be insufficient to fully assess the 
degree of flow disturbance in the basin. StonyPrn (01401000) had the next highest deviation for MH5, which exceeded the 75 th-percentile value by 158 percent $\left(206 \mathrm{ft}^{3} / \mathrm{s}\right)$. The increase in magnitude of spring high flows at this site is likely related to increases in ISC resulting from increasing urbanization, as these two factors are commonly linked (for example, Roy and others, 2005; Kennen and others, 2005; Wenger and others, 2008; Cuffney and others, 2010). The 75th-percentile value of MH5 was exceeded by 142 percent $\left(117 \mathrm{ft}^{3} / \mathrm{s}\right)$ at SpRClin (01396800). In this basin, flow alterations likely are related to a combination of hydrologic stressors including Spruce Run Reservoir releases and ongoing anthropogenic activity in the basin. The mean of monthly July flow (MA18) exceeded the 75 th-percentile value by nearly 120 percent $\left(38.1 \mathrm{ft}^{3} / \mathrm{s}\right)$ at SpRClin. DH2 exceeded the 75th-percentile value by 314 percent $\left(329 \mathrm{ft}^{3} / \mathrm{s}\right)$ (app. 2). The annual fall rate (RA3) at SpRClin fell below the 25 th-percentile value by 343 percent, which is equivalent to a $6-\mathrm{ft}^{3} / \mathrm{d}$ decrease. The Julian date of the annual maximum flow (TH1) exceeded the 75th-percentile value by 56 percent (43 days) - nearly a 1-1/2-month delay. The Julian date of annual minimum flow (TL1) was similarly delayed, by about 42 days (app. 2). The annual minimum of 30-day moving average flow (DL4) was below the 25th-percentile value by almost 24 percent $\left(1.5 \mathrm{ft}^{3} / \mathrm{s}\right)$. The cumulative changes in hydrologic processes that have occurred at $\mathrm{SpRClin}$ relative to the SB record appear to be extensive, especially the large deviations in the magnitude and duration of high and low flows, respectively. These changes represent a general overall decline in natural flow characteristics that is commonly associated with dams and diversion structures (Graf, 1999; Poff and others, 2007); this type of streamflow alteration was recently found to be one of the most important indicators of diminished ecological integrity throughout the United States (Carlisle and others, 2010). The annual maximum of 3-day moving-average flows (DH2, a measure of the duration of high flows) exceeded the 75 th-percentile value at 9 of the 11 sites, with deviations ranging from 133 to 355 percent (app. 2). The maximum, at BoundMid (01403900), is $506 \mathrm{ft}^{3} / \mathrm{s}$ above (about 3.5 times) the expected 75 th-percentile value for a stream with near-natural flow conditions and minimal anthropogenic disturbance as simulated with the SWRM. Values of most flow parameters at this site showed a general upward trend; therefore, the observed increase in $\mathrm{DH} 2$ relative to the $\mathrm{SB}$ is not surprising given the large amount of ISC (28.6 percent; table 1) and the concomitant increase in the amount of stormwater runoff. The value of the flow index $\mathrm{DH} 2$ was also found to greatly exceed (by 314 percent) the 75th-percentile value at SpRClin (app. 2). Many other class A streams with simulated baseline records had exceedances of the 75th-percentile value nearing 200 percent; however, exceedances were highest for BoundMid and SpRClin.

DL4 fell below the 25th-percentile value at six of the class A SB sites by 14 to 99 percent. The greatest deviation from the 25 th-percentile value, $0.277 \mathrm{ft}^{3} / \mathrm{s}$ (99 percent), occurred at HoneyPen (01400953). This site has the smallest drainage area in the study $\left(0.7 \mathrm{mi}^{2}\right)$; because the observed value is so small $\left(0.003 \mathrm{ft}^{3} / \mathrm{s}\right)$ relative to the 25 th-percentile value, it yielded a large percentage deviation. Therefore, the overall significance of this change, especially for such a small system, should be interpreted with caution. Similarly, DL4 at BaldPen (01400932), in another small basin, fell below the 25 th-percentile value by a large percentage ( 97 percent); however, these large deviations reflect a relatively small absolute change in DL4. In contrast, the annual minimum at BoundMid was about $18.7 \mathrm{ft}^{3} / \mathrm{s}$ (56 percent) lower than the 25 th-percentile value. BoundMid is in a larger $\left(48.4 \mathrm{mi}^{2}\right)$, highly urban basin with high ISC (28.6 percent), and these characteristics are directly reflected in the number of high- and low-flow indices that deviated from the established percentile ranges. DL4 at MillKing (01401500) was 44.3 percent $\left(33.6 \mathrm{ft}^{3} / \mathrm{s}\right)$ below the 25th-percentile value. Many public-supply wells are distributed throughout the basin in which this site is located, which, in concert with unregulated water use (for example, agricultural wells with pumpage that falls below the 100,000 -gal/d permitted-use criterion in New Jersey) could indirectly and cumulatively affect long-term low flows. For example, MA18 at MillKing fell below the 25th-percentile value by nearly 28 percent (about $26.5 \mathrm{ft}^{3} / \mathrm{s}$ ). DL4 at RarBound (01403000) exceeded the 75th-percentile value by 19 percent $\left(43.6 \mathrm{ft}^{3} / \mathrm{s}\right)$. At this site, the combined effects of human activity throughout the upper basin appear to have produced a streamflow record that exhibits severe flow disturbances.

RA3, which represents the change in flow for days in which the change is negative for the entire flow record, was 3.9 to 439 percent below the 25 th-percentile value at eight of the SB sites (app. 2). The largest (439-percent) difference, at BoundMid, is equivalent to a $5-\left(\mathrm{ft}^{3} / \mathrm{s}\right) / \mathrm{d}$ change in the fall rate relative to the SB condition. As mentioned above, the high ISC in this basin results in a flashy stream (greatly increases stream rise and fall rates) and likely explains the extreme deviation of this hydrologic index as well as the ongoing flooding this basin has experienced over the last two decades. SpRClin also had a high deviation for RA3 (343 percent below the 25th percentile, or a $6.2-\left(\mathrm{ft}^{3} / \mathrm{s}\right) / \mathrm{d}$ difference).

The Julian date of the annual minimum flow (TL1) fell outside the 25th-to-75th-percentile range at 7 of the 11 SB sites. The largest deviation was 16 percent above the 75 thpercentile value at SpRClin, which is equivalent to a 42-day delay in annual low flow. Large deviations for TL1 were also found at SROldBr (01405500), where the observed value was 4.5 percent below the 25 th-percentile value, which indicates that annual low flows are occurring about 11 days earlier than during the baseline period. At BaldPen, the annual minimum occurred about 10 days earlier.

TH1 fell outside the 25th-to-75th-percentile range at 6 of the 11 SB sites (app. 2). The largest deviation in TH1, 120 percent (equivalent to a high-flow delay of about 134 days), was at Honey Branch near Pennington. TH1 at Bound Brook at Middlesex and SpRClin exceeded the 75th-percentile value by 66 percent ( 74 days) and 56 percent (43 days), respectively. MA18 was outside the 25th-to-75th-percentile range at 5 of the 11 SB sites. MA18 at HoneyPen fell below the 
25th-percentile value by almost 55 percent, which is equivalent to about $0.30 \mathrm{ft}^{3} / \mathrm{s}$. As mentioned previously, because this basin is the smallest in this study, relatively small differences in discharge can yield large percent differences in index values. This stream experiences a number of $0-\mathrm{ft}^{3} / \mathrm{s}$ flow days per year. MA18 at MillKing was nearly 28 percent $\left(26.5 \mathrm{ft}^{3} / \mathrm{s}\right)$ below the 25 th-percentile value. MA18 at Baldwins Creek near Pennington was 18 percent (about $0.09 \mathrm{ft}^{3} / \mathrm{s}$ ) below the 25th-percentile value; however, these percent differences only appear to be large because the observed values are small.

Flow constancy (TA1) was outside the 25th-to-75thpercentile range at five of the SB sites. The largest TA1 deviation was 56 percent above the 75th-percentile value at HoneyPen. The constancy value for HoneyPen (0.69; app. 2) indicates that annual month-to-month streamflow variability is much less than that for BaldPen, with a comparably sized drainage basin and an observed constancy value nearer to 0.3 , indicating greater overall monthly streamflow variability at BaldPen.

\section{Class C Streams}

Class C stream sites represent moderately stable streams with moderately high base-flow contributions. Eleven class C sites were examined as part of the hydro-TMDL assessment (table 2). None of these study sites had a hydrologic baseline POR that could be statistically differentiated from the existing observed POR (table 1); therefore, all hydrologic comparisons for these sites were made by using the SB hydrograph. The drainage areas of class $\mathrm{C}$ streams generally were smaller than those of class A streams and ranged from 2.0 to $40.7 \mathrm{mi}^{2}$, and percent ISC ranged from 3.4 to 16.6. Percent deviations outside the defined flow-management range (25thto-75th-percentile) at the class $\mathrm{C}$ streams were, in general, much larger than those found for the class A streams. This difference may be directly related to the fact that all comparisons for the class $\mathrm{C}$ streams were made with a simulated rather than an observed baseline.

The variability in monthly flow for January (MA24) exceeded the 75th-percentile value at all 11 of the class C streams, with deviations ranging from 179 to 1,931 percent (app. 2). The largest deviation was at Rockaway Creek at Whitehouse (RockWh, 01399700). MA24 at South Branch Rockaway Creek at Whitehouse Station (SBRkWhS, 01399670), which is upstream from the RockWh site, exceeded the 75th-percentile value by 1,046 percent. South Branch Rockaway Creek at Whitehouse (SBRkWh, 01399690) had the third largest exceedance, 909 percent. These three sites also had the largest exceedances for MH14 (median of annual maximum flows) and DH11 (annual maximum of 1-day moving-average flows). At the three Rockaway sites, MH14 exceeded the 75th-percentile value by 1,405 percent (RockWh), 1,211 percent (SBRkWhS), and
1,164 percent (SBRkWh). DH11 exceeded the 75th-percentile value at these sites by 1,277 percent (SBRkWhS), 1,102 percent (RockWh), and 965 percent (SBRkWh). Flow at all three of these sites is greatly influenced by releases from the Round Valley Reservoir.

Many indices accounting for the timing of flows were also outside the targeted 25th-to-75th-percentile range at these three sites. The variability in Julian date of annual minimum flow (TL2) exceeded the 75th-percentile value at all three of the Rockaway sites by 2, 4, and nearly 20 Julian days at SBRkWhS, RockWh, and SBRkWh, respectively (app. 2). The annual variability in Julian date of annual maximum flow (TH2) exceeded the 75th-percentile value by 4 days at SBRkWhS and was less than the 25th-percentile value at SBRkWh (4.5 days) and RockWh (9 days), indicating that the annual low flows appear to be occurring later and the high flows are occurring earlier than during the baseline period at two of the three sites.

Low flow pulse duration (DL16) was less than the 25thpercentile value at 9 of the 11 sites (app. 2). Deviations ranged from 18 to 63 percent below the 25th-percentile value; the largest deviation, at West Branch Middle Brook near Martinsville (WBMdMart, 01403150), is equivalent to flows being less than the 25th-percentile threshold for 11 days. Mean minimum March flows (ML3) at this site also were low, $1.3 \mathrm{ft}^{3} / \mathrm{s}$ below the 25th-percentile value (app. 2). Because the drainage area of this site is small $\left(2.0 \mathrm{mi}^{2}\right)$, changes in discharge at or exceeding $1.3 \mathrm{ft}^{3} / \mathrm{s}$ could substantially affect streamflow and alter low-flow periods sufficiently to increase the likelihood of the stream becoming dry in the spring. The variability of monthly January flows (MA24) and the median of annual maximum flows (MH14) at WBMdMart exceeded the 75thpercentile values by 641 and 711 percent, respectively. ISC at WBMdMart is 11 percent (table 2), so it is also possible that increased runoff resulting from ISC may be contributing to the greatly increased flashiness of the stream (that is, greater monthly flow variability combined with higher annual maximum flows). Timing indices for WBMdMart fell within the 25th-to-75th-percentile range, which might further indicate that flow alterations are linked to land-use change rather than to increasing water use or abstraction.

The second largest deviation for DL16 was at the North Branch Raritan River near Far Hills (NBRarFar, 01398500), where the annual average low flow pulse duration was less than the 25th-percentile value by about 60 percent, the equivalent of about 12 days. QR plots for NBRarFar (POR 19222006; fig. 4) show little evidence of flow alteration resulting from human activity. The results of the NJHAT analyses, however, indicate some high- and low-flow magnitude and duration index values outside the 25 th-to- 75 th-percentile range (app. 2).

TL2 fell outside the 25th-to-75th-percentile range at 7 of the 11 class $C$ stream sites (app. 2); the value of this index exceeded the 75th-percentile value at 4 sites and was less than the 25 th-percentile value at 3 sites. The largest 
percentage deviation above the 75th-percentile value was at SBRkWh (45 percent), which is equivalent to an 18-day delay in the annual minimum. The second largest deviation was 28 percent below the 25 th-percentile value at Tennent Brook near Browntown (TennBrn, 01406500), which represents the occurrence of the annual low flows 10 days earlier than during the baseline period. Only 9 years of hydrologic record were available for this site; therefore, some of these findings may be slightly skewed because a longer POR tends to be more robust for developing hydrologic index values for comparison between the observed conditions and the simulated baseline hydrograph. However, not only is the timing of flows at TennBrn altered, but the variability of January flows (MA24), the median of annual maximum flows (MH14), and the high-flow durations (DH11) increased (app. 2). Concomitantly, the mean minimum monthly flows for March (ML3) and the low flow pulse duration (DL16) decreased. In general, the high flows have increased and occur more frequently, indicating an increase in stream flashiness, and spring low flows have decreased. With an ISC of 16.6 percent in this basin (table 1), stormwater runoff may be contributing to the increases in high flows. The timing of low and high flows has also been altered, which may indicate that water abstraction associated with human water use has increased. TennBrn appears to be representative of a stream that has been modified by urbanization and increased ISC. Flow constancy (TA1, a measure of similarity of monthly means within a year that reflects conditions of relative hydrologic stability) deviated from the 25th-to-75th-percentile range at 5 of the 11 class $C$ stream sites (app. 2). As stated previously, constancy ranges from 0 to 1 , and a highly regulated stream with low streamflow variability would have a constancy near 1. At TennBrn, NBRarFar, and Deep Run near Browntown (DeepBrn, 01406000), constancy fell below the 25th-percentile value by 70,2.3, and 15.4 percent, respectively, indicating that these streams are more variable than during the baseline period. In contrast, constancy at RockWh and Manalapan Brook at Spotswood (ManalSpt, 01405400 ) exceeded the 75 th-percentile value by 7.5 and 8.0 percent, respectively, indicating that these streams are more constant than during the baseline period and show flow alterations consistent with regulated systems. As discussed previously, RockWh is likely influenced by releases from the Round Valley Reservoir and Cushetunk Lake Dam; therefore, it is not surprising that constancy at this site has increased. The observed constancy value at ManalSpt was 0.502 (low variability), whereas the 75 th-percentile value was 0.465 , indicating that the stream is slightly less variable from month to month than during the baseline period. This site is located downstream from Lake Manalapan, Helmetta Pond, and the DeVoe Lake Dam in Spotswood; discharge at the latter site includes flow through sluice gates that are open at various times throughout the year, which likely accounts for the increase in constancy at this site.

\section{Management Implications}

Many of the sites in this study appear to fall into one of three primary flow-alteration categories: those that may have been affected by (1) reservoir and (or) dam operations, (2) impervious surface cover (ISC), or (3) groundwater abstraction. In some cases, flow alteration may result from a combination of these factors.

\section{Reservoirs and Dams}

Stream sites in this study with upstream reservoirs or dam operations include SBRarSt, RarMan, RarCalco, SpRClin, SBRkWhS, SBRkWh, RockWh, and ManalSpt. Even though reservoirs and dams provide many benefits to society and maintaining adequate streamflow can be important in maintaining hydrologic functionality and supporting downstream human water uses, artificially stabilizing water levels throughout the year may produce unintended consequences on the aquatic assemblages that inhabit these systems. For example, water is released from New Jersey water-supply reservoirs to meet established minimum passing-flow requirements, which maintain the mandated flow of water in streams downstream from a reservoir. Such releases, however, are not intended to mimic seasonality or temporal variability of natural streamflow and therefore may not meet the life-history requirements of some aquatic fauna. Research over the last two decades has shown that changes in the annual timing of flow events are particularly relevant for synchronization of life-history processes, especially for those aquatic species whose life cycle (spawning and reproduction) is tied to annual fluctuations in streamflow. Lytle and Poff (2004) suggest that, even though it is difficult to forecast individual flow events, it is likely that aquatic organisms adapt to the long-term average timing, especially if such occurrences are in regions where there is some level of flow predictability (for example, high spring flows or low summer flows in the northeastern United States). A difference of a few days for such hydrologic measures certainly falls well within the variability of annual fluctuations in yearly precipitation; however, if such changes in flow timing are exacerbated by predicted climate change in the region, they can potentially disrupt aquatic organism life-history processes. Synchronizing reproductive processes with high- or low-flow periods helps to optimize reproductive success and avoid high mortality rates during extreme events such as floods or droughts (Lytle, 2002; Boulton, 2003).

An opportunity exists to define the timing and quantity of reservoir releases not only to meet the needs of human consumption, but also to increase streamflow variability to better accommodate the flow needs of aquatic species that depend on annual high- and low-flow periods as life-cycle cues for reproduction and migration. A protection-based hydro-TMDL for sites downstream from water-supply reservoirs may 
consist of a framework that incorporates a holistic hydrologic management plan that maintains current streamflow levels to maximize downstream human water use, but also modifies reservoir releases such that they are synchronized with natural fluctuations in annual streamflow variability. It might be possible to design varied release rates that incorporate components of natural hydrologic variability. Such an approach could be part of a decision-making strategy that incorporates timing, magnitude, frequency, and duration of flows in a way that promotes the long-term health and survival of aquatic organisms. With careful consideration of both downstream human water-supply needs and ecological needs (for example, spawning and reproduction of trout), release periods that more closely mimic natural streamflow hydrology and hydrologic variability that more closely represents prereservoir conditions could be promoted.

The Round Valley Reservoir in Clinton Township, New Jersey, was created in 1960 when the New Jersey Water Supply Authority (NJWSA) constructed two dams and flooded a large valley in Hunterdon County. This reservoir, which became operational in 1965 , has a capacity of 55 billion gallons of water and provides a dependable supply of water to approximately 1.2 million people in central New Jersey. Additionally, the NJWSA supplements reservoir inflows by pumping water into the reservoir through the Hamden Pump Station located on the South Branch of the Raritan River. The NJWSA is required to maintain a minimum flow of $61.6 \mathrm{ft}^{3} / \mathrm{s}(40 \mathrm{mil}-$ lion gallons per day (Mgal/d)) at the South Branch of the Raritan River at Stanton (USGS station number 01397000).

Releases from Round Valley Reservoir enter Rockaway Creek directly upstream from the SBRkWhS gaging station. Reservoirs such as Round Valley Reservoir can alter flow processes at such sites by creating non-natural water-release patterns. The changes seen in flow processes at SBRkWhS, SBRkWh, and RockWh, all of which are influenced by Round Valley Reservoir releases, are highly similar to those observed at sites downstream from Spruce Run Reservoir. These three stream sites show an overall increase in streamflow (for example, increases in MA24, MH14, and DH11) that is commonly associated with dam and reservoir releases designed to maintain a minimum flow (Richter and Thomas, 2007).

Reservoir release strategies that incorporate Natural Flow Regime Paradigm principles (that is, incorporate release rates that mimic natural streamflow variability) could offset some of the changes in flow processes (for example, magnitude and timing of high and low flows) currently observed. Flows at these sites, however, are also related to release rates over the dam at Cushetunk Lake, which is located downstream from Round Valley reservoir and about 1,000 feet upstream from the SBRkWhS gage. The extreme departures (in some cases, more than 1,000 percent) of low and high flows from baseline conditions seen at these sites, however, might be beyond the scope of any existing flow-management measures that are designed to modify flows on the Rockaway River to a point at which natural flow patterns are restored. Like reservoirs, dams and impoundments are known to alter the annual pattern of flows (that is, regular cycles of low and high flows) on which some aquatic invertebrates and fish depend for life-cycle cues. For example, changes in annual flow variability, especially processes that remove flood peaks and release the water later during normally low flow periods, are a management technique that commonly results in inflated minimum flows (Magilligan and Nislow, 2005), which greatly delay annual low flows and may modify seasonal flow patterns. Such alteration of natural hydrologic variability may ultimately compromise the longterm survival of some endemic or sensitive aquatic fauna. For example, regulation of flows and conversion of rivers to slowor still-water habitat has been shown to affect diversity and the functional organization of aquatic assemblages, increasing the dominance of generalist species and favoring introduced species (Bunn and Arthington, 2002). Additionally, dams, which are commonly constructed for water-supply purposes (that is, they are designed as water-retention devices), tend to dampen the effects of moderate high flows and, in some cases, increasing low flows on downstream areas (Wenger and Freeman, 2007). Although seemingly beneficial for downstream water use, such changes can come at the expense of hydrologic variability at upstream reaches, where detention storage can result in alteration of habitat, geomorphology, and stream assemblages (for example, Freeman and Marcinek, 2006). Like those from reservoirs, the flows released from some dams are commonly based on minimum passing-flow criteria that have been implemented to prevent streamflow from falling below specific flow rates.

Aquatic fauna are dependent on more than just streamflow (that is, stream level); they are also dependent on annual fluctuations in the duration and magnitude of high and low flows, which are rarely considered in flow releases (for example, see The Nature Conservancy's Sustainable Rivers Project at http://www.nature.org/ourinitiatives/habitats/ riverslakes/sustainable-rivers-project.xml). In general, both reservoirs and dams are known to move streams away from "natural" hydrologic cycles, and such changes may ultimately delay or modify reproductive processes, limit species distribution, disrupt fish migration, and hinder survival, especially for those aquatic taxa that are particularly sensitive to hydrologic alteration and are dependent on hydrologic variability to support life-cycle needs.

The removal of impoundments is becoming a common management approach to restoring natural streamflow variability and is a technique that is currently being practiced in many areas throughout the country in both large (for example, Elwha River dam removal; Duda and others, 2011) and small (for example, Manatawny Creek Dam Removal Project; Bushaw-Newton and others, 2002; Thomson and others, 2005; New Jersey Department of Environmental Protection, 2011) systems as a method for restoring the natural flow and ecological integrity of streams and rivers and as a way to re-establish uninterrupted flow and improve water quality and biological integrity. Increased awareness of the adverse effects of dams in concert with an aging infrastructure and dam maintenance costs has led to a heightened interest in dam removal in the 
United States (Orr and others, 2008), where more than 500 dams have been removed in the past two decades (Stanley and Doyle, 2003). The ecological benefits of dam removal include increased fish passage and broader access to spawning habitats, reestablishment of riverine taxa, declines in nonendemics, and restoration of stream integrity (for example, Catalano and Bozek, 2007); however, large amounts of trapped sediment released after dam removal can adversely affect biotic integrity for months or even years after dam removal (Thomson and others, 2005). This effect is temporary, however, as aquatic assemblages will continue to recover as fine sediments are reduced in downstream habitats. Ideally, the ecological costs and benefits of dam removal would be considered, and where the long-term benefits of restoring river flows outweigh the relatively short-term ecological effects, dam removal may be one of the few management measures that can be implemented in some streams (for example, ManalSpt) to restore natural flows and improve ecological integrity. Still, dam or impoundment removal may be impractical in areas where multiple historic dams or impoundments, typically located on the same stream segment, have greatly altered streamflow.

\section{Impervious Surface Cover}

It is well established that increases in urban land use are highly correlated with increases in ISC, which have been shown to alter stream hydrology and affect ecological assemblages (Kennen and Ayers, 2002; Kennen and others, 2005; Roy and others, 2005; Wenger and others, 2008; Brown and others, 2009a,b; see also Schueler and others (2009) for a comprehensive review). Recent findings by Cuffney and others (2010) indicate that aquatic invertebrates may be adversely affected by even smaller amounts of ISC (for example, $<10$ percent) than previous studies have indicated. Stormwater moves rapidly across impervious surfaces and is transmitted to streams through storm drain pipes and other water-conveyance devices, resulting in a characteristic pattern of higher peak flows and "flashy" streamflow response (Henshaw and Booth, 2000; Fongers and Fulcher, 2002; Walsh and others, 2005b). MillPla, WBMdMart, BoundMid, MatchSpt, DeepBrn, and TennBrn are examples of study sites whose drainage areas are associated with relatively high percentages of ISC $(>10$ percent; table 1).

There are many challenges associated with mitigating the effects of urbanization on hydrology. Ideally, watershedprotection strategies would be developed and implemented to prevent hydrologic alterations before they occur. In most cases, however, such plans are not considered until water resources and stream biological integrity have already started to decline. In urban and suburban systems, a comprehensive management strategy that addresses runoff volume, duration, velocity, frequency, groundwater recharge, and protection of stream channels would likely be most effective. If development patterns and stormwater-management strategies that preserve the predevelopment hydrologic regime are encouraged, the adverse effects resulting from urban development may be minimized.

Runoff-reduction approaches that comprehensively address runoff volume, duration, velocity, and frequency and groundwater recharge are growing in acceptance (National Research Council, 2008), and a number of States (for example, Virginia) are implementing strategies that provide numerous options for the design and specifications of best management practices (BMPs) (see the Virginia Runoff Reduction Method Web site at http://www.dcr.virginia.gov/laws_and_regulations/ lr2f.shtml). Dampening the effect of urban runoff by increasing infiltration is one way to offset increases in high-flow magnitude. BMPs that facilitate the infiltration of precipitation and slowly release it will likely reduce the intensity and duration of floods and flood peaks, respectively. This increased infiltration can often be accomplished with minimal efforts designed to protect groundwater-recharge areas, reduce the extent of ISC in the watershed, and protect and enhance the amount of forested riparian buffers, especially in those areas where buffers are not directly bypassed by existing storm drains. Appropriately designed water-detention basins and biofiltration systems including grassed waterways and filter strips are examples of possible measures that have been suggested to reduce surface runoff and increase infiltration of precipitation (for example, Walsh and others, 2005a).

Construction of BMPs (through either retrofits or direct application) that retain the first 1 to 1.5 inches of stormwater and then slowly discharge it to a stormwater system (and (or) the stream if necessary) can help to reduce the duration of high-flow events (for example, see Carter and others, 2009). Systems that are designed to successfully retain stormwater would increase infiltration and groundwater recharge, thus reducing stormwater runoff to streams.

Land-protection strategies that restrict development in least impaired watersheds (for example, by using tools such as land-use planning and zoning) may help to protect or restore hydrologic variability and stream biological integrity. Reuse of existing urban lands through redevelopment and revitalization could create opportunities for reversing adverse hydrologic effects by reducing, disconnecting, and (or) treating ISC-for example, incorporating low-impact development (LID) and restoring green infrastructure (a network of open green space that conserves the infiltration capacity of natural ecosystems; Benedict and McMahon, 2001) throughout the built environment. These types of comprehensive strategies can provide incremental improvements in the hydrology of local waters and, when used in conjunction with established State TMDL limits, the approach may result in considerable reduction in the load of contaminants delivered to downstream waters (Nisenson, 2005).

A runoff-prevention or -reduction strategy that incentivizes stormwater retrofits, detention storage, or other BMPs as a way to minimize the direct effects of high flow and thereby replicate a more natural hydrologic response may be highly beneficial to the long-term health of aquatic fauna. For example, providing incentives to homeowners in the basin to 
disconnect impervious surfaces from streams by using rain barrels or constructing rain gardens (that is, small-scale bioretention areas that are designed to allow rainwater runoff to infiltrate from impervious areas such as rooftops, parking lots, and driveways) could help to reduce runoff in small basins such as WBMdMart. This type of decentralized BMP approach is less costly than large engineering infrastructure, captures rainwater where it falls and reduces stormwater volumes, peak flows, and contaminant loads (Bitting and Kloss, 2008) and has been used successfully to improve stream conditions in small watersheds in Ohio (for example, Roy and others, 2006). Other methods that could be used to reduce the magnitude of high-flow events include the disconnection or redistribution of stormwater sewer lines to stream outfalls, swales, or retention devices.

\section{Water Abstraction}

Some examples of streams in the Raritan River Basin that may have been affected by water abstraction (that is, withdrawals of groundwater or surface water for agricultural and human supply) include NeshRea, MillKing, and HoneyPen. According to the New Jersey Division of Water Supply, agricultural water use registration must be obtained if a landowner has the capability to withdraw ground- and (or) surface water in excess of 100,000 gal/d for agricultural, aquaculture, or horticultural purposes (http://www.nj.gov/dep/watersupply/a_ag.html). Unregulated water withdrawals or the extraction of large volumes of water that fall just under that limit could be affecting flow at some of these study sites. Unregulated and unsustainable use of groundwater can compromise environmental-flow objectives by reducing surface-water flows (Richter, 2009). These types of water withdrawals are compounded by the fact that agricultural water use typically spikes at times of the year (generally spring) when irrigation demands are highest and the need for streamflow to support the life history (migration and reproduction) of many endemic fauna is greatest. Water abstraction is another stressor that poses the fundamental challenge of balancing human needs with the Clean Water Act requirements to sustain and protect natural aquatic resources within rivers. Evaluating the ecological effects of water abstraction at unregulated streams can be challenging, however, because it involves many geographically dispersed users who pump water intermittently; because such use generally is not metered, the pumpage is typically unknown (Chessman and others, 2011).

Improved accountability for agricultural and human water use through metering, especially for those withdrawals that are less than the regulated minimum, or the reduction of water use during critical time periods (for example, during summer lowflow periods) might ease hydrologic stress or possibly even "reset" the timing of the seasonal low-flow patterns. Balancing water extraction for municipal, commercial, and agricultural uses with that needed to support ecological integrity may be useful in stream systems like MillKing that, with minimal additional hydrologic stress, could experience even greater hydrologic deviations at both the high- and low-flow ends of the hydrograph. If, for example, low flows become lower and wetted stream widths decrease, aquatic-invertebrate or fish eggs deposited near the river edge may become dewatered and desiccate, or streamflow may be inadequate to properly disperse newly emerging larvae, resulting in stranding or death. The implementation of guidelines that largely restrict withdrawals to higher flow periods when more water is available or to times that do not coincide with critical life-cycle periods may also be helpful. Aquatic invertebrates can also be indirectly affected by withdrawals because of changes in water quality associated with extended periods of low flow, such as increases in water temperature, changes in conductivity, and decreases in dissolved-oxygen concentration (Boulton, 2003). Changes to aquatic-invertebrate assemblages have also been observed as a result of increased periphyton biomass, which can occur naturally in rivers during summer low flows but also can be exacerbated if velocities are reduced by abstraction (Suren and others, 2003). Suren and others (2003) suggest that the degree of enrichment of a river should perhaps be considered when assessing minimum flow for the development of flow-management guidelines.

Results of recent studies assessing the effects of water abstraction on aquatic-invertebrate assemblages vary. Many of the differences appear to depend on the amount of flow diverted (type or intensity of the abstraction); particular climatic conditions; and the timing, proximity, and relative location of sample collection with respect to the diversion (upstream or downstream). The application of widespread metering of irrigation and water-supply wells would help to improve current knowledge about the location and magnitude of these withdrawals; however, implementation of such methods can be prohibitively expensive. The Georgia State Legislature, however, implemented the Georgia Agricultural Water Conservation and Metering Program in 2003 and, by the end of 2010, more than 10,000 water meters had been installed on agricultural irrigation-supply wells in the middle and lower Chattahoochee and Flint River Basins (Torak and Painter, 2011). Such detailed geospatial information is essential for informing farmers and water managers about water use, crop selection, and the effects of climate (for example, drought conditions) and pumpage changes on groundwater and surface-water resources. Additionally, more complete water-use data from such efforts could be integrated with corresponding national water-use datasets through the National Water Census, which is part of the USGS WaterSMART (Sustain and Manage America's Resources for Tomorrow) Availability and Use Assessment Program (U.S. Geological Survey, 2011; Alley and others, 2013); see http://water.usgs. gov/watercensus/.

Grouping sites into stressor categories (for example, reservoirs and dams, ISC, water abstraction) provides waterresource managers with a general understanding of some of the mechanistic pathways that potentially may alter natural streamflow processes in New Jersey. Managers and decision 
makers can then use this information to establish sustainable ranges in high- and low-flow criteria to support ecological and human uses at these sites and, by extension, at other sites that may fall into one or more of these stressor categories. Some study sites are likely altered through multiple hydrologic stressor pathways; however, disaggregation of these complex pathways is beyond the scope of this report. Nevertheless, these general stressor groups represent a starting point for the development of hydroecological targets.

\section{Linking Hydrologic Alteration to Invertebrate-Assemblage Response}

Developing flow-ecology response relations that emphasize the linkage between changes in hydrologic processes and ecological response is a fundamental component of the ELOHA-Ecological Limits of Hydrologic Alteration process (Poff and other, 2010). In general, these relations correlate measures of ecological condition (for example, aquatic-invertebrate species richness) to measures of streamflow condition (for example, DL4-the annual minimum of 30-day movingaverage flow). Described below are a series of technical and analytical steps taken to develop flow-ecology response relations for a subset of Raritan River Basin study sites where aquatic-invertebrate and hydrologic data overlap.

\section{Site Selection and Data Aggregation}

As previously stated, selection criteria were based on a U.S. Geological Survey (USGS)-N.J. Department of Environmental Protection (NJDEP) cooperative approach that identified sites in the Raritan River Basin that, in general, had only slight to moderate anthropogenic degradation of the aquatic system (that is, none was considered to be severely impaired as determined from its NJIS score) and were at or near an existing USGS real-time continuous streamflow-gaging station. A database was designed to link all available aquaticinvertebrate data with hydrologic information for these sites where overlap occurred. The primary purpose of this database was to merge hydrologic and ecological data for the purpose of developing flow-ecology response relations. This work required (1) the acquisition of Ambient Biomonitoring Network (AMNET) data (round 3) with all available metrics from the NJDEP; (2) the creation of the database by compiling data from multiple sources in order to link all available data from USGS and NJDEP, including current and historic AMNET data, National Water Quality Assessment (NAWQA) program ecological data, and New Jersey volunteer invertebrate-monitoring data; and (3) proximally linking invertebrate-monitoring sites with corresponding USGS streamgages. The initial AMNET dataset included five NJIS metrics - taxa richness, EPT index, percent dominance, percent EPT, and the modified Family Biotic Index. To increase the number of invertebrate metrics available for developing flow-ecology response relations, however, the invertebrate data were processed further by using the Invertebrate Data Analysis System (IDAS; Cuffney and Brightbill, 2011), which provides a larger suite of structural, functional, and behavioral assemblage metrics for comparison with hydrologic indices.

In order to relate hydrologic to ecological data, a set of aquatic-invertebrate sampling sites needed to be identified that are near the hydrologic study sites. Distance-based criteria were established to identify AMNET or other aquatic-invertebrate sampling sites for inclusion in the analysis. The following conditions were required: (1) all invertebrate sampling sites had to be located on the same stream segment (that is, there could be no stream confluences with other major tributaries between the streamflow-gaging station and the invertebrate sampling site, and (2) the invertebrate sampling site needed to be within 2.5 stream miles of the USGS real-time continuous streamflow-gaging station. To maintain consistency with the comparative hydrologic analysis, only stream classes A (semiflashy streams with moderately low base flow) and C (moderately stable streams with moderately high base flow) were targeted as before and as cooperatively agreed upon with the NJDEP. A geographic information system (GIS) approach was used to pair aquatic-invertebrate sampling sites and streamflow-gaging stations spatially by using the conservative criteria above. GIS analysis identified 23 of the 29 class A and $\mathrm{C}$ streams used in the hydrologic analysis that met the above requirements and were subsequently paired for hydroecological analysis (fig. 9). Most of the assembled invertebrate data were collected from April to September in 2003, 2004, and 2005. In two instances, aquatic-invertebrate samples collected from two time periods at the same location (that is, AMNET site AN0368 and USGS NAWQA station number 01403300) were associated with separate, but proximal, continuousrecord locations (table 3 ) following the pre-established selection criteria listed above.

\section{Aquatic-Invertebrate Analysis}

Aquatic-invertebrate assemblage data for the 23 class $\mathrm{A}$ and $\mathrm{C}$ stream sites compiled for this study combined State AMNET data, NAWQA data, and data from volunteer monitoring networks by using IDAS. All datasets were comparable in terms of sampling protocols (that is, the methods were similar regarding sampled habitat, number of composite samples collected, and total sampled area) and laboratory procedures (sorting, subsample count level, and taxonomic resolution) (see N.J. Department of Environmental Protection (2007, 2012b) and Moulton and others (2002) for detailed sampling protocols). For the NAWQA sites, the assemblage data were randomly resampled to a fixed count $(n=100)$ using IDAS to match the subsample size of the volunteer and AMNET datasets. The data were reviewed extensively to ensure that the aggregated data from the three separate sources included the same taxonomic groups, followed the same spelling and 


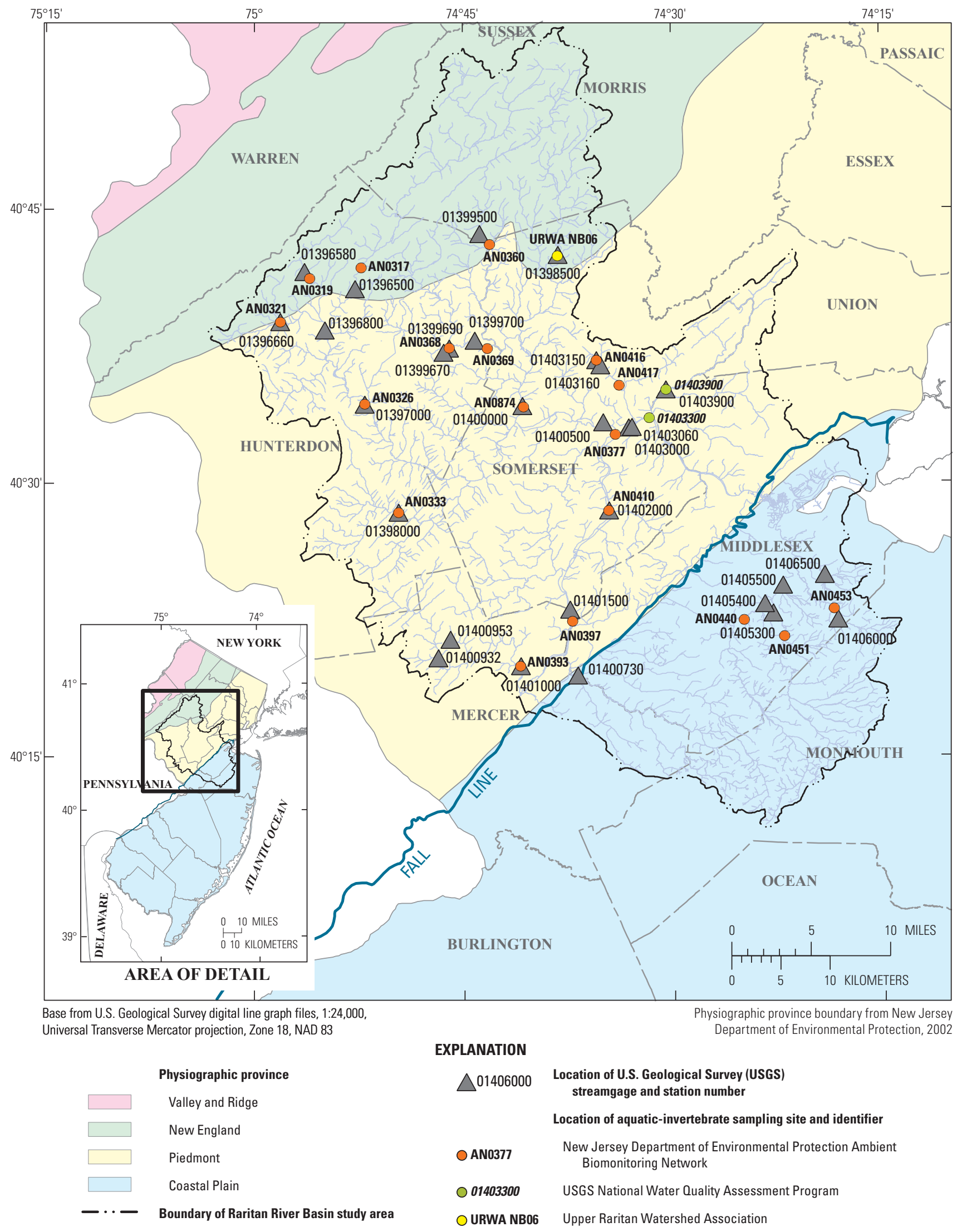

Figure 9. Location of hydrologic and ecological sites used for the flow-ecology response analysis for the Raritan River Basin study area, New Jersey. 
Table 3. Aquatic-invertebrate sampling sites and their corresponding U.S. Geological Survey streamgage station numbers used in the flow-ecology response analysis.

[USGS, U.S. Geological Survey; ecology site identifier beginning with AN, New Jersey Department of Environmental Protection Ambient Monitoring Network (AMNET) site number; ecology site identifier beginning with URWA, Upper Raritan Watershed Association site number; AMR3, sample collected during round 3 of the AMNET program; AMR2, sample collected during round 2 of the AMNET program; NAWQA, U.S. Geological Survey National Water Quality Assessment; NJIS, New Jersey impairment score]

\begin{tabular}{|c|c|c|c|c|c|c|}
\hline $\begin{array}{l}\text { USGS station } \\
\text { number }\end{array}$ & $\begin{array}{l}\text { Ecology site } \\
\text { identifier }\end{array}$ & $\begin{array}{c}\text { Data } \\
\text { source }\end{array}$ & $\begin{array}{c}\text { Sample } \\
\text { date }\end{array}$ & NJIS & Impairment & Dominant taxon \\
\hline 01396500 & AN0317 & AMR3 & $4 / 27 / 2004$ & 30 & Non-impaired & Chironomidae \\
\hline 01396580 & AN0319 & AMR3 & $4 / 7 / 2004$ & 21 & Moderately impaired & Chironomidae \\
\hline 01396660 & AN0321 & AMR3 & $4 / 22 / 2004$ & 21 & Moderately impaired & Lumbriculidae \\
\hline 01397000 & AN0326 & AMR3 & $4 / 29 / 2004$ & 30 & Non-impaired & Lepidostomatidae \\
\hline 01398000 & AN0333 & AMR3 & $5 / 11 / 2004$ & 21 & Moderately impaired & Naididae \\
\hline 01398500 & URWA NB06 & URWA & $6 / 22 / 2005$ & 21 & Moderately impaired & Hydropsychidae, Chironomidae \\
\hline 01399500 & AN0360 & AMR3 & $5 / 25 / 2004$ & 30 & Non-impaired & Chironomidae \\
\hline 01399670 & AN0368 & AMR2 & $5 / 13 / 1999$ & 21 & Moderately impaired & Chironomidae \\
\hline 01399690 & AN0368 & AMR3 & $5 / 4 / 2004$ & 15 & Moderately impaired & Chironomidae \\
\hline 01399700 & AN0369 & AMR3 & $4 / 20 / 2004$ & 15 & Moderately impaired & Chironomidae \\
\hline 01400000 & AN0374 & AMR3 & $6 / 2 / 2004$ & 30 & Non-impaired & Gammaridae \\
\hline 01400500 & AN0377 & AMR3 & $6 / 3 / 2004$ & 12 & Moderately impaired & Gammaridae \\
\hline 01401000 & AN0393 & AMR3 & 9/9/2004 & 21 & Moderately impaired & Elmidae \\
\hline 01401500 & AN0397 & AMR3 & $9 / 21 / 2004$ & 18 & Moderately impaired & Chironomidae \\
\hline 01402000 & AN0410 & AMR3 & $9 / 23 / 2004$ & 15 & Moderately impaired & Asellidae \\
\hline 01403000 & 01403300 & NAWQA & $7 / 29 / 2003$ & 24 & Non-impaired & Elmidae \\
\hline 01403060 & 01403300 & NAWQA & $8 / 8 / 2005$ & 27 & Non-impaired & Elmidae \\
\hline 01403150 & AN0416 & AMR3 & $6 / 3 / 2004$ & 9 & Moderately impaired & Chironomidae \\
\hline 01403160 & AN0417 & AMR3 & $5 / 25 / 2004$ & 18 & Moderately impaired & Chironomidae \\
\hline 01403900 & 01403900 & NAWQA & $7 / 28 / 2003$ & 21 & Moderately impaired & Hydropsychidae \\
\hline 01405300 & AN0451 & AMR3 & $8 / 24 / 2004$ & 9 & Moderately impaired & Chironomidae \\
\hline 01405400 & AN0440 & AMR3 & $8 / 5 / 2004$ & 15 & Moderately impaired & Chironomidae \\
\hline 01406000 & AN0453 & AMR3 & $9 / 2 / 2004$ & 9 & Moderately impaired & Chironomidae \\
\hline
\end{tabular}


abbreviation procedures, and had appropriate taxonomic resolution (that is, organisms were identified to the lowest taxonomic level) before data analysis was attempted.

The IDAS software (Cuffney and Brightbill, 2011) was used to resolve all taxonomic issues (taxonomic identification level and nomenclature) and to resolve taxonomic ambiguities (this process is commonly referred to as taxonomic harmonization). Ambiguities in the taxonomic hierarchy (that is, organisms that are not completely identified because of small size, incomplete development, damage, or poor preservation) were typically resolved by distributing the abundance of the ambiguous parents among their children in accordance with the relative abundance of each child (Cuffney and Brightbill, 2011). This approach, which represents a compromise between removing redundant taxonomic information and conserving quantitative information on taxa richness and abundance (Taylor, 1997), is one of the methods suggested by Cuffney and others (2007). When this approach was not possible, other approaches for resolving taxonomic ambiguities were applied. For example, rare organisms or those with difficult taxonomy were sometimes aggregated to family or higher. The dipteran family, Chironomidae, is considered an important bioindicator group, yet is historically a difficult group to identify to genus or species. As a result, data for this group were typically assigned to six taxa levels (five subfamilies plus Chironomidae) from the various family- to genus-level identifications that occurred within the original data. In some cases, where appropriate, genus-level identification was maintained. After data preparation, the IDAS program was used to calculate 184 aquatic-invertebrate assemblage metrics, many of which are commonly used in stream bioassessment (Rosenberg and Resh, 1993; Davis and Simon, 1995; Barbour and others, 1999) and some of which are comparable to those used by the NJDEP for the AMNET program (for example, N.J. Department of Environmental Protection, 2007). Tolerance and functional group metrics were calculated by using values from Barbour and others (1999). Tolerances were calculated on the basis of richness (average of tolerance values assigned to each taxon) (Cuffney and Brightbill, 2011).

\section{Use of Ecological Impairment to Define a Hydrologic Disturbance Gradient}

Within stream classes $\mathrm{A}$ and $\mathrm{C}$ are study basins associated with varying intensities of anthropogenic disturbance as indicated by their New Jersey Impairment Score (NJIS) (table 3). This multimetric index is derived from combining ecological measures of the aquatic-invertebrate assemblage, including dominance, tolerance, richness, and characteristics of taxonomic groups (see previous section on the Statewide Ambient Biomonitoring Network) (N.J. Department of Environmental Protection, 2007). In the context of this report, the
NJIS (or its component metrics) or IDAS metrics can be used as a general guideline to rank the relative level of ecological impairment in the study basin, or within stream classes, and indirectly establish a hydrologic disturbance gradient along which the effects of urbanization and development increase (for example, Kennen and others, 2002; Coles and others, 2004; Cuffney and others, 2005; Kennen and others, 2005). If at least one basin representing minimally impaired conditions (for example, South Branch Raritan River near High Bridge, NJ (01396500)) exists, that basin can represent an impairment endpoint for stream classes A and C. By using the hydrologic information for each class, changes in a subset of the HIP indices can be evaluated on the basis of their ranking along the NJIS disturbance gradient. In other words, changes can be evaluated by relating ecological metrics (the response variables) to hydrologic attributes (the explanatory variables) to derive flow-ecology response relations. Linear and multivariate statistical analyses can be used to determine whether a quantitative link exists between the metric scores and the mean change in the flow indices for a specific stream class or combination of stream classes. A subset of hydrologic indices that are ecologically relevant and nonredundant are presented. Hydrologic indices determined to be statistically significant predictors of stream impairment represent the basis of the flow-ecology response model building phase presented in this report.

\section{Data-Reduction Procedures and Analytical Approach}

Scatterplots and correlation matrices were used to examine data distributions and to detect potential outliers in the hydrologic and invertebrate metric data. Several hydrologic indices (MA1, 15, 20; MH5; ML4, 8; DL4; DH1) were significantly influenced by sites with large drainage areas that consequently had higher-than-average flow values. Therefore, hydrologic indices found to be affected by drainage area (those with a Pearson product-moment correlation coefficient (r) $>0.70$ with drainage area) were standardized by drainage area in order to "downweight" the influence of the larger study basins on the analyses. Standard data-reduction techniques were used to achieve a workable dataset and eliminate redundancy among the 184 IDAS metrics. In general, invertebrate metric response variables with a limited range of response to hydrologic variables $(r<0.50)$ were removed from consideration. Remaining invertebrate metric and hydrologic variable groups were correlated separately to identify redundancies. Several parsimonious surrogate invertebrate and hydrologic variables were selected to represent intercorrelated $(r>0.70)$ groups of variables. If all quantitative factors were equal between two invertebrate or hydrologic variables, the general management applicability of the variables to the Raritan River 
Basin and ease of measurement were considered. In effect, an attempt was made to identify and choose the most parsimonious variables for analysis. Correlations of aquatic-invertebrate metrics with hydrologic variables were then examined by means of Spearman correlation and variables that had a $r h o<0.40$ were removed from further analysis. All univariate and multivariate analyses were completed by using a combination of Primer v6 (Clarke and Gorley, 2006) and SAS (version 9.2; SAS Institute Inc., 2006). The remaining set of hydrologic and ecological variables was used to develop bivariate and multivariate flow-ecology response models (see tables 4 and 5 for definitions and variable codes for the final set of ecological metrics used in the analyses). Spearman correlations and MLR models were developed on the basis of combined analysis of class A and C streams $(n=23)$. MLR model performance was assessed by using the mean sum of squares $\left(\mathrm{R}^{2}\right)$, root mean squared error (RMSE), Akaike Information Criterion (AIC), predicted sum of squares (PRESS), and regression coefficients (SAS Institute Inc., 1991). A consistent MLR model-fitting approach was adopted for each invertebrate metric response variable. Stepwise selection criteria (with forward-selection and backward-elimination procedures) based on AIC and $\mathrm{R}^{2}$ for all two- and three-variable models was used. Model residuals, potential outliers, variance inflation factors (VIFs), and interaction terms were evaluated. When the final or "best" MLR model was selected, consideration was given to the AIC and the overall model fit. That is, MLR models were generally ranked in order of their $\mathrm{R}^{2}$ value, with higher rankings assigned to models with the lowest AIC and (or) no interaction term. To help evaluate the relative importance of each variable within the final MLR models, partial $\mathrm{R}^{2}$ values were determined for each variable.

Table 4. Flow-ecology response relations of selected New Jersey Department of Environmental Protection (NJDEP) Ambient Monitoring Network (AMNET) metrics significantly correlated (Spearman's rho) with the reduced set of hydrologic indices.

[Hydrologic index definitions can be found in appendix 1; EPT, Ephemeroptera, Plecoptera, Trichoptera; D/D, downward/decrease; U/I, upward/increase]

\begin{tabular}{|c|c|c|c|c|c|}
\hline $\begin{array}{c}\text { Metric } \\
\text { abbreviation }\end{array}$ & Metric description & $\begin{array}{c}\text { Predicted } \\
\text { metric response }\end{array}$ & $\begin{array}{l}\text { Hydrologic } \\
\text { index }\end{array}$ & rho & $p$-value \\
\hline \multirow{3}{*}{$\mathrm{NJIS}^{2}$} & \multirow{3}{*}{ New Jersey Impairment Score } & \multirow{3}{*}{$\mathrm{D} / \mathrm{D}$} & MA27 & -0.484 & 0.0193 \\
\hline & & & ML21 & -0.436 & 0.0377 \\
\hline & & & FH1 & -0.466 & 0.0249 \\
\hline \multirow{3}{*}{ EPT Index } & \multirow{3}{*}{ Total richness of EPT taxa } & \multirow{3}{*}{$\mathrm{D} / \mathrm{D}$} & MA27 & -0.493 & 0.0170 \\
\hline & & & ML15 & 0.486 & 0.0187 \\
\hline & & & ML21 & -0.525 & 0.0101 \\
\hline \multirow{3}{*}{ Percent $\mathrm{EPT}^{3}$} & \multirow{3}{*}{ Percentage abundance of EPT taxa } & \multirow{3}{*}{$\mathrm{D} / \mathrm{D}$} & MA27 & -0.480 & 0.0204 \\
\hline & & & ML18 & -0.462 & 0.0264 \\
\hline & & & DL11 & 0.420 & 0.0463 \\
\hline \multirow{3}{*}{ FBI } & \multirow{3}{*}{ Modified Family Biotic Index ${ }^{4}$} & \multirow{3}{*}{$\mathrm{U} / \mathrm{I}$} & MA27 & 0.476 & 0.0216 \\
\hline & & & ML15 & -0.487 & 0.0184 \\
\hline & & & ML18 & 0.456 & 0.0289 \\
\hline
\end{tabular}

${ }^{1}$ Predicted response pattern (direction of temporal change) for the aquatic-invertebrate metric with increasing anthropogenic disturbance within the Raritan River Basin, New Jersey.

${ }^{2}$ The NJDEP uses five metrics to calculate the New Jersey Impairment Score (NJIS): Taxa Richness (total families), EPT Index, Percent Dominance (percent of total abundance composed of the dominant family in the subsample), Percent EPT, and Modified Family Biotic Index (FBI). These metrics are summarized (New Jersey Department of Enironmental Protection, 1994; 2008) to produce the NJIS (New Jersey Department of Enironmental Protection, 1994; 2007). The NJIS, which ranges from non-impaired to severely impaired, is one of the criteria used by the NJDEP to assess stream biotic integrity.

${ }^{3}$ Includes the hydropsychid family.

${ }^{4} \mathrm{~A}$ weighted sum of the Family Tolerance Values (FTV), based on Hilsenhoff's tolerance scores assigned to families ranging from 0 (intolerant) and 10 (tolerant) (Hilsenhoff, 1987; New Jersey Department of Enironmental Protection, 2007). 
Table 5. Flow-ecology response relations of selected invertebrate-assemblage metrics significantly correlated (Spearman's rho) with the reduced set of hydrologic indices.

[Hydrologic index definitions can be found in appendix 1. A detailed explanation of all invertebrate metrics can be found in Cuffney and others (2005). Tolerance values (RichTOL and Tol_rich) and functional feeding groups (for example, scrapers (SC) and shredders (SH)) are derived from Appendix B in the U.S. Environmental Protection Agency (USEPA) Rapid Bioassessment Protocols (Barbour and others, 1999). <, less than; EPT, Ephemeroptera, Plecoptera, Trichoptera; D/D, downward/decrease; U/I, upward/increase]

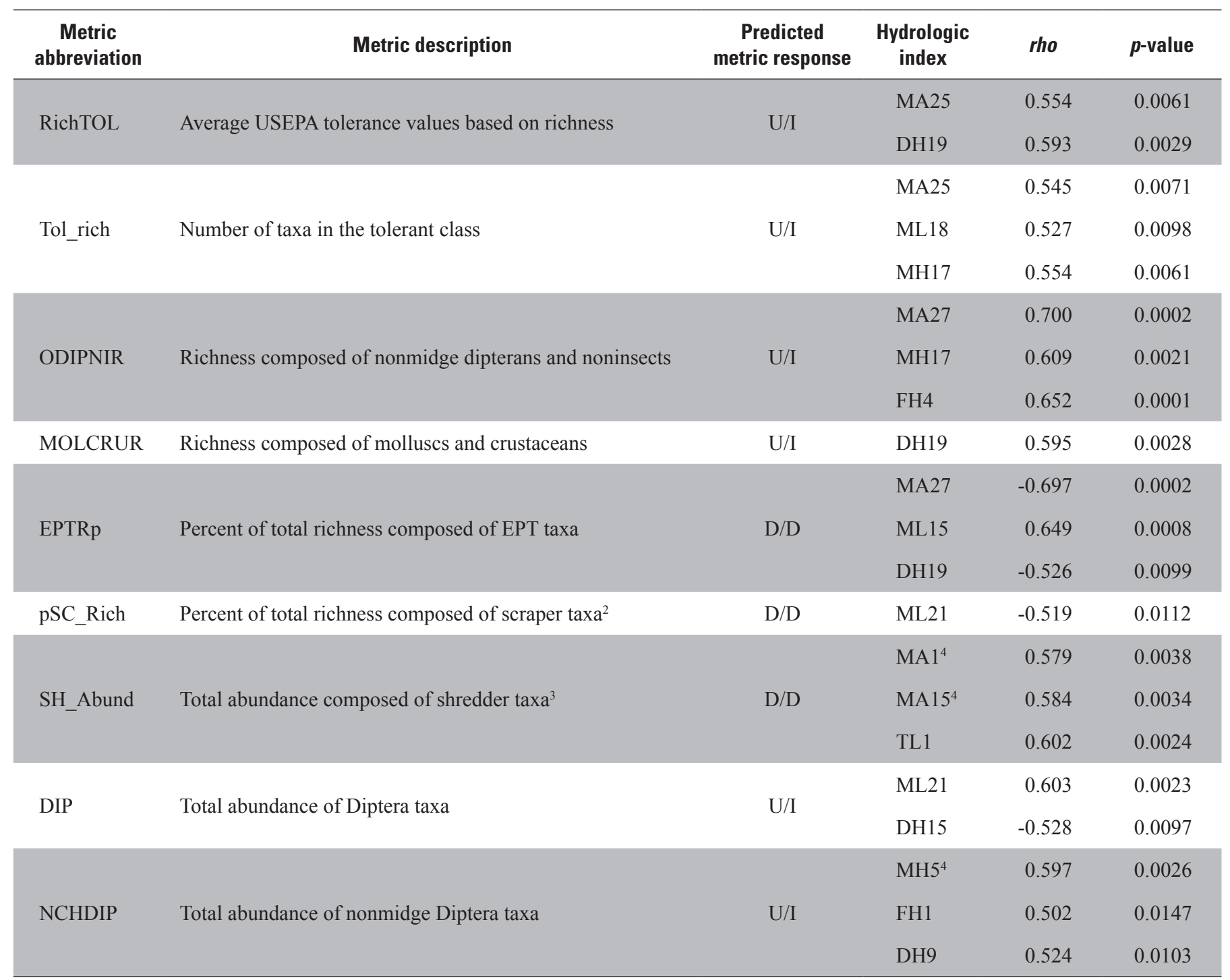

${ }^{1}$ Predicted response pattern (direction of temporal change) for the aquatic-invertebrate metric with increasing anthropogenic disturbance within the Raritan River Basin, New Jersey.

${ }^{2}$ Scrapers (SC) are aquatic organisms that shear and feed on attached algae and associated material located on submerged underwater surfaces such as rocks, twigs, and leaf debris (for example, Stenelmis sp., Phaenopsectra sp., Amnicola sp., and Glossosoma sp.) (Vannote and others, 1980; Merritt and Cummins, 1996).

${ }^{3}$ Shredders (SH) are aquatic organisms that chew primarily large pieces of decomposing vascular plant tissue ( $>1$ millimeter diameter), with a significant dependence on the associated microbial biomass (for example, Crictopus sp., Lepidostoma sp., Brillia sp., and Pycnopsyche sp.) (Vannote and others, 1980; Merritt and Cummins, 1996).

${ }^{4}$ Hydrologic index standardized to drainage area. 


\section{Evaluation of Aquatic-Invertebrate Metrics as a Basis for Flow-Ecology Response Model Development}

Stream impairment levels in the study area, as indicated by the NJIS for each site, ranged from moderately impaired (NJIS $=9-21$ ) to non-impaired (NJIS $=24-30$ ), with no sites listed as severely impaired (table 3 ). Six sites were listed as non-impaired and 17 sites were classified as moderately impaired. The initial compilation of aquatic-invertebrate data for the 23 sites yielded 556 taxa. After ambiguities with IDAS were removed, the number of taxa for the processed dataset was reduced to 536 . The number of taxa at a site ranged from 14 to 33 (median 23), Chironomidae was the dominant family at 12 sites (table 3 ), with percent dominance ranging from 22 to 64 percent. The range of values for the aquatic-invertebrate metrics varied and was associated with invertebrate-assemblage conditions ranging from poor to very good. For example, the percent richness of Ephemeroptera, Plecoptera, and Trichoptera taxa (EPTRp) ranged from 3.3 to 53.1 (median 24), and percent richness as nonmidge Diptera and noninsects (ODIPNIRp) ranged from 15.6 to 53 (median 30.8). The percent abundance of EPT (EPTp) ranged from 0.9 to 65.2 (median 16.8), and percent abundance of nonmidge Diptera and noninsects (ODIPNIp) ranged from 9.1 to 93.0 (median 26.3). The modified Family Biotic Index (FBI), which measures the relative tolerances of aquatic invertebrates to organic enrichment, ranged from 2.7 to 7.4 (median 5.5).

A tolerant taxon is one that is likely to be found at a site that has been altered by some type of environmental stressor (U.S. Environmental Protection Agency, 2006). In contrast, a sensitive taxon is one that tends to decline in abundance or occurrence probability along a defined stressor gradient (for example, urbanization or streamflow modification). Ecological tolerance values assigned to a taxon typically indicate how well the taxon tolerates the presence of organic enrichment in the stream (Hilsenhoff, 1987). Tolerance values range from 0 (extremely sensitive organism) to 10 (tolerant organism), with low values indicative of intolerant taxa that will disappear quickly from assemblages as water quality degrades. High values indicate tolerant taxa that will remain in the aquaticinvertebrate assemblage as water quality degrades (Cuffney and Brightbill, 2011). In the IDAS software, the tolerance values chosen for each taxon were based on values derived from Barbour and others (1999) and the Mid-Atlantic Coastal Plain Work Group (U.S. Environmental Protection Agency, 1997), which included representatives from the States of New Jersey, Delaware, Maryland, North Carolina, and South Carolina.

For each ecological site, tolerance values were assigned to each taxon and the taxa richness of the intolerant, moderately tolerant, and tolerant class of aquatic invertebrates was quantified in IDAS. The intolerant-class richness (Intol_rich) ranged from 0 to 18 (median 4), the moderately tolerant-class richness (Modtol_rich) ranged from 7 to 17 (median 12), and the tolerant-class richness (Tol_rich) ranged from 0 to 8 (median 3). Although the study sites exhibit both non-impaired $($ Intol_rich $=18)$ and impaired (Intol_rich $=0)$ conditions, the aquatic-invertebrate data indicate that the majority of the Raritan River Basin ecological sites included in this study are characterized by moderately tolerant taxa.

\section{Bivariate Flow-Ecology Response Relations}

Flow-ecology response relations were developed to evaluate potential linkages between flow indices and aquaticinvertebrate assemblage metrics that could potentially be useful to water managers. Flow-ecology response relations were evaluated for a subset of aquatic-invertebrate metrics (tables 4 and 5) for the 23 study sites that met the previously described criteria by using Spearman's correlation and regression procedures. For the development of all flow-ecology relations, class $\mathrm{A}$ and $\mathrm{C}$ streams were combined because too few sites with both hydrologic and ecological data existed in any single stream class to provide sufficient power for univariate or multivariate analysis. Class A and C streams have many similar characteristics but, in general, differ in size and proportion of base flow.

Many hydrologic measures accounting for the duration, magnitude, timing, and frequency of flows were significantly correlated with ecological response (tables 4 and 5). Many invertebrate-assemblage metrics $(n=184)$ accounting for richness, abundance, and function of the aquatic-invertebrate assemblage were computed by using the IDAS software (Cuffney and others, 2005); however, only a subset $(n=9)$ that met the screening criteria was retained for further analysis (table 5). In addition, a smaller suite of AMNET metrics $(\mathrm{n}=4)$ used by the NJDEP, which includes the NJIS, was also retained for development of flow-ecology response relations (table 4). Although some of the AMNET and IDAS metrics were comparable (for example, EPT richness (AMNET) and percent of total richness composed of EPT taxa (IDAS)), stronger relations with some hydrologic variables were seen for the IDAS metrics than for the AMNET metrics. This difference may result from the different approaches used to deal with taxonomic hierarchy and resolution when the taxonomic data were processed. NJDEP round 3 AMNET metrics are typically derived from data aggregated to the family level, whereas IDAS metrics are derived from data aggregated to the lowest practical taxonomic level (most commonly the genus level) where appropriate. These differences in data resolution may ultimately affect the comparability of the calculated richness values of the aquatic-invertebrate data used to determine the score for some of the NJIS component metrics relative to those calculated for the entire aquatic-invertebrate dataset using IDAS.

In general, invertebrate flow-ecology relations followed response patterns that would be expected in streams with some degree of hydrologic disturbance. The metrics most highly correlated to flow processes were the total richness composed of nonmidge Diptera and noninsects (ODIPNIR) as well as the percentage of total richness composed of EPT species 
(EPTRp) (table 5). A significant relation was identified with the variability in magnitude of April flow values (MA27) for both of these metrics. As the variability in MA27 increased, there was an increase in the richness of more tolerant aquatic invertebrates (ODIPNIR, rho $=0.700)$ and a decrease in the percent richness of aquatic invertebrates considered to be highly sensitive to changes in stream condition (EPTRp, $r h o=-0.697)$. Many of the AMNET metrics used in the analysis (for example, NJIS, EPT index, percent EPT), with the exception of FBI, showed a negative correlation with MA27 (table 4). Higher high flows are common in streams in urbanizing drainage basins, and in the Raritan River Basin this type of alteration in flow appears to negatively affect the richness and abundance of aquatic-invertebrate fauna (for example, EPT taxa) (table 5). In contrast, the average U.S. Environmental Protection Agency tolerance values for samples based on richness (RichTOL) and the overall richness of tolerant invertebrate taxa (Tol_rich) increased with the variability in the magnitude of February flow values (MA25) (table 5). These relations may indicate that changing variability in the magnitude of streamflows, especially during critical flow periods, may have an appreciable effect on assemblage integrity (for example, Kennen and others, 2010).

A common effect of urbanization on stream hydrology is that the frequency and magnitude of high flows generally increase and flow durations generally decrease as a result of rapid runoff from impervious surfaces (Walsh and others, 2005b). This increased flashiness is a consistent trait of the "urban stream syndrome," and can be caused by a combination of increased runoff from ISC and more efficient transport of stormwater runoff within the catchment by piped stormwaterdrainage systems that drain directly to streams (Dunne and Leopold, 1978; Walsh and others, 2005a). In streams draining conventionally urban areas, the frequency of small to moderate flows from direct surface runoff may increase, even after small rain events (Walsh and others, 2004). This increased drainage of stormwater to streams alters the natural flow regime and has a direct effect on the aquatic-invertebrate assemblage. For example, when the average frequency of days (annually) in which the flow exceeds seven times the median flow (FH4), metrics that account for the richness of more tolerant taxa (for example, ODIPNIR) tend to increase ( $r h o=0.652, p>0.001$ ). Similarly, as the average frequency of annual high-flow events exceeding the 75th-percentile value (FH1) increases, NJIS decreases $(r h o=-0.466)$ and the abundance of nonmidge Diptera, NCHDIP, increases ( $r h o=0.502)$.

The magnitude of low and high flows, timing of low flows, and duration of high flows were significantly linked to the abundance and richness of certain aquatic-invertebrate taxa (tables 4 and 5). As the variability across annual minimum flows (ML21) increased, the abundance of Diptera taxa $(\mathrm{DIP}, r h o=0.603)$ increased and the percent richness composed of scraper taxa (pSC_Rich, rho $=-0.519)$, EPT index $(r h o=-0.525)$, and impairment score (NJIS, rho $=-0.436)$ decreased. Scrapers feed on materials attached to submerged underwater surfaces such as rocks, twigs, and leaf debris
(Vannote and others, 1980; Merritt and Cummins, 1996); therefore, a decrease in minimum flows may decrease habitat and food availability for many scraper organisms. Reductions in minimum annual streamflows, as indicated by ML21, may result in lower low flows that favor more tolerant taxa or taxa that prefer slower velocities (Jowett, 1997), or those taxa that are more tolerant of stressors (for example, oxygen depletion and increased water temperatures), such as some Diptera species. Chironomidae, for example, was the dominant family at 12 of the Raritan River Basin ecological sites (table 3). Many chironomid taxa are particularly adaptable to degraded stream habitats, and some, such as those that survive in sediment, even have the capacity to respire in oxygen-depleted environments (Paine and Gaufin, 1956), even under extreme low-flow conditions. In contrast, the EPT and the EPTRp indices were positively correlated to the low-flow index (ML15) (tables 4 and 5, respectively). These significant relations may indicate that the presence of some sensitive taxa (for example, Ephemeroptera) is highly coupled with changes in minimum annual flows. In addition, Carlisle and others (2010) found a shift in the functional traits of aquatic-invertebrate taxa in streams with diminished minimum flows. Taxa favoring slow-moving waters and fine substrates associated with lower flows replaced riffle-loving aquatic invertebrates that prefer coarse substrates in streams (such as EPT taxa), and aquatic invertebrates with the ability to move quickly within a stream (strong swimmers, fast crawlers) replaced taxa lacking these traits. The timing of minimum flows may also affect the aquatic-invertebrate assemblage in the Raritan River Basin study area. The abundance of shredder taxa (SH_Abund) was positively correlated with the Julian date of annual minimum flows (TL1), but when the annual minimum flow occurred before September 1st, the abundance of shredder taxa was reduced $(r h o=0.602)$.

As the variability in base flow (ML18) increases as a result of increased surface runoff and diminished groundwater recharge, streams become flashier with higher peak flows and lower low flows. Again, lower low flows tend to support increases in more tolerant taxa (Tol_rich, $r h o=0.527$; FBI, $r h o=0.456)$ while promoting a decrease in the percent abundance of more sensitive taxa (percent EPT, $r h o=-0.462$ ). Altered low flows at many of the Raritan River Basin study sites likely have an adverse effect on sensitive aquatic invertebrates with life-history and behavioral constraints that rely on flow cues for support of crucial life-cycle stages (Lytle and Poff, 2004). Additionally, flows with higher magnitudes followed a similar pattern - that is, a positive correlation was found between the 25-percent median flow exceedance values for the entire hydrologic record (MH17) and an increase in the richness of more tolerant species (Tol_rich, rho $=0.554$; ODIPNIR, $r h o=0.609$ ), which may indicate that some moderately impaired Raritan River Basin study area streams at the more highly altered end of the disturbance gradient are becoming more flashy. It has been demonstrated that in conventionally drained urban catchments, more frequent high-flow events, such as MH17, may be an important driver of channel incision, thereby reducing instream habitat while consequently 
reducing the abundance of sensitive species (MacRae and Rowney, 1992; Walsh and others, 2005b).

In general, as streams become more urbanized (that is, they reflect flows of higher frequency and magnitude and shorter duration), the richness and abundance of tolerant organisms tend to increase and intolerant organisms decrease (Harding and others, 1998; Walsh and others, 2005b). Many of the IDAS metrics evaluated in this study reflect this relation (table 5); however, this was not always the case. For example, as the average duration of high flows above the 75th-percentile value for each year (DH15) increases, there is a corresponding decrease in Diptera taxa $(r h o=-0.528)$. Similarly, as high-flow duration seven times the median for the entire flow record (DH19) increased, the percent richness of EPT species $($ EPTRp, rho $=-0.526)$ decreased (table 5). Even though most results of this study indicate that Diptera taxa appear to be resilient to stress associated with reductions in streamflow and appear to be highly adaptable to "flashy" streams, the inverse relation of Diptera taxa with DH15 as well as the decreases in EPTRp with increases in DH19 may indicate the presence of a change point for dipteran and other aquatic species in regard to increased duration and magnitude of the more extreme highflow events. Such high flows of long duration may heavily scour the stream bottom and ultimately result in a general, but often temporary reduction in the richness of dipteran as well as many other taxa.

\section{Multivariate Flow-Ecology Response Models}

Multiple linear regression (MLR) analysis of hydrologic attributes and invertebrate-assemblage metrics was used to develop a series of equations defining the probability of assemblage alteration from hydrologic disturbance. MLR analysis is typically used to predict or model a response variable (for example, EPT metric scores) from one or more continuous explanatory variables (for example, hydrologic characteristics). The result is a regression equation that identifies the minimum set of explanatory variables needed to account for the observed variation in the response variable. By using multiple explanatory variables to estimate values of a response variable, errors in prediction can be minimized while still accounting for a large proportion of the variance in the response variable.

As would be expected, MLR models accounted for a relatively high proportion of the variability in the assemblage metric response. As more variables are incorporated into a regression model, higher $\mathrm{R}^{2}$ values will typically result. Therefore, although simple univariate flow-ecology response models using only one hydrologic variable (for example, tables 4 and 5) may be significant, multiple regression models fit with two to three hydrologic variables (table 6) typically represent a more integrative model with greater predictive capability. In addition, multivariate flow-ecology response models may provide a more holistic perspective of the types of hydrologic changes that are affecting the aquatic-invertebrate assemblages in the Raritan River Basin.
Two- and three-variable MLR models were derived on the basis of hydrologic attributes that explained from 35 to 75 percent of the variability in metric scores (table 6). Twentyfour hydrologic variables were significantly $(p<0.05)$ related to the ecological metrics for the aquatic-invertebrate assemblage, and all these variables had low variance inflation factors (VIF < 10.0). Combined, these hydrologic measures accounted for all five major components of the flow regime-magnitude, frequency, duration, timing, and rate of change. In general, multivariate models derived by using the IDAS metrics performed better (had a higher $\mathrm{R}^{2}$ ) than those derived for comparable AMNET metrics. No significant multivariate model could be derived for the AMNET metric percent EPT. The three ecological metrics with the strongest relation to changes in streamflow were SH_Abund $\left(\mathrm{R}^{2}=0.751, p<0.0001\right)$, $\operatorname{NCHDIP}\left(\mathrm{R}^{2}=0.749, p<0.0001\right)$, and EPTRp $\left(\mathrm{R}^{2}=0.667\right.$, $p=0.0001$ ) (table 6). All were three-variable models and all were metrics derived by using the IDAS program. The variability in monthly February streamflow (MA25), mean annual high flow for May (MH5), high flow discharge index (MH17), and mean annual September flow (MA20) each appeared four or more times in the represented models and accounted for 58 to 71 percent, 45 to 79 percent, 25 to 38 percent, and 18 to 49 percent of the overall variability, respectively. Mean annual high flow for May (MH5) accounted for the greatest amount of variability in any single model (79 percent in the two-variable model for SH_Abund) (table 6).

Predictive MLR models were derived by linking assemblage structure and function (that is, ecological metrics or a multimetric) with hydrologic attributes, and these models appear to indicate that hydrologic alteration resulting from landscape change, water abstraction, and streamflow regulation have modified stream biotic integrity in the Raritan River Basin, even for the subset of non- to moderately impaired sites targeted in this analysis. Most prominent were changes in the duration and magnitude of high and low flows that individually and cumulatively appeared to account for the greatest amount of variability in the aquatic-invertebrate metrics. Frequency, timing, and rate-of-change variables were much less prominent in the MLR models and generally accounted for a smaller proportion of the model variance (table 6). Most susceptible to hydrologic alteration were indices accounting for changes in sensitive taxa (for example, EPTRp), structural attributes such as those based on invertebrate richness (for example, ODIPNIR), and functional components (for example, pSC_Rich). The AMNET multimetric NJIS appeared to be slightly less responsive to overall changes in flow for streams in the Raritan River Basin than many of the individual taxa-based metrics. This finding is not unexpected, however, given that NJIS is a composite multimetric that is designed to provide a holistic assessment of stream health and was not specifically designed to assess streamflow alteration. The functional measure SH_Abund (total abundance of shredder taxa) was the metric most strongly related to changes in streamflow among all MLR models developed (table 6). All of these changes in biotic-assemblage metrics may be, in part, 
Table 6. Two- and three-variable multiple regression models relating selected New Jersey Department of Environmental Protection Ambient Monitoring Network (AMNET) and Invertebrate Data Analysis System (IDAS) metrics to hydrologic indices.

[All model intercepts were significant at the $p<0.001$ level. Hydrologic index definitions can be found in appendix 1; ecological metrics are defined in tables 4 and $5 ; \mathrm{R}^{2}$, coefficient of determination; $p$, probability value; VIF, variance inflation factor]

\begin{tabular}{|c|c|c|c|c|c|c|c|c|c|}
\hline $\begin{array}{l}\text { Ecological } \\
\text { metric }\end{array}$ & $\begin{array}{c}\text { Number in } \\
\text { model }\end{array}$ & Source & Model $\mathbf{R}^{2}$ & Model $p$ & Partial $\mathbf{R}^{2}$ & $p$-value & $\begin{array}{l}\text { Variable } \\
\text { influence }\end{array}$ & $\begin{array}{c}\text { Hydrologic } \\
\text { index }\end{array}$ & VIF \\
\hline \multirow{2}{*}{ NJIS } & \multirow{2}{*}{2} & \multirow{2}{*}{ AMNET } & \multirow{2}{*}{0.3503} & \multirow{2}{*}{0.0134} & 0.2202 & 0.0039 & - & MA25 & 1.89 \\
\hline & & & & & 0.1301 & 0.0500 & + & MH17 & 1.89 \\
\hline \multirow{2}{*}{ NJIS } & \multirow{2}{*}{2} & \multirow{2}{*}{ AMNET } & \multirow{2}{*}{0.3643} & \multirow{2}{*}{0.0135} & 0.2166 & 0.0039 & - & ML22 & 1.46 \\
\hline & & & & & 0.1477 & 0.0492 & - & MA20 ${ }^{1}$ & 1.46 \\
\hline \multirow{2}{*}{ FBI } & \multirow{2}{*}{2} & \multirow{2}{*}{ AMNET } & \multirow{2}{*}{0.4249} & \multirow{2}{*}{0.0040} & 0.2846 & 0.0010 & - & ML22 & 1.71 \\
\hline & & & & & 0.1403 & 0.0390 & - & MH17 & 1.71 \\
\hline \multirow{2}{*}{ EPT Index } & \multirow{2}{*}{2} & \multirow{2}{*}{ AMNET } & \multirow{2}{*}{0.3787} & \multirow{2}{*}{0.0086} & 0.2384 & 0.0311 & - & DL6 & 1.04 \\
\hline & & & & & 0.1403 & 0.0463 & - & FH8 & 1.04 \\
\hline \multirow{3}{*}{ EPT Index } & \multirow{3}{*}{3} & \multirow{3}{*}{ AMNET } & & & 0.2626 & 0.0039 & - & MA201 & 1.94 \\
\hline & & & 0.5669 & 0.0015 & 0.2472 & 0.0021 & - & DL6 & 1.09 \\
\hline & & & & & 0.0571 & 0.0037 & - & DH19 & 1.82 \\
\hline RichTOI & 2 & IDAS & 04453 & 00028 & 0.3144 & 0.0014 & + & MA25 & 3.15 \\
\hline NIUIII I & 2 & 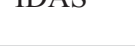 & $0.4+35$ & 0.0020 & 0.1309 & 0.0402 & - & $\mathrm{DH} 1^{1}$ & 3.15 \\
\hline & & & & & 0.3144 & 0.0106 & + & MA25 & 1.94 \\
\hline RichTOL & 3 & IDAS & 0.5133 & 0.0029 & 0.1271 & 0.0383 & - & MH17 & 2.16 \\
\hline & & & & & 0.0718 & 0.0179 & + & DH19 & 1.98 \\
\hline Tol rich & 2 & IDAS & 0.4675 & 00015 & 0.3451 & 0.0029 & + & MA25 & 1.01 \\
\hline 101_11011 & 2 & IDAS & 0.4075 & $0.001 \mathrm{~J}$ & 0.1314 & 0.0365 & + & $\mathrm{DH}^{2}$ & 1.01 \\
\hline & & & & & 0.3451 & 0.0065 & + & MA25 & 5.49 \\
\hline Tol_rich & 3 & IDAS & 0.5973 & 0.0005 & 0.1442 & 0.0173 & + & FH4 & 5.35 \\
\hline & & & & & 0.1080 & 0.0035 & + & RA7 & 7.59 \\
\hline ODIPNIR & 2 & IDAS & 04255 & 00039 & 0.2338 & 0.0063 & - & ML4 ${ }^{1}$ & 1.01 \\
\hline ODII IVIK & 2 & IDAS & 0.4205 & 0.0039 & 0.1917 & 0.0178 & + & $\mathrm{MH}^{1}$ & 1.01 \\
\hline & & & & & 0.3502 & 0.0082 & + & MA27 & 1.40 \\
\hline ODIPNIR & 3 & IDAS & 0.5455 & 0.0022 & 0.0982 & 0.0079 & - & MA201 & 5.82 \\
\hline & & & & & 0.0971 & 0.0654 & + & RA7 & 6.68 \\
\hline MOICRIIR & 2 & IDAS & 04648 & 00019 & 0.3362 & 0.0007 & + & DH19 & 1.07 \\
\hline VIULCNUК & 2 & IDAS & 0.4040 & 0.0013 & 0.1286 & 0.0403 & + & TL1 & 1.07 \\
\hline & & & & & 0.2963 & 0.0028 & + & $\mathrm{MH}^{1}$ & 2.23 \\
\hline MOLCRUR & 3 & IDAS & 0.5214 & 0.0025 & 0.1650 & 0.0003 & - & $\mathrm{ML}^{1}$ & 2.48 \\
\hline & & & & & 0.0601 & 0.0020 & - & MA26 & 3.48 \\
\hline FPTRn & 2 & IDAS & 05205 & 00009 & 0.3127 & 0.0002 & + & DL4 ${ }^{1}$ & 1.97 \\
\hline Li 110 & 2 & IDAS & $0 . J 20 J$ & 0.0009 & 0.2078 & 0.0098 & - & MA20 ${ }^{1}$ & 1.97 \\
\hline & & & & & 0.3696 & 0.0001 & + & ML19 & 9.88 \\
\hline EPTRp & 3 & IDAS & 0.6669 & 0.0001 & 0.1498 & 0.0050 & - & DL11 & 8.93 \\
\hline & & & & & 0.1475 & 0.0113 & - & MA20 ${ }^{1}$ & 1.48 \\
\hline nSC Rich & 2 & IDAS & 03086 & 00300 & 0.1581 & 0.0177 & - & DL6 & 1.10 \\
\hline pSC_NICII & 2 & IDAS & 0.5000 & 0.0500 & 0.1505 & 0.0502 & - & MA20 ${ }^{1}$ & 1.10 \\
\hline & & & & & 0.3200 & 0.0026 & - & RA7 & 4.63 \\
\hline pSC_Rich & 3 & IDAS & 0.4915 & 0.0043 & 0.1448 & 0.0025 & + & DH15 & 1.46 \\
\hline & & & & & 0.0267 & 0.0026 & + & ML22 & 3.78 \\
\hline
\end{tabular}


Table 6. Two- and three-variable multiple regression models relating selected New Jersey Department of Environmental Protection Ambient Monitoring Network (AMNET) and Invertebrate Data Analysis System (IDAS) metrics to hydrologic indices.-Continued

[All model intercepts were significant at the $p<0.001$ level. Hydrologic index definitions can be found in appendix 1; ecological metrics are defined in tables 4 and $5 ; \mathrm{R}^{2}$, coefficient of determination; $p$, probability value; VIF, variance inflation factor]

\begin{tabular}{|c|c|c|c|c|c|c|c|c|c|}
\hline $\begin{array}{c}\text { Ecological } \\
\text { metric }\end{array}$ & $\begin{array}{c}\text { Number in } \\
\text { model }\end{array}$ & Source & Model R ${ }^{2}$ & Model p & Partial $\mathbf{R}^{2}$ & $p$-value & $\begin{array}{l}\text { Variable } \\
\text { influence }\end{array}$ & $\begin{array}{c}\text { Hydrologic } \\
\text { index }\end{array}$ & VIF \\
\hline \multirow{2}{*}{ SH_Abund } & \multirow{2}{*}{2} & \multirow{2}{*}{ IDAS } & \multirow{2}{*}{0.5921} & \multirow{2}{*}{0.0001} & 0.4663 & 0.0028 & + & $\mathrm{MH}^{1}$ & 1.18 \\
\hline & & & & & 0.1258 & 0.0220 & + & TL1 & 1.18 \\
\hline \multirow{2}{*}{ DIP } & \multirow{2}{*}{2} & \multirow{2}{*}{ IDAS } & \multirow{2}{*}{0.5413} & \multirow{2}{*}{0.0004} & 0.3594 & 0.0005 & + & ML18 2 & 1.01 \\
\hline & & & & & 0.1819 & 0.0107 & + & MA15' & 1.01 \\
\hline \multirow{2}{*}{ NCHDIP } & \multirow{2}{*}{2} & \multirow{2}{*}{ IDAS } & \multirow{2}{*}{0.6365} & \multirow{2}{*}{$<0.0001$} & 0.4988 & 0.0005 & + & $\mathrm{MH}^{1}$ & 1.11 \\
\hline & & & & & 0.1377 & 0.0123 & + & $\mathrm{DH} 9^{2}$ & 1.11 \\
\hline
\end{tabular}

a direct result of hydrologic alteration, or may be a result of changes in landscape factors associated with hydrologic alteration (Lytle and Poff, 2004), such as artificially maintained passing flows at dams or impoundments, greater surface- and groundwater use, and increasing ISC. Magnitude of average, high, and low flows and duration and timing of low and high flows were identified as important hydrologic variables in the MLR analysis. For example, magnitude of low flow (that is, ML22, ML4, ML19, and ML18) accounted for a significant amount of the variability in many of the two- and threevariable models, especially for NJIS, FBI, ODIPNIR, EPTRp, and DIP (table 6). Periods of low flow tend to favor taxa that prefer slower velocities (Jowett, 1997) or are more tolerant of stressors (for example, oxygen depletion and higher water temperatures) associated with more slowly flowing water. In particular, minimum flows appeared to be highly important in maintaining invertebrate-assemblage integrity, and spring low flow (that is, ML4) accounted for a significant portion of the variability ( 55 percent) in the two-variable ODIPNIR model (table 6). As low flows become lower and occur later, the richness of tolerant taxa such as many nonmidge dipterans and other noninsect taxa tends to increase, whereas the richness of more sensitive EPT taxa tends to decrease. The variability and magnitude of mean annual flow values (MA25 and MA20, respectively) and the mean maximum flow for May across all years (MH5) accounted for a significant proportion of the variability in the two- and three-variable MLR models, especially for NJIS, EPT index, EPTRp, RichTOL, ODIPNIR, MOLCRUR, and NCHDIP (table 6). Increasing magnitudes and variability in annual and high flows are indicative of streams that are becoming more flashy (Walsh and others, 2005b), and this type of flow alteration appears to negatively affect the richness, abundance, and function of aquatic-invertebrate fauna. For example, EPTRp taxa tend to be negatively related to changes in the magnitude of annual flows, whereas RichTOL is positively related to an increase in annual high-flow variability. In general, the magnitude, frequency, and variability of high flows are increasing and the magnitude of low flows is decreasing with increasing assemblage impairment, indicating that many of the study streams in the Raritan River Basin are becoming flashier and tend to have high flows of shorter duration and lower low flows. Streams with more unpredictable high-flow events in combination with extreme low flows are indicative of catchments that are affected by changes in the landscape associated with urbanization (Konrad and Booth, 2005; Walsh and others, 2005b), flow regulation (Freeman and Marcinek, 2006), and water abstraction (Chessman and others, 2011). Such changes in runoff and streamflow patterns alter the natural flow regime and greatly affect sensitive native and endemic species. 


\section{Data Limitations}

A major premise of the streamflow modeling approach used in support of the hydro-TMDL methodology is that the Statewide Watershed Runoff Model (SWRM) results reasonably and relatively accurately represent (or mimic) the natural hydrograph and are an appropriate surrogate for a baseline hydrograph in locations in the Raritan River Basin for which an observed baseline record did not exist or could not be differentiated from an existing long-term U.S. Geological Survey hydrologic record. As previously mentioned in the section "Determining Deviation of Streamflow from Baseline Conditions," observed baseline (OB) sites are sites where an existing baseline/reference or "minimally altered" time period of change could be differentiated (by using quantile regression) from an existing long-term period of record (POR). When such a record was not available, a simulated baseline (SB) was developed by using the SWRM. SB hydrographs were developed to reduce the effects of anthropogenic stressors (for example, urban land use, impervious surface cover (ISC), compacted soils, etc.) on the hydrologic response and simulate a "natural" baseline POR. For example, in this study ISC in the SWRM model was typically set to 0 percent, indicating no pre-existing anthropogenic disturbance.

\section{Differences between Observed and Simulated Baseline Periods of Record}

Results of the hydro-TMDL comparisons appear to indicate that greater deviations from the 25th-to-75th-percentile ranges occurred more often at the SB sites than at the $\mathrm{OB}$ sites (app. 2). On the basis of this observation, it was hypothesized that the SB record derived by using 0 percent ISC may ultimately represent a more conservative endpoint from a regulatory perspective than an $\mathrm{OB}$ record, as it is unlikely that any given stream in New Jersey has not undergone, at some point in its history, at least some anthropogenic alteration of the landscape. In an effort to test this hypothesis, an $\mathrm{SB}$ record was simulated for three sites for which an existing OB record was previously identified (using the same POR) and the two were directly compared to evaluate the differences in percent deviations between corresponding hydrologic variables. For example, table 7 shows percent deviations using both the OB and SB records for the Raritan River at Manville, NJ (RarMan). For the hydrologic variables whose values fell outside the 25th-to-75th-percentile range for the SB record but not the OB record, the OB 25th-to-75th-percentile ranges were included in the tables to exhibit the difference in ranges between the two hydrologic-record types. The annual

Table 7. Deviations of flow-management targets for the observed and simulated baseline records for the Raritan River at Manville, NJ, study site that fall outside the established 25th-to-75th-percentile range.

$\left[\mathrm{ft}^{3} / \mathrm{s}\right.$, cubic feet per second; $\left(\mathrm{ft}^{3} / \mathrm{s}\right) / \mathrm{d}$, cubic feet per second per day; D, dimensionless; JD, Julian day; --, no deviations above the 75th or below the 25th percentile; hydrologic indices are defined in appendix 1; values less than 1 were rounded to the thousandths place to show precision]

\begin{tabular}{|c|c|c|c|c|c|c|}
\hline \multicolumn{7}{|c|}{ U.S. Geological Survey station number 01400500 Raritan River at Manville, NJ } \\
\hline $\begin{array}{l}\text { Hydrologic } \\
\text { index }\end{array}$ & Units & 25th percentile & $\begin{array}{c}\text { Observed } \\
\text { NJHAT value }\end{array}$ & 75th percentile & $\begin{array}{c}\text { Percent } \\
\text { deviation } \\
\text { below the } \\
\text { 25th percentile }\end{array}$ & $\begin{array}{c}\text { Percent } \\
\text { deviation } \\
\text { above the } \\
\text { 75th percentile }\end{array}$ \\
\hline \multicolumn{7}{|c|}{ Stream class A, observed baseline dataset } \\
\hline MH5 & $\mathrm{ft}^{3} / \mathrm{s}$ & 960.0 & 2,360 & 3,820 & -- & -- \\
\hline DL4 & $\mathrm{ft}^{3} / \mathrm{s}$ & 81.1 & 231.2 & 147.0 & -- & 57.3 \\
\hline DH2 & $\mathrm{ft}^{3} / \mathrm{s}$ & 4,897 & 6,643 & 7,737 & -- & -- \\
\hline TA1 & $\mathrm{D}$ & 0.432 & 0.652 & 0.553 & -- & 17.9 \\
\hline TL1 & JD & 246.8 & 262.6 & 262.5 & -- & 0.040 \\
\hline TH1 & JD & 42.8 & 73.2 & 70.4 & -- & 4.0 \\
\hline RA3 & $\left(\mathrm{ft}^{3} / \mathrm{s}\right) / \mathrm{d}$ & -168.0 & -57.0 & -19.0 & -- & -- \\
\hline \multicolumn{7}{|c|}{ Stream class $A$, simulated baseline dataset } \\
\hline MH5 & $\mathrm{ft}^{3} / \mathrm{s}$ & 730.6 & 2,360 & 1,380 & -- & 71.0 \\
\hline DL4 & $\mathrm{ft}^{3} / \mathrm{s}$ & 86.9 & 231.2 & 222.0 & -- & 4.1 \\
\hline DH2 & $\mathrm{ft}^{3} / \mathrm{s}$ & 1,168 & 6,643 & 1,825 & -- & 264.0 \\
\hline TA1 & $\mathrm{D}$ & 0.432 & 0.652 & 0.553 & -- & 17.9 \\
\hline TL1 & JD & 246.8 & 262.6 & 262.5 & -- & 0.040 \\
\hline TH1 & JD & 42.8 & 73.2 & 70.4 & -- & 4.0 \\
\hline RA3 & $\left(\mathrm{ft}^{3} / \mathrm{s}\right) / \mathrm{d}$ & -21.9 & -57.0 & -7.1 & 160.3 & -- \\
\hline
\end{tabular}


minimum of 30-day moving-average flow (DL4), flow constancy (TA1), and the Julian date of the annual maximum (TH1) for the OB record fell outside the established 25thto-75th-percentile range. In contrast, the same indices for the SB record fell outside the 25th-to-75th-percentile range, but the percent deviations differed. Additionally, four other hydrologic variables fell outside the established percentile range for the SB record (table 7). Most notable was the difference in percentage deviation for DL4, which was an order of magnitude greater for the $\mathrm{OB}$ than for the SB record (57.3 and 4.1 percent, respectively). This difference is likely explained by the implementation of the minimum passing flows established at this site after reservoir operations began in the early 1960s. Most New Jersey reservoirs release water to meet minimum passing-flow criteria that are typically designed to support human water use farther downstream. Such releases, however, are not intended to mimic the natural variability of the stream and invariably result in sustained periods of higher flow throughout the low-flow period, as was identified in the OB record comparisons for RarMan (table 7, app. 2). Because streamflow simulations done by using the SWRM do not include a routine for reservoir operations, values of hydrologic indices such as DL4 would be expected to be lower for the SB than for the OB record, as it is simulating prereservoir conditions. Values of hydrologic variables like mean maximum flow for May (MH5) and the annual maximum of 3-day moving average of flow (DH2) that did not fall outside the 25th-to-75th-percentile range for the $\mathrm{OB}$ record, but did fall outside the range for the SB record (by 71.0 and 264.0 percent, respectively), also exemplify differences between the simulated prereservoir and post-reservoir baseline records. Reservoirs tend to dampen the effects of periodic high-flow events because they are designed to capture and retain water; therefore, variability in the magnitude and duration of high flows will ultimately be reduced for streams with an OB record established after passing-flow criteria were implemented.

The South Branch Raritan River at Stanton, NJ (SBRarSt), is another site where, on the basis of the OB record, three hydrologic indices (DL4, TA1, and the Julian date of the annual minimum (TL1)) fell outside the established 25th-to-75th-percentile range (table 8). Three additional indices for the SB record also fell outside the 25th-to-75thpercentile range, including mean monthly flow for June (MA18), MH5, and DH2. Like RarMan, SBRarSt is downstream from the Spruce Run Reservoir (constructed in 1963) and is therefore subject to a similar type of flow augmentation. For example, the percent deviation for DL4, the annual minimum of 30-day moving-average flow, is greater for the

Table 8. Deviations of flow-management targets for the observed and simulated baseline records for the Raritan River at Stanton, NJ, study site that fall outside the established 25th-to-75th-percentile range.

[ $\mathrm{ft}^{3} / \mathrm{s}$, cubic feet per second; D, dimensionless; JD, Julian day; --, no deviations above the 75 th or below the 25 th percentile; hydrologic indices are defined in appendix 1; values less than 1 were rounded to the thousandths place to show precision]

\begin{tabular}{|c|c|c|c|c|c|c|}
\hline \multicolumn{7}{|c|}{ U.S. Geological Survey station number 01397000 South Branch Raritan River at Stanton, NJ } \\
\hline $\begin{array}{l}\text { Hydrologic } \\
\text { index }\end{array}$ & Units & 25th percentile & $\begin{array}{c}\text { Observed } \\
\text { NJHAT value }\end{array}$ & 75th percentile & $\begin{array}{c}\text { Percent } \\
\text { deviation } \\
\text { below the 25th } \\
\text { percentile }\end{array}$ & $\begin{array}{c}\text { Percent } \\
\text { deviation } \\
\text { above the 75th } \\
\text { percentile }\end{array}$ \\
\hline \multicolumn{7}{|c|}{ Stream class A, observed baseline dataset } \\
\hline MA18 & $\mathrm{ft}^{3} / \mathrm{s}$ & 73.8 & 179.9 & 211.1 & -- & -- \\
\hline MH5 & $\mathrm{ft}^{3} / \mathrm{s}$ & 400.0 & 785.0 & 940.0 & -- & -- \\
\hline DL4 & $\mathrm{ft}^{3} / \mathrm{s}$ & 45.5 & 107.6 & 71.8 & -- & 49.8 \\
\hline $\mathrm{DH} 2$ & $\mathrm{ft}^{3} / \mathrm{s}$ & 1,149 & 1,703 & 1,992 & -- & -- \\
\hline TA1 & $\mathrm{D}$ & 0.432 & 0.634 & 0.553 & -- & 14.6 \\
\hline TL1 & JD & 246.8 & 273.5 & 262.5 & -- & 4.2 \\
\hline \multicolumn{7}{|c|}{ Stream class $A$, simulated baseline dataset } \\
\hline MA18 & $\mathrm{ft}^{3} / \mathrm{s}$ & 88.4 & 179.9 & 176.6 & -- & 1.9 \\
\hline MH5 & $\mathrm{ft}^{3} / \mathrm{s}$ & 223.3 & 785.0 & 379.3 & -- & 107.0 \\
\hline DL4 & $\mathrm{ft}^{3} / \mathrm{s}$ & 51.9 & 107.6 & 96.1 & -- & 11.9 \\
\hline $\mathrm{DH} 2$ & $\mathrm{ft}^{3} / \mathrm{s}$ & 300 & 1,703 & 450 & -- & 278.5 \\
\hline TA1 & $\mathrm{D}$ & 0.432 & 0.634 & 0.553 & -- & 14.6 \\
\hline TL1 & JD & 246.8 & 273.5 & 262.5 & -- & 4.2 \\
\hline
\end{tabular}


OB (49.8 percent) record than for the SB (11.9 percent) record (table 8). Releases from the Spruce Run Reservoir are highly regulated and, therefore, DL4 will tend to be higher for an OB than an SB record because flows during low-flow periods are artificially maintained above those that would be expected naturally during low-flow periods. Values of MH5 and DH2 fell outside the 25th-to-75th-percentile range for the SB record by 107.0 and 278.5 percent, respectively. These deviations are comparable to those for these two hydrologic variables at RarMan and similarly illustrate the differences between a prereservoir SB record and a post-reservoir OB record. MA18 for the SB record also deviated from the established 25thto-75th-percentile range (table 8), but by only 1.9 percent, a value well within the expected range of annual variability for this hydrologic variable.

Two hydrologic variables, constancy (TA1) and the Julian date of the annual minimum flow (TL1), deviated from the established 25th-to-75th-percentile range for the $\mathrm{OB}$ record at NeshRea (table 9). Unlike the two previous examples, values of DL4 did not fall outside the 25th-to-75th-percentile range for the OB record because the reservoir influence is absent (that is, there are no established minimum passing-flow criteria) immediately upstream from the NeshRea gage. NeshRea, however, is likely affected by water abstraction resulting from water withdrawals from numerous domestic and publicsupply wells located in the basin upstream from the site. These withdrawals could potentially explain the identified deviation of low-flow timing (table 9) because, whether the withdrawals are made for agricultural or human water use, their timing would not necessarily be synchronized with natural seasonal flow patterns, especially if the wells are unregulated. Additionally, agricultural water use typically spikes at times of the year (generally, spring) when irrigation demands are highest and when the need for streamflow to support the life history (migration and reproduction) of many endemic fauna is greatest.

The values of four additional hydrologic variables were found to fall outside the established 25th-to-75th-percentile range for the $\mathrm{SB}$ record but not for the $\mathrm{OB}$ record. These variables include MH5, high flow pulse count (FH4), DL4, and DH2 (table 9). As previously stated, the upper and lower percentage boundaries for the SB record typically represent more conservative endpoints than those for the OB record because the SWRM uses an ISC of 0 percent, which greatly reduces or eliminates the effects of impervious surface runoff. For example, the mean May maximum flows (MH5) for the SB record exceeded the 75th-percentile value by nearly 30 percent (table 9). On the basis of the observed NJHAT value for MH5 (129.5 $\mathrm{ft}^{3} / \mathrm{s}$ ), it is clear that the 75 th-percentile value for the SB record $\left(99.7 \mathrm{ft}^{3} / \mathrm{s}\right)$ represents a more conservative endpoint than the 75th-percentile value for the OB record $\left(233 \mathrm{ft}^{3} / \mathrm{s}\right)$. Therefore, it is not unexpected that higher percent deviations from the

Table 9. Deviations of flow-management targets for the observed and simulated baseline record for the Neshanic River at Reaville, NJ, study site that fall outside the established 25th-to-75th-percentile range.

$\left[\mathrm{ft}^{3} / \mathrm{s}\right.$, cubic feet per second; $\mathrm{d} / \mathrm{yr}$, days per year; D, dimensionless; JD, Julian day; --, no deviations above the 75 th or below the 25 th percentile; hydrologic indices are defined in appendix 1; values less than 1 were rounded to the thousandths place to show precision]

\begin{tabular}{|c|c|c|c|c|c|c|}
\hline \multicolumn{7}{|c|}{ U.S. Geological Survey station number 01398000 Neshanic River at Reaville, NJ } \\
\hline $\begin{array}{l}\text { Hydrologic } \\
\text { index }\end{array}$ & Units & 25th percentile & $\begin{array}{c}\text { Observed } \\
\text { NJHAT value }\end{array}$ & 75th percentile & $\begin{array}{c}\text { Percent } \\
\text { deviation } \\
\text { below the } \\
\text { 25th percentile }\end{array}$ & $\begin{array}{c}\text { Percent } \\
\text { deviation } \\
\text { above the } \\
\text { 75th percentile }\end{array}$ \\
\hline \multicolumn{7}{|c|}{ Stream class A, observed baseline dataset } \\
\hline MH5 & $\mathrm{ft}^{3} / \mathrm{s}$ & 37.3 & 129.5 & 233.0 & -- & -- \\
\hline FH4 & $\mathrm{d} / \mathrm{yr}$ & 26.8 & 27.5 & 45.0 & -- & -- \\
\hline DL4 & $\mathrm{ft}^{3} / \mathrm{s}$ & 1.1 & 1.9 & 2.2 & -- & -- \\
\hline DH2 & $\mathrm{ft}^{3} / \mathrm{s}$ & 332.2 & 563.0 & 648.9 & -- & -- \\
\hline TA1 & $\mathrm{D}$ & 0.432 & 0.197 & 0.553 & 54.4 & -- \\
\hline TL1 & JD & 246.8 & 241.1 & 262.5 & 2.3 & -- \\
\hline \multicolumn{7}{|c|}{ Stream class $A$, simulated baseline dataset } \\
\hline MH5 & $\mathrm{ft}^{3} / \mathrm{s}$ & 29.9 & 129.5 & 99.7 & -- & 29.9 \\
\hline FH4 & $\mathrm{d} / \mathrm{yr}$ & 4.8 & 27.5 & 15.8 & -- & 74.1 \\
\hline DL4 & $\mathrm{ft}^{3} / \mathrm{s}$ & 2.0 & 1.9 & 3.7 & 6.1 & -- \\
\hline DH2 & $\mathrm{ft}^{3} / \mathrm{s}$ & 202.0 & 563.0 & 359.5 & -- & 56.6 \\
\hline TA1 & $\mathrm{D}$ & 0.432 & 0.197 & 0.553 & 54.4 & -- \\
\hline TL1 & JD & 246.8 & 241.1 & 262.5 & 2.3 & -- \\
\hline
\end{tabular}


flow-management target range in high-flow magnitudes, frequencies, and duration would be found for the SB record than for the OB record (table 9), because the OB record represents a baseline for a known time period where some amount of anthropogenic alteration (for example, ISC) already exists. Even minor changes (in some cases less than 5 percent) in the amount of ISC in a basin can result in significant increases in runoff (Schueler, 1994; Cuffney and others, 2010).

The duration and frequency of high flows for the SB record exceeded the 75th-percentile value by 74.1 and 56.6 percent, respectively. These differences are also likely attributable to the lack of impervious surface runoff associated with the more conservative simulated hydrograph. That is, the $\mathrm{SB}$ record tends to be less flashy than the OB record because it does not include an implicit amount of ISC. The annual minimum of 30-day moving-average flow (DL4) for the SB record fell below the 25 th-percentile value by 6.1 percent. Given the absence of ISC in the SB record, more groundwater infiltration would be expected in the SB than in the OB, therefore the SB 25th-percentile value (2.0) would be higher than the OB 25th-percentile value (1.1), because the OB record is a response to less infiltration and greater runoff, and the actual value would then fall below the simulated limits. Additionally, the SWRM did not use actual daily values for permitted withdrawals and discharges; rather, withdrawals and discharges (unpublished data on file at the U.S. Geological Survey office, West Trenton, New Jersey) were quantified by distributing the annual average values evenly throughout the year (Kennen and others, 2008). Therefore, for certain times of the year, the OB record may actually reflect a narrower range and shorter duration of low flows as a result of regulated and unregulated daily withdrawals on pumping. The SB record, therefore, would be less likely than the $\mathrm{OB}$ record to accurately account for this variation in seasonal water use.

The data in tables 7, 8, and 9 appear to validate the hypothesis that values of hydrologic indices more frequently deviate from the 25th-to-75th-percentile range and often by a higher percentage for sites with an SB record than for sites with an $\mathrm{OB}$ record. These comparisons indicate that $\mathrm{OB}$ records may be the most realistic from a management perspective because they represent an established baseline POR that was not derived from simulated data. However, both types of record are useful and can be important depending on specific management intentions. OB records for minimally to moderately altered New Jersey streams like those discussed above include an implicit amount of anthropogenically driven watershed disturbance (for example, urban land use, ISC, water abstraction, reservoirs, etc.) that has, to some degree, altered the existing hydrograph. In some cases, however, the more conservative SB record may better represent the management target for high-quality reference streams or for special protection waters that are highly valued for water-supply purposes and therefore require a higher level of protection or restoration. The SB record could also be useful in helping to identify streams that currently are not of concern hydrologically, but that could be in the near future if steps are not taken to protect the stream corridor from changes associated with urban development and other anthropogenic processes. In other words, the SB record can be used to help identify those class A or C streams with hydrologic index values that fall just within the established 25th-to-75th-percentile range so that appropriate management measures can be implemented to prevent further degradation.

Understanding the limitations associated with using an SB hydrograph as a basis for streamflow comparison is an important consideration for managers and stakeholders interested in streamflow protection and (or) remediation. Additionally, knowing how these records are affected by anthropogenic influences (that is, dams, wells, ISC) can help explain discrepancies that can be seen only if simulated data are available. Although an OB record appears to be preferable for comparing current with baseline conditions, long-term streamflow information is not available for every stream segment in New Jersey. When the SB record is the only hydrologic basis of comparison available, it should be applied with an awareness of its limitations as an accurate representation of the baseline period of record.

The approach used to simulate baseline streamflow (that is, to derive an SB record) with the SWRM model was consistent for all the sites. Although a closer calibration might have been achieved for some streams by adjusting the percentage of ISC used in the model to simulate a moderate level of anthropogenic disturbance, this additional complexity was considered to be outside the scope of the study. The HIP methodology developed cooperatively with the N.J. Department of Environmental Protection (NJDEP) to divide the State into distinct hydrologic regions (Kennen and others, 2007), however, greatly enhanced our ability to derive useful baseline hydrographs for specific stream types that represent the basis of hydroecological comparison for the hydro-TMDL methodology. The simulated baseline results also are limited, to some degree, in that the discharges and withdrawals used as input to the model are based on average annual values. Had the actual daily values for permitted withdrawals and discharges been available, the saturation deficit could have been determined more accurately, ultimately improving the accuracy of the simulated hydrographs.

\section{Flow-Ecology Response Models}

Generally, most bivariate and multivariate ecological response models developed during this study represented a strong response to changes in hydrologic processes (tables 4 and 5, respectively). The large implicit variability of hydrologic and ecological data, however, may have hampered our ability to develop even stronger response relations. For example, ecological data are inherently variable and differences in substrate complexity among streams, year-to-year changes in sampling crews, or differences in stream size could increase variability and affect response models. Aquatic-invertebrate data for this study, however, were considered to be comparable 
in terms of sampling protocols (sampled habitat, number of composite samples, and total sampled area) and laboratory procedures, including sorting, subsample count level, and taxonomic resolution, because, for the most part, aquaticinvertebrate samples were collected in similar habitats by using comparable sampling techniques. Additionally, the data were reviewed extensively to ensure that all data aggregated from separate sources (that is, NJDEP and the National Water Quality Assessment Program (NAWQA)) included the same taxonomic groups and had appropriate taxonomic resolution before data analysis was attempted. This task was accomplished by using the Invertebrate Data Analysis System (IDAS) software (Cuffney and Brightbill, 2011), which is designed to resolve all taxonomic issues (taxonomic identification level and nomenclature), to remove ambiguous taxa (Cuffney and others, 2007), and to randomly subsample raw counts to an equal 100-specimen count (the highest possible count based on the NJDEP monitoring program protocols for New Jersey). To address any innate variability related to basin size, all hydrologic variables correlated with basin size were standardized by basin area.

Improvement in the overall fit between flow variables and assemblage metrics would likely require a larger number of sites having both aquatic-invertebrate and long-term hydrologic data (see Poff and others, 2010). The ability to develop flow-altered hydrographs for any NJDEP ecological monitoring site would greatly increase the "N" for developing such relations. The level of effort required for this type of modeling is beyond the scope of the current investigation, but certainly is a process that would provide the needed information if pursued in the future for New Jersey. Such efforts are already underway in the Apalachicola-ChattahoocheeFlint River Basin (Georgia), where relations between simulated daily water withdrawals and the predicted change in the richness of fish species are being developed to provide quantitative river management alternatives (Freeman and others, 2012). Incorporating multiple aquatic assemblages, particularly fish assemblages, may also be useful as a result of their longer life span and sensitivity to physical disturbances and habitat change (for example, Kennen and others, 2012). Other limitations may include our inability to specifically account for the effects of ongoing human-induced impacts on water availability (for example, surface- and groundwater abstraction) in the SWRM that likely reduced our ability to fully account for the amount of water in the streams and may, in some cases, accentuate the high and low flows for streams at specific times of the year. These types of hydrologic alterations no doubt have a cumulative effect on the aquatic assemblage; however, their effect is extremely difficult to separate from variability in yearly precipitation and concomitant anthropogenic effects because the records for such data are typically scarce, lacking, or unregulated for movement of water or direct withdrawals less than a specific amount, especially in some transitional agricultural areas in New Jersey where withdrawals that do not exceed a preset rate are not regulated.

\section{Summary and Conclusions}

As a result of the large number of stream sites in New Jersey with aquatic-life impairment and no specific chemical or physical stressor identified, as well as the understanding that applying a standard, pollutant-based Total Maximum Daily Load (TMDL) to more than 300 such sites is fiscally challenging, the U.S. Geological Survey, in cooperation with the N.J. Department of Environmental Protection, developed a hydrologically based TMDL (hydro-TMDL) methodology that accounts for a broad suite of streamflow alterations in order to address aquatic-life impairments in New Jersey streams. Additionally, flow-ecology response models based on stream class were produced to complement the hydro-TMDL approach and provide managers with a set of response relations that identifies important individual or multiple hydrologic attributes that can be used to support broader regional flow targets for other class A and C New Jersey streams that were not part of this study.

Unaltered ("minimally impaired") hydrographs represented the regulatory endpoint of the hydro-TMDL approach used in this study. In some cases, an observed baseline hydrograph was differentiated from the existing period of record (POR) by using quantile regression $(\mathrm{QR})$ procedures. In this approach, flow quantiles and precipitation quantiles were directly compared across the POR; this is an objective and statistically robust procedure for identifying anomalous periods in the record during which changes in flow occurred that were not directly driven by variability in annual precipitation. When either the length of the existing POR was insufficient to identify a baseline POR or the baseline hydrograph could not be statistically differentiated from the existing hydrograph using $\mathrm{QR}$, a simulated baseline hydrograph was developed. The simulated baseline was produced by using the Statewide Watershed Runoff Model (SWRM) and represents an essential step in the Ecological Limits of Hydrologic Alteration (ELOHA) approach. Two ranges encapsulating the 25th-to-75th (less conservative) and the 40th-to-60th (more conservative) percentiles of flow were the TMDL boundaries established for the hydro-TMDL comparisons presented. The 25th-to-75th-percentile range has been broadly accepted as the established flow range needed to support healthy aquatic assemblages, and as an extension, aquatic-life uses. Recent work by Richter and others (2011) has expanded upon this concept with a "presumptive standard" that provides ecological flow practitioners with a sustainability boundary that restricts hydrologic alteration to within some percentage range and is presented as a "stopgap" measure for use in streamflow management where no other flow-protection strategy currently exists. Results of the hydro-TMDL approach applied in this study are highly complementary to that presented by Richter and others (2011), but more directly identify proportional differences between baseline hydrographs and observed hydrographs for a subset of non- to moderately impaired streams within the Raritan River Basin, New Jersey, as a basis for streamflow management and meeting Clean Water Act goals. 
Because the physical and chemical properties of many of the Raritan River Basin streams assessed were altered prior to the current study, many of the biological assemblages have shifted from native populations to populations that are more tolerant of the existing conditions associated with extant landscape modification. That is, the biological assemblages found in natural systems are often, but not always, more complex (for example, higher diversity, richness, and abundance) than those found in disturbed ecosystems. As ecosystems are hydrologically altered and habitat, substrate conditions, and water quality are degraded, more tolerant species are able to survive while sensitive species typically decline. As additional changes in the landscape occur, however, even the more resilient species are displaced as conditions degrade to a point where few species can survive. This study, however, targeted only those sites in the Raritan River Basin that represented minimal to moderate aquatic-invertebrate impairment. If hydrologic alteration was identified on the basis of the hydro-TMDL assessment, management techniques (for example, streamflow best management practices (BMPs) such as stormwater retrofits, pervious pavement, variable reservoir release rates, etc.) could still be implemented in an attempt to offset those deviations that fall outside the established range of flows identified during comparative evaluations.

Many flow values that fall outside the 25th-to-75th and 40th-to-60th percentiles were identified as part of this study for many non-impaired as well as moderately impaired streams. In general, more deviations in flow indices were seen in streams identified as moderately impaired than in those identified as non-impaired. Additionally, percent deviations outside the established boundaries tended to be greater and more numerous at streams where comparisons were based on simulated baseline (SB) hydrographs than where comparisons were based on observed baseline (OB) hydrographs derived from an existing long-term POR by using $Q R$. The occurrence of such large percentage deviations is not unexpected as the simulated baseline represents a hydrograph derived with the assumption of little or no historic anthropogenic alteration of the drainage basin. From a regulatory perspective, this may ultimately represent an unattainable endpoint from which to implement a hydro-TMDL for surface-water management. That is, if a given flow deviation value for a subset of critical flow indices is so far outside a manageable percentage that no amount of mitigation can return the stream to compliance from a hydro-TMDL perspective, then it may be more appropriate to use modeled baseline hydrographs with a small amount of anthropogenic alteration added (for example, 2 to 5 percent impervious surface cover (ISC) or 5 to 10 percent urban land use) for comparison, such that the simulated endpoints are more comparable to observed baselines derived from an existing streamflow POR. A small amount of anthropogenic influence is implicit within the observed baseline even for non-impaired basins; therefore, in retrospect, it might have been appropriate to supplement the simulated baseline hydrographs by incorporating a minimal amount of anthropogenic alteration into the flow-modeling process. Even though it was possible to identify periods of significant changes in flow at sites with observed baselines by using the QR approach, these changes were occurring in addition to an existing background level of anthropogenic activity associated with processes that likely occurred many times over the prior century. It is unlikely that the basin of any given river or stream in New Jersey has not undergone, at some point in its history, at least some amount of anthropogenic alteration of the landscape (for example, changes driven by legacy fire, damming/milling, logging, or agricultural activities).

The major challenge facing water managers who may wish to maintain environmental flows is the complexity associated with determining how much alteration of natural flows can be tolerated without compromising the ecological health of a stream. In this study, annual flow variability, specifically the variability across minimum and maximum streamflow, was shown to be particularly important for the health of the aquatic-invertebrate assemblage. Loss of permeable surfaces in the basin can decrease infiltration rates and reduce recharge to shallow groundwater, resulting in reduced base-flow inputs to streams. Such changes can exacerbate low-flow conditions and affect aquatic-assemblage integrity. For example, stream sites in the Raritan River Basin study area that show increased variability in the magnitude and timing of low flows (low flow index), variability in base flow index, variability across annual minimum flows, and the Julian date of annual minimum flows, respectively) and in the magnitude of historically higher flows (variability of monthly February and April flows) exhibit hydrologic conditions that differ greatly from the natural flow regime and tend to be populated with taxa that are known to be resilient and tolerant of environmental stressors. These results indicate that as the magnitude of high and low flows is altered, some species with life-history and behavioral constraints that rely on annual flow patterns or fluctuations in flow for reproduction may become less abundant and species with greater resilience to changes in natural streamflow variability may become more abundant.

All of the sites evaluated in this study are located in drainage basins that have undergone some degree of urbanization or anthropogenic influence leading to varying levels of hydrologic stress. The source of the modifications is more readily identifiable for some of the sites than for others, but all are affected, to some degree, by changes in hydrology. Sites near dams or reservoirs or sites in basins that have a large amount of ISC or multiple pumped wells may, in some cases, be more easily managed because the source(s) of hydrologic stress can be identified.

There are many examples of sites in this study where the hydrology may have been altered by reservoir and (or) dam operations. Water-supply reservoirs are typically operated to store water captured during higher flow periods for off-stream use during low-flow periods, with the effect of dampening moderate to high flows and, in some cases, increasing low flows. Changes in the timing of spring high flows and summer low flows appear to be a common thread among streams whose annual flow variability has been modified by the 
construction of dams. The releases of water from reservoirs and (or) dams are typically based on minimum-passingflow requirements designed to maintain a regulated amount of water in streams downstream from a reservoir with little regard to the seasonality or timing of flows. It has been suggested that the primary challenge in setting flow-protection standards is to employ a practical method that limits water withdrawals and dam operations in such a way as to protect essential flow variability. Therefore, management strategies that most closely mimic natural flows, developed in collaboration with reservoir authorities (for example, the New Jersey Water Supply Authority), could potentially enhance or restore ecological integrity. For example, the timing and magnitudes of flow releases could be implemented in a way that supports "ecologically sustainable passing flows," which would aim to restore a more variable system that supports the long-term survival and life history of aquatic organisms rather than to maintain a "passing-flow" standard that was established, in part, to maintain streamflow to meet downstream human uses. A protection-based hydro-TMDL for flow-regulated sites might consist of a framework that incorporates a holistic hydroecological management plan that seeks to maintain current streamflow levels to maximize human water use, but also modifies reservoir or dam releases such that they are more closely synchronized with natural fluctuations in annual streamflow variability. For example, flow BMPs could not only maintain the quantity of flow but also augment the timing of reservoir releases to coincide with fish spawning cycles and migration periods, to coincide with aquatic-invertebrate emergence and reproduction, or to increase stream variability and reduce the frequency of long-duration low-flow events.

The drainage basins of some of the Raritan River Basin sites evaluated in this study have relatively high ISC percentages ( $>10$ percent) that appear to be directly linked to hydrologic alteration at these sites. Over the past several decades, growth has expanded beyond cities and older suburbs into many areas that were once rural. Lowland urban development typically leads to increased ISC, losses of riparian vegetation, and subsequent increases in sediment inputs to streams as a result of erosion. Increased ISC promotes increased surface runoff which can, in turn, result in reduced groundwater recharge, flashier hydrology, habitat degradation, riparian-corridor encroachment, channel modifications, and an increase in runoff of associated contaminants from impervious surfaces. The frequency of moderate flooding can increase substantially after land use in a basin shifts from forested to increasingly urban. Flashy streamflows are typically associated with urban runoff and create a system in which stormflow frequency and intensity increase and base flows decrease. Within the Raritan River Basin study area, more frequent higher magnitude flows (high flood pulse counts and the high-flow discharge index), or increased flashiness, increase the proportion of tolerant organisms and reduce the abundance of sensitive species. These types of responses have been seen in numerous studies relating urbanization and increases in ISC to aquatic-assemblage impairment. These more frequent, higher magnitude flows are not limited to large storm events but can also occur after small to moderate storm events as a result of increased inputs of stormwater from overland flow by conventional drainage directly to streams. During these smaller storm events, streamflow can reach bankfull width and erode banks, increase sedimentation, and create a general loss of habitat for sensitive species. Controlling overland runoff (in the basin) by utilizing flow-alteration strategies may help to reduce the effects of these smaller flow events.

Flow-alteration strategies that could be implemented to restore watershed hydrology to more closely resemble natural streamflow at sites in urbanizing basins could include both structural and nonstructural methods. Nonstructural methods aim for a general reduction in the volume of runoff from developments and include disconnection of downspouts from hard surfaces, conservation of natural areas, and watershed planning. Structural methods target runoff-volume reduction by capturing and reusing stormwater through infiltration into porous pavement or retention ponds, infiltration trenches, rain gardens, and swales, and rainwater harvesting by means of rain barrels, tanks, and cisterns. Such measures promote increased base flow and reduce rapid stormwater runoff and the magnitude of high-flow events. Planting trees in riparian zones to attenuate stormwater flow through flood plains is another viable option to decrease rapid runoff and reduce the flashiness of such systems, as long as riparian zones are not directly bypassed by stormwater pipes and conveyances.

Increasing the amount of green infrastructure in urban environments has been presented as means to offset increased stormwater runoff from impervious surfaces. Green infrastructure refers to a network of open green space that conserves the infiltration capacity of natural ecosystems in addition to providing benefits to human populations by bringing natural aspects of the environment to inhabited space. Examples of green infrastructure include the planting of trees or other types of vegetation in and around roads, pavements, or buildings, or even the creation of green roofs on homes or businesses. Use of green infrastructure for urban stormwater retrofits can reduce stormwater contamination by reducing the conversion of rainfall to runoff by capturing rainwater where it falls in an effort to reduce stormwater volumes, peak-flow rates, and contaminant loads (water quality). In catchments where these methods are utilized, a large percentage of runoff from small to moderate storms may be diverted from overland flow to groundwater recharge, thereby reducing the effect of more frequent high flows on sensitive taxa in streams in an effort to return the streams to a more natural flow regime.

Some streams in the Raritan River Basin may have been affected by water abstraction (that is, groundwater or surfacewater withdrawals used for agricultural and human supply). In New Jersey, agricultural water-use registration must be obtained if a landowner has the capability to withdraw ground and (or) surface water in excess of 100,000 gallons per day (gal/d) for agricultural, aquacultural, or horticultural purposes. 
Unregulated water withdrawals or the extraction of large volumes of water slightly less than the 100,000-gal/d limit could affect flow at some of these study sites. Focusing management efforts on (1) developing stricter regulatory guidelines about the quantity of water being removed at locations at or near the affected streams (that is, either lower the minimum gallon-per-day limit or require registration for all water withdrawals, regardless of size), and (2) implementing guidelines that restrict withdrawals to periods of relatively high flow or to times that do not coincide with critical life-cycle periods, would provide better water accounting and give managers greater flexibility in the development and implementation of flow-based BMPs.

Continued and persistent stressors (for example, unmitigated runoff, increases in impervious surfaces, increases in stormwater runoff, etc.) on stream hydrology can negatively affect biological integrity and, if the system is pushed to a point beyond its capacity to withstand flow stress, implementing management measures that protect native and endemic stream assemblages, even in the non- to moderately impaired Raritan River Basin streams assessed in this study, may become difficult. Depending on the resistance and resilience of stream assemblages, frequent high-energy flow events coupled with prolonged periods of low or no flow can dramatically affect lotic ecosystem structure and function, often resulting in a highly simplified trophic structure with low taxonomic diversity and a dominance of relatively few tolerant taxa. In contrast, moderate- to low-magnitude flow events (natural flow patterns) appear to strongly influence processes that act at the population level of ecosystem organization, and may ultimately be responsible for maintaining healthy and diverse lotic ecosystems. Even though recent studies have indicated that aquatic invertebrates appear to be resilient to stress associated with short-term reductions in streamflow, results of this study may indicate that changes in streamflow indices, especially those that fall outside the more conservative 40th-to-60thpercentile range, may result in greatly altered streamflows that modify natural-assemblage complexity and push the aquatic assemblages beyond their capacity for resistance or resilience. Consequently, sensitive aquatic organisms may become less abundant, whereas species with greater resilience to temporal changes in stream variability (tolerant organisms) may become more abundant.

Scientific evidence strongly indicates that hydrology accounts for a significant portion of the variability in the composition, structure, and function of aquatic systems. Management practices that promote natural hydrologic patterns and processes are likely to reduce the effects of hydrologic alteration on stream biota. The stream-type-based hydrologic deviations and flow-ecology response relations presented in this report can be used by managers and policy makers to establish a hydro-TMDL that can be used to address designated aquaticlife uses in the Raritan River Basin with potential application to other parts of New Jersey and elsewhere. In many streams across the United States where no unambiguous stressors are identified, State monitoring agencies could implement surrogate measures (for example, flow-based TMDL approaches) that support designated uses, meet the regulatory requirements under the Clean Water Act, and support a balance between water supply intended to meet human needs and the conservation of biological integrity.

\section{References Cited}

Alley, W.M., Evenson, E.J., Barber, N.L., Bruce, B.W., Dennehy, K.F., Freeman, M.C., Freeman, W.O., Fischer, J.M., Hughes, W.B., Kennen, J.G., Kiang, J.E., Maloney, K.O., Musgrove, MaryLynn, Ralston, Barbara, Tessler, Steven, and Verdin, J.P., 2013, Progress toward establishing a national assessment of water availability and use: U.S. Geological Survey Circular 1384, 34 p. (Also available at http:// pubs.usgs.gov/circ/1384).

Arnold, C.L., and Gibbons, C.J., 1996, Impervious surface coverage - The emergence of a key environmental indicator: American Planners Association Journal, v. 62, p. 243-258 (Also available at http://dx.doi. org/10.1080/01944369608975688).

Arthington, A.H., Bunn, S.E., Poff, N.L., and Naiman, R.J., 2006, The challenge of providing environmental flow rules to sustain river ecosystems: Ecological Applications, v. 16, p. 1,311-1,318 (Also available at http://dx.doi. org/10.1890/1051-0761(2006)016[1311:TCOPEF]2.0 . $\mathrm{CO} ; 2)$.

Arthington, A.H., King, J.M., O’Keefe, J.H., Bunn, S.E., Day, J.A., Pusey, B.J., Bluhdorn, D.R., and Thame, R., 1992, Development of an holistic approach for assessing environmental flow requirements of riverine ecosystems, in Pigram, J.J., and Hooper, B.A., eds., Water allocation for the environment-Proceedings of an international seminar and workshop: Armidale, Australia, University of New England, The Centre for Water Policy Research, p. 69-76.

Barbour, M.T., Gerritsen, J., Snyder, B.D., and Stribling, J.B., 1999, Rapid bioassessment protocols for use in streams and wadeable rivers - Periphyton, benthic macroinvertebrates, and fish (2d ed.): U.S. Environmental Protection Agency Report, EPA 841-B-99-002, 226 p. (Also available at http://water.epa.gov/scitech/monitoring/rsl/bioassessment/ download.cfm).

Beaujouan, V., Durand, P., and Ruiz, L., 2001, Modelling the effect of the spatial distribution of agricultural practices on nitrogen fluxes in rural catchments: Ecological Modelling, v. 137, no. 1, p. 93-105 (Also available at http://dx.doi. org/10.1016/S0304-3800(00)00435-X). 
Benedict, M., and McMahon, E., 2001, Green infrastructureSmart conservation for the 21 st century: Washington, D.C., Sprawl Watch Clearinghouse Monograph Series, 32 p.

Beven, K.J., 2001, Rainfall-runoff modelling-The primer: Chichester, New York, John Wiley, 372 p.

Beven, K.J., and Kirkby, M.J., 1979, A physically based variable contributing area model of basin hydrology: Hydrologic Science Bulletin, v. 24, no. 1, p. 43-69 (Also available at http://dx.doi.org/10.1080/02626667909491834).

Bicknell, B.R., Imhoff, J.C., Kittle, J.L., Jr., Donigian, A.S., Jr., and Johanson, R.C., 1997, Hydrological simulation program, Fortran-User's manual for version 11: U.S. Environmental Protection Agency, Athens, Georgia, National Exposure Research Laboratory Report EPA/600/R-97/080, $755 \mathrm{p}$.

Biggs, B.J.F., Nikora, V.I., and Snelder, T.H., 2005, Linking scales of flow variability to lotic ecosystem structure and function: River Research and Applications, v. 21, p. 283-298 (Also available at http://dx.doi.org/10.1002/ rra.847).

Bitting, J., and Kloss, C., 2008, Managing wet weather with green infrastructure-Municipal handbook: U.S. Environmental Protection Agency, Low Impact Development Center, Olympia, Wash., EPA/833/F-08/008, 23 p.

Bobba, A.G., Singh, V.P., and Bengtsson, L., 2000, Application of environmental models to different hydrological systems: Ecological Modelling, v. 125, p. 15-49 (Also available at http://dx.doi.org/10.1016/S0304-3800(99)00175-1).

Boulton, A.J., 2003, Parallels and contrasts in the effects of drought on stream macroinvertebrate assemblages: Freshwater Biology, v. 48, p. 1,173-1,185 (Also available at http://dx.doi.org/10.1046/j.1365-2427.2003.01084.x).

Boyer, E.W., Hornberger, G.M., Bencala, K.E., and McKnight, D., 1996, Overview of a simple model describing variation of dissolved organic carbon in an upland catchment: Ecological Modelling, v. 86, p. 183-188 (Also available at http://dx.doi.org/10.1016/0304-3800(95)00049-6).

Brown, L.R., Cuffney, T.F., Coles, J.F., Fitzpatrick, F.A., McMahon, G., Steuer, J.J., Bell, A.H., and May, J.T., 2009a, Urban streams across the USA - Lessons learned from studies in 9 metropolitan areas: Journal of the North American Benthological Society, v. 28, p. 1,051-1,069 (Also available at http://dx.doi.org/10.1899/08-153.1).

Brown, L.R., Gregory, M.B., and May, J.T., 2009b, Relation of urbanization to stream fish assemblages and species traits in nine metropolitan areas of the United States: Urban Ecosystems, v. 12, p. 391-416 (Also available at http://dx.doi. org/10.1007/s11252-009-0082-2).
Bunn, S.E., and Arthington, A.H., 2002, Basic principles and ecological consequences of altered flow regimes for aquatic biodiversity: Environmental Management, v. 30, no. 4, p. 492-507 (Also available at http://dx.doi.org/10.1007/ s00267-002-2737-0).

Bushaw-Newton, K.L., Hart, D.D., Pizzuto, J.E., Thomson, J.R., Egan, J., Ashley, J.T., Johnson, T.E., Horwitz, R.J., Keeley, M., Lawrence, J., Charles, D.F., Gatenby, C., Kreeger, D.A., Nightengale, T., Thomas, R.L., and Velinsky, D.J., 2002, An integrative approach towards understanding ecological responses to dam removal - The Manatawny Creek study: Journal of the American Water Resources Association, v. 38, p. 1,581-1,599.

Cade, B.S., and Noon, B.R., 2003, A gentle introduction to quantile regression for ecologists: Frontiers in Ecology and the Environment, v. 1, p. 412-420 (Also available at http:// dx.doi.org/10.1890/1540-9295(2003)001[0412:AGITQR]2. $0 . \mathrm{CO} ; 2)$.

Carlisle, D.M., Wolock, D.M., and Meador, M.R., 2010, Alteration of streamflow magnitudes and potential ecological consequences - A multiregional assessment: Frontiers in Ecology and the Environment, v. 9, p. 264-270 (Also available at http://dx.doi.org/10.1890/100053).

Carter, T., Wenger, S., Seymour, R.M., and Stewart, D., 2009, Etowah Habitat Conservation Plan runoff limits manual, Final draft, September 2007, 146 p., accessed February 6, 2013, at http://www.etowahhcp.org/runoff/runoff_limits_ manual_draft_2009_09_15.pdf.

Castleberry, D.T., Cech, J.J., Jr., Erman, D.C., Hankin, D., Healey, M., Kondolf, G.M., Mangel, M., Mohr, M., Moyle, P.B., Nielsen, J., Speed, T.P., and Williams, J.G., 1996, Uncertainty and instream flow standards: Fisheries, v. 21, p. 20-21.

Catalano, M.J., and Bozek, M.A., 2007, Effects of dam removal on fish assemblage structure and spatial distributions in the Baraboo River, Wisconsin: North American Journal of Fisheries Management, v. 27, p. 519-530 (Also available at http://dx.doi.org/10.1577/M06-001.1).

Chessman, B., Royal, M., and Muschal, M., 2011, The challenge of monitoring impacts of water abstraction on macroinvertebrate assemblages in unregulated streams: River Research and Applications, v. 27, p. 76-86.

Clarke, K.R., and Gorley, R.N., 2006, PRIMER v6-Users Manual/Tutorial PRIMER-E: Plymouth, England, 190 p.

Clausen, B., and Biggs, B.J.F., 1997, Relationships between benthic biota and hydrological indices in New Zealand streams: Freshwater Biology, v. 38, p. 327-342 (Also available at http://dx.doi.org/10.1046/j.13652427.1997.00230.x). 
Coles, J.F., Cuffney, T.F., McMahon, G., and Beaulieu, K., 2004, The effects of urbanization on the biological, physical, and chemical characteristics of coastal New England streams: U.S. Geological Survey Professional Paper 1695, 47 p. (Also available at http://pubs.usgs.gov/pp/pp1695/).

Colwell, R.K., 1974, Predictability, constancy, and contingency of periodic phenomena: Ecology, v. 55, p. $1,148-1,153$.

Cuffney, T.F., and Brightbill, R.A., 2011, User's manual for the National Water-Quality Assessment Program Invertebrate Data Analysis System (IDAS) software, version 5.0: U.S. Geological Survey Techniques and Methods 7-C4, 126 p. (Available only online at http://pubs.usgs.gov/ $\mathrm{tm} / 7 \mathrm{c} 4 /)$.

Cuffney, T.F., Bilger, M.D., and Haigler, A.M., 2007, Ambiguous taxa-Effects on the characterization and interpretation of invertebrate assemblages: Journal of the North American Benthological Society, v. 26, p. 286-307 (Also available at http://dx.doi.org/10.1899/0887-3593(2007)26[286:ATEOT C]2.0.CO;2).

Cuffney, T.F., Brightbill, R.A., May, J.T., and Waite, I.R., 2010, Responses of benthic macroinvertebrates to environmental changes associated with urbanization in nine metropolitan areas: Ecological Applications, v. 20, p. 1,384-1,401 (Also available at $h t t p: / / d x . d o i . o r g / 10.1890 / 08-1311.1$ ).

Cuffney, T.F., Zappia, H., Giddings, E.M.P., and Coles, J.F., 2005, Effects of urbanization on benthic macroinvertebrate assemblages in contrasting environmental settings-Boston, Massachusetts; Birmingham, Alabama; and Salt Lake City, Utah: American Fisheries Society Symposium, v. 47, Bethesda, Maryland, p. 361-407 (Also available at $h t t p: / /$ water.usgs.gov/nawqa/urban/pdf/361-408_Cuffney.pdf).

Dantzig, G.B., 1951, Maximization of linear function of variables subject to linear inequalities, in Koopmans, T.C., ed., Activity analysis of production and allocation: New York, John Wiley and Sons, p. 339-347.

Davis, W.S., and Simon, T.P., 1995, Biological assessment and criteria-Tools for water resource planning and decision making: Boca Raton, Fla., Lewis Publishers, 415 p.

Dewson, Z.S., James, A.B.W., and De'ath, R.G., 2007, Invertebrate responses to short-term water abstraction in small New Zealand streams: Freshwater Biology, v. 52, p. 357-369 (Also available at $h t t p: / / d x$.doi.org/10.1111/ j.1365-2427.2006.01682.x).

Duda, J.J., Warrick, J.A., and Magirl, C.S., 2011, Elwha River dam removal-Rebirth of a river: U.S. Geological Survey Fact Sheet 2011-3097, 4 p.

Dunne, T., and Leopold, L.B., 1978, Water in environmental planning: New York, Freeman Press, 818 p.
Dynesius, M., and Nilsson, C., 1994, Fragmentation and flow regulation of river systems in the northern third of the world: Science, v. 266, p. 753-762 (Also available at http:// dx.doi.org/10.1126/science.266.5186.753).

Engel, V.C., Stieglitz, M., Williams, M., and Griffin, K.L., 2002, Forest canopy hydraulic properties and catchment water balance - Observations and modeling: Ecological Modelling, v. 154, no. 3, p. 263-288 (Also available at http://dx.doi.org/10.1016/S0304-3800(02)00068-6).

Espey, W.H., Jr., Morgan, C.W., and Masch, F.D., 1966, A study of some effects of urbanization on storm runoff from a small watershed: Austin, Texas, Technical Report 44D 07-6501 CRWR-2, Center for Research in Water Resources, University of Texas, Austin, Texas, 110 p. (Also available at http://www.twdb.texas.gov/publications/reports/numbered_ reports/doc/R23/R23.pdf).

Esralew, R.A., and Baker, R.J., 2008, Determination of baseline periods of record for selected streamflow-gaging stations in New Jersey for determining Ecologically Relevant Hydrologic Indices (ERHI): U.S. Geological Survey Scientific Investigations Report 2008-5077, 70 p. (Also available at http://pubs.usgs.gov/sir/2008/5077/pdf/sir2008-5077.pdf).

Fongers, D., and Fulcher, J., 2002, Hydrologic impacts due to development - The need for adequate runoff detention and stream protection: Lansing, Michigan, Michigan Department of Environmental Quality, 23 p. (Also available at http://www.michigan.gov/documents/deq/lwmimpact_202416_7.pdf).

Freeman, M.C., Buell, G.R., Hay, L.E., Hughes, W.B, Jacobson, R.B., Jones, J.W., Jones, S.A., Lafontaine, J.H., Odom, K.R., Peterson, J.T., Riley, J.W., Schindler, J.S., Shea, C., and Weaver, J.D., 2012, Linking river management to species conservation using dynamic landscape-scale models: River research and applications, accessed April 20, 2012 at $h$ ttp://dx.doi.org/10.1002/rra.2575.

Freeman, M.C., and Marcinek, P.A., 2006, Fish assemblage responses to water withdrawals and water supply reservoirs in Piedmont streams: Journal of Environmental Management, v. 38, p. 435-450 (Also available at $h t t p: / / d x . d o i$. org/10.1007/s00267-005-0169-3).

Gibson, C.A., Meyer, J.L., Poff, N.L., Hay, L.E., and Georgakakos, A., 2005, Flow regime alterations under changing climate in two river basins - Implications for freshwater ecosystems: River Research and Applications, v. 21, p. 849-864 (Also available at $h t t p: / / d x . d o i . o r g / 10.1002 /$ rra.855).

Graf, W.L., 1999, Dam nation-A geographic census of American dams and their large-scale hydrologic impacts: Water Resources Research, v. 35, p. 1,305-1,311. 
Graham, D.N., and Butts, M.B., 2005, Flexible, integrated watershed modeling with MIKE SHE, in Singh, V.P., and Frevert, D.K., eds., Watershed models: Boca Raton, Florida, CRC Press, p. 245-272.

Grossman, G.D., 1982, Dynamics and organization of a rocky intertidal fish assemblage-The persistence and resilience of taxocene structure: American Naturalist, v. 119, p. 611-637 (Also available at http://www.jstor.org/ stable/2461182? origin $=J S T O R-p d f)$.

Harding, J.S., Benfield, E.F., Bolstad, P.V., Helfman, G.S., and Jones, E.B.D., III, 1998, Stream biodiversity-The ghost of land use past: Proceedings of the National Academy of Sciences, v. 95, p. 14,843-14,847.

Henriksen, J.A., Heasley, J., Kennen, J.G., and Nieswand, S.P., 2006, Users' manual for the Hydroecological Integrity Assessment Process software (including the New Jersey Assessment Tools): U.S. Geological Survey Open-File Report 2006-1093, 71 p. (Also available at http://pubs. er.usgs.gov/usgspubs/ofr/ofr20061093).

Henshaw, P.C., and Booth, D.B., 2000, Natural restabilization of stream channels in urban watersheds: Journal of the American Water Resources Association, v. 36, no. 6, p. 1,219-1,236 (Also available at http://dx.doi. org/10.1111/j.1752-1688.2000.tb05722.x).

Hill, M.T., Platts, W.S., and Beschta, R.L., 1991, Ecological and geomorphological concepts for instream and out-ofchannel flow requirements: Rivers, v. 2, p. 198-210.

Hilsenhoff, W.L., 1987, An improved biotic index of organic stream pollution: The Great Lakes Entomologist, v. 20, p. 31-39.

Hirsch, R.M., Walker, J.F., Day, J.C., and Kallio, R., 1990, The influence of man on hydrologic systems, in Wolman, W.G., and Riggs, H.C., eds., Surface water hydrology - The geology of North America, v. O-1: Boulder, Colorado, Geological Society of America, p. 329-359.

Hornberger, G.M., and Spear, R.C., 1981, An approach to the preliminary analysis of environmental systems: Journal of Environmental Management, v. 12, p. 7-18.

Horner, R.R., and May, C.W., 1999, Regional study supports natural land cover protection as leading Best Management Practice for maintaining stream ecological integrity, in Proceedings of Comprehensive Stormwater and Aquatic Ecosystem Management Conference, Auckland, New Zealand, February 22-26, 1999, v. 1, p. 233-247.

James, A.B.W., Dewson, Z.E., and De'ath, R.G., 2008, Do stream invertebrates use instream refugia in response to severe short-term flow reduction in New Zealand streams?: Freshwater Biology, v. 53, p. 1,316-1,334 (Also available at http://dx.doi.org/10.1111/j.1365-2427.2008.01969.x).
Johnson, W.C., Burgess, R.L., and Keammerer, W.R., 1976, Forest overstory vegetation and environment on the Missouri River floodplain in North Dakota: Ecological Monographs, v. 46, p. 59-84 (Also available at http://dx.doi. org/10.2307/1942394).

Jowett, J.G., 1997, Environmental effects of extreme flows, in Mosely, M.P., and Pearson, C.P., eds., Floods and droughts - The New Zealand experience: Christchurch, Caxton Press, p. 104-116.

Kennen, J.G., and Ayers, M.A., 2002, Relation of environmental characteristics to the composition of aquatic assemblages along a gradient of urban land use in New Jersey, 1996-98: U.S. Geological Survey Water-Resources Investigations Report 02-4069, 77 p. (Also available at http://pubs.usgs. gov/wri/wri024069/pdf/wri024069.pdf).

Kennen, J.G., Chang, M., and Tracy, B.H., 2005, Effects of landscape change on fish assemblage structure in a rapidly growing metropolitan area in North Carolina, USA, in Brown, L.R., Gray, R.H., Hughes, R.M., and Meador, M.R., eds., Effects of urbanization on stream ecosystems: American Fisheries Society Symposium, v. 47, Bethesda, Maryland, p. 39-52.

Kennen, J.G., Henriksen, J.A., Heasley, J., Cade, B.S., and Terrell, J.W., 2009, Application of the Hydroecological Integrity Assessment Process for Missouri streams: U.S. Geological Survey Open-File Report 2009-1138, 57 p. (Also available at http://pubs.usgs.gov/of/2009/1138/).

Kennen, J.G., Henriksen, J.A., and Nieswand, S.P., 2007, Development of the Hydroecological Integrity Assessment Process for determining environmental flows for New Jersey streams: U.S. Geological Survey Scientific Investigations Report 2007-5206, 55 p. (Also available at http:// pubs.usgs.gov/sir/2007/5206/pdf/sir2007-5206-508.pdf).

Kennen, J.G., Kauffman, L.J., Ayers, M.A., and Wolock, D.M., 2008, Use of an integrated flow model to estimate ecologically relevant hydrologic characteristics at stream biomonitoring sites: Ecological Modelling, v. 211, p. 57-76 (Also available at http://dx.doi.org/10.1016/j. ecolmodel.2007.08.014).

Kennen, J.G., Riva-Murray, K., and Beaulieu, K.M., 2010, Determining hydrologic factors that influence stream macroinvertebrate assemblages in the northeastern US: Ecohydrology, v. 3, p. 88-106 (Also available at http://dx.doi. org/10.1002/eco.99).

Kennen, J.G., Sullivan, D.J., May, J.T., Bell, A.H., Beaulieu, K.M., and Rice, D.E., 2012, Temporal changes in aquaticinvertebrate and fish communities in streams of the north central and northeastern US: Ecological Indicators, v. 18, p. 312-329 (Also available at http://dx.doi.org/10.1016/j. ecolind.2011.11.022). 
Klein, R.D., 1979, Urbanization and stream quality impairment: Water Resources Bulletin, v. 15, p. 948-963 (Also available at $h t t p: / / d x . d o i . o r g / 10.1111 / j .1752-1688.1979$. tb01074.x).

Konrad, C.P., and Booth, D.B., 2005, Hydrologic changes in urban streams and their ecological significance, in Brown, L.R., Gray, R.H., Hughes, R.M., and Meador, M.R., eds., Effects of urbanization on stream ecosystems: American Fisheries Society, Bethesda, Md., p. 157-177.

Legesse, D., Vallet-Coulomba, C., and Gasse, F., 2003, Hydrological response of a catchment to climate and land use changes in Tropical Africa-Case study South Central Ethiopia: Journal of Hydrology, v. 275, p. 67-85 (Also available at http://dx.doi.org/10.1016/S00221694(03)00019-2).

Leopold, L.B., 1968, Hydrology for urban land planning-A guidebook on the hydrologic effects of urban land use: U.S. Geological Survey Circular 554, 18 p. (Also available at http://onlinepubs.er.usgs.gov/djvu/CIR/circ_554.djvu).

Lytle, D.A., 2002, Flash floods and aquatic insect life history evolution-Evaluation of multiple models: Ecology, v. 8, p. 370-385 (Also available at http://dx.doi. org/10.2307/2680021).

Lytle, D..A., and Poff, N.L., 2004, Adaptation to natural flow regimes: Trends in Ecology \& Evolution, v. 19, p. 94-100 (Also available at http://dx.doi.org/10.1016/j. tree.2003.10.002).

MacRae, C., and Rowney, A., 1992, The role of moderate flow events and bank structure in the determination of channel response to urbanization-45th Annual Conference, Resolving Conflicts and Uncertainty in Water Management: Proceeding of the Canadian Water Resources Association, Kingston, Ontario, June 1992, p. 12.1-12.21.

Magilligan, F.J., and Nislow, K.H., 2005, Changes in hydrologic regime by dams: Geomorphology, v. 71, p. 61-78.

Maine Department of Environmental Protection, 2004, Modeling report to support Total Maximum Daily Load (TMDL) development for Penjajawoc Stream (AKA Meadow Brook) -Draft report: Prepared by Tetra Tech, Inc., Fairfax, Virginia, 26 p., accessed July 9, 2013, at http://www. bangormaine.gov/image_upload/ModelingReport.pdf.

Massachusetts Department of Environmental Protection, 2003, Draft storm water pollutant total maximum daily load for headwaters of the Shawsheen River: Boston, Mass., Massachusetts Department of Environmental Protection, Department of Watershed Management, TMDL Report MA83-082003-01, June 9, 2003, 31 p., accessed March 14, 2013, at http://www.mass.gov/dep/water/resources/shawhead.pdf.
Mathews, R., 2005, A six-step framework for ecologically sustainable water management: Universities Council on Water Resources-Journal of Contemporary Water Research and Education, v. 131, p. 60-65 (Also available at http://dx.doi. org/10.1111/j.1936-704X.2005.mp131001010.x).

May, C.W., Horner, R.R., Karr, J.R., Mar, B.W., and Welch, E.B., 1997, Effects of urbanization on small streams in the Puget Sound Lowland Ecoregion: Watershed Protection Techniques, v. 2, no. 4, p. 485-494.

McCabe, D.J., and Gotelli, N.J., 2000, Effects of disturbance frequency, intensity, and area on assemblages of stream macroinvertebrates: Oecologia, v. 124, p. 270-279 (Also available at http://dx.doi.org/10.1007/s004420000369).

Merritt, R.W., and Cummins, K.W., 1996, An introduction to the aquatic insects of north America (3d ed.): Dubuque, Iowa, Kendall/Hunt Publishing Company, 772 p.

Merritt, W.S., Croke, B.F.W., Jakeman, A.J., Letcher, R.A., and Perez, P., 2004, A biophysical toolbox for assessment and management of land and water resources in rural catchments in Northern Thailand: Ecological Modelling, v. 171, p. 279-300 (Also available at http://dx.doi.org/10.1016/j. ecolmodel.2003.08.010).

Meyer, J.L., Paul, M.J., and Taulbee, W.K., 2005, Stream ecosystem function in urbanizing landscapes: Journal of the North American Benthological Society, v. 24, p. 602-612 (Also available at http://dx.doi.org/10.1899/04-021.1).

Miller, S.W., Wooster, D., and Li, J., 2007, Resistance and resilience of macroinvertebrates to irrigation and water withdrawals: Freshwater Biology, v. 52, p. 2,494-2,510 (Also available at $h t t p: / / d x . d o i . o r g / 10.1111 / j .1365-$ 2427.2007.01850.x).

Moulton, S.R., Kennen, J.G., Goldstein, R.M., and Hambrook, J.A., 2002, Revised protocols for sampling algal, invertebrate and fish communities as part of the National WaterQuality Assessment Program: U.S. Geological Survey Open-File Report 2002-150, 75 p.

National Research Council, 2008, Urban stormwater management in the United States: Washington, D.C., The National Academies Press, 610 p. (Also available at http://books.nap. edu/openbook.php?record_id=12465).

Natural Resources Conservation Service, 1986, Urban hydrology for small watersheds (TR-55): U.S. Department of Agriculture Technical Release 55, June 1986, 164 p.

New Jersey Department of Environmental Protection, 1994, Ambient Biomonitoring Network, Arthur Kill, Passaic, Hackensack, and Wallkill River drainage basins: Trenton, N.J., New Jersey Department of Environmental Protection, $22 \mathrm{p}$. 
New Jersey Department of Environmental Protection, 2008, Ambient Biomonitoring Network-Generalized executive summary-Watershed management areas and benthic macroinvertebrate data water monitoring report: Trenton, N.J., New Jersey Department of Environmental Protection, Bureau of Freshwater and Biological Monitoring, $12 \mathrm{p}$. (Also available at http://www.state.nj.us/dep/wms/bfbm/ GenExecSum.html).

New Jersey Department of Environmental Protection, 2008, Bureau of Freshwater and Biological Monitoring-Rapid bioassessment protocol: accessed February 20, 2013, at http://www.nj.gov/dep/wms/bfbm/rbpinfo.html.

New Jersey Department of Environmental Protection, 2008, Bureau of Geographic Information Systems (BGIS)-ArcGis 2002 Land use/land cover polygon by watershed management area (WMA): accessed December 28, 2010, at $h t t p: / /$ www.state.nj.us/dep/gis/lulc02cshp.html.

New Jersey Department of Environmental Protection, 2011, DEP agreement will remove three dams, open up segment of Raritan River to fish spawning for first time in decades:

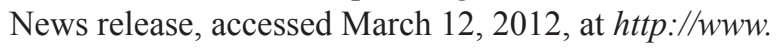
nj.gov/dep/newsrel/2011/11_0010.htm.

New Jersey Department of Environmental Protection, 2012b, New Jersey's four-tiered approach to volunteer monitoring: Trenton, N.J., New Jersey Department of Environmental Protection, Division of Watershed Management, $4 \mathrm{p}$. (Also available at http://www.state.nj.us/dep/wms/bwqsa/vm/docs/ WatershedWatchFinal.pdf).

New Jersey Department of Environmental Protection, 2012a, New Jersey Integrated Water Quality Monitoring and Assessment Report: Trenton, N.J., New Jersey Department of Environmental Protection, Division of Water Monitoring and Standards, $75 \mathrm{p}$. (Also available at $h t t p: / / w w w$. state.nj.us/dep/wms/bwqsa/2010_revised_final_integrated_ report_complete.pdf).

New Jersey Department of Environmental Protection, New Jersey Geological Survey, 2002, Digital Geologic Series DGS02-7: Physiographic Provinces of New Jersey: accessed December 28, 2010, at http://www.state.nj.us/dep/ njgs/geodata/dgs02-7.htm.

New Jersey Department of Environmental Protection, 2007, Standard operating procedures-Ambient biological monitoring using benthic macroinvertebrates-Field, lab, and assessment methods: Trenton, N.J., New Jersey Department of Environmental Protection, Bureau of Freshwater and Biological Monitoring, $40 \mathrm{p}$.

Nisenson, L., 2005, Using smart growth techniques as stormwater best management practices: Washington, D.C., U.S. Environmental Protection Agency, EPA 231-B-05-002, $108 \mathrm{p}$.
Olden, J.D., and Poff, N.L., 2003, Redundancy and the choice of hydrologic indices for characterizing streamflow regimes: River Research and Applications, v. 19, p. 101-121 (Also available at $h t t p: / / d x$.doi.org/10.1002/rra.700).

Orr, C.H., Kroiss, S.J., Rogers, K.L., and Stanley, E.H., 2008, Downstream benthic responses to small dam removal in a coldwater stream: River Research and Applications, v. 24, p. $804-822$.

Paine, G.H., and Gaufin, A.R., 1956, Aquatic Diptera as indicators of pollution in a Midwestern stream: The Ohio Journal of Science, v. 56, no. 5, p. 291-304.

Palmer, M.A., Liermann, C.A.R., Nilsson, C., Flörke, M., Alcamo, J., Lake, P.S., and Bond, N., 2008, Climate change and the world's river basins: Frontiers in Ecology and the Environment, v. 6, p. 81-89 (Also available at $h t t p: / / d x$.doi. org/10.1890/060148).

Paul, M.J., and Meyer, J.L., 2001, Streams in the urban landscape: Annual Review of Ecological Systems, v. 32, p. 333-365.

Peckarsky, B.L., Taylor, B.W., and Caudill, C.C., 2000, Hydrologic and behavioral constraints on oviposition of stream insects-Implications for adult dispersal: Oecologia, v. 125, p.186-200 (Also available at http://dx.doi. org/10.1007/s004420000446).

Poff, N.L., and Allan, J.D., 1995, Functional organization of stream fish assemblages in relation to hydrologic variability: Ecology, v. 76. no. 2, p. 606-627 (Also available at $h t t p: / /$ dx.doi.org/10.2307/1941217).

Poff, N.L., Allan, J.D., Bain, M.B., Karr, J.R., Prestegaard, K.L., Richter, B.D., Sparks, R.E., and Stromberg, J.C., 1997, The natural flow regime - A paradigm for river conservation and restoration: BioScience, v. 47, p. 769-784 (Also available at $h t t p: / / d x$.doi.org/10.2307/1313099).

Poff, N.L., Olden, J.D., Merritt, D., and Pepin, D., 2007, Homogenization of regional river dynamics by dams and global biodiversity implications: Proceedings of the National Academy of Sciences, v. 104, p. 5,732-5,737 (Also available at $h t t p: / / d x . d o i . o r g / 10.1073 /$ pnas.0609812104).

Poff, N.L., Olden, J.D., Vieira, N.K.M., Finn, D.S., Simmons, M.P., and Kondratieff, B.C., 2006, Functional trait niches of North American lotic insects-Traits-based ecological applications in light of phylogenetic relationships: Journal of the North American Benthological Society, v. 25 , no. 4 , p. $730-755$ (Also available at $h t t p: / / d x$. doi. org/10.1899/0887-3593(2006)025[0730:FTNONA]2.0 .CO;2). 
Poff, N.L., Richter, B.D., Arthington, A.H., Bunn, S.E., Naiman, R.J., Kendy, E., Acreman, M., Apse, C., Bledsoe, B.P., Freeman, M.C., Henriksen, J.A., Jacobson, R.B., Kennen, J.G., Meritt, D.M., O'Keeffe, J., Olden, J.D., Rogers, K.H., Tharme, R.E., and Warner, A.T., 2010, The ecological limits of hydrologic alteration (ELOHA) - A new framework for developing regional environmental flow standards: Freshwater Biology: v. 55, p. 147-170 (Also available at http://dx.doi.org/10.1111/j.1365-2427.2009.02204.x).

Poff, N.L., and Ward, J.V., 1989, Implications of streamflow variability and predictability for lotic community structure-A regional analysis of streamflow patterns: Canadian Journal of Fisheries and Aquatic Sciences, v. 46, p. 1,805-1,818 (Also available at http://dx.doi.org/10.1139/ f89-228).

Poff, N.L., and Zimmerman, J.K.H., 2010, Ecological responses to altered flow regimes-A literature review to inform environmental flows science and management: Freshwater Biology, v. 55, p. 194-200 (Also available at http://dx.doi.org/10.1111/j.1365-2427.2009.02272.x).

Power, M.E., and Stewart, A.J., 1987, Disturbance and recovery of an algal assemblage following flooding in an Oklahoma stream: American Midland Naturalist, v. 117, p. 333-345 (Also available at http://dx.doi. org/10.2307/2425975).

Pusey, B.J., Kennard, M.J., and Arthington, A.H., 2000, Discharge variability and the development of predictive models relating stream fish assemblage structure to habitat in northeastern Australia: Ecology of Freshwater Fish, v. 9, p. 30-50 (Also available at http://dx.doi.org/10.1034/ j.1600-0633.2000.90105.x).

Reiser, R.G., 2004, Evaluation of streamflow, water quality, and permitted and nonpermitted loads and yields in the Raritan River Basin, New Jersey, water years 1991-98: U.S. Geological Survey Water-Resources Investigations Report 03-4207, 224 p. (Also available at http://pubs.usgs.gov/wri/ wri03-4207/).

Richter, B.D., 2009, Re-thinking environmental flows-From allocations and reserves to sustainability boundaries: River Research and Applications, v. 26, p. 1,052-1,063 (Also available at http://dx.doi.org/10.1002/rra.1320).

Richter, B.D., Baumgartner, J.V., Powell, J., and Braun, D.P., 1996, A method for assessing hydrologic alteration within ecosystems: Conservation Biology, v. 10, p. 1,163-1,174 (Also available at http://dx.doi.org/10.1046/j.15231739.1996.10041163.x).

Richter, B.D., Baumgartner, J.V., Wigington, R., and Braun, D.P., 1997, How much water does a river need?: Freshwater Biology, v. 37, p. 231-249 (Also available at http://dx.doi. org/10.1046/j.1365-2427.1997.00153.x).
Richter, B.D., Davis, M.M., Apse, C., and Konrad, C., 2011, A presumptive standard for environmental flow protection: River Research and Applications, v. 28, p. 1,312-1,321 (Also available at http://dx.doi.org/10.1002/rra.1511).

Richter, B.D., and Thomas, T.A., 2007, Restoring environmental flows by modifying dam operations: Ecology and Society, v. 12, no. 1, article 12 (Also available at http:// www.ecologyandsociety.org/vol12/iss 1/art12/).

Robinson, C.T., and Minshall, G.W., 1986, Effects of disturbance frequency on stream benthic community structure in relation to canopy cover and season: Journal of the North American Benthological Society, v. 5, p. 237-248 (Also available at http://dx.doi.org/10.2307/1467711).

Rosenberg, D.M., Berkes, F., Bodaly, R.A., Hecky, R.E., Kelly, C.A., and Rudd, J.W.M., 1997, Large-scale impacts of hydroelectric development: Environmental Reviews, v. 5, p. 27-54 (Also available at http://dx.doi.org/10.1139/er-51-27).

Rosenberg, D.M., and Resh, V.H., 1993, Freshwater biomonitoring and benthic macroinvertebrates: New York, Routledge, Chapman and Hall, Inc., 488 p.

Roy, A.H., Cabezas, H., Clagett, M.P., Hoagland, N.T., Mayer, A.L., Morrison, M.A., Shuster, W.D., Templeton, J.J., and Thurston, H.W., 2006, Retrofit stormwater management: Navigating multidisciplinary hurdles at the watershed scale-Stormwater, v. 7, p. 16-29 (Also available at http:// www.stormh2o.com/SW/Articles/16660.aspx).

Roy, A.H., Freeman, M.C., Freeman, B.J., Wenger, S.J., Ensign, W.E., and Meyer, J.L., 2005, Investigating hydrologic alteration as a mechanism of fish assemblage shifts in urbanizing streams: Journal of the North American Benthological Society, v. 24, no. 3, p. 656-678.

Roy, A.H., Rosemond, A.D., Paul, M.J., Leigh, D.S., and Wallace, J.B., 2003, Stream macroinvertebrate response to catchment urbanisation (Georgia, U.S.A.): Freshwater Biology, v. 48, p. 1-18 (Also available at http://dx.doi. org/10.1046/j.1365-2427.2003.00979.x).

Sanborn, S.C., and Bledsoe, B.P., 2006, Predicting streamflow regime metrics for ungaged streams in Colorado, Washington, and Oregon: Journal of Hydrology, v. 325, p. 241-261 (Also available at http://dx.doi.org/10.1016/j. jhydrol.2005.10.018).

SAS Institute Inc., 2006, SAS/STAT ${ }^{\circledR}$ users guide, version 9.2 (4th ed.), v. 2: Cary, North Carolina, SAS Institute Inc., $1,682 \mathrm{p}$.

SAS Institute Inc., 1991, SAS ${ }$ system for regression (2d ed.): Cary, North Carolina, SAS Institute Inc., 210 p. 
Schlosser, I.J., 1985, Flow regime, juvenile abundance, and the assemblage structure of stream fishes: Ecology, v. 66, p.1,484-1,490 (Also available at $h t t p: / / d x . d o i$. org/10.2307/1938011).

Schueler, T.R., 1994, The importance of imperviousness: Watershed Protection, v. 1, no. 3, p. 100-111.

Schueler, T.R., Fraley-McNeal, L., and Cappiella, K., 2009, Is impervious cover still important? - A review of recent research: Journal of Hydrologic Engineering, v. 14, no. 4, p. 309-315.

Seaburn, G.E., 1969, Effects of urban development on direct runoff to East Meadow Brook, Nassau County, New York: U.S. Geological Survey Professional Paper 627-B, 14 p. (Also available at http://pubs.er.usgs.gov/publication/ pp627B).

Sefton, C.E.M., and Boorman, D.B., 1997, A regional investigation of climate change impacts on UK streamflows: Journal of Hydrology, v. 195, p. 26-44 (Also available at http://dx.doi.org/10.1016/S0022-1694(96)03257-X).

Snelder, T.H., Biggs, B.J.F., and Woods, R.A., 2005, Improved eco-hydrological classification of rivers: River Research and Applications, v. 21, no. 66, p. 609-628 (Also available at $h t$ tp://dx.doi.org/10.1002/rra.826).

Sparks, R.E., 1995, Need for ecosystem management of large rivers and their floodplains: BioScience, v. 45, p. 168-182 (Also available at $h t t p: / / d x$.doi.org/10.2307/1312556).

Stanford, J.A., Ward, J.V., Liss, W.J., Frissell, C.A., Williams, R.N., Lichatowich, J.A., and Coutant, C.C., 1996, A general protocol for restoration of regulated rivers: Regulated Rivers: Research and Management, v. 12, p. 391-414 (Also available at $h t t p: / / d x . d o i . o r g / 10.1002 /(S I C I) 1099-$ 1646(199607)12:4/5<391::AID-RRR436>3.3.CO;2-W).

Stanley, E.H., and Doyle, M.W., 2003, Trading off-The ecological effects of dam removal: Frontiers in Ecology and the Environment, v. 1, p. 15-22.

Stuckey, M.H., 2006, Low-flow, base-flow, and meanflow regression equations for Pennsylvania streams: U.S. Geological Survey Scientific Investigations Report 2006-5130, 84 p. (Also available at http://pubs.usgs.gov/ sir/2006/5130/).

Suren, A.M., Biggs, B., Duncan, M.J., Burgey, L., and Lambert, P., 2003, Benthic community dynamics during summer low-flows in two rivers contrasting enrichment-2. Invertebrates: New Zealand Journal of Marine and Freshwater Research, v. 37, p. 71-83 (Also available at $h$ ttp://dx.doi.org /10.1080/00288330.2003.9517147).
Taylor, B.R., 1997, Optimization of field and laboratory methods for benthic invertebrate biomonitoring - Final report to Canada Centre for Mineral and Energy Technology: Taylor Mazier Associates, St. Andrews, Nova Scotia, January 1997, $67 \mathrm{p}$.

Thoms, M.C., and Parsons, M., 2003, Identifying spatial and temporal patterns in the hydrological character of the Condamine-Balonne River, Australia, using multivariate statistics: River Research and Applications, v. 19, p. 443-457 (Also available at $h t t p: / / d x$.doi.org/10.1002/rra.737).

Thomson, J.R., Hart, D.D., Charles, D.F., Nightengale, T.L., and Winter, D.M., 2005, Effects of removal of a small dam on downstream macroinvertebrate and algal assemblages in a Pennsylvania stream: Journal of the North American Benthological Society, v. 24, p. 192-207.

Torak, L.J., and Painter, J.A., 2011, Summary of the Georgia Agricultural Water Conservation and Metering Program and evaluation of methods used to collect and analyze irrigation data in the middle and lower Chattahoochee and Flint River basins, 2004-2010: U.S. Geological Survey Scientific Investigations Report 2011-5126, 25 p.

Toth, L.A., 1995, Principles and guidelines for restoration of river/floodplain ecosystems - Kissimmee River, Florida ( $2 \mathrm{~d}$ ed.), in Cairns, J., ed., Rehabilitating damaged ecosystems: Boca Raton, Fla., Lewis Publishers/CRC Press, p. 49-73.

Tyus, H.M., 1990, Effects of altered stream flows on fisheries resources: Fisheries v. 15, p. 18-20.

Urban, M.C., Skelly, D.K., Burchsted, D., Price, W., and Lowry, S., 2006, Stream communities across a rural-urban landscape gradient: Diversity and Distributions, v. 12, p. $337-350$.

Utz, R.M., Hilderbrand, R.H., and Boward, D.M., 2009, Identifying regional differences in threshold responses of aquatic invertebrates to land cover gradients: Ecological Indicators, v. 9 , p. $556-567$.

U.S. Army Corps of Engineers, 2000, HEC-HMS Hydrologic Modeling System, User's manual: Davis, California, U.S. Army Corps of Engineers Hydrologic Engineering Center, $149 \mathrm{p}$.

U.S. Census Bureau, 2012, 2010 Census of Population and Housing, Population and Housing Unit Counts, CPH-2-32, New Jersey: U.S. Government Printing Office, Washington, D.C., 65 p. plus appendix, accessed August 6, 2013, at http:// www.census.gov/prod/cen2010/cph-2-32.pdf.

U.S. Environmental Protection Agency, 1997, Field and laboratory methods for macroinvertebrates and habitat assessment of low gradient, nontidal streams: Wheeling, W.Va., Mid-Atlantic Coastal Streams Workgroup, Environmental Services Divisions, Region 3, 23 p. 
U.S. Environmental Protection Agency, 2006, Estimation and application of macroinvertebrate tolerance values: Washington, D.C., National Center for Environmental Assessment, Office of Research and Development, EPA/600/P-04/116F, $80 \mathrm{p}$.

U.S. Geological Survey, 2011, WaterSMART —Departmental highlights: accessed June 2, 2012, at http://www.doi.gov/budget/appropriations/2011/highlights/upload/WaterSMART.pdf.

Vannote, R.L., Minshall, G.W., Cummins, K.W., Sedell, J.R., and Cushing, C.E., 1980, The river continuum concept: Canadian Journal of Fisheries and Aquatic Sciences, v. 37, p. 130-137 (Also available at $h t t p: / / d x$.doi.org/doi:10.1139/ f80-017).

Van Sickel, J., Baker, J., Herlihy, A., Bayley, P., Gregory, S., Haggerty, P., Ashkenas, L., and Li, J., 2006, Projecting the biological condition of streams under alternative scenarios of human land use: Ecological Applications, v. 14, p. 368-380 (Also available at $h t t p: / / d x$.doi.org/10.1890/02-5009).

Vieira, N.K.M., Poff, N.L., Carlisle, D.M., Moulton, S.R., II, Koski, M.L., and Kondratieff, B.C., 2006, A database of lotic invertebrate traits for North America: U.S. Geological Survey Data Series 187, 15 p. (Also available at http://pubs. usgs.gov/ds/ds187/pdf/ds187.pdf).

Virginia Department of Environmental Quality, 2004, Benthic TMDL for Toms Brook in Shenandoah County: Richmond, Virginia, Virginia Department of Environmental Quality, prepared by Department of Biological Systems Engineering, Virginia Polytechnic Institute and State University, Blacksburg, Virginia, $93 \mathrm{p}$.

Vorosmarty, C.J., and Sahagian, D., 2000, Anthropogenic disturbance of the terrestrial water cycle: BioScience, v. 50, p. 753-765 (Also available at http://dx.doi.org/10.1641/00063568(2000)050[0753:ADOTTW]2.0.CO;2).

Waldron, M.C., and Archfield, S.A., 2006, Factors affecting firm yield and the estimation of firm yield for selected streamflow-dominated drinking-water-supply reservoirs in Massachusetts: U.S. Geological Survey Scientific Investigations Report 2006-5044, 39 p. (Also available at http://pubs. usgs.gov/sir/2006/5044/).

Walsh, C.J., Fletcher, T.D., and Ladson, A.R, 2005a, Stream restoration in urban catchments through redesigning stormwater systems - Looking to the catchment to save the stream: Journal of the North American Benthological Society, v. 24 , no. 3, p. 690-705 (Also available at $h t t p: / / d x . d o i$. org/10.1899/04-020.1).

Walsh, C.J., Leonard, A.W., Ladson, A.R., and Fletcher, T.D., 2004, Urban stormwater and the ecology of streams: Canberra, Australia, Cooperative Research Centre for Freshwater Ecology and Cooperative Research Centre for Catchment Hydrology, 44 p.
Walsh, C.J., Roy, A.H., Feminella, J.W., Cottingham, P.D., Groffman, P.M., and Morgan, R.P., II, 2005b, The urban stream syndrome: Current knowledge and the search for a cure: Journal of the North American Benthological Society, v. 24, p. 706-723 (Also available at $h t t p: / / d x . d o i$. org/10.1899/04-028.1).

Wang, L., Brendon, T., Seelbach, P., Cooper, A., Allan, D., Clark, R., Jr., and Wiley, M., 2008, Landscape based identification of human disturbance gradients and reference conditions for Michigan streams: Environmental Monitoring and Assessment, v. 141, p. 1-17, http://dx.doi.org/10.1007/ s10661-006-9510-4.

Ward, J.V., and Stanford, J.A., 1989, Riverine ecosystemsThe influence of man on catchment dynamics and fish ecology: Canadian Special Publications in Fisheries and Aquatic Sciences, v. 106, p. 56-64.

Watson, K.M., Reiser, R.G., Nieswand, S.P., and Schopp, R.D., 2005, Streamflow characteristics and trends in New Jersey, water years 1897-2003: U.S. Geological Scientific Investigations Report 2005-5105, $131 \mathrm{p}$. (Also available at http://pubs.usgs.gov/sir/2005/5105/pdf/NJsir2005-5105_ report.pdf).

Wenger, S.J., and Freeman, M., 2007, Stressors to imperiled fishes in the Etowah Basin-Mechanisms, sources and management under the Etowah HCP: For the Etowah Regional Habitat Conservation Plan, September 25, 2006, 42 p., http://rivercenter.uga.edu/publications/pdf/stressors_2007. $p d f$.

Wenger, S.J., Peterson, J.T., Freeman, M.C., Freeman, B.J., and Homans, D.D., 2008, Stream fish occurrence in response to impervious cover, historic land use, and hydrogeomorphic factors: Canadian Journal of Fisheries and Aquatic Sciences, v. 65, p. 1,250-1,264 (Also available at $h t t p: / / d x$.doi.org/10.1139/F08-046).

Wolock, D.M., 1993, Simulating the variable-source-area concept of streamflow generation with the watershed model TOPMODEL: U.S. Geological Survey Water-Resources Investigations Report 93-4124, 33 p. (Also available at http://pubs.er.usgs.gov/publication/wri934124).

Woodruff, J.F., and Hewlett, J.D., 1970, Predicting and mapping the average hydrologic response for the eastern United States: Water Resource Research, v. 6, p. 1,312-1,326 (Also available at $h t t p: / / d x$.doi.org/10.1029/WR006i005p01312).

Zapecza, O.S., 1989, Hydrogeologic framework of the New Jersey Coastal Plain: U.S. Geological Survey Professional Paper 1404-B, 49 p., 24 pl. (Also available at http://pubs. er.usgs.gov/usgspubs/pp/pp1404B). 


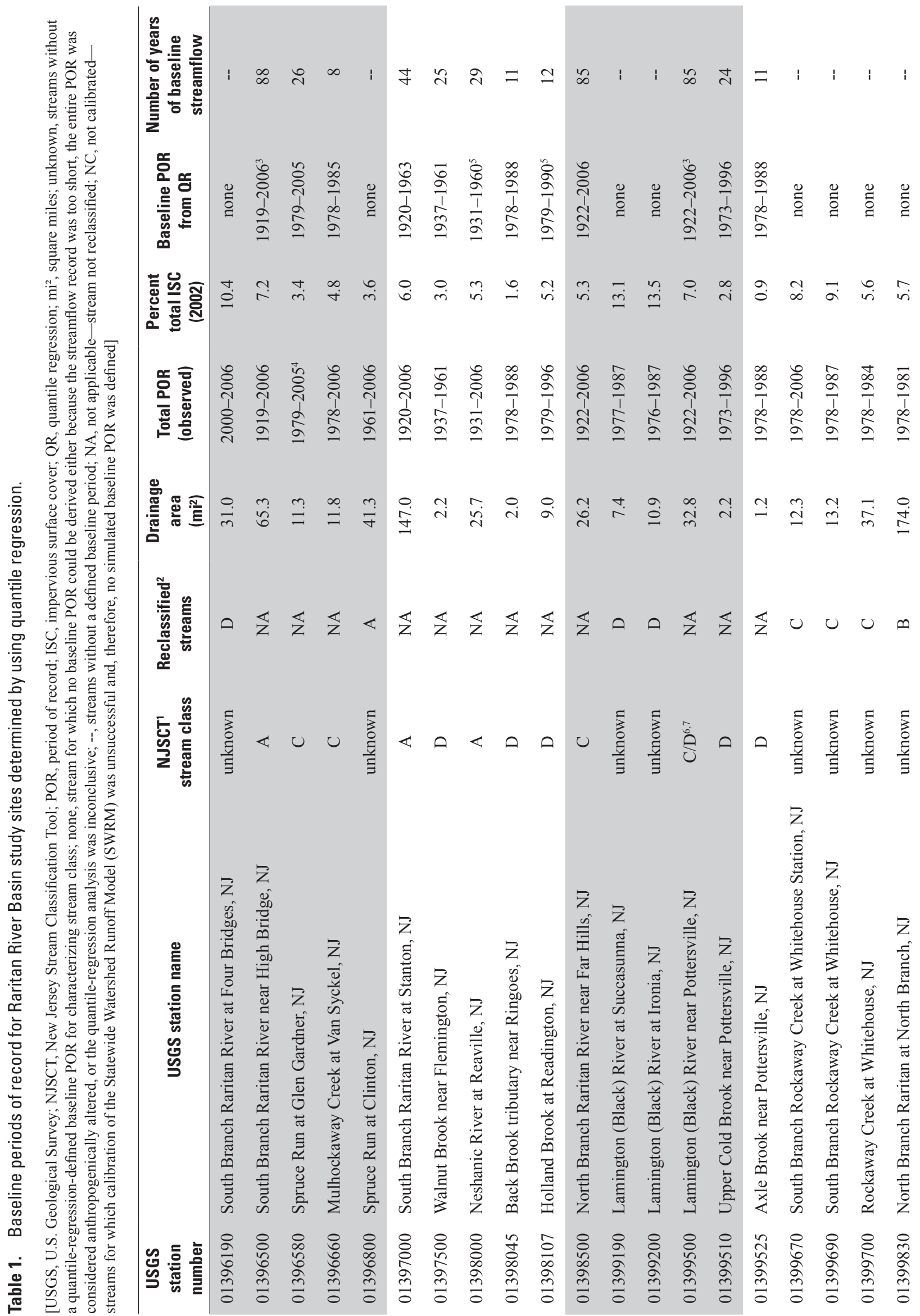




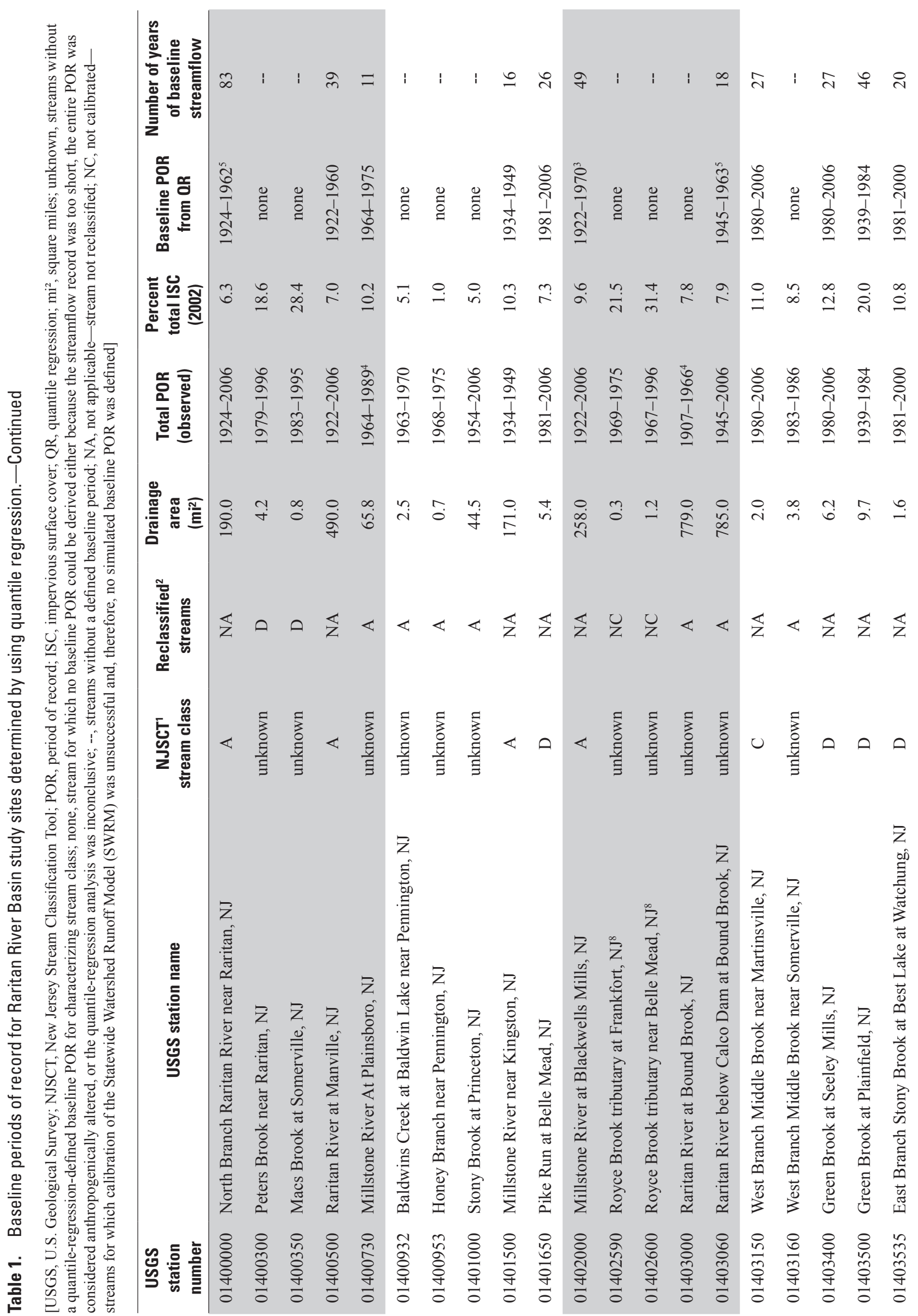




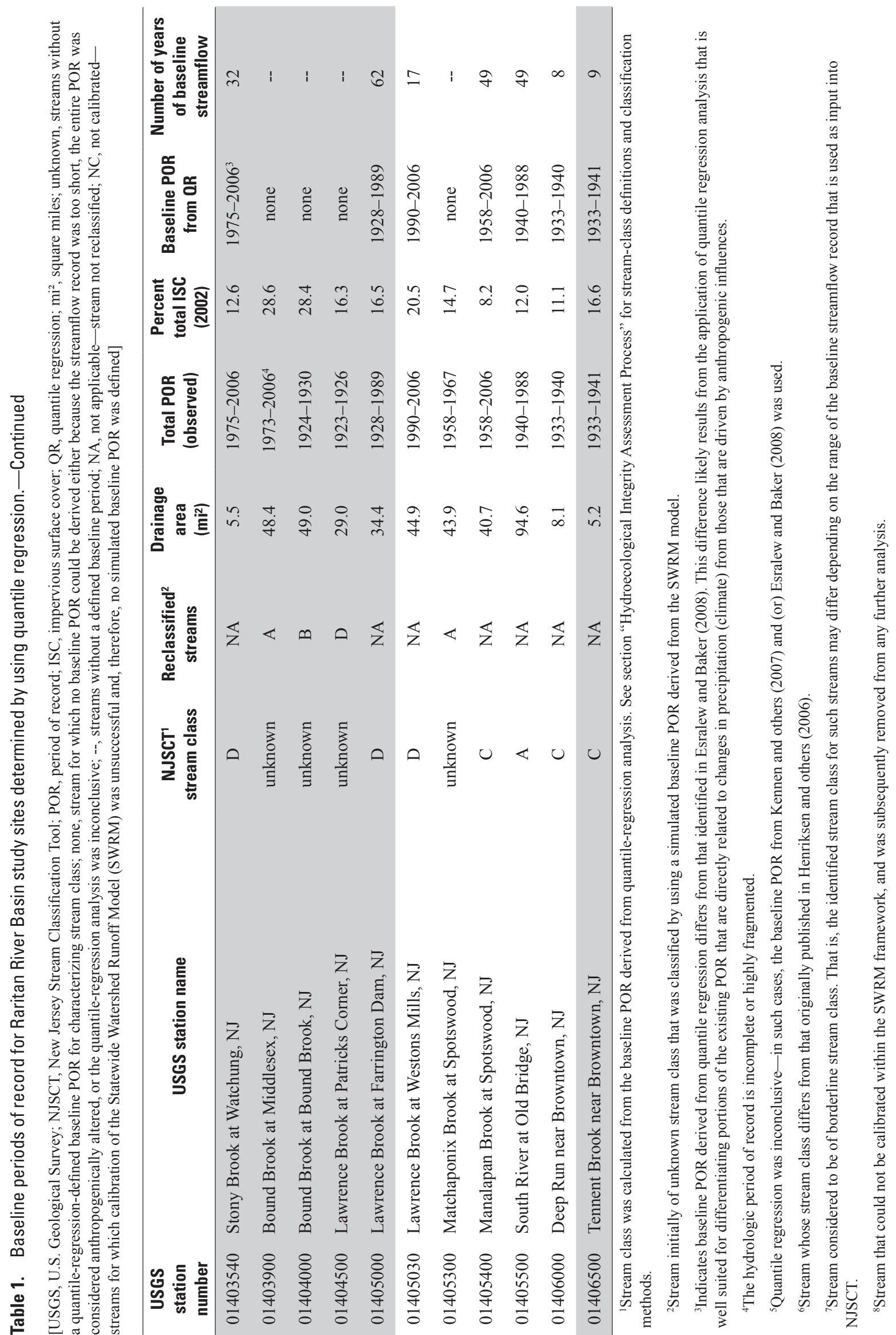




\section{Appendix 1. Definitions of the 171 hydrologic indices}

The following information for the 171 hydrologic indices is from Olden and Poff (2003). The U.S. Geological Survey revised a limited number of the formulas and (or) definitions when deemed appropriate for a given study (for example, MA6, MA7, and MA8). Olden and Poff (2003) contains 12 additional references from which the indices were derived; 2 of these references (Colwell, 1974; Poff, 1996) are cited here because they provide examples and additional explanation for complex indices.

The alphanumeric code preceding each definition refers to the category of the flow regime (magnitude, frequency, duration, timing, and rate of change) and type of flow event (A, average; L, low; and $\mathrm{H}$, high) the hydrologic index was developed to describe. Indices are numbered successively within each category. For example, MA1 is the first index describing magnitude of the average flow condition and FL1 is the first index describing frequency of the low flow condition.

\begin{tabular}{cl}
\hline Code prefix & \multicolumn{1}{c}{ Event } \\
\hline MA & Magnitude, average flow event \\
\hline ML & Magnitude, low flow event \\
MH & Magnitude, high flow event \\
\hline FL & Frequency, low flow event \\
\hline FH & Frequency, high flow event \\
\hline DL & Duration, low flow event \\
\hline DH & Duration, high flow event \\
\hline TA & Timing, average flow event \\
\hline TL & Timing, low flow event \\
\hline TH & Timing, high flow event \\
RA & Rate of change, average event \\
\hline
\end{tabular}

Following each definition, in parentheses, are (1) the units of the index, and (2) the type of data (temporal or spatial data) from which the upper and lower percentile limits (for example, 25th and 75th) are derived. Temporal data are from a multiyear daily flow record from a single streamgage. For example, index MA1, mean for the entire flow record, uses 365 mean daily flow values for each year in the flow record to calculate the mean for the entire flow record. Consequently, there are 365 values for each year from which to calculate upper and lower percentile limits. However, formulas for 60 of the indices do not produce a range of values from which percentile limits can be calculated. For example, MA5 (skewness), the mean for the entire flow record divided by the median for the entire record, results in a single value; therefore, upper and lower percentile limits cannot be directly calculated. The New Jersey Hydrologic Assessment Tool uses available spatial data, which are values for each streamgage for all the streams within a stream class, to compute upper and lower percentile limits (for example, 25th and 75th) for hydrologic metrics that are identified as spatial.

Exceedence and percentile are used in the calculation for a number of indices. Note the difference: a 90-percent exceedance means that 90 percent of the values are equal to or greater than the value, whereas 10 percent of the values are equal to or greater than the 90th-percentile value. 


\begin{tabular}{|c|c|}
\hline Code & Definition \\
\hline MA1 & Mean of the daily mean flow values for the entire flow record (cubic feet per second-temporal). \\
\hline MA2 & Median of the daily mean flow values for the entire flow record (cubic feet per second-temporal). \\
\hline MA3 & $\begin{array}{l}\text { Mean (or median-Use Preference option) of the coefficients of variation (standard deviation/mean) for each year. Compute } \\
\text { the coefficient of variation for each year of daily flows. Compute the mean of the annual coefficients of variation } \\
\text { (percent-temporal). }\end{array}$ \\
\hline MA4 & $\begin{array}{l}\text { Standard deviation of the percentiles of the entire flow record divided by the mean of percentiles. Compute the } 5 \text { th, } 10 \text { th, } 15 \text { th, } \\
\text { 20th, } 25 \text { th, 30th, 35th, 40th, } 45 \text { th, 50th, 55th, 60th, 65th, 70th, 75th, 80th, 85th, 90th, and 95th percentiles for the entire flow } \\
\text { record. Percentiles are computed by interpolating between the ordered (ascending) flow values. Compute the standard deviation } \\
\text { and mean for the percentile values. Divide the standard deviation by the mean to get MA4. (percent-spatial) }\end{array}$ \\
\hline MA5 & $\begin{array}{l}\text { The skewness of the entire flow record is computed as the mean for the entire flow record (MA1) divided by the median (MA2) } \\
\text { for the entire flow record (dimensionless-spatial). }\end{array}$ \\
\hline MA6 & $\begin{array}{l}\text { Range in daily flows is the ratio of the 10-percent to } 90 \text {-percent exceedance values for the entire flow record. Compute the } \\
5 \text {-percent to 95-percent exceedance values for the entire flow record. Exceedance is computed by interpolating between the } \\
\text { ordered (descending) flow values. Divide the 10-percent exceedance value by the } 90 \text {-percent value (dimensionless-spatial). }\end{array}$ \\
\hline MA7 & $\begin{array}{l}\text { Range in daily flows is computed as for MA6 except using the 20-percent and 80-percent exceedance values. Divide the } \\
20 \text {-percent exceedance value by the } 80 \text {-percent value (dimensionless-spatial). }\end{array}$ \\
\hline MA8 & $\begin{array}{l}\text { Range in daily flows is computed as for MA6 except using the } 25 \text {-percent and } 75 \text {-percent exceedance values. Divide the } \\
25 \text {-percent exceedance value by the } 75 \text {-percent exceedance value (dimensionless-spatial). }\end{array}$ \\
\hline MA9 & $\begin{array}{l}\text { Spread in daily flows is the ratio of the difference between the } 90 \text { th and } 10 \text { th percentile of the flow data to median of the entire } \\
\text { flow record. Compute the } 5 \text { th, } 10 \text { th, } 15 \text { th, } 20 \text { th, } 25 \text { th, } 30 \text { th, } 35 \text { th, } 40 \text { th, } 45 \text { th, } 50 \text { th, } 55 \text { th, } 60 \text { th, } 65 \text { th, } 70 \text { th, } 75 \text { th, } 80 \text { th, } 85 \text { th, } 90 \text { th, } \\
\text { and } 95 \text { th percentiles for the entire flow record. Percentiles are computed by interpolating between the ordered (ascending) flow } \\
\text { values. Compute MA9 as ( } 90 \text { th-10th)/MA2 (dimensionless-spatial). }\end{array}$ \\
\hline MA10 & Spread in daily flows is computed as for MA9 except using the 20th and 80th percentiles (dimensionless-spatial). \\
\hline MA11 & Spread in daily flows is computed as for MA9 except using the 25 th and 75 th percentiles (dimensionless-spatial). \\
\hline $\begin{array}{l}\text { MA12- } \\
\text { MA23 }\end{array}$ & $\begin{array}{l}\text { Means (or medians-Use Preference option) of monthly flow values. Compute the means for each month over the entire flow } \\
\text { record. For example, MA12 is the mean of all January flow values over the entire record (cubic feet per second-temporal). }\end{array}$ \\
\hline $\begin{array}{l}\text { MA24- } \\
\text { MA35 }\end{array}$ & $\begin{array}{l}\text { Variability (coefficient of variation) of monthly flow values. Compute the standard deviation for each month in each year over the } \\
\text { entire flow record. Divide the standard deviation by the mean for each month. Average (or median-Use Preference option) these } \\
\text { values for each month across all years (percent-temporal). }\end{array}$ \\
\hline MA36 & $\begin{array}{l}\text { Variability across monthly flows. Compute the minimum, maximum, and mean flows for each month in the entire flow } \\
\text { record. MA36 is the maximum monthly flow minus the minimum monthly flow divided by the median monthly flow } \\
\text { (dimensionless-spatial). }\end{array}$ \\
\hline MA37 & $\begin{array}{l}\text { Variability across monthly flows. Compute the first ( } 25 \text { th percentile) and the third ( } 75 \text { th percentile) quartiles (every month } \\
\text { in the flow record). MA37 is the third quartile minus the first quartile divided by the median of the monthly means } \\
\text { (dimensionless-spatial). }\end{array}$ \\
\hline MA38 & $\begin{array}{l}\text { Variability across monthly flows. Compute the 10th and } 90 \text { th percentiles for the monthly means (every month in the flow record). } \\
\text { MA38 is the 90th percentile minus the 10th percentile divided by the median of the monthly means (dimensionless-spatial). }\end{array}$ \\
\hline MA39 & $\begin{array}{l}\text { Variability across monthly flows. Compute the standard deviation for the monthly means. MA39 is the standard deviation times } \\
100 \text { divided by the mean of the monthly means (percent-spatial). }\end{array}$ \\
\hline MA40 & $\begin{array}{l}\text { Skewness in the monthly flows. MA } 40 \text { is the mean of the monthly flow means minus the median of the monthly means divided by } \\
\text { the median of the monthly means (dimensionless-spatial). }\end{array}$ \\
\hline MA41 & $\begin{array}{l}\text { Annual runoff. Compute the annual mean daily flows. MA41 is the mean of the annual means divided by the drainage area (cubic } \\
\text { feet per second/square mile-temporal). }\end{array}$ \\
\hline MA42 & $\begin{array}{l}\text { Variability across annual flows. MA42 is the maximum annual flow minus the minimum annual flow divided by the median of } \\
\text { mean annual flows (dimensionless-spatial). }\end{array}$ \\
\hline MA43 & $\begin{array}{l}\text { Variability across annual flows. Compute the first ( } 25 \text { th percentile) and third ( } 75 \text { th percentile) quartiles and the } 10 \text { th and } 90 \text { th } \\
\text { percentiles for the annual means (every year in the flow record). MA43 is the third quartile minus the first quartile divided by } \\
\text { the median of the annual means (dimensionless-spatial). }\end{array}$ \\
\hline
\end{tabular}




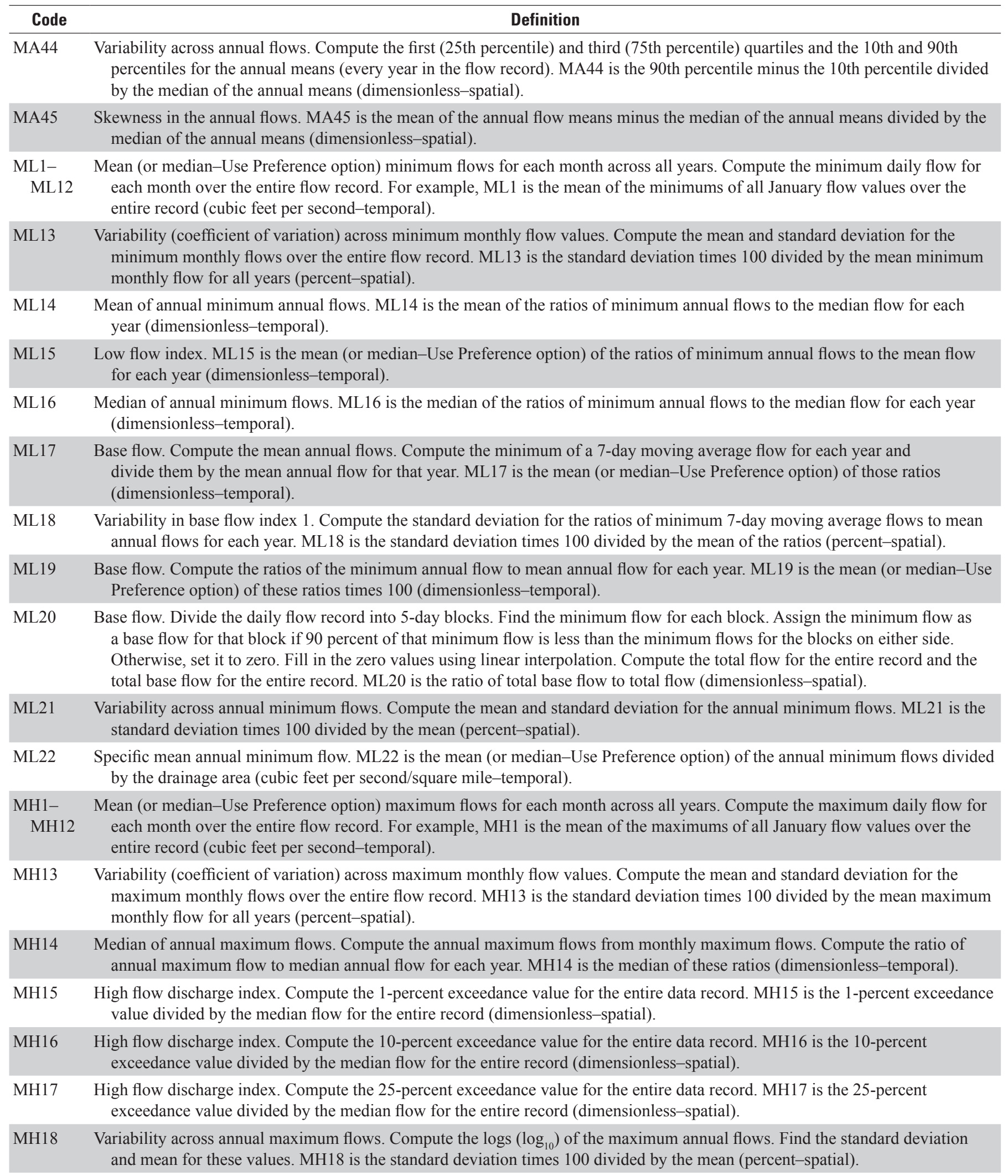




\begin{tabular}{cc}
\hline Code & Definition \\
\hline MH19 & Skewness in annual maximum flows. Use the equation: \\
& $M H 19=\frac{N^{2} \times \operatorname{sum}\left(q m^{3}\right)-3 N \times \operatorname{sum}(q m) \times \operatorname{sum}\left(q m^{2}\right)+2 \times \operatorname{sum}(q m)^{3}}{N \times(N-1) \times(N-2) \times s t d d e v^{3}}$
\end{tabular}

Where:

$N=$ Number of years

$q m=\log _{10}$ (annual maximum flows)

stddev $=$ Standard deviation of the annual maximum flows

(dimensionless-spatial).

MH20 Specific mean annual maximum flow. MH20 is the mean (or median-Use Preference option) of the annual maximum flows divided by the drainage area (cubic feet per second/square mile-temporal).

MH21 High flow volume index. Compute the average volume for flow events above a threshold equal to the median flow for the entire record. MH21 is the average volume divided by the median flow for the entire record (days-temporal).

MH22 High flow volume. Compute the average volume for flow events above a threshold equal to three times the median flow for the entire record. $\mathrm{MH} 22$ is the average volume divided by the median flow for the entire record (days-temporal).

MH23 High flow volume. Compute the average volume for flow events above a threshold equal to seven times the median flow for the entire record. MH23 is the average volume divided by the median flow for the entire record (days-temporal).

MH24 High peak flow. Compute the average peak flow value for flow events above a threshold equal to the median flow for the entire record. MH24 is the average peak flow divided by the median flow for the entire record (dimensionless-temporal).

MH25 High peak flow. Compute the average peak flow value for flow events above a threshold equal to three times the median flow for the entire record. MH25 is the average peak flow divided by the median flow for the entire record (dimensionless-temporal).

MH26 High peak flow. Compute the average peak flow value for flow events above a threshold equal to seven times the median flow for the entire record. MH26 is the average peak flow divided by the median flow for the entire record (dimensionless-temporal).

MH27 High peak flow. Compute the average peak flow value for flow events above a threshold equal to 75th percentile value for the entire flow record. MH27 is the average peak flow divided by the median flow for the entire record (dimensionless-temporal).

FL1 Low flood pulse count. Compute the average number of flow events with flows below a threshold equal to the 25th percentile value for the entire flow record. FL1 is the average (or median-Use Preference option) number of events (number of events/year-temporal).

FL2 Variability in low pulse count. Compute the standard deviation in the annual pulse counts for FL1. FL2 is 100 times the standard deviation divided by the mean pulse count (percent-spatial).

FL3 Frequency of low pulse spells. Compute the average number of flow events with flows below a threshold equal to 5 percent of the mean flow value for the entire flow record. FL3 is the average (or median-Use Preference option) number of events (number of events/year-temporal).

FH1 High flood pulse count. Compute the average number of flow events with flows above a threshold equal to the 75th percentile value for the entire flow record. FH1 is the average (or median-Use Preference option) number of events (number of events/year-temporal).

FH2 Variability in high pulse count. Compute the standard deviation in the annual pulse counts for FH1. FH2 is 100 times the standard deviation divided by the mean pulse count (number of events/year-spatial).

FH3 High flood pulse count. Compute the average number of days per year that the flow is above a threshold equal to three times the median flow for the entire record. FH3 is the mean (or median-Use Preference option) of the annual number of days for all years (number of days/year-temporal).

FH4 High flood pulse count. Compute the average number of days per year that the flow is above a threshold equal to seven times the median flow for the entire record. FH4 is the mean (or median-Use Preference option) of the annual number of days for all years (number of days/year-temporal).

FH5 Flood frequency. Compute the average number of flow events with flows above a threshold equal to the median flow value for the entire flow record. FH5 is the average (or median-Use Preference option) number of events (number of events/year-temporal).

FH6 Flood frequency. Compute the average number of flow events with flows above a threshold equal to three times the median flow value for the entire flow record. FH6 is the average (or median-Use Preference option) number of events (number of events/year-temporal).

FH7 Flood frequency. Compute the average number of flow events with flows above a threshold equal to seven times the median flow value for the entire flow record. FH7 is the average (or median-Use Preference option) number of events (number of events/year-temporal). 


\begin{tabular}{|c|c|}
\hline Code & Definition \\
\hline FH8 & $\begin{array}{l}\text { Flood frequency. Compute the average number of flow events with flows above a threshold equal to 25-percent } \\
\text { exceedance value for the entire flow record. FH8 is the average (or median-Use Preference option) number of events } \\
\text { (number of events/year-temporal). }\end{array}$ \\
\hline FH9 & $\begin{array}{l}\text { Flood frequency. Compute the average number of flow events with flows above a threshold equal to } 75 \text {-percent } \\
\text { exceedance value for the entire flow record. FH9 is the average (or median-Use Preference option) number of events } \\
\text { (number of events/year-temporal). }\end{array}$ \\
\hline FH1 $11^{1}$ & $\begin{array}{l}\text { Flood frequency. Compute the average number of flow events with flows above a threshold equal to flow corresponding } \\
\text { to a 1.67-year recurrence interval. FH11 is the average (or median-Use Preference option) number of events } \\
\text { (number of events/year-temporal). }\end{array}$ \\
\hline DL1 & $\begin{array}{l}\text { Annual minimum daily flow. Compute the minimum 1-day average flow for each year. DL1 is the mean (or median-Use } \\
\text { Preference option) of these values (cubic feet per second-temporal). }\end{array}$ \\
\hline DL3 & $\begin{array}{l}\text { Annual minimum of 7-day moving average flow. Compute the minimum of a 7-day moving average flow for each year. DL3 is the } \\
\text { mean (or median-Use Preference option) of these values (cubic feet per second-temporal). }\end{array}$ \\
\hline DL4 & $\begin{array}{l}\text { Annual minimum of } 30 \text {-day moving average flow. Compute the minimum of a 30-day moving average flow for each year. DL4 is } \\
\text { the mean (or median-Use Preference option) of these values (cubic feet per second-temporal). }\end{array}$ \\
\hline DL5 & $\begin{array}{l}\text { Annual minimum of 90-day moving average flow. Compute the minimum of a 90-day moving average flow for each year. DL5 is } \\
\text { the mean (or median-Use Preference option) of these values (cubic feet per second-temporal). }\end{array}$ \\
\hline DL6 & $\begin{array}{l}\text { Variability of annual minimum daily average flow. Compute the standard deviation for the minimum daily average flow. DL6 is } \\
100 \text { times the standard deviation divided by the mean (percent-spatial). }\end{array}$ \\
\hline DL7 & $\begin{array}{l}\text { Variability of annual minimum of 3-day moving average flow. Compute the standard deviation for the minimum 3-day moving } \\
\text { averages. DL7 is } 100 \text { times the standard deviation divided by the mean (percent-spatial). }\end{array}$ \\
\hline DL11 & $\begin{array}{l}\text { Annual minimum daily flow divided by the median for the entire record. Compute the minimum daily flow for each year. DL11 is } \\
\text { the mean of these values divided by the median for the entire record (dimensionless-temporal). }\end{array}$ \\
\hline DL12 & $\begin{array}{l}\text { Annual minimum of 7-day moving average flow divided by the median for the entire record. Compute the minimum of a } \\
\text { 7-day moving average flow for each year. DL12 is the mean of these values divided by the median for the entire record } \\
\text { (dimensionless-temporal). }\end{array}$ \\
\hline DL13 & $\begin{array}{l}\text { Annual minimum of } 30 \text {-day moving average flow divided by the median for the entire record. Compute the minimum of a } \\
\text { 30-day moving average flow for each year. DL13 is the mean of these values divided by the median for the entire record } \\
\text { (dimensionless-temporal). }\end{array}$ \\
\hline DL14 & $\begin{array}{l}\text { Low exceedance flows. Compute the } 75 \text {-percent exceedance value for the entire flow record. DL14 is the exceedance value } \\
\text { divided by the median for the entire record (dimensionless-spatial). }\end{array}$ \\
\hline DL15 & $\begin{array}{l}\text { Low exceedance flows. Compute the } 90 \text {-percent exceedance value for the entire flow record. DL15 is the exceedance value } \\
\text { divided by the median for the entire record (dimensionless-spatial). }\end{array}$ \\
\hline DL16 & $\begin{array}{l}\text { Low flow pulse duration. Compute the average pulse duration for each year for flow events below a threshold equal to the } 25 \text { th } \\
\text { percentile value for the entire flow record. DL16 is the median of the yearly average durations (number of days-temporal). }\end{array}$ \\
\hline DL17 & $\begin{array}{l}\text { Variability in low pulse duration. Compute the standard deviation for the yearly average low pulse durations. DL17 is } 100 \text { times } \\
\text { the standard deviation divided by the mean of the yearly average low pulse durations (percent-spatial). }\end{array}$ \\
\hline DL18 & $\begin{array}{l}\text { Number of zero-flow days. Count the number of zero-flow days for the entire flow record. DL18 is the mean (or median-Use } \\
\text { Preference option) annual number of zero-flow days (number of days/year-temporal). }\end{array}$ \\
\hline DL19 & $\begin{array}{l}\text { Variability in the number of zero-flow days. Compute the standard deviation for the annual number of zero-flow days. DL19 is } \\
100 \text { times the standard deviation divided by the mean annual number of zero-flow days (percent-spatial). }\end{array}$ \\
\hline
\end{tabular}




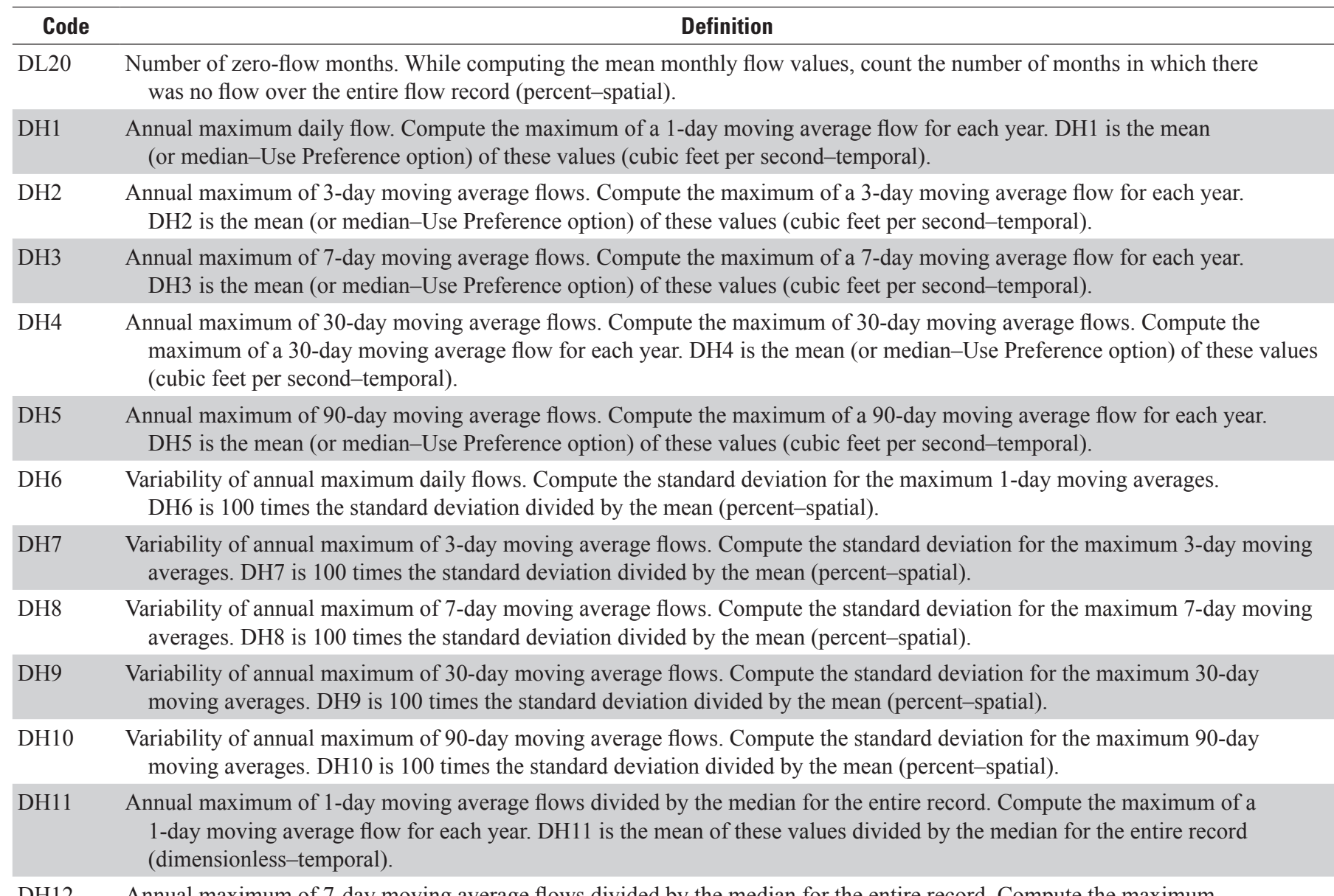

DH12 Annual maximum of 7-day moving average flows divided by the median for the entire record. Compute the maximum daily average flow for each year. DH12 is the mean of these values divided by the median for the entire record (dimensionless-spatial).

DH13 Annual maximum of 30-day moving average flows divided by the median for the entire record. Compute the maximum of a 30 -day moving average flow for each year. DH13 is the mean of these values divided by the median for the entire record (dimensionless-temporal).

DH14 Flood duration. Compute the mean of the mean monthly flow values. Find the 95th percentile for the mean monthly flows. DH14 is the 95th percentile value divided by the mean of the monthly means (dimensionless-spatial).

DH15 High flow pulse duration. Compute the average duration for flow events with flows above a threshold equal to the 75 th percentile value for each year in the flow record. DH15 is the median of the yearly average durations (days/year-temporal).

DH16 Variability in high flow pulse duration. Compute the standard deviation for the yearly average high pulse durations. DH16 is 100 times the standard deviation divided by the mean of the yearly average high pulse durations (percent-spatial).

DH17 High flow duration. Compute the average duration of flow events with flows above a threshold equal to the median flow value for the entire flow record. DH17 is the average (or median-Use Preference option) duration of the events (days-temporal).

DH18 High flow duration. Compute the average duration of flow events with flows above a threshold equal to three times the median flow value for the entire flow record. DH18 is the average (or median-Use Preference option) duration of the events (days-temporal).

DH19 High flow duration. Compute the average duration of flow events with flows above a threshold equal to seven times the median flow value for the entire flow record. DH19 is the average (or median-Use Preference option) duration of the events (days-temporal).

DH20 High flow duration. Compute the 75th percentile value for the entire flow record. Compute the average duration of flow events with flows above a threshold equal to the 75 th percentile value for the median annual flows. DH20 is the average (or medianUse Preference option) duration of the events (days-temporal).

DH21 High flow duration. Compute the 25th percentile value for the entire flow record. Compute the average duration of flow events with flows above a threshold equal to the 25 th percentile value for the entire set of flows. DH2 1 is the average (or median-Use Preference option) duration of the events (days-temporal). 


\begin{tabular}{|c|c|}
\hline Code & Def \\
\hline DH221 & $\begin{array}{l}\text { Flood interval. Compute the flood threshold as the flow equival } \\
\text { number of days between flood events for each year. DH22 is } \\
\text { number of days between flood events (days--temporal). }\end{array}$ \\
\hline DH231 & $\begin{array}{l}\text { Flood duration. Compute the flood threshold as the flow equiva } \\
\text { of days each year that the flow remains above the flood thres } \\
\text { number of flood days for years in which floods occur (days-t }\end{array}$ \\
\hline DH241 & $\begin{array}{l}\text { Flood-free days. Compute the flood threshold as the flow equiv } \\
\text { number of days that the flow is below the threshold for each } \\
\text { maximum yearly no-flood days (days-temporal). }\end{array}$ \\
\hline TA1 & $\begin{array}{l}\text { Constancy. Constancy is computed with the formulation of Col } \\
\text { compiled where the rows are } 11 \text { flow categories and the colur } \\
\text { are the number of times that a flow falls into a category on ea } \\
\log (\text { flow })<0.1 \times \log (\text { mean flow }) \text {, } \\
0.1 \times \log (\text { mean flow }) \leq \log (\text { flow })<0.25 \times \log (\text { mean flow }) \\
0.25 \times \log (\text { mean flow }) \leq \log (\text { flow })<0.5 \times \log (\text { mean flow }) \\
0.5 \times \log (\text { mean flow }) \leq \log (\text { flow })<0.75 \times \log (\text { mean flow }) \\
0.75 \times \log (\text { mean flow }) \leq \log (\text { flow })<1.0 \times \log (\text { mean flow }) \\
1.0 \times \log (\text { mean flow }) \leq \log (\text { flow })<1.25 \times \log (\text { mean flow }) \\
1.25 \times \log (\text { mean flow }) \leq \log (\text { flow })<1.5 \times \log (\text { mean flow }) \\
1.5 \times \log (\text { mean flow }) \leq \log (\text { flow })<1.75 \times \log (\text { mean flow }) \\
1.75 \times \log (\text { mean flow }) \leq \log (\text { flow })<2.0 \times \log (\text { mean flow }) \\
2.0 \times \log (\text { mean flow }) \leq \log (\text { flow })<2.25 \times \log (\text { mean flow }) \\
\log (\text { flow }) \geq 2.25 \times \log (\text { mean flow })\end{array}$ \\
\hline
\end{tabular}

The row totals, column totals, and grand total are computed. Using the equations for Shannon information theory parameters, constancy is computed as:

$$
1-\frac{(\text { uncertainty with respect to state })}{\log (\text { number of state })}
$$

(dimensionless-spatial).

TA2 Predictability. Predictability is computed from the same matrix as constancy (see example in Colwell, 1974). It is computed as:

$$
1-\frac{(\text { uncertainty with respect to interaction of time and state-uncertainty with respect to time })}{\log (\text { number of state })}
$$

(dimensionless-spatial).

TA3 ${ }^{1} \quad$ Seasonal predictability of flooding. Divide years into 2-month periods (that is, Oct.-Nov., Dec.-Jan., and so forth). Count the number of flood days (flow events with flows $>1.67$-year flood) in each period over the entire flow record. TA3 is the maximum number of flood days in any one period divided by the total number of flood days (dimensionless-temporal).

TL1 Julian date of annual minimum. Determine the Julian date that the minimum flow occurs for each water year. Transform the dates to relative values on a circular scale (radians or degrees). Compute the $\mathrm{x}$ and $\mathrm{y}$ components for each year and average them across all years. Compute the mean angle as the arc tangent of y-mean divided by x-mean. Transform the resultant angle back to Julian date (Julian day-spatial).

TL2 Variability in Julian date of annual minima. Compute the coefficient of variation for the mean $\mathrm{x}$ and $\mathrm{y}$ components and convert to a date (Julian day-spatial).

TL3 $^{2} \quad$ Seasonal predictability of low flow. Divide years into 2-month periods (that is, Oct.-Nov., Dec.-Jan., and so forth). Count the number of low-flow events (flow events with flows $\leq 5$-year flood threshold) in each period over the entire flow record. TL3 is the maximum number of low-flow events in any one period divided by the total number of low-flow events (dimensionless-spatial).

TL4 ${ }^{2}$ Seasonal predictability of non-low flow. Compute the number of days that flow is above the 5-year flood threshold as the ratio of number of days to 365 or 366 (leap year) for each year. TL4 is the maximum of the yearly ratios (dimensionless-spatial).

TH1 Julian date of annual maximum. Determine the Julian date that the maximum flow occurs for each year. Transform the dates to relative values on a circular scale (radians or degrees). Compute the $\mathrm{x}$ and $\mathrm{y}$ components for each year and average them across all years. Compute the mean angle as the arc tangent of y-mean divided by x-mean. Transform the resultant angle back to Julian date (Julian day-spatial). 


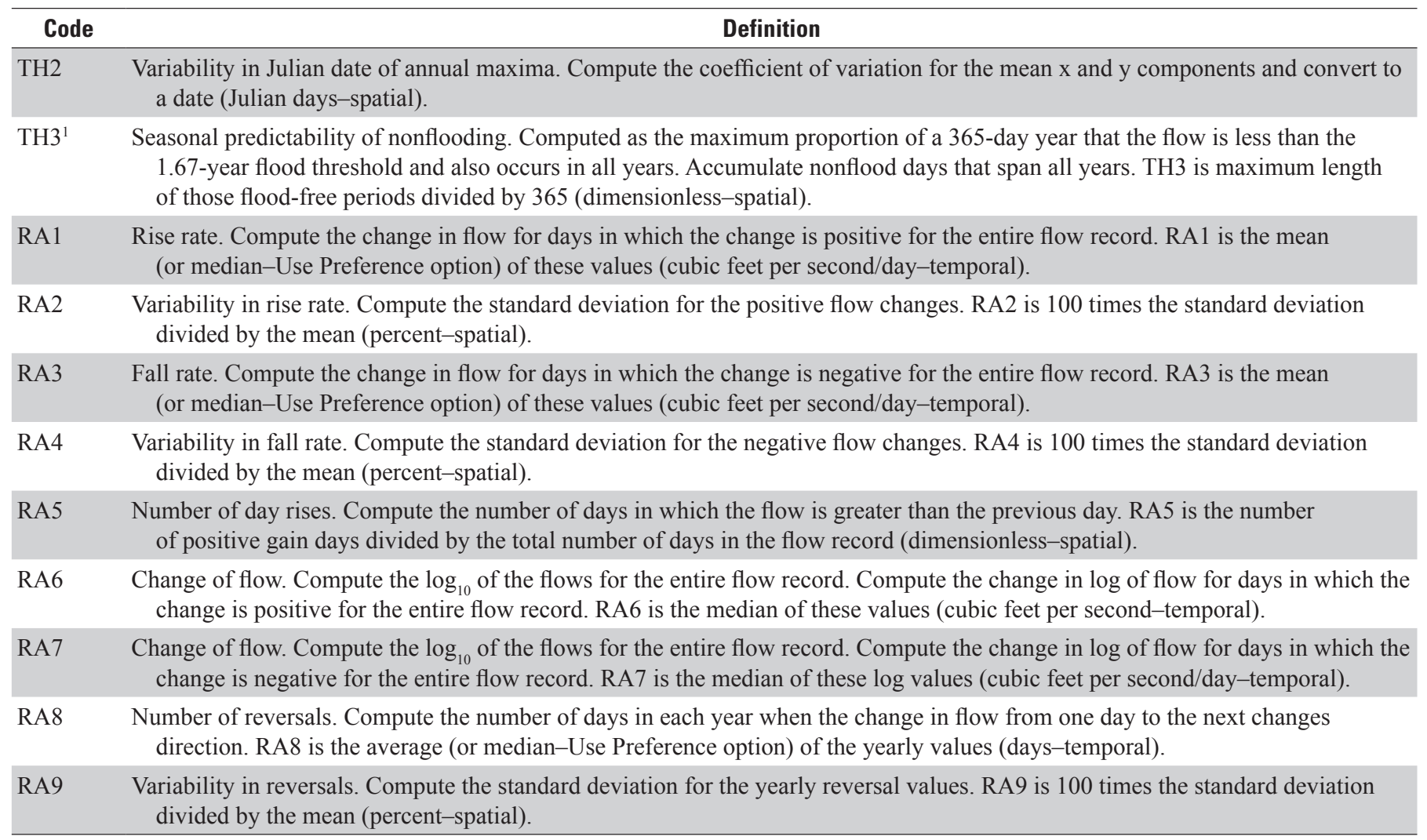

${ }^{1} 1.67$-year flood threshold (Olden and Poff, 2003)-For indices FH11, DH22, DH23, DH24, TA3, and TH3, compute the $\log _{10}$ of the peak annual flows. Compute the $\log _{10}$ of the daily flows for the peak annual flow days. Calculate the coefficients for a linear regression equation for logs of peak annual flow with respect to logs of average daily flow for peak days. Using the log peak flow for the 1.67-year recurrence interval (60th percentile) as input to the regression equation, predict the $\log _{10}$ of the average daily flow. The threshold is 10 to the $\log _{10}$ (average daily flow) power (cubic feet per second).

25-year flood threshold (Olden and Poff, 2003)-For TL3 and TL4, compute the $\log _{10}$ of the peak annual flows. Compute the $\log _{10}$ of the daily flows for the peak annual flow days. Calculate the coefficients for a linear regression equation for logs of peak annual flow with respect to logs of average daily flow for peak days. Using the log peak flow for the 5 -year recurrence interval (80th percentile) as input to the regression equation, predict the $\log _{10}$ of the average daily flow. The threshold is 10 to the $\log _{10}$ (average daily flow) power (cubic feet per second). 
Appendix 2. Deviations of flow-management targets for the Raritan River Basin study area, New Jersey, by U.S. Geological Survey station number, determined by using observed New Jersey Hydrologic Assessment Tool (NJHAT) values for specific nonredundant hydrologic indices that fall outside the established 25th-to-75th-percentile range and the more conservative 40th-to-60th-percentile range.

\section{Station index for appendix 2}

\begin{tabular}{clc}
\hline & U.S. Geological Survey station number and name & $\begin{array}{c}\text { Page } \\
\text { number }\end{array}$ \\
\hline & \multicolumn{1}{c}{ Observed baseline } \\
\hline 01397000 & South Branch Raritan River at Stanton, NJ & 72 \\
01398000 & Neshanic River at Reaville, NJ & 72 \\
01400000 & North Branch Raritan River near Raritan, NJ & 76 \\
01400500 & Raritan River at Manville, NJ & 77 \\
01400730 & Millstone River At Plainsboro, NJ & 77 \\
01402000 & Millstone River at Blackwells Mills, NJ & 80 \\
01403060 & Raritan River below Calco Dam at Bound Brook, NJ & 81
\end{tabular}

\begin{tabular}{lll}
\hline \multicolumn{1}{c}{ Simulated baseline } & \\
\hline 01396500 & South Branch Raritan River near High Bridge, NJ & 70 \\
01396580 & Spruce Run at Glen Gardner, NJ & 70 \\
01396660 & Mulhockaway Creek at Van Syckel, NJ & 71 \\
01396800 & Spruce Run at Clinton, NJ & 71 \\
01398500 & North Branch Raritan River near Far Hills, NJ & 73 \\
01399500 & Lamington (Black) River near Pottersville, NJ & 73 \\
01399670 & South Branch Rockaway Creek at Whitehouse Station, NJ & 74 \\
01399690 & South Branch Rockaway Creek at Whitehouse, NJ & 75 \\
01399700 & Rockaway Creek at Whitehouse, NJ & 76 \\
01400932 & Baldwins Creek at Baldwin Lake near Pennington, NJ & 78 \\
01400953 & Honey Branch near Pennington, NJ & 78 \\
01401000 & Stony Brook at Princeton, NJ & 79 \\
01401500 & Millstone River near Kingston, NJ & 79 \\
01403000 & Raritan River at Bound Brook, NJ & 80 \\
01403150 & West Branch Middle Brook near Martinsville, NJ & 81 \\
01403160 & West Branch Middle Brook near Somerville, NJ & 82 \\
01403900 & Bound Brook at Middlesex, NJ & 82 \\
01405300 & Matchaponix Brook at Spotswood, NJ & 83 \\
01405400 & Manalapan Brook at Spotswood, NJ & 84 \\
01405500 & South River at Old Bridge, NJ & 85 \\
01406000 & Deep Run near Browntown, NJ & 85 \\
01406500 & Tennent Brook near Browntown, NJ & 86 \\
\hline
\end{tabular}


Appendix 2. Deviations of flow-management targets for the Raritan River Basin study area, New Jersey, by U.S. Geological Survey station number, determined by using observed New Jersey Hydrologic Assessment Tool (NJHAT) values for specific nonredundant hydrologic indices that fall outside the established 25th-to-75th-percentile range and the more conservative 40th-to-60th-percentile range.-Continued

$\left[\mathrm{ft}^{3} / \mathrm{s}\right.$, cubic feet per second; $\left(\mathrm{ft}^{3} / \mathrm{s}\right) / \mathrm{d}$, cubic feet per second per day; days, number of days; $\mathrm{d} / \mathrm{yr}$, days per year; D, dimensionless; JD, Julian day; \%, percent; -- , no deviations above the 75 th or 60 th or below the 25 th or 40 th percentile range; hydrologic indices defined in appendix 1 ; values less than 1 were rounded to the thousandths place to show precision]

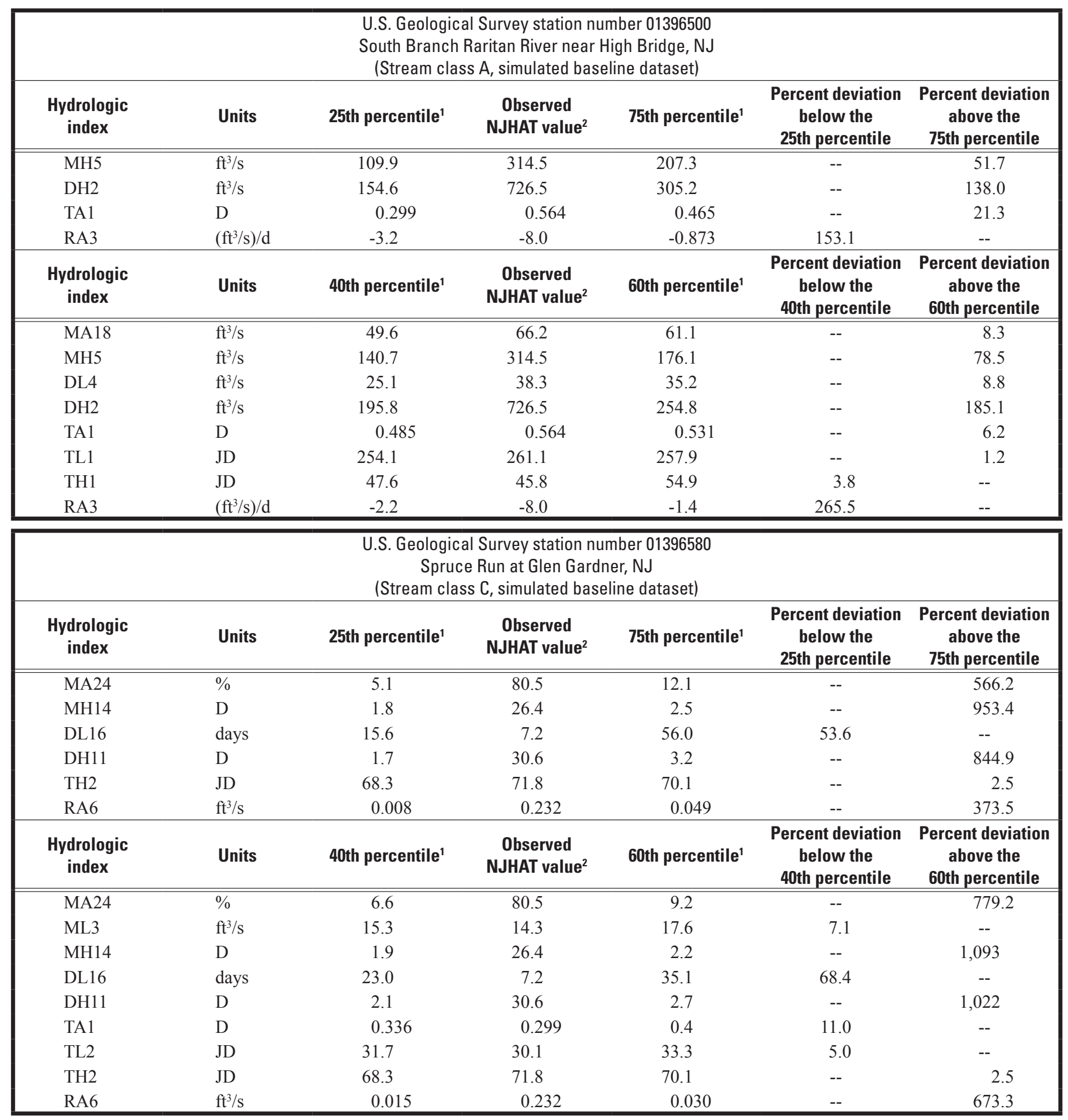


Appendix 2. Deviations of flow-management targets for the Raritan River Basin study area, New Jersey, by U.S. Geological Survey station number, determined by using observed New Jersey Hydrologic Assessment Tool (NJHAT) values for specific nonredundant hydrologic indices that fall outside the established 25th-to-75th-percentile range and the more conservative 40th-to-60th-percentile range.-Continued

$\left[\mathrm{ft}^{3} / \mathrm{s}\right.$, cubic feet per second; $\left(\mathrm{ft}^{3} / \mathrm{s}\right) / \mathrm{d}$, cubic feet per second per day; days, number of days; $\mathrm{d} / \mathrm{yr}$, days per year; D, dimensionless; JD, Julian day; \%, percent; -- , no deviations above the 75 th or 60 th or below the 25 th or 40 th percentile range; hydrologic indices defined in appendix 1 ; values less than 1 were rounded to the thousandths place to show precision]

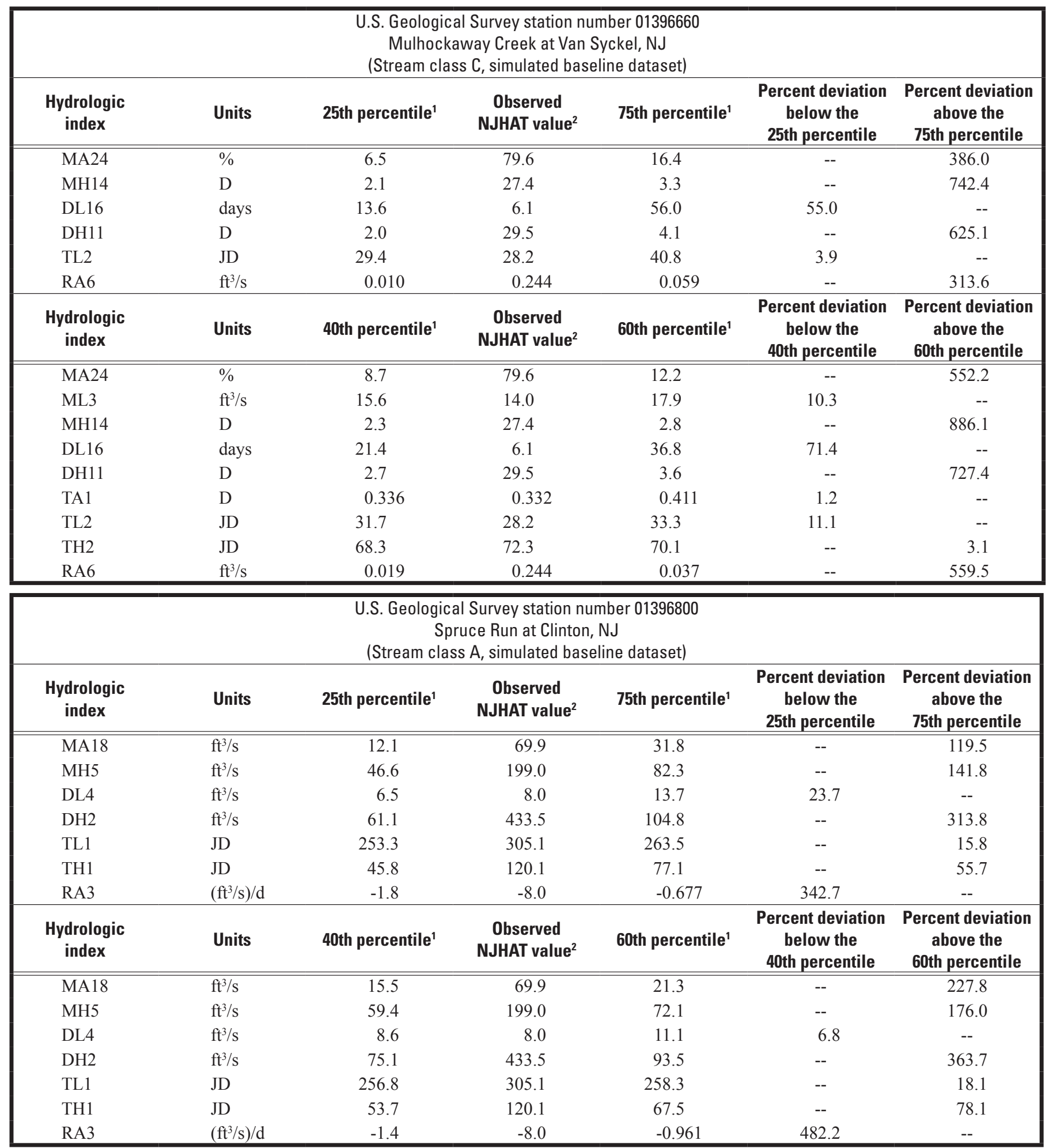


Appendix 2. Deviations of flow-management targets for the Raritan River Basin study area, New Jersey, by U.S. Geological Survey station number, determined by using observed New Jersey Hydrologic Assessment Tool (NJHAT) values for specific nonredundant hydrologic indices that fall outside the established 25th-to-75th-percentile range and the more conservative 40th-to-60th-percentile range.-Continued

$\left[\mathrm{ft}^{3} / \mathrm{s}\right.$, cubic feet per second; $(\mathrm{ft} / \mathrm{s}) / \mathrm{d}$, cubic feet per second per day; days, number of days; $\mathrm{d} / \mathrm{yr}$, days per year; $\mathrm{D}$, dimensionless; JD, Julian day; \%, percent; -- , no deviations above the 75 th or 60 th or below the 25 th or 40th percentile range; hydrologic indices defined in appendix 1 ; values less than 1 were rounded to the thousandths place to show precision]

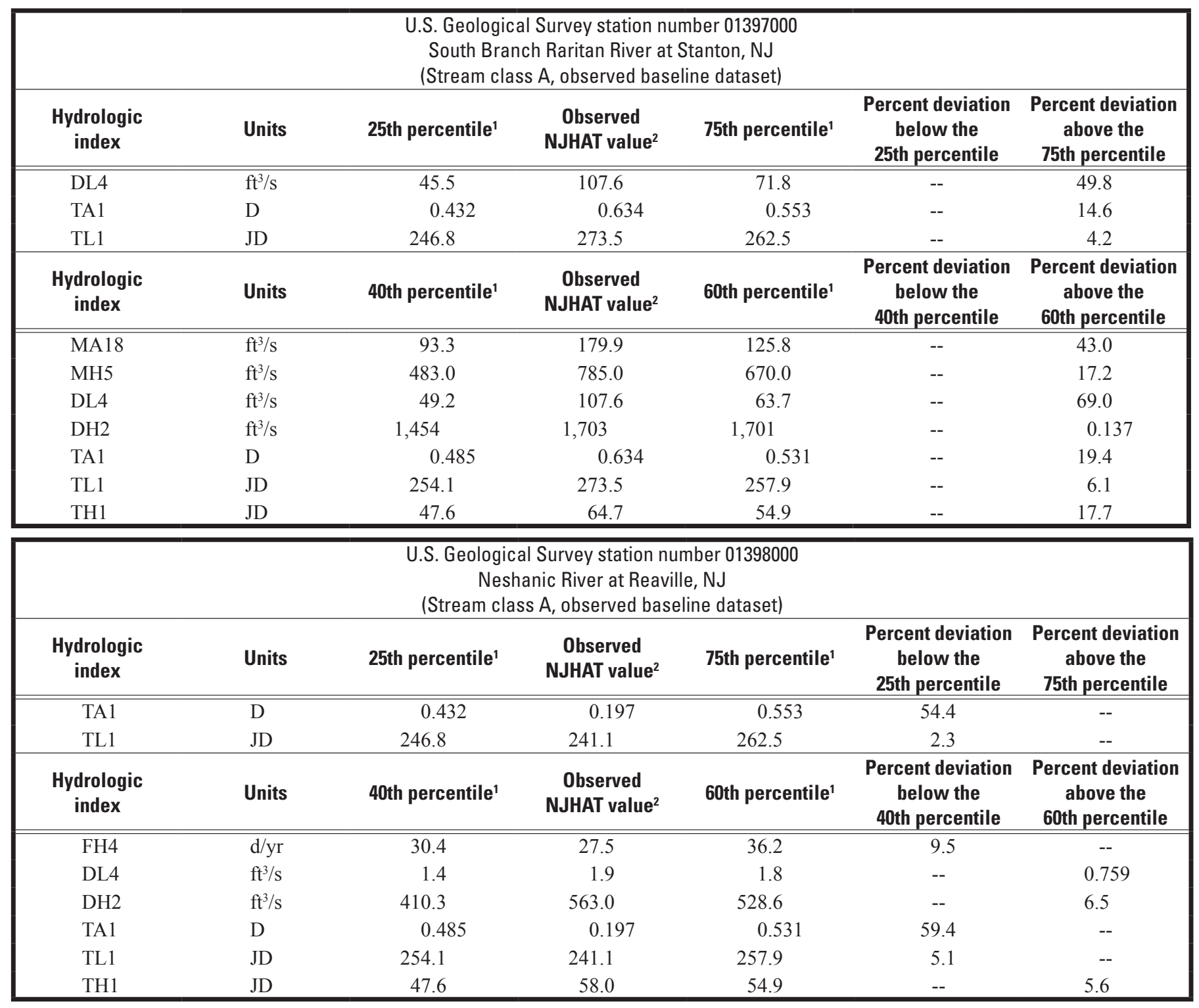


Appendix 2. Deviations of flow-management targets for the Raritan River Basin study area, New Jersey, by U.S. Geological Survey station number, determined by using observed New Jersey Hydrologic Assessment Tool (NJHAT) values for specific nonredundant hydrologic indices that fall outside the established 25th-to-75th-percentile range and the more conservative 40th-to-60th-percentile range.-Continued

$\left[\mathrm{ft}^{3} / \mathrm{s}\right.$, cubic feet per second; $\left(\mathrm{ft}^{3} / \mathrm{s}\right) / \mathrm{d}$, cubic feet per second per day; days, number of days; $\mathrm{d} / \mathrm{yr}$, days per year; D, dimensionless; JD, Julian day; \%, percent; -- , no deviations above the 75 th or 60 th or below the 25 th or 40 th percentile range; hydrologic indices defined in appendix 1 ; values less than 1 were rounded to the thousandths place to show precision]

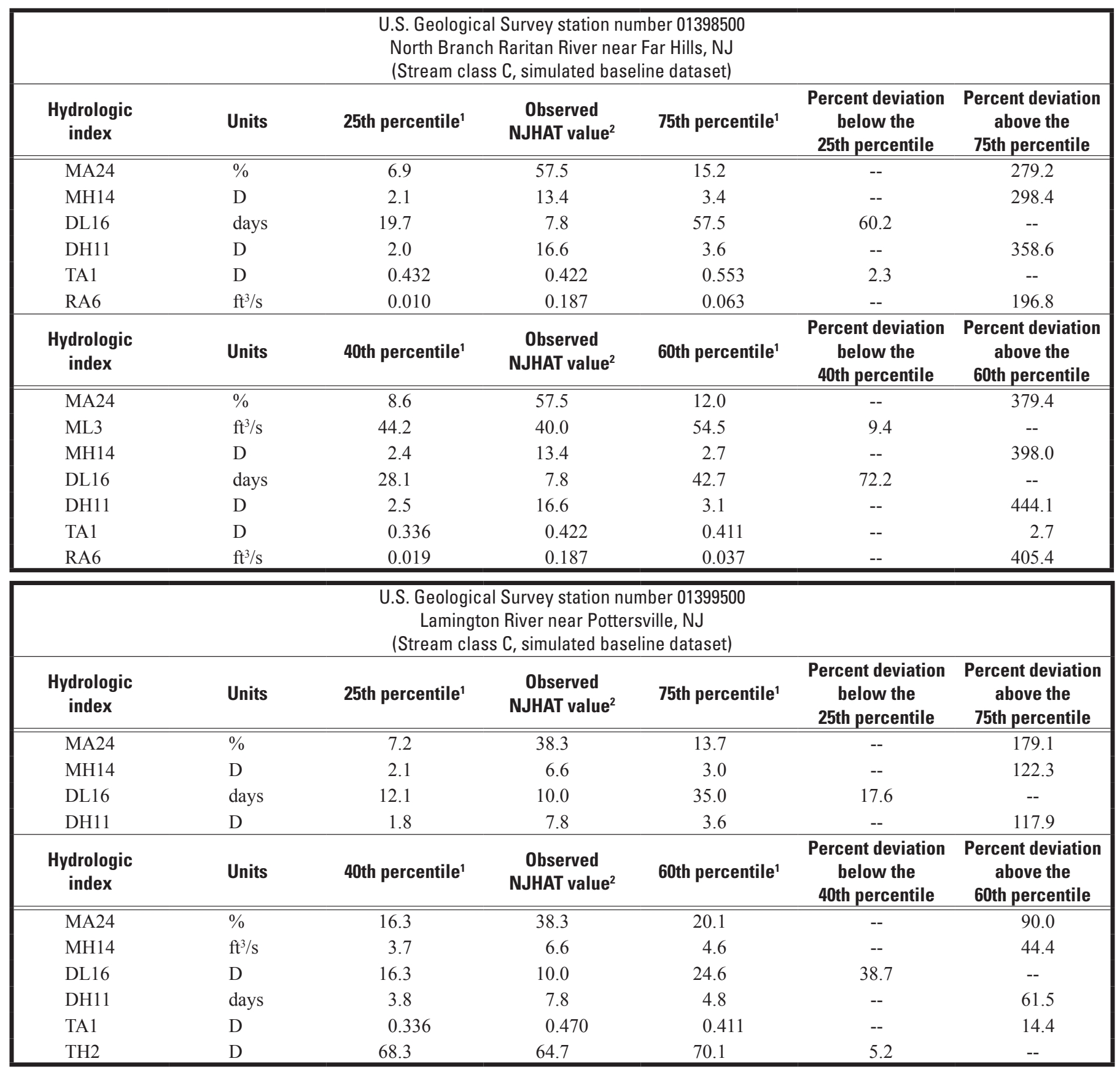


Appendix 2. Deviations of flow-management targets for the Raritan River Basin study area, New Jersey, by U.S. Geological Survey station number, determined by using observed New Jersey Hydrologic Assessment Tool (NJHAT) values for specific nonredundant hydrologic indices that fall outside the established 25th-to-75th-percentile range and the more conservative 40th-to-60th-percentile range.-Continued

$\left[\mathrm{ft}^{3} / \mathrm{s}\right.$, cubic feet per second; $\left(\mathrm{ft}^{3} / \mathrm{s}\right) / \mathrm{d}$, cubic feet per second per day; days, number of days; $\mathrm{d} / \mathrm{yr}$, days per year; $\mathrm{D}$, dimensionless; JD, Julian day; $\%$, percent; -- , no deviations above the 75 th or 60th or below the 25 th or 40 th percentile range; hydrologic indices defined in appendix 1 ; values less than 1 were rounded to the thousandths place to show precision]

\begin{tabular}{|c|c|c|c|c|c|c|}
\hline \multirow[b]{2}{*}{$\begin{array}{l}\text { Hydrologic } \\
\text { index }\end{array}$} & \multicolumn{4}{|c|}{$\begin{array}{c}\text { U.S. Geological Survey station number } 01399670 \\
\text { South Branch Rockaway Creek at Whitehouse Station, NJ } \\
\text { (Stream class C, simulated baseline dataset) }\end{array}$} & \multirow[b]{2}{*}{$\begin{array}{l}\text { Percent deviation } \\
\text { below the } \\
\text { 25th percentile } \\
\end{array}$} & \multirow[b]{2}{*}{$\begin{array}{c}\text { Percent deviation } \\
\text { above the } \\
\text { 75th percentile }\end{array}$} \\
\hline & Units & 25th percentile ${ }^{1}$ & $\begin{array}{c}\text { Observed } \\
\text { NJHAT value }^{2}\end{array}$ & 75th percentile ${ }^{1}$ & & \\
\hline MA24 & $\%$ & 5.2 & 102.3 & 8.9 & -- & 1,046 \\
\hline ML3 & $\mathrm{ft}^{3} / \mathrm{s}$ & 14.2 & 11.0 & 17.6 & 22.3 & -- \\
\hline MH14 & $\mathrm{D}$ & 1.6 & 26.5 & 2.0 & -- & 1,211 \\
\hline DH11 & $\mathrm{D}$ & 1.6 & 28.2 & 2.1 & -- & 1,277 \\
\hline TL2 & JD & 29.4 & 42.9 & 40.8 & -- & 5.2 \\
\hline TH2 & JD & 64.5 & 76.8 & 72.5 & -- & 5.9 \\
\hline RA6 & $\mathrm{ft}^{3} / \mathrm{s}$ & 0.015 & 0.266 & 0.144 & -- & 84.7 \\
\hline $\begin{array}{l}\text { Hydrologic } \\
\text { index }\end{array}$ & Units & 40th percentile ${ }^{1}$ & $\begin{array}{c}\text { Observed } \\
\text { NJHAT value }\end{array}$ & 60th percentile ${ }^{1}$ & $\begin{array}{l}\text { Percent deviation } \\
\text { below the } \\
\text { 40th percentile } \\
\end{array}$ & $\begin{array}{c}\text { Percent deviation } \\
\text { above the } \\
\text { 60th percentile } \\
\end{array}$ \\
\hline MA24 & $\%$ & 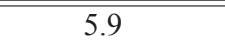 & 102.3 & 7.2 & "-- & 1,319 \\
\hline ML3 & $\mathrm{ft}^{3} / \mathrm{s}$ & 14.9 & 11.0 & 16.3 & 26.0 & -- \\
\hline MH14 & $\mathrm{D}$ & 1.7 & 26.5 & 1.8 & -- & 1,351 \\
\hline DL16 & days & 5.9 & 5.7 & 8.2 & 3.9 & -- \\
\hline DH11 & $\mathrm{D}$ & 1.8 & 28.2 & 1.9 & -- & 1,396 \\
\hline TL2 & JD & 31.7 & 42.9 & 33.3 & -- & 28.9 \\
\hline TH2 & JD & 68.3 & 76.8 & 70.1 & -- & 9.5 \\
\hline RA6 & $\mathrm{ft}^{3} / \mathrm{s}$ & 0.037 & 0.266 & 0.083 & -- & 220.5 \\
\hline
\end{tabular}


Appendix 2. Deviations of flow-management targets for the Raritan River Basin study area, New Jersey, by U.S. Geological Survey station number, determined by using observed New Jersey Hydrologic Assessment Tool (NJHAT) values for specific nonredundant hydrologic indices that fall outside the established 25th-to-75th-percentile range and the more conservative 40th-to-60th-percentile range.-Continued

$\left[\mathrm{ft}^{3} / \mathrm{s}\right.$, cubic feet per second; $\left(\mathrm{ft}^{3} / \mathrm{s}\right) / \mathrm{d}$, cubic feet per second per day; days, number of days; $\mathrm{d} / \mathrm{yr}$, days per year; D, dimensionless; JD, Julian day; \%, percent; -- , no deviations above the 75 th or 60 th or below the 25 th or 40 th percentile range; hydrologic indices defined in appendix 1 ; values less than 1 were rounded to the thousandths place to show precision]

\begin{tabular}{|c|c|c|c|c|c|c|}
\hline \multicolumn{7}{|c|}{$\begin{array}{c}\text { U.S. Geological Survey station number } 01399690 \\
\text { South Branch Rockaway Creek at Whitehouse, NJ } \\
\text { (Stream class C, simulated baseline dataset) }\end{array}$} \\
\hline $\begin{array}{l}\text { Hydrologic } \\
\text { index }\end{array}$ & Units & 25th percentile ${ }^{1}$ & $\begin{array}{c}\text { Observed } \\
\text { NJHAT value }^{2}\end{array}$ & 75th percentile ${ }^{1}$ & $\begin{array}{l}\text { Percent deviation } \\
\text { below the } \\
\text { 25th percentile }\end{array}$ & $\begin{array}{l}\text { Percent deviation } \\
\text { above the } \\
\text { 75th percentile }\end{array}$ \\
\hline MA24 & $\%$ & 5.2 & 108.4 & 10.7 & "-- & 909.5 \\
\hline DH11 & $\mathrm{D}$ & 1.6 & 23.0 & 2.2 & -- & 964.8 \\
\hline TL2 & JD & 29.4 & 59.2 & 40.8 & -- & 45.2 \\
\hline TH2 & JD & 64.5 & 60.0 & 72.5 & 6.9 & -- \\
\hline RA6 & $\mathrm{ft}^{3} / \mathrm{s}$ & 0.006 & 0.268 & 0.125 & -- & 114.4 \\
\hline $\begin{array}{l}\text { Hydrologic } \\
\text { index }\end{array}$ & Units & 40th percentile ${ }^{1}$ & $\begin{array}{c}\text { Observed } \\
\text { NJHAT value }^{2}\end{array}$ & 60th percentile ${ }^{1}$ & $\begin{array}{l}\text { Percent deviation } \\
\text { below the } \\
\text { 40th percentile }\end{array}$ & $\begin{array}{c}\text { Percent deviation } \\
\text { above the } \\
\text { 60th percentile }\end{array}$ \\
\hline MH14 & $\mathrm{D}$ & 1.8 & 27.8 & 1.9 & -- & 1,389 \\
\hline DL16 & days & 6.0 & 5.1 & 7.1 & 14.4 & -- \\
\hline DH11 & $\mathrm{D}$ & 1.8 & 23.0 & 2.0 & -- & 1,030 \\
\hline TL2 & JD & 31.7 & 59.2 & 33.3 & -- & 77.8 \\
\hline TH2 & $\mathrm{JD}$ & 68.3 & 60.0 & 70.1 & 12.0 & -- \\
\hline RA6 & $\mathrm{ft}^{3} / \mathrm{s}$ & 0.018 & 0.268 & 0.063 & -- & 325.4 \\
\hline
\end{tabular}


Appendix 2. Deviations of flow-management targets for the Raritan River Basin study area, New Jersey, by U.S. Geological Survey station number, determined by using observed New Jersey Hydrologic Assessment Tool (NJHAT) values for specific nonredundant hydrologic indices that fall outside the established 25th-to-75th-percentile range and the more conservative 40th-to-60th-percentile range.-Continued

$\left[\mathrm{ft}^{3} / \mathrm{s}\right.$, cubic feet per second; $\left(\mathrm{ft}^{3} / \mathrm{s}\right) / \mathrm{d}$, cubic feet per second per day; days, number of days; $\mathrm{d} / \mathrm{yr}$, days per year; D, dimensionless; JD, Julian day; \%, percent; -- , no deviations above the 75 th or 60 th or below the 25 th or 40 th percentile range; hydrologic indices defined in appendix 1 ; values less than 1 were rounded to the thousandths place to show precision]

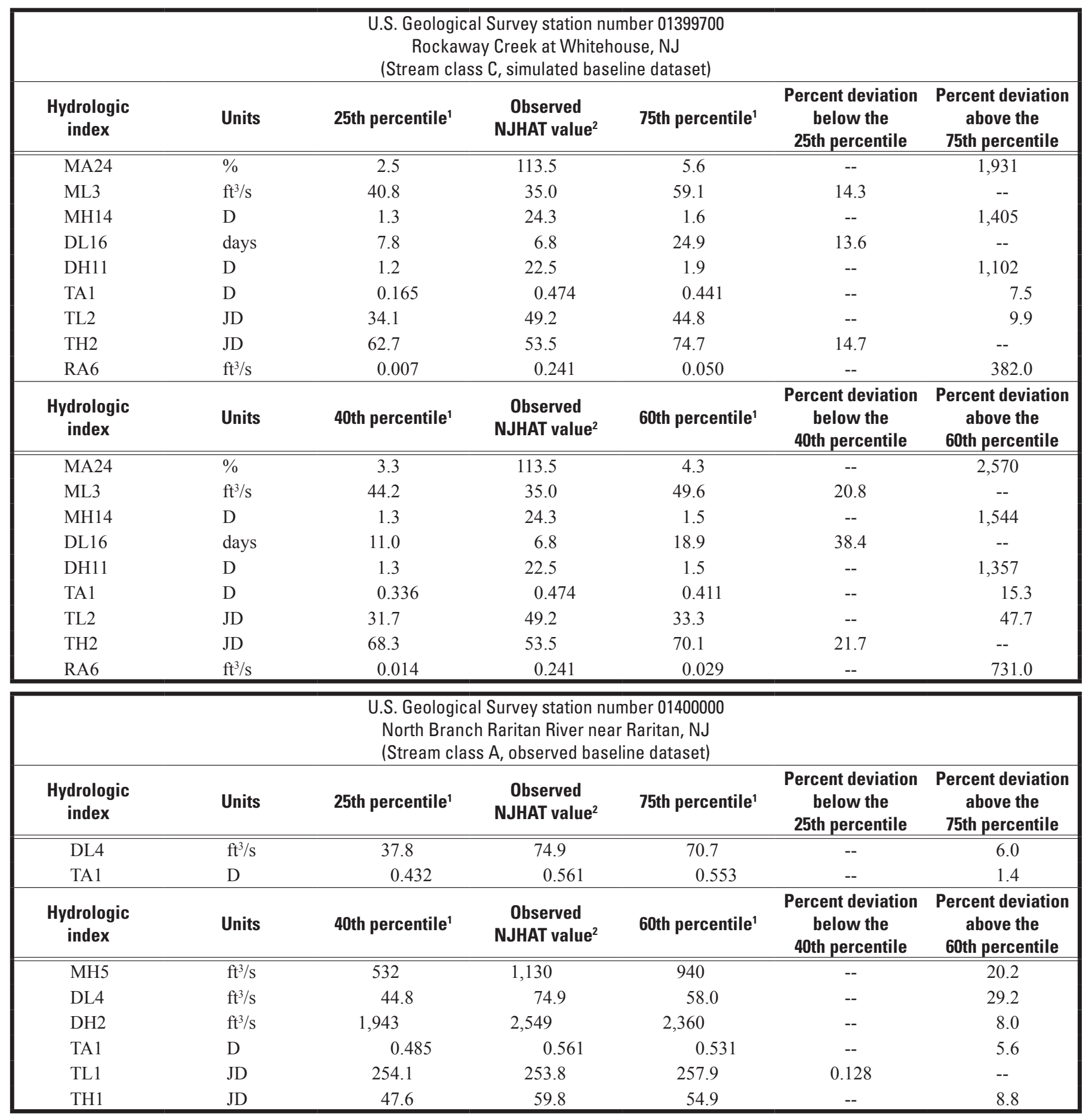


Appendix 2. Deviations of flow-management targets for the Raritan River Basin study area, New Jersey, by U.S. Geological Survey station number, determined by using observed New Jersey Hydrologic Assessment Tool (NJHAT) values for specific nonredundant hydrologic indices that fall outside the established 25th-to-75th-percentile range and the more conservative 40th-to-60th-percentile range.-Continued

[ $\mathrm{ft}^{3} / \mathrm{s}$, cubic feet per second; ( $\left.\mathrm{ft}^{3} / \mathrm{s}\right) / \mathrm{d}$, cubic feet per second per day; days, number of days; $\mathrm{d} / \mathrm{yr}$, days per year; D, dimensionless; JD, Julian day; \%, percent; -- , no deviations above the 75 th or 60 th or below the 25 th or 40 th percentile range; hydrologic indices defined in appendix 1 ; values less than 1 were rounded to the thousandths place to show precision]

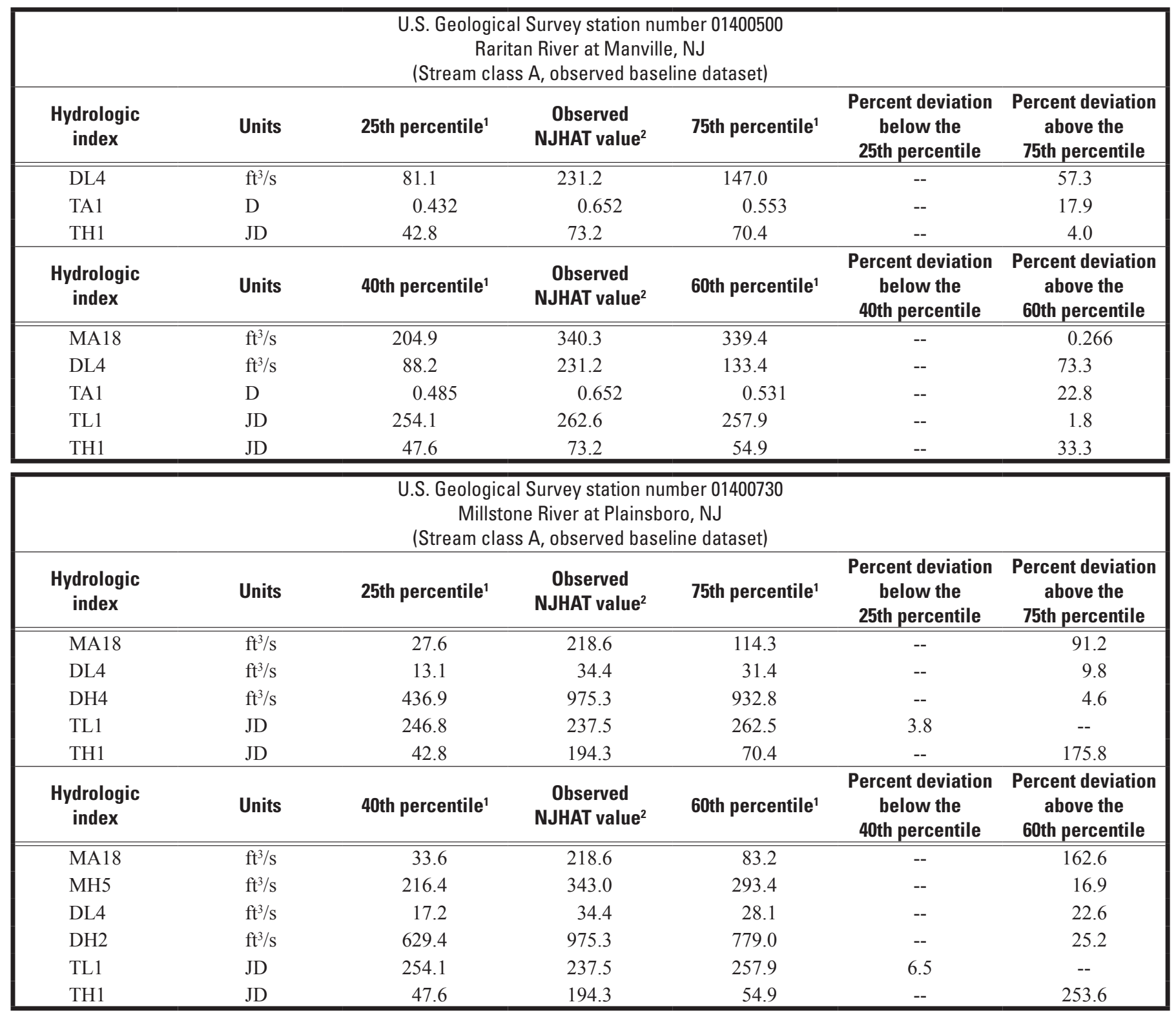


Appendix 2. Deviations of flow-management targets for the Raritan River Basin study area, New Jersey, by U.S. Geological Survey station number, determined by using observed New Jersey Hydrologic Assessment Tool (NJHAT) values for specific nonredundant hydrologic indices that fall outside the established 25th-to-75th-percentile range and the more conservative 40th-to-60th-percentile range.-Continued

$\left[\mathrm{ft}^{3} / \mathrm{s}\right.$, cubic feet per second; $\left(\mathrm{ft}^{3} / \mathrm{s}\right) / \mathrm{d}$, cubic feet per second per day; days, number of days; d/yr, days per year; D, dimensionless; JD, Julian day; \%, percent; --, no deviations above the 75 th or 60 th or below the 25 th or 40th percentile range; hydrologic indices defined in appendix 1 ; values less than 1 were rounded to the thousandths place to show precision]

\begin{tabular}{|c|c|c|c|c|c|c|}
\hline \multicolumn{7}{|c|}{$\begin{array}{c}\text { U.S. Geological Survey station number } 01400932 \\
\text { Baldwins Creek at Baldwin Lake near Pennington, NJ } \\
\text { (Stream class A, simulated baseline dataset) }\end{array}$} \\
\hline $\begin{array}{l}\text { Hydrologic } \\
\text { index }\end{array}$ & Units & 25th percentile ${ }^{1}$ & $\begin{array}{c}\text { Observed } \\
\text { NJHAT value }{ }^{2}\end{array}$ & 75th percentile ${ }^{1}$ & $\begin{array}{l}\text { Percent deviation } \\
\text { below the } \\
\text { 25th percentile } \\
\end{array}$ & $\begin{array}{c}\text { Percent deviation } \\
\text { above the } \\
\text { 75th percentile } \\
\end{array}$ \\
\hline MA18 & $\mathrm{ft}^{3} / \mathrm{s}$ & 0.488 & 0.399 & 1.8 & 18.2 & --- \\
\hline $\mathrm{DH} 2$ & $\mathrm{ft}^{3} / \mathrm{s}$ & 6.4 & 42.2 & 14.2 & -- & 197.0 \\
\hline TA1 & $\mathrm{D}$ & 0.432 & 0.314 & 0.553 & 27.3 & -- \\
\hline TL1 & JD & 246.8 & 236.6 & 262.5 & 4.2 & -- \\
\hline TH1 & JD & 42.8 & 71.4 & 70.4 & -- & 1.3 \\
\hline RA3 & $\left(\mathrm{ft}^{3} / \mathrm{s}\right) / \mathrm{d}$ & -0.122 & -0.300 & -0.023 & 145.9 & -- \\
\hline MH5 & $\mathrm{ft}^{3} / \mathrm{s}$ & 4.1 & 11.2 & 5.6 & -- & 99.7 \\
\hline DL4 & $\mathrm{ft}^{3} / \mathrm{s}$ & 0.247 & 0.004 & 0.379 & 98.4 & -- \\
\hline DH2 & $\mathrm{ft}^{3} / \mathrm{s}$ & 7.8 & 42.2 & 10.5 & -- & 302.1 \\
\hline TA1 & $\mathrm{D}$ & 0.485 & 0.314 & 0.531 & 35.3 & -- \\
\hline TL1 & JD & 254.1 & 236.6 & 257.9 & 6.9 & -- \\
\hline TH1 & $\mathrm{JD}$ & 47.6 & 71.4 & 54.9 & -- & 29.9 \\
\hline RA3 & $\left(\mathrm{ft}^{3} / \mathrm{s}\right) / \mathrm{d}$ & -0.078 & -0.3 & -0.041 & 284.6 & -- \\
\hline \multicolumn{7}{|c|}{$\begin{array}{c}\text { U.S. Geological Survey station number } 01400953 \\
\text { Honey Branch near Pennington, NJ } \\
\text { (Stream class A, simulated baseline dataset) }\end{array}$} \\
\hline $\begin{array}{l}\text { Hydrologic } \\
\text { index }\end{array}$ & Units & 25th percentile ${ }^{1}$ & $\begin{array}{c}\text { Observed } \\
\text { NJHAT value }^{2}\end{array}$ & 75th percentile ${ }^{1}$ & $\begin{array}{l}\text { Percent deviation } \\
\text { below the } \\
\text { 25th percentile } \\
\end{array}$ & $\begin{array}{c}\text { Percent deviation } \\
\text { above the } \\
\text { 75th percentile } \\
\end{array}$ \\
\hline MA18 & $\mathrm{ft}^{3} / \mathrm{s}$ & 0.505 & 0.229 & 1.4 & 54.7 & -- \\
\hline DL4 & $\mathrm{ft}^{3} / \mathrm{s}$ & 0.280 & 0.003 & 0.446 & 98.9 & -- \\
\hline TA1 & $\mathrm{D}$ & 0.165 & 0.689 & 0.441 & -- & 56.2 \\
\hline TL1 & JD & 241.0 & 232.4 & 266.9 & 3.6 & -- \\
\hline TH1 & $\mathrm{JD}$ & 31.0 & 245.3 & 111.5 & -- & 120.1 \\
\hline $\begin{array}{l}\text { Hydrologic } \\
\text { index }\end{array}$ & Units & 40th percentile ${ }^{1}$ & $\begin{array}{c}\text { Observed } \\
\text { NJHAT value }^{2}\end{array}$ & 60th percentile ${ }^{1}$ & $\begin{array}{c}\text { Percent deviation } \\
\text { below the } \\
\text { 40th percentile } \\
\end{array}$ & $\begin{array}{c}\text { Percent deviation } \\
\text { above the } \\
\text { 60th percentile } \\
\end{array}$ \\
\hline MA18 & $\mathrm{ft}^{3} / \mathrm{s}$ & 0.656 & 0.229 & 1.0 & 65.1 & $\begin{array}{l}-- \\
\text { - }\end{array}$ \\
\hline MH5 & $\mathrm{ft}^{3} / \mathrm{s}$ & 1.6 & 4.1 & 2.6 & -- & 57.0 \\
\hline DL4 & $\mathrm{ft}^{3} / \mathrm{s}$ & 0.334 & 0.003 & 0.399 & 99.1 & -- \\
\hline $\mathrm{DH} 2$ & $\mathrm{ft}^{3} / \mathrm{s}$ & 12.0 & 17.8 & 14.3 & -- & 24.3 \\
\hline TA1 & $\mathrm{D}$ & 0.485 & 0.689 & 0.531 & -- & 29.8 \\
\hline TL1 & JD & 254.1 & 232.4 & 257.9 & 8.6 & -- \\
\hline TH1 & JD & 47.6 & 245.3 & 54.9 & -- & 346.4 \\
\hline RA3 & $\left(\mathrm{ft}^{3} / \mathrm{s}\right) / \mathrm{d}$ & -0.080 & -0.120 & -0.040 & 50.0 & -- \\
\hline
\end{tabular}


Appendix 2. Deviations of flow-management targets for the Raritan River Basin study area, New Jersey, by U.S. Geological Survey station number, determined by using observed New Jersey Hydrologic Assessment Tool (NJHAT) values for specific nonredundant hydrologic indices that fall outside the established 25th-to-75th-percentile range and the more conservative 40th-to-60th-percentile range.-Continued

[ $\mathrm{ft}^{3} / \mathrm{s}$, cubic feet per second; ( $\left.\mathrm{ft}^{3} / \mathrm{s}\right) / \mathrm{d}$, cubic feet per second per day; days, number of days; $\mathrm{d} / \mathrm{yr}$, days per year; D, dimensionless; JD, Julian day; \%, percent; -- , no deviations above the 75 th or 60 th or below the 25 th or 40 th percentile range; hydrologic indices defined in appendix 1 ; values less than 1 were rounded to the thousandths place to show precision]

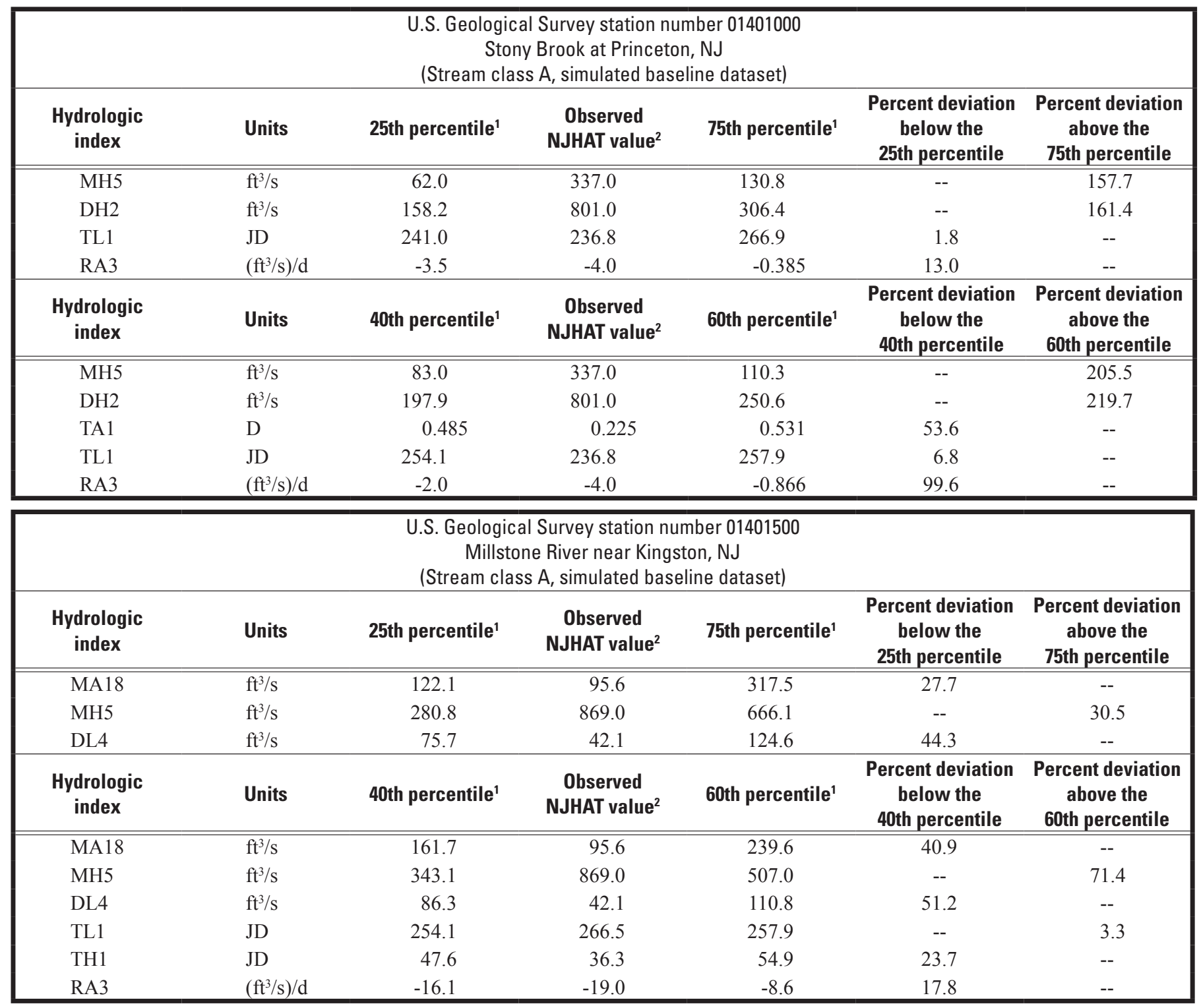


Appendix 2. Deviations of flow-management targets for the Raritan River Basin study area, New Jersey, by U.S. Geological Survey station number, determined by using observed New Jersey Hydrologic Assessment Tool (NJHAT) values for specific nonredundant hydrologic indices that fall outside the established 25th-to-75th-percentile range and the more conservative 40th-to-60th-percentile range.-Continued

$\left[\mathrm{ft}^{3} / \mathrm{s}\right.$, cubic feet per second; $\left(\mathrm{ft}^{3} / \mathrm{s}\right) / \mathrm{d}$, cubic feet per second per day; days, number of days; $\mathrm{d} / \mathrm{yr}$, days per year; D, dimensionless; JD, Julian day; \%, percent; --, no deviations above the 75 th or 60 th or below the 25 th or 40th percentile range; hydrologic indices defined in appendix 1 ; values less than 1 were rounded to the thousandths place to show precision]

\begin{tabular}{|c|c|c|c|c|c|c|}
\hline \multicolumn{7}{|c|}{$\begin{array}{l}\text { U.S. Geological Survey station number } 01402000 \\
\text { Millstone River at Blackwells Mills, NJ } \\
\text { (Stream class A, observed baseline dataset) }\end{array}$} \\
\hline $\begin{array}{l}\text { Hydrologic } \\
\text { index }\end{array}$ & Units & 25th percentile ${ }^{1}$ & $\begin{array}{c}\text { Observed } \\
\text { NJHAT value }^{2}\end{array}$ & 75th percentile ${ }^{1}$ & $\begin{array}{l}\text { Percent deviation } \\
\text { below the } \\
\text { 25th percentile } \\
\end{array}$ & $\begin{array}{c}\text { Percent deviation } \\
\text { above the } \\
\text { 75th percentile } \\
\end{array}$ \\
\hline FH4 & days/yr & 9.5 & 22.5 & 22.0 & ב-- & 2.3 \\
\hline $\begin{array}{l}\text { Hydrologic } \\
\text { index }\end{array}$ & Units & 40th percentile ${ }^{1}$ & $\begin{array}{c}\text { Observed } \\
\text { NJHAT value }^{2}\end{array}$ & 60th percentile ${ }^{1}$ & $\begin{array}{c}\text { Percent deviation } \\
\text { below the } \\
\text { 40th percentile } \\
\end{array}$ & $\begin{array}{c}\text { Percent deviation } \\
\text { above the } \\
\text { 60th percentile }\end{array}$ \\
\hline MH5 & $\mathrm{ft}^{3} / \mathrm{s}$ & 588.0 & 1,500 & 1,110 & "-- & 35.1 \\
\hline FH4 & days/yr & 13.0 & 22.5 & 17.0 & -- & 32.4 \\
\hline \multicolumn{7}{|c|}{$\begin{array}{c}\text { U.S. Geological Survey station number } 01403000 \\
\text { Raritan River at Bound Brook, NJ } \\
\text { (Stream class A, simulated baseline dataset) }\end{array}$} \\
\hline $\begin{array}{l}\text { Hydrologic } \\
\text { index }\end{array}$ & Units & 25th percentile ${ }^{1}$ & $\begin{array}{c}\text { Observed } \\
\text { NJHAT value }\end{array}$ & 75th percentile ${ }^{1}$ & $\begin{array}{c}\text { Percent deviation } \\
\text { below the } \\
\text { 25th percentile } \\
\end{array}$ & $\begin{array}{c}\text { Percent deviation } \\
\text { above the } \\
\text { 75th percentile } \\
\end{array}$ \\
\hline MH5 & $\mathrm{ft}^{3} / \mathrm{s}$ & 1,179 & 4,120 & 2,218 & \begin{tabular}{c|}
-- \\
\end{tabular} & 85.8 \\
\hline DL4 & $\mathrm{ft}^{3} / \mathrm{s}$ & 65.0 & 272.1 & 228.5 & -- & 19.1 \\
\hline $\mathrm{DH} 2$ & $\mathrm{ft}^{3} / \mathrm{s}$ & 2,075 & 9,061 & 3,895 & -- & 132.6 \\
\hline TA1 & $\mathrm{D}$ & 0.432 & 0.642 & 0.553 & -- & 16.0 \\
\hline RA3 & $\left(\mathrm{ft}^{3} / \mathrm{s}\right) / \mathrm{d}$ & -43.8 & -110.0 & -10.5 & 151.1 & -- \\
\hline MA18 & $\mathrm{ft}^{3} / \mathrm{s}$ & 280.5 & 454.2 & 387.2 & -- & 17.3 \\
\hline MH5 & $\mathrm{ft}^{3} / \mathrm{s}$ & 1,476 & 4,120 & 1,899 & -- & 116.9 \\
\hline DL4 & $\mathrm{ft}^{3} / \mathrm{s}$ & 95.2 & 272.1 & 172.0 & -- & 58.2 \\
\hline $\mathrm{DH} 2$ & $\mathrm{ft}^{3} / \mathrm{s}$ & 2,499 & 9,061 & 3,218 & -- & 181.6 \\
\hline TA1 & $\mathrm{D}$ & 0.485 & 0.642 & 0.531 & -- & 20.8 \\
\hline RA3 & $\left(\mathrm{ft}^{3} / \mathrm{s}\right) / \mathrm{d}$ & -29.2 & -110.0 & -17.7 & 276.2 & -- \\
\hline
\end{tabular}


Appendix 2. Deviations of flow-management targets for the Raritan River Basin study area, New Jersey, by U.S. Geological Survey station number, determined by using observed New Jersey Hydrologic Assessment Tool (NJHAT) values for specific nonredundant hydrologic indices that fall outside the established 25th-to-75th-percentile range and the more conservative 40th-to-60th-percentile range.-Continued

$\left[\mathrm{ft}^{3} / \mathrm{s}\right.$, cubic feet per second; ( $\left.\mathrm{ft}^{3} / \mathrm{s}\right) / \mathrm{d}$, cubic feet per second per day; days, number of days; $\mathrm{d} / \mathrm{yr}$, days per year; D, dimensionless; JD, Julian day; \%, percent; -- , no deviations above the 75 th or 60 th or below the 25 th or 40 th percentile range; hydrologic indices defined in appendix 1 ; values less than 1 were rounded to the thousandths place to show precision]

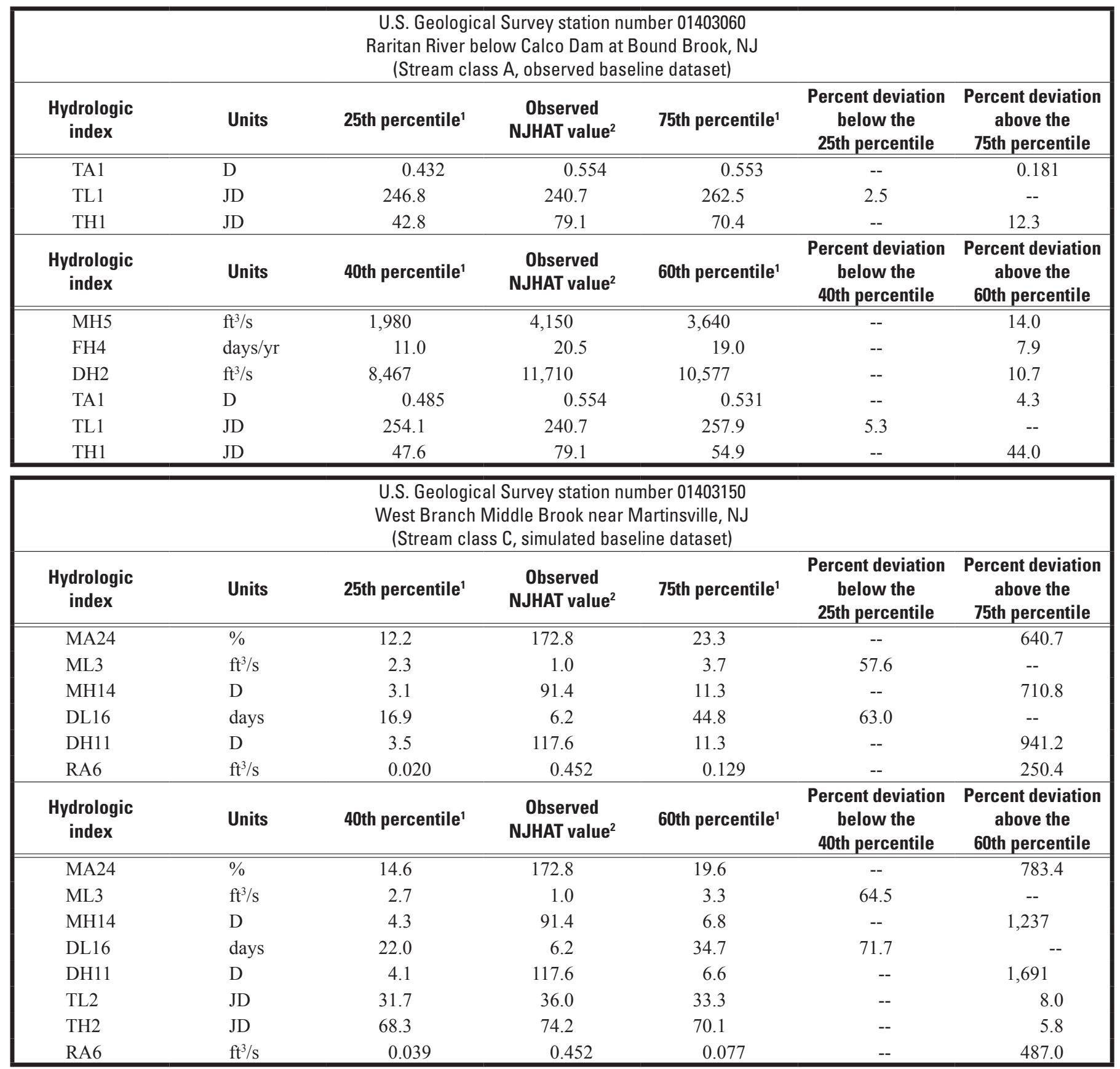


Appendix 2. Deviations of flow-management targets for the Raritan River Basin study area, New Jersey, by U.S. Geological Survey station number, determined by using observed New Jersey Hydrologic Assessment Tool (NJHAT) values for specific nonredundant hydrologic indices that fall outside the established 25th-to-75th-percentile range and the more conservative 40th-to-60th-percentile range.-Continued

$\left[\mathrm{ft}^{3} / \mathrm{s}\right.$, cubic feet per second; $\left(\mathrm{ft}^{3} / \mathrm{s}\right) / \mathrm{d}$, cubic feet per second per day; days, number of days; $\mathrm{d} / \mathrm{yr}$, days per year; D, dimensionless; JD, Julian day; \%, percent; --, no deviations above the 75 th or 60 th or below the 25 th or 40th percentile range; hydrologic indices defined in appendix 1 ; values less than 1 were rounded to the thousandths place to show precision]

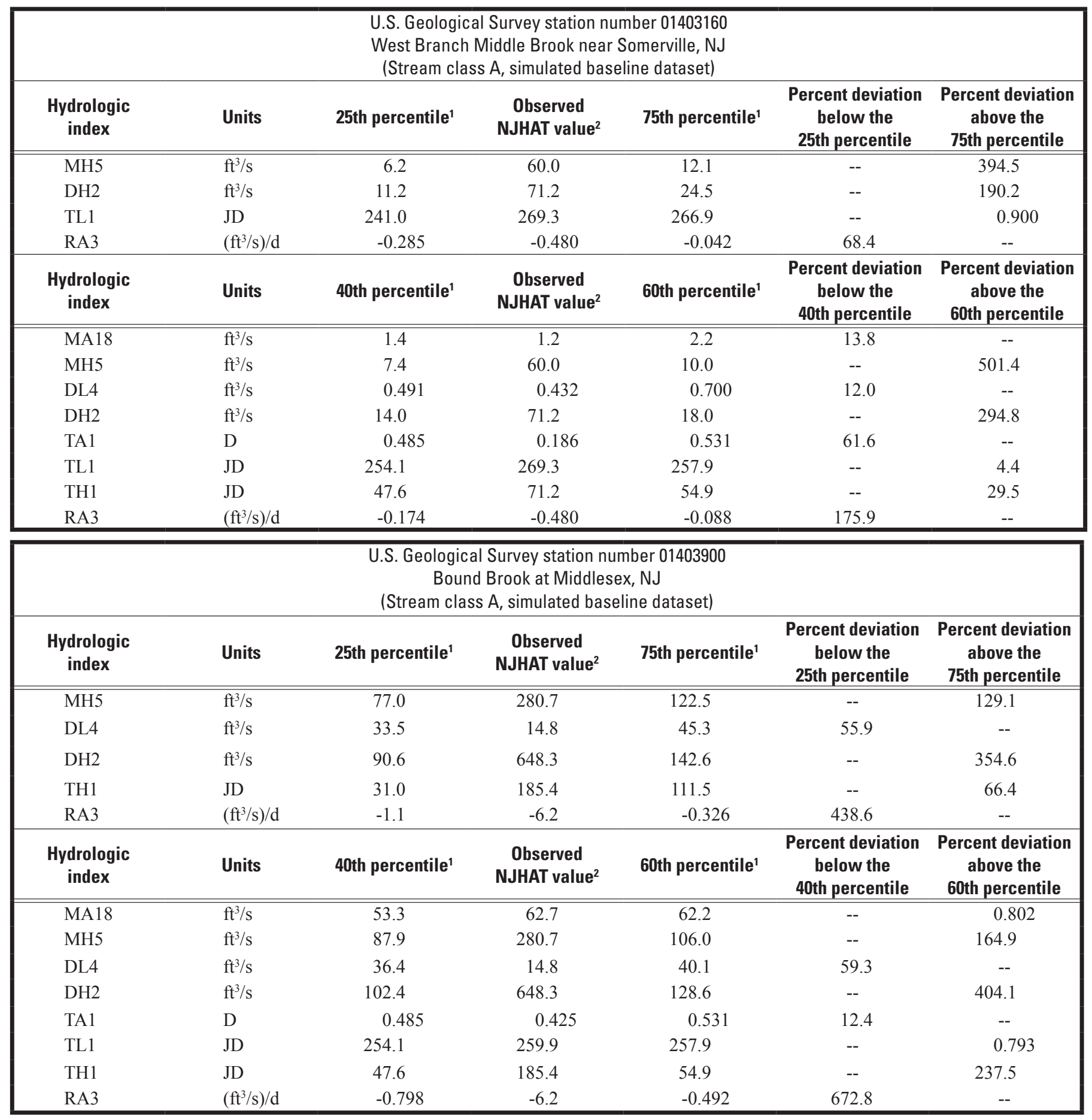


Appendix 2. Deviations of flow-management targets for the Raritan River Basin study area, New Jersey, by U.S. Geological Survey station number, determined by using observed New Jersey Hydrologic Assessment Tool (NJHAT) values for specific nonredundant hydrologic indices that fall outside the established 25th-to-75th-percentile range and the more conservative 40th-to-60th-percentile range.-Continued

[ft 3 s, cubic feet per second; ( $\left.\mathrm{ft}^{3} / \mathrm{s}\right) / \mathrm{d}$, cubic feet per second per day; days, number of days; d/yr, days per year; D, dimensionless; JD, Julian day; \%, percent; -- , no deviations above the 75th or 60th or below the 25th or 40th percentile range; hydrologic indices defined in appendix 1; values less than 1 were rounded to the thousandths place to show precision]

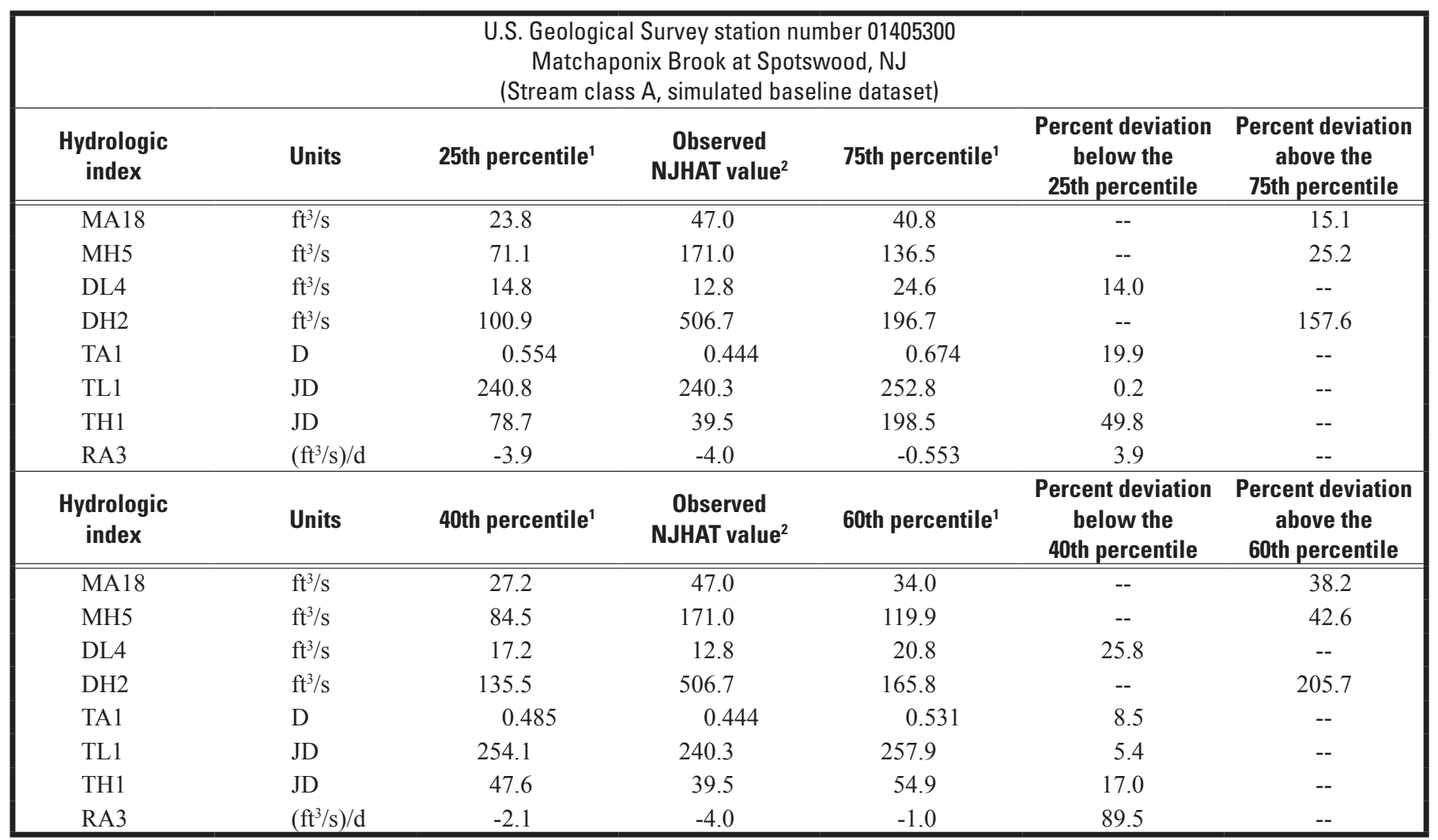


Appendix 2. Deviations of flow-management targets for the Raritan River Basin study area, New Jersey, by U.S. Geological Survey station number, determined by using observed New Jersey Hydrologic Assessment Tool (NJHAT) values for specific nonredundant hydrologic indices that fall outside the established 25th-to-75th-percentile range and the more conservative 40th-to-60th-percentile range.-Continued

$\left[\mathrm{ft}^{3} / \mathrm{s}\right.$, cubic feet per second; $\left(\mathrm{ft}^{3} / \mathrm{s}\right) / \mathrm{d}$, cubic feet per second per day; days, number of days; d/yr, days per year; D, dimensionless; JD, Julian day; \%, percent; --, no deviations above the 75th or 60th or below the 25th or 40th percentile range; hydrologic indices defined in appendix 1 ; values less than 1 were rounded to the thousandths place to show precision]

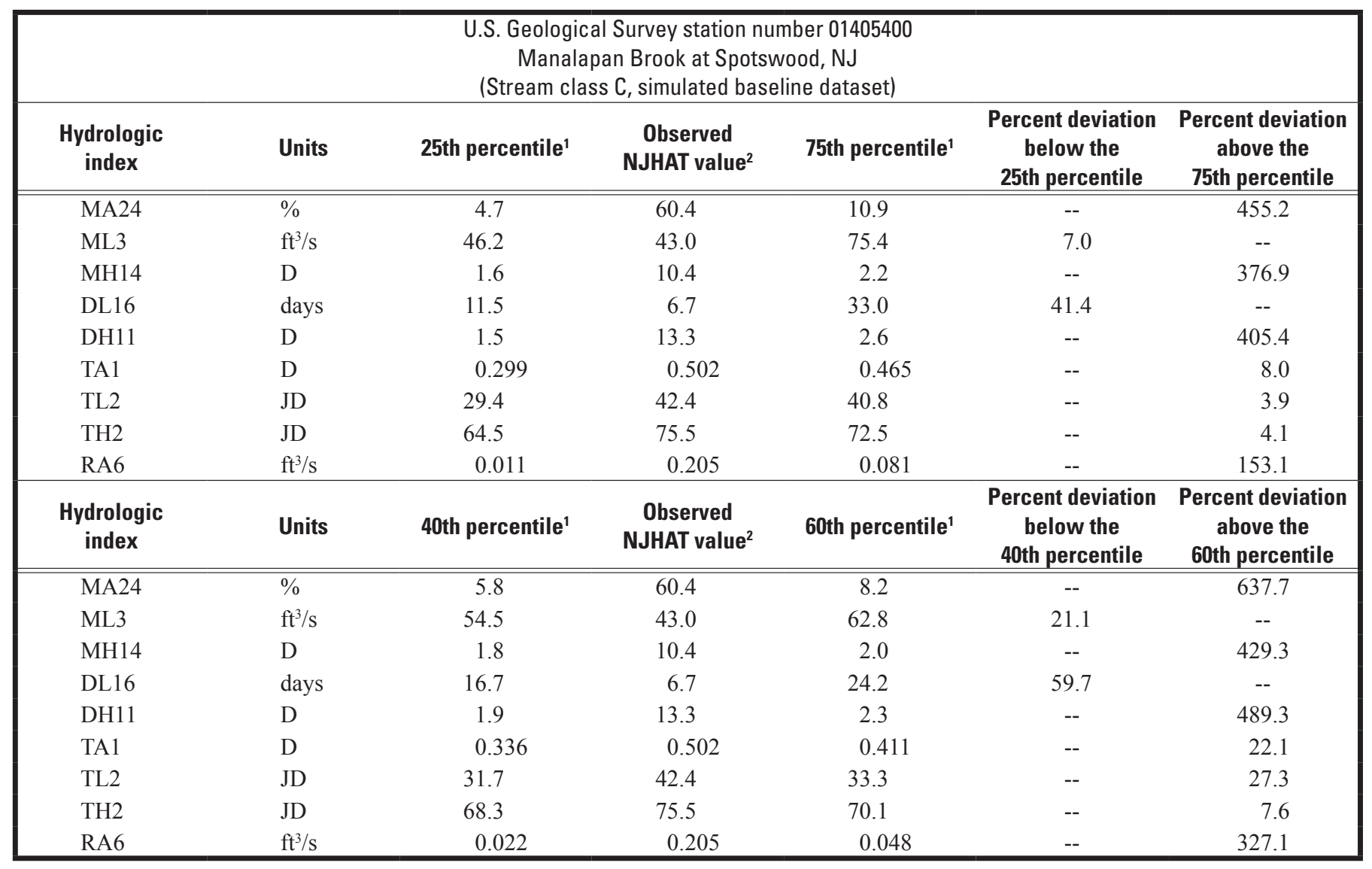


Appendix 2. Deviations of flow-management targets for the Raritan River Basin study area, New Jersey, by U.S. Geological Survey station number, determined by using observed New Jersey Hydrologic Assessment Tool (NJHAT) values for specific nonredundant hydrologic indices that fall outside the established 25th-to-75th-percentile range and the more conservative 40th-to-60th-percentile range.-Continued

[ $\mathrm{ft}^{3} / \mathrm{s}$, cubic feet per second; ( $\left.\mathrm{ft}^{3} / \mathrm{s}\right) / \mathrm{d}$, cubic feet per second per day; days, number of days; $\mathrm{d} / \mathrm{yr}$, days per year; D, dimensionless; JD, Julian day; \%, percent; -- , no deviations above the 75 th or 60 th or below the 25 th or 40 th percentile range; hydrologic indices defined in appendix 1 ; values less than 1 were rounded to the thousandths place to show precision]

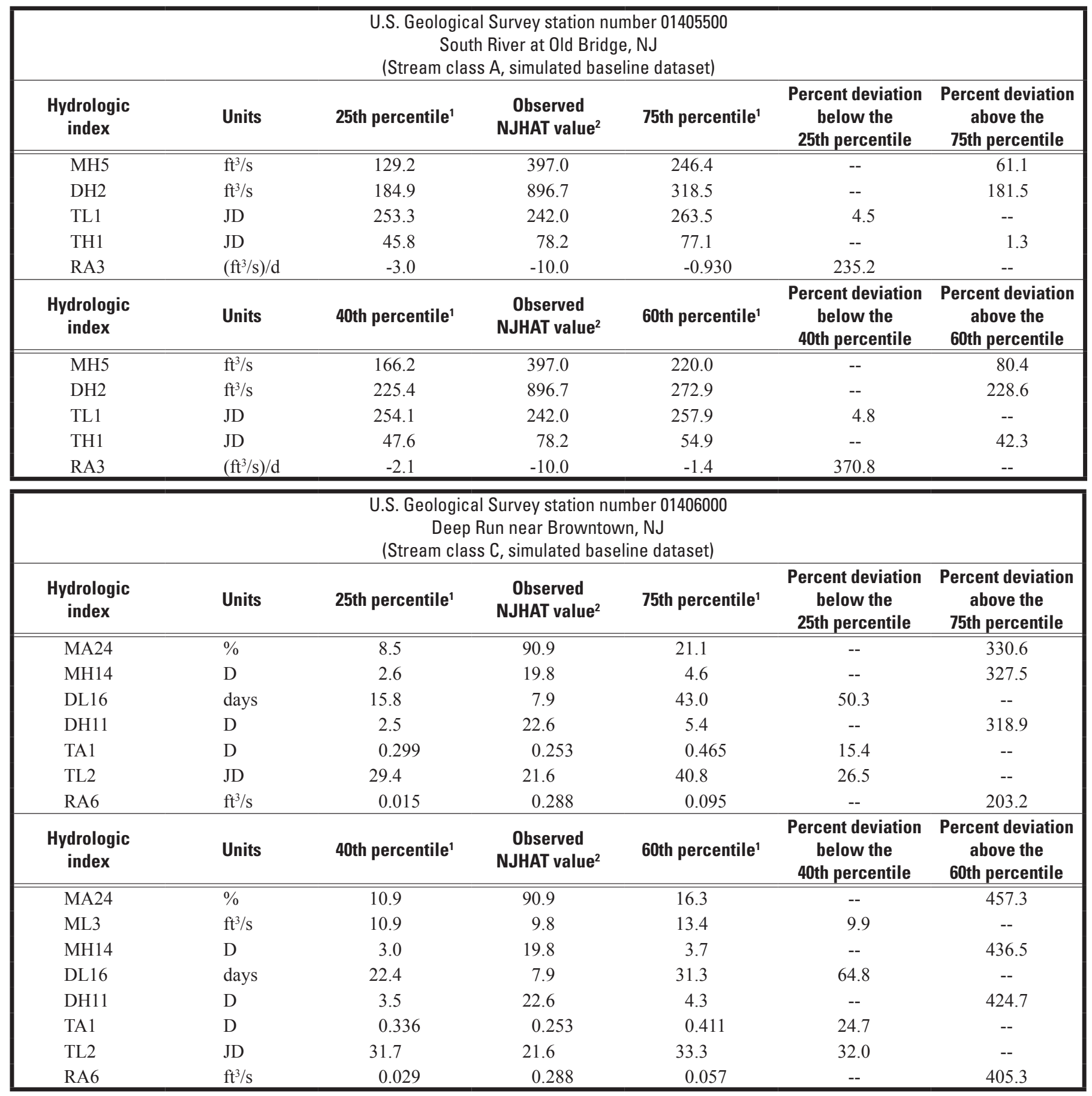


Appendix 2. Deviations of flow-management targets for the Raritan River Basin study area, New Jersey, by U.S. Geological Survey station number, determined by using observed New Jersey Hydrologic Assessment Tool (NJHAT) values for specific nonredundant hydrologic indices that fall outside the established 25th-to-75th-percentile range and the more conservative 40th-to-60th-percentile range.-Continued

$\left[\mathrm{ft}^{3} / \mathrm{s}\right.$, cubic feet per second; $\left(\mathrm{ft}^{3} / \mathrm{s}\right) / \mathrm{d}$, cubic feet per second per day; days, number of days; $\mathrm{d} / \mathrm{yr}$, days per year; D, dimensionless; JD, Julian day; \%, percent; -- , no deviations above the 75 th or 60 th or below the 25 th or 40 th percentile range; hydrologic indices defined in appendix 1 ; values less than 1 were rounded to the thousandths place to show precision]

\begin{tabular}{|c|c|c|c|c|c|c|}
\hline \multicolumn{7}{|c|}{$\begin{array}{c}\text { U.S. Geological Survey station number } 01406500 \\
\text { Tennent Brook near Browntown, NJ } \\
\text { (Stream class C, simulated baseline dataset) }\end{array}$} \\
\hline $\begin{array}{l}\text { Hydrologic } \\
\text { index }\end{array}$ & Units & 25th percentile ${ }^{1}$ & $\begin{array}{c}\text { Observed } \\
\text { NJHAT value }\end{array}$ & 75th percentile ${ }^{1}$ & $\begin{array}{c}\text { Percent deviation } \\
\text { below the } \\
\text { 25th percentile } \\
\end{array}$ & $\begin{array}{c}\text { Percent deviation } \\
\text { above the } \\
\text { 75th percentile }\end{array}$ \\
\hline MA24 & $\%$ & 11.5 & 108.2 & 24.7 & $\begin{array}{l}-- \\
\end{array}$ & 337.5 \\
\hline ML3 & $\mathrm{ft}^{3} / \mathrm{s}$ & 6.2 & 2.1 & 9.0 & 66.0 & -- \\
\hline MH14 & $\mathrm{D}$ & 3.1 & 27.8 & 5.7 & -- & 387.6 \\
\hline DL16 & days & 17.7 & 8.4 & 53.0 & 52.4 & -- \\
\hline DH11 & $\mathrm{D}$ & 3.0 & 29.4 & 5.7 & -- & 414.4 \\
\hline TA1 & $\mathrm{D}$ & 0.554 & 0.167 & 0.674 & 69.9 & -- \\
\hline TL2 & $\mathrm{JD}$ & 35.4 & 25.5 & 42.2 & 27.9 & -- \\
\hline TH2 & $\mathrm{JD}$ & 71.9 & 52.4 & 78.2 & 27.2 & -- \\
\hline RA6 & $\mathrm{ft}^{3} / \mathrm{s}$ & 0.014 & 0.452 & 0.143 & -- & 216.1 \\
\hline $\begin{array}{l}\text { Hydrologic } \\
\text { index }\end{array}$ & Units & 40th percentile ${ }^{1}$ & $\begin{array}{l}\text { Observed } \\
\text { NJHAT value }\end{array}$ & 60th percentile ${ }^{1}$ & $\begin{array}{c}\text { Percent deviation } \\
\text { below the } \\
\text { 40th percentile }\end{array}$ & $\begin{array}{c}\text { Percent deviation } \\
\text { above the } \\
\text { 60th percentile }\end{array}$ \\
\hline MA24 & $\%$ & 13.8 & 108.2 & 20.2 & $\begin{array}{l}-- \\
\end{array}$ & 434.7 \\
\hline ML3 & $\mathrm{ft}^{3} / \mathrm{s}$ & 7.0 & 2.1 & 8.1 & 70.1 & -- \\
\hline MH14 & $\mathrm{D}$ & 3.6 & 27.8 & 4.5 & -- & 512.5 \\
\hline DL16 & days & 28.7 & 8.4 & 42.6 & 70.6 & -- \\
\hline DH11 & $\mathrm{D}$ & 3.7 & 29.4 & 4.7 & -- & 528.7 \\
\hline TA1 & $\mathrm{D}$ & 0.336 & 0.167 & 0.411 & 50.3 & -- \\
\hline TL2 & JD & 31.7 & 25.5 & 33.3 & 19.6 & -- \\
\hline TH2 & JD & 68.3 & 52.4 & 70.1 & 23.2 & -- \\
\hline RA6 & $\mathrm{ft}^{3} / \mathrm{s}$ & 0.033 & 0.452 & 0.080 & -- & 465.0 \\
\hline
\end{tabular}

${ }^{1}$ Percentile range derived from either the quantile regression baseline period (observed baseline) or the Statewide Watershed Runoff Model (SWRM) simulated baseline.

${ }^{2}$ Value derived from the analysis of the entire period of altered streamflow record. 
Prepared by the West Trenton Publishing Service Center

For more information, contact:

New Jersey Water Science Center

U.S. Geological Survey

810 Bear Tavern Road, Suite 206

West Trenton, NJ 08628

http://nj.usgs.gov/ 
